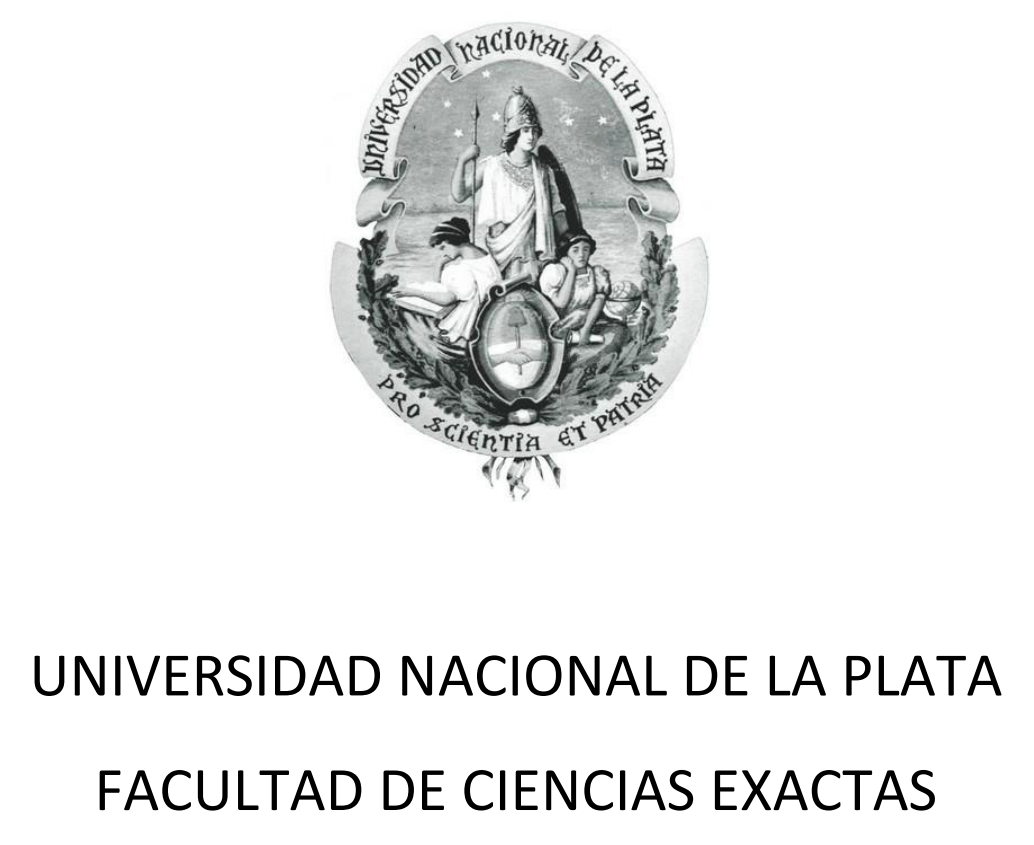

Departamento de Química

Trabajo de Tesis Doctoral

\title{
“ESTUDIOS FOTOQUÍMICOS Y FOTOFÍSICOS EN COMPLEJOS TRICARBONÍLICOS DE RENIO(I) Y SU INTERACCIÓN CON BIOPOLÍMEROS"
}

\section{Bioq. Fabricio Ragone}

Director: Dr. Ezequiel Wolcan /Codirector: Dr. Gustavo T. Ruiz 2015 

El presente trabajo se realizó en el laboratorio de fotoquímica inorgánica, Instituto de Investigaciones Fisicoquímicas Teóricas y Aplicadas, INIFTA

Bajo la dirección del Dr. Ezequiel Wolcan y la codirección del Dr. Gustavo T. Ruiz Este trabajo de Tesis es presentado para optar al título de Doctor de la Facultad de Ciencias Exactas 



\section{Agradecimientos}

Quiero expresar mi agradecimiento a todas aquellas personas e instituciones que apoyaron la realización de este trabajo de Tesis:

- Al director del INIFTA, Dr. Felix Requejo, por permitir que realice el trabajo de tesis doctoral en dicho centro.

- A la ANPCYT por otorgarme la beca inicial.

- Al CONICET por otorgarme las beca de Tipo II para la finalización de este trabajo de Tesis doctoral.

- A la ANPCYT, CONICET y UNLP por el otorgamiento de fondos necesarios para llevar a cabo las tareas de investigación.

- A Mis directores Gustavo y Ezequiel por permitirme, en primer lugar, desarrollar la tesis con ellos, por la enseñanza diaria, las explicaciones, la dedicación, la ayuda constante y la infinita paciencia.

Tambien quiero expresar mi agradecimiento a quienes colaboraron en la realización de este trabajo:

A las Dras. Rosa Erra-Balsells y Gabriela Petroselli (CIHIDECAR, UBA), por su colaboración con las técnicas de espectrometría de masas. Al Dr. Oscar E. Piro (Departamento de Física, Facultad de Ciencias Exactas, UNLP) por su colaboración en la determinación de la estructura cirstalina del complejo. Al Dr. Fernando S. García Einschlag (INIFTA), por su ayuda y colaboración con la implementación de modelos de ajuste bilineal. Al Dr. Franco M. Cabrerizo y al Biol. Gabriel Yañuk (IIB-INTECH, UNSAM) por su ayuda y colaboración con los ensayos sobrea cambios conformacionales en plasmidos. Al Qco. Héctor H. Martinez Saavedra (INIFTA), al Qco. P. Facundo Garcia y al Dr. Gerardo Arguello (INFIQC, UNC) por su colaboración con las medidas de interaccion con proteínas. Al Dr. Pedro M. David Gara (CIOP) por su ayuda con las medidas de optoacústica, al Dr. Gustavo Prietto (INIFTA) por su colaboración con las determinaciones de AFM y al Dr. Guillermo Ferraudi (Radietion Lab N. Dame EE.UU) por su ayuda y dirección en las medidas de LFF y PR. 



\section{Prólogo}

El presente trabajo de tesis se compone de tres partes, que se encuentran, a su vez, separadas en capítulos. La primera parte se compone de los primeros tres capítulos. Contiene una introducción a los objetivos planteados en el trabajo, seguida de una descripción de la actualidad del tema de estudio y finaliza con un capítulo en el cual se encuentran los detalles del equipamiento y materiales empleados en este trabajo. Contiene también, un detalle de las técnicas empleadas junto a los fundamentos fotofísicos necesarios para su correcta interpretación.

La segunda parte contiene tres capítulos con los resultados de los experimentos realizados, junto con su análisis y las respectivas conclusiones parciales.

Finalmente la última parte contiene un único capitulo con una discusión más amplia de los resultados de la tesis en forma de conclusiones generales. 



\section{Índice general}

\section{Primera parte}

\section{Introducción}

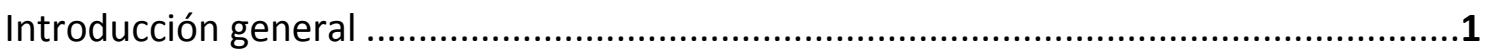

\section{Capítulo I}

Fundamentos, materiales, técnicas, e instrumentación

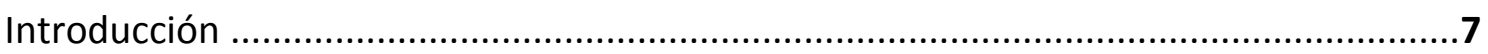

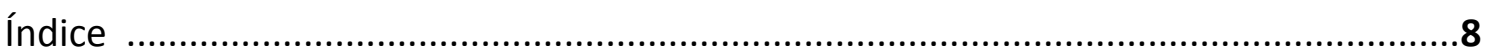

1. Reactivos generales, técnicas de síntesis y caracterización ....................................11

2. Técnicas fotofísicas, fotoquímicas y químicas .....................................................17

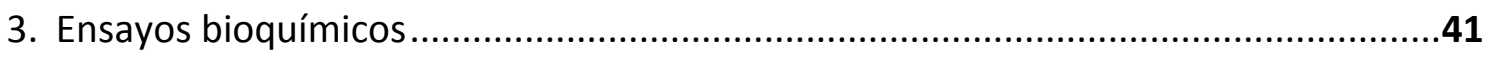

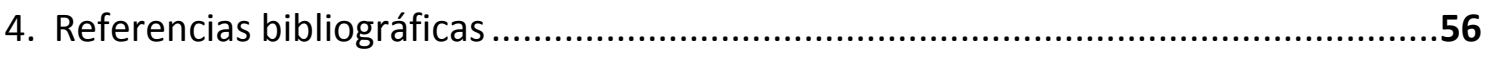

\section{Capítulo II}

Estado del arte

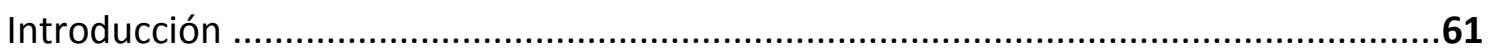

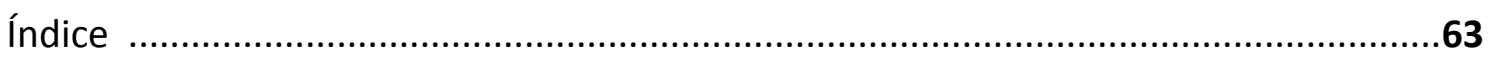

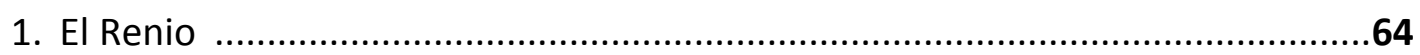

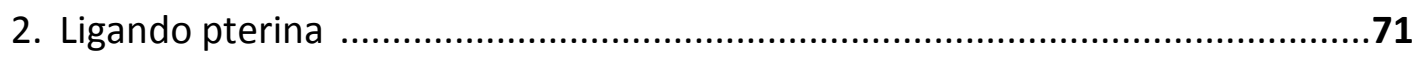

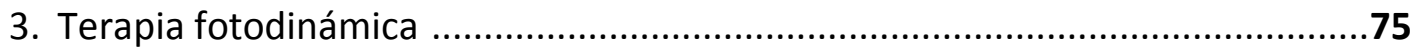

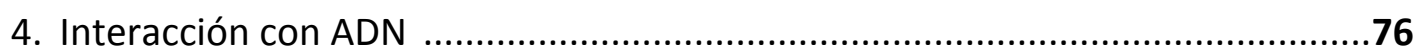

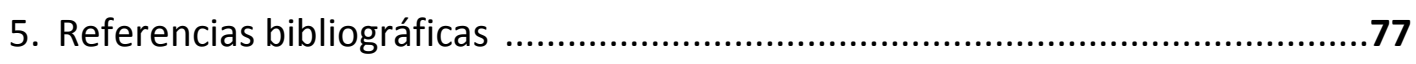




\section{Segunda parte}

\section{Resultados}

\section{Capítulo III}

Síntesis y caracterización del complejo fac- $\operatorname{Re}^{\prime}(\mathrm{CO})_{3}($ pterina $)\left(\mathrm{H}_{2} \mathrm{O}\right)$

Introducción

Índice

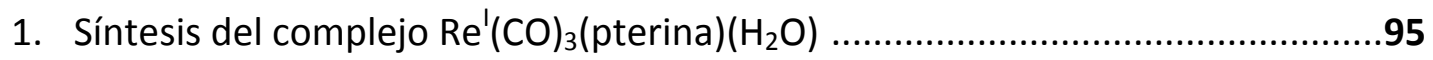

2. Caracterización del complejo $\operatorname{Re}^{\prime}(\mathrm{CO})_{3}\left(\mathrm{H}_{2} \mathrm{O}\right)$ (pterina) ....................................99

3. Preparación de soluciones .........................................................................113

4. Estudio de los equilibrios de protonación ....................................................120

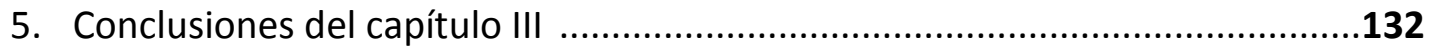

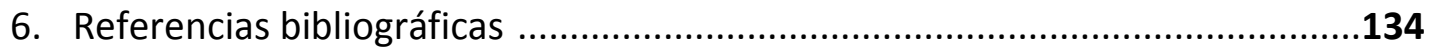

\section{Capítulo IV}

Estudio de las propiedades fotofísicas y fotoquímicas de complejos tricarbonílicos de $\operatorname{Re}(I)$

Introducción

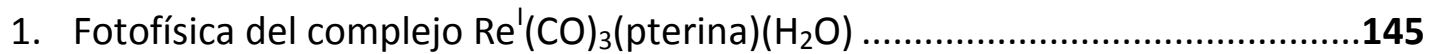

2. Fotofísica de los complejos ReBpyTF, RePhenTf y ReBpyPy..........................161

3. Estudios de reacciones térmicas y fotoquímicas del complejo fac$\operatorname{Re}^{\prime}(\mathrm{CO})_{3}$ (pterina) $\left(\mathrm{H}_{2} \mathrm{O}\right)$

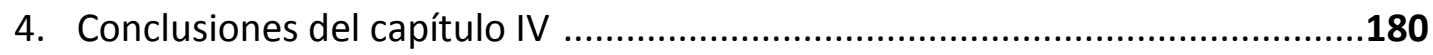

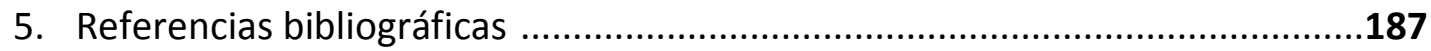




\section{Capítulo V}

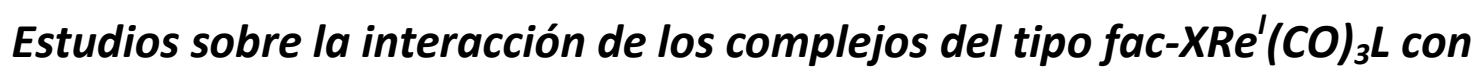
biopolímeros.

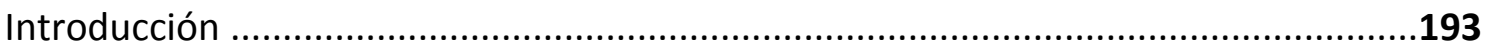

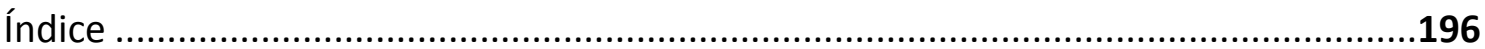

1. Estudios de la interacción con ácidos nucleicos ............................................198

1.1. Cambios en la absorción y emisión inducidos por la interacción con ADN ......198

1.2. Cambios estructurales inducidos en plásmidos seguidos por electroforesis....207

1.3. Cambios en plásmidos seguidos por AFM.....................................................216

2. Estudios de interacción entre fac- $\mathrm{Re}^{\prime}(\mathrm{CO})_{3}($ pterina $)\left(\mathrm{H}_{2} \mathrm{O}\right)$ y sero-albuminas....224

3. Referencias bibliográficas .239

\section{Tercera parte}

Conclusiones

Capítulo VI

Resumen de las conclusiones

Índice 249

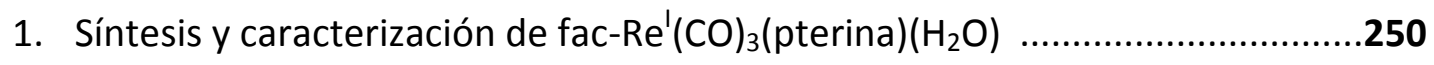

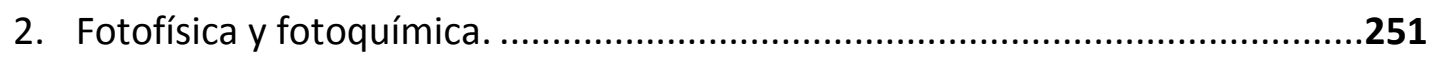

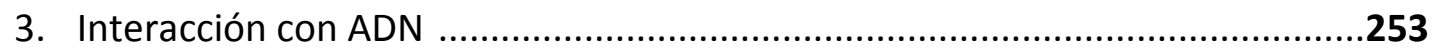

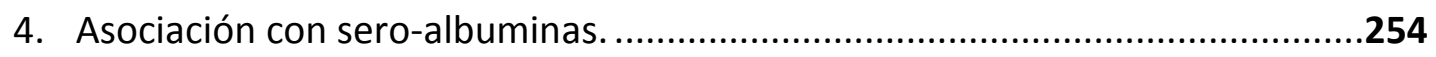

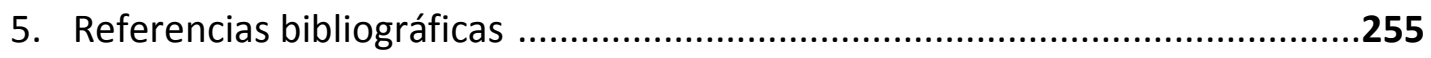




\section{Referencias bibliográficas}

[1] E. Wolcan and G. Ferraudi, "Photochemical and Photophysical Properties of FacRe(I) Tricarbonyl Complexes: A Comparison of Monomer and Polymer Species with -Rel(CO)3Phen Chromophores," J. Phys. Chem. A, vol. 104, no. 41, pp. 3-8, 2000.

[2] E. Wolcan and M. R. Feliz, "Temperature and medium effects on the photophysical properties of $\operatorname{Re}(\mathrm{CO}) 3\left(2,2^{\prime}\right.$-bipyridine) pendant chromophores coordinated to a poly(4-vinylpyridine) backbone," Photochem. Photobiol. Sci., vol. 2, no. 4, p. 412, 2003. 


\section{Primera parte}

\section{Introducción}





\section{Introducción general}

La coordinación de un ligando orgánico por un ion metálico modifica de forma sustancial sus propiedades. De este modo se le suman, a las vastas e interesantes propiedades de los compuestos orgánicos, la posibilidad de ser modificadas de forma controlada. El estudio de los compuestos organometálicos, aprovecha los conocimientos acumulados sobre los ligandos libres y sobre los efectos que induce la coordinación, para sintetizar nuevos compuestos.

Los objetivos que se plantearon en este trabajo de tesis están relacionados con la síntesis y estudios químicos, bioquímicos, fotoquímicos y fotofísicos de complejos organometálicos. En particular, los complejos seleccionados para este trabajo, pertenecen a la familia de complejos tricarbonílicos de Renio, fac-Re'(CO) ${ }_{3} \mathrm{~L}_{1} \mathrm{~L}_{2}$. Los mismos, pueden ser diseñados seleccionando ligandos, $L_{1} y / o L_{2}$, adecuados con los cuales modular sus propiedades espectroscópicas, electroquímicas y de capacidad de unión a diferentes biopolímeros.

Las propiedades fotofísicas en este tipo de complejos se encuentran determinadas, en gran medida, por la naturaleza de los estados excitados tripletes de menor energía. Estos pueden ser del tipo transferencia de carga del metal al ligando (MLCT), de transferencia de carga entre ligandos (LLCT) o bien deberse a transiciones centradas en el ligando (IL). De este modo, por ejemplo, coordinar ligandos capaces de deslocalizar carga en su estructura por conjugación de anillos aromáticos extendidos, favorece la generación de estados excitado IL de baja energía luego de la excitación con luz visible. Estos complejos pueden participar de procesos de sensibilización actuando como fotosensiblilizadores frente a distintas macromoléculas. En estos procesos la energía lumínica es absorbida por el complejo, generando un estado excitado, para luego ser transferida a la molécula blanco incapaz de absorber esta radiación. Así, en macromoléculas biológicas como por ejemplo el ácido desoxirribonucleico (ADN), se pueden generar daño fotoinducido con los consecuentes cambios estructurales y funcionales en estos sistemas. Buscando realizar aportes en este sentido, se propuso determinar los modos de unión al ADN de los complejos a investigar y dilucidar los mecanismos de los fotoprocesos que generen fotoclivaje del ADN. Además, se propuso 
profundizar las investigaciones sobre el uso de éstos complejos como agentes fotoquimioterapéuticos, en particular, sobre aquellos capaces de generar daño a biomoléculas esenciales tales como el ADN.

El conocimiento básico de la dinámica y naturaleza de los estados excitados presentes en los complejos obtenidos es de gran utilidad para decidir los posibles campos potenciales de aplicación. Estos estados excitados generados, pueden tener aplicaciones concretas, tales como sondas luminiscentes para biomoléculas, catalizadores en distintas reacciones y como sensores luminiscentes. En este sentido, si esta emisión es desactivada por el oxígeno, podrían usarse en el diseño de sensores de este gas.

Se planeó la síntesis de un nuevo complejo tricarbonilico de $\operatorname{Re}(\mathrm{I})$ que coordine el ligando, extensamente estudiado, pterina (2-amino-4-oxo-3H-pteridina). Hasta el momento de las escritura de este trabajo, no se cuenta con trabajos publicados sobre complejos tricarbonilicos de Renio coordinados a pterina. Es por esto que nos propusimos realizar una completa caracterización de este complejo utilizando tecinas cristalográficas de difracción de Rayos $X$, espectrometrías ${ }^{1} \mathrm{H}-\mathrm{RMN}, \mathrm{FT}-\mathrm{IR}$, UV-MALDI Y ESI. Se proyectó también, realizar completos estudios de sus propiedades químicas, fotoquímicas y fotofísicas. Las técnicas utilizadas en estos estudios comprenden, espectrometría de emisión y de absorción UV-Vis, determinación de oxigeno singlete, estudios de laser flash fotolisis y de radiólisis de pulso.

Adicionalmente, fueron seleccionados tres complejos para ser estudiados mediante técnicas fotofísicas y fotoquímicas fueron los complejo $f a c-\mathrm{Re}^{\prime}(\mathrm{CO})_{3}(\mathrm{bpy}) \mathrm{CF}_{3} \mathrm{SO}_{3}, \mathrm{fac}$ $\operatorname{Re}^{\prime}(\mathrm{CO})_{3}$ (phen) $\mathrm{CF}_{3} \mathrm{SO}_{3}$ y $\left[\right.$ fac- $\operatorname{Re}^{\prime}(\mathrm{CO})_{3}($ bpy $)($ py) $] \mathrm{CF}_{3} \mathrm{SO}_{3}$ (bpy = 2,2'-bipiridina, phen = 1,10-fenantrolina, py = piridina). Estos complejos han sido sintetizados y estudiados dentro del grupo de trabajo [1], [2]. Se propuso, complementar el conocimiento acumulado con nuevas medidas sobre sus propiedades realizando medidas de absorción de luz y emisión luminiscente. Además, investigar su capacidad, para generar especies reactivas de oxígeno, tales como, oxígeno singlete.

Por otro lado, se propuso también, el estudio de la interacción de un grupo de complejos tricarbonilicos de $\operatorname{Re}(I)$ con diferentes tipos de ADN. En este grupo de complejos se incluye el nuevo complejo con pterina y otros dos complejos sintetizados y caracterizados en el grupo, fac- $\operatorname{Re}^{\prime}(\mathrm{CO})_{3}(\mathrm{bpy}) \mathrm{CF}_{3} \mathrm{SO}_{3}$ y [fac- 
(dppz) $\operatorname{Re}^{\prime}(\mathrm{CO})_{3}\left(4,4^{\prime}\right.$ bipiridina $) \quad \mathrm{CF}_{3} \mathrm{SO}_{3} \quad(\mathrm{dppz} \quad=$ dipiridil[3,2-a:2'3'-c]fenazina). Se estudiaron los modos de unión y los mecanismos de ruptura de la doble hélice en ADN de timo de ternero, poli-nucleótidos sintéticos y ácido nucleico circular (plásmido). Finalmente se planeó la evaluación de la interacción entre el complejo con pterina y proteínas de transporte en sangre tales como seroalbúmina bobina y humana. 


\section{Capítulo I}

Fundamentos, materiales,

técnicas e instrumentación 


\section{Introducción}

La descripción de las técnicas y metodología empleadas en este trabajo, requiere para su completo desarrollo, la enunciación y análisis de los fundamentos fotofísicos y fotoquímicos subyacentes a las determinaciones. Es así, que estos se presentan junto a una descripción detallada de los materiales, las técnicas y el instrumental, que han sido empleados. En este capítulo se presentan tres secciones divididas del siguiente modo:

- Los reactivos empleados durante todo el trabajo, las técnicas químicas y las determinaciones analíticas empleadas en la síntesis y la caracterización del complejo en estudio, se detallan, junto a una breve descripción del instrumental empleado para este fin.

- Se desarrolla una descripción de cada técnica empleada en las determinaciones químicas, fisicoquímicas y fotofísicas, incluyendo: la metodología, el instrumental empleado y la interpretación de los resultados. Junto a éstas se presentan los fundamentos fotofísicos y fotoquímicos necesarios.

- Se presentan, los fundamentos de las técnicas bioquímicas empleadas, junto a la interpretación de sus resultados y los materiales e instrumental empleados.

El orden en que se presentan estas secciones responde a su disposición dentro de este trabajo de tesis.

Algunas medidas de caracterización tales como: espectrometría de masas, difracción de rayos $X$ y resonancia magnética nuclear, fueron realizados por colaboradores de otros grupos. Sin embargo se describen aquí a fin de completar la interpretación de sus resultados. 


\section{Índice}

\section{Capítulo I}

\section{Fundamentos, materiales, técnicas e instrumentación}

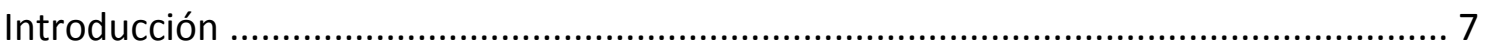

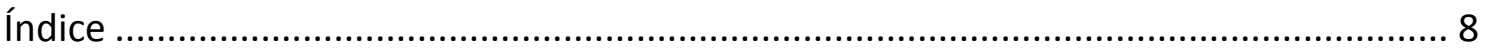

1. Reactivos generales, técnicas de síntesis y caracterización ................................... 11

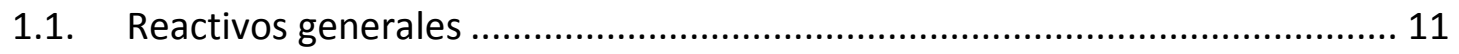

1.2. Reactivos utilizados en la síntesis y caracterización .................................... 11

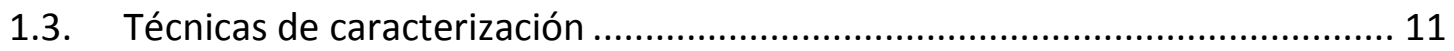

1.3.1. Espectrometría de masas ................................................................... 11

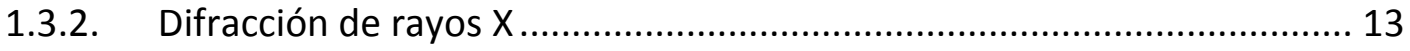

1.3.3. Espectroscopía infrarroja .............................................................. 13

1.3.4. Resonancia magnética nuclear .......................................................... 13

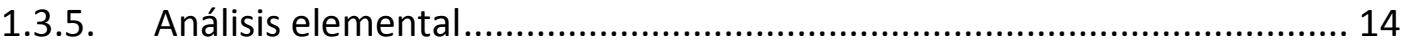

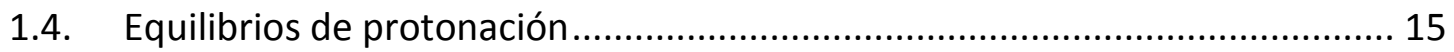

1.4.1. Análisis de regresión bilineal. ............................................................ 15

1.4.2. Descripción del instrumental............................................................. 16

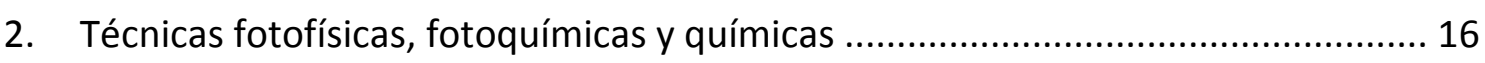

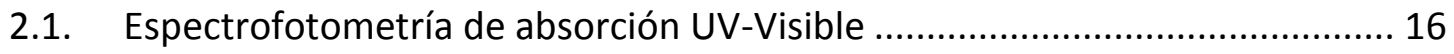

2.1.1. Descripción del instrumental.............................................................. 17

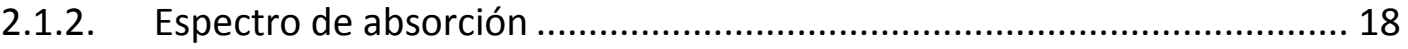

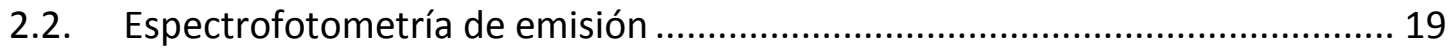

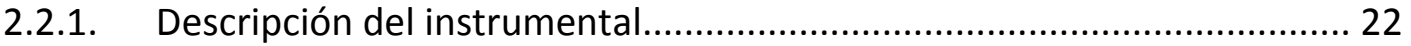

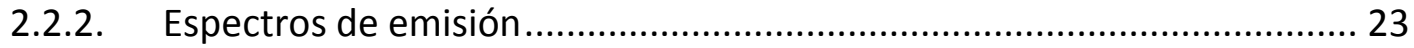




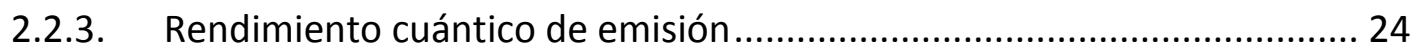

2.3. Espectroscopía de emisión resuelta en el tiempo ......................................... 26

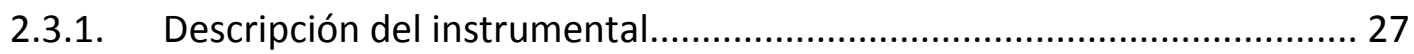

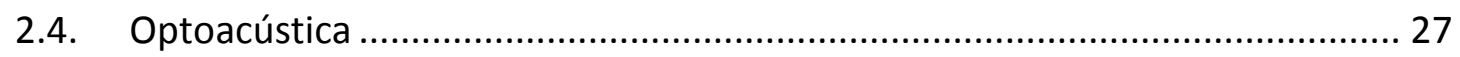

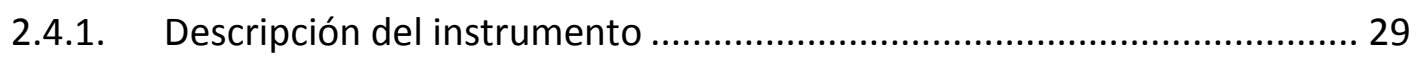

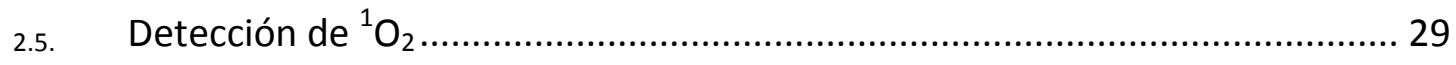

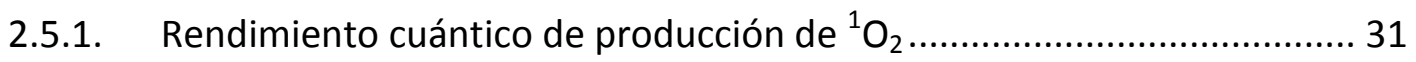

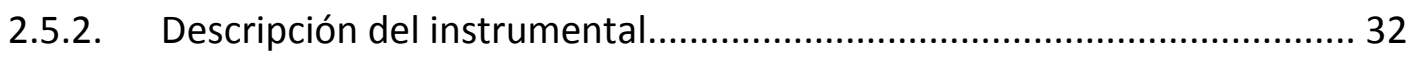

2.6. Reactivos utilizados en las determinaciones fotofísicas................................ 32

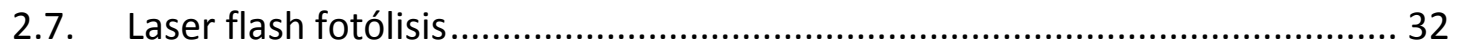

2.7.1. Descripción del instrumental.............................................................. 34

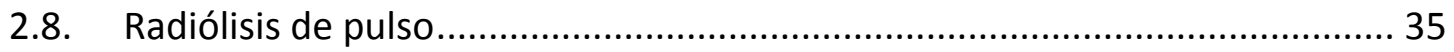

2.8.1. Formación y detección de los radicales y sus productos .......................... 36

2.8.2. Descripción del instrumental.......................................................... 40

2.9. Cromatografía liquida de alta performance ............................................ 40

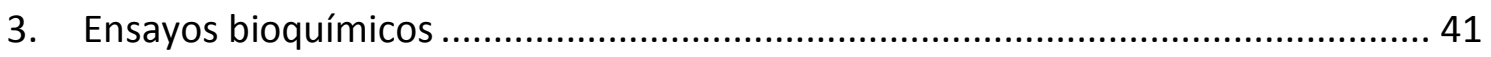

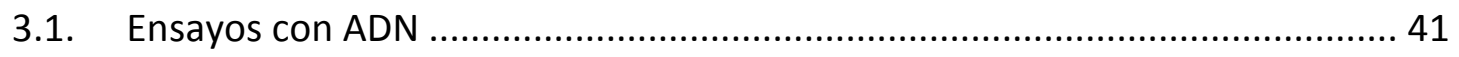

3.1.1. Materiales empleados ................................................................ 43

3.2. Cambios conformacionales en plásmidos ................................................ 44

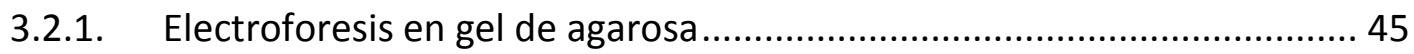

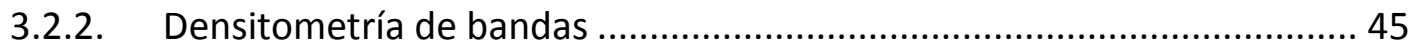

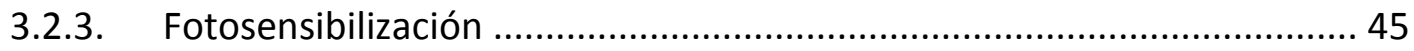

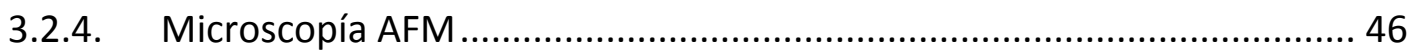

3.3. Interacción polinucleótido-complejo........................................................... 48

3.3.1. Desactivación de la emisión ............................................................ 48

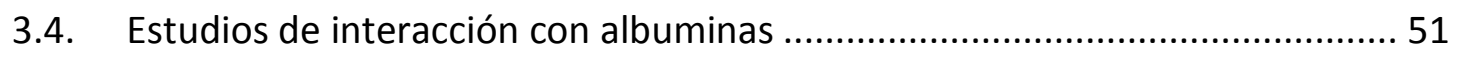




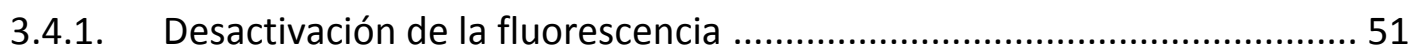

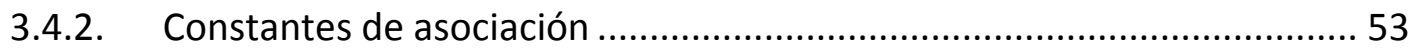

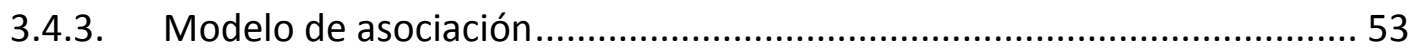

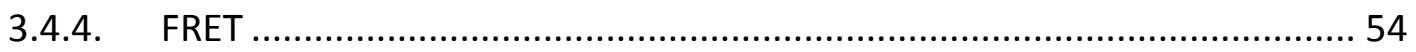

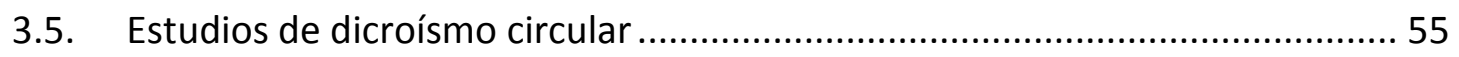

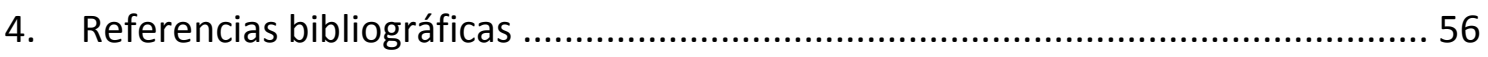

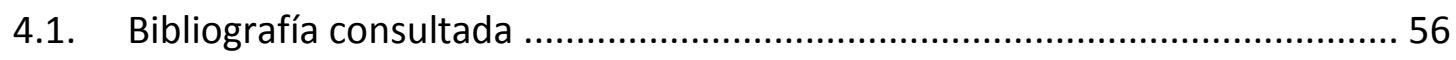

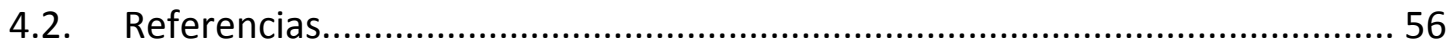




\section{Reactivos generales, técnicas de síntesis y caracterización}

\subsection{Reactivos generales}

El agua que se utilizó en los ensayos fue agua de muy baja conductividad (grado Milli Q). Todos los solventes utilizados durante el trabajo de tesis, fueron de grado HPLC. Los reactivos particulares de cada ensayo, están detallados junto a sus respectivas técnicas.

\subsection{Reactivos utilizados en la síntesis y caracterización}

Los reactivos utilizados en la síntesis del complejo de Renio(I) con pterina (RePtr) fueron, pterina comprada a SIGMA y $\mathrm{CIRe}^{\prime}(\mathrm{CO})_{5}$ comprado a ALDRICH.

\subsection{Técnicas de caracterización}

Para obtener una completa caracterización de la estructura química del complejo se utilizaron las técnicas de: espectrometría de masas (con sus variantes ESI, PESI, MALDI y LDI); espectrometría de difracción de rayos X; espectrometría de absorción infrarroja, con transformada de Fourier; espectrometría de resonancia magnética nuclear de ${ }^{13} \mathrm{C} e$

${ }^{1} \mathrm{H}$ y análisis elemental. Para la caracterización también se utilizó la espectroscopía de absorción UV-Visible, la cual se describe junto a las técnicas fotoquímicas.

\subsubsection{Espectrometría de masas}

Esta potente técnica permite identificar la composición y peso molecular de los iones volatilizados utilizando la relación isotópica característica de cada elemento.

La técnica de espectrometría de masas (MS) consiste en la ionización y volatilización de una muestra la que es introducida en un campo magnético que dirige los iones a un analizador de masas, este mide la relación masa/carga de estos iones. Con los datos obtenidos se construye un espectro en el que se grafica la intensidad de la señal en 
función del peso molecular del fragmento. Adicionalmente, pueden inducirse colisiones entre iones seleccionados y luego analizar los fragmentos resultantes.

En esta tesis las determinaciones por MS se utilizaron como técnica complementaria en la caracterización del complejo estudiado. Esta técnica permite combinar distintos métodos de ionización y detección, a continuación se describen brevemente los detalles experimentales de estas técnicas empleadas.

\subsubsection{Análisis ESI-MS}

El análisis fue realizado con un espectrómetro de masas con trampa de iones operado en los modos ion positivo y negativo, se utilizó ionización de electro-spray de alto flujo asistido con descarga en corona [1]. Los espectros fueron obtenidos y analizados con el programa Thermo Xcalibur Qual Browser.

\subsubsection{Análisis PESI-MS}

En las determinaciones con la técnica de ionización con sonda por electro-spray (PESI) [2], las especies ionicas fueron analizadas por un espectrómetro de masas lineal con trampa de iones equipado con, un inductor de disociación por colisión y otro de colisión inducida por pulsos Q. Las soluciones stock del complejo fueron preparadas en metanol y cada experimento fue repetido al menos tres veces para garantizar su reproducibilidad. Los espectros fueron obtenidos y analizados con el programa Thermo Xcalibur Qual Browser.

\subsubsection{Análisis MALDI-TOF/TOF MS y LDI-TOF/TOF MS}

El complejo RePtr fue analizado por espectrometría de masas con desorción/ionización laser ultravioleta asistida por matriz (UV-MALDI MS) y espectrometría de masas con desorción/ionización laser ultravioleta (UV-LDI MS). En esta variante la ionización se logra excitando una matriz que transfiere su energía al analito. El espectrómetro de masas fue utilizado en los modos ion positivo y negativo (MS/MS). Para UV-MALDI MS, las soluciones de la matriz fueron de norharmano. Para los experimentos de UV-MALDI MS, se usó el método de gotita seca o sándwich de acuerdo con Nonami et al. [3]. Los espectros fueron obtenidos y analizados con los programas Flex Control y Flex Analysis, respectivamente. 


\subsubsection{Difracción de rayos $X$}

La técnica de difracción de rayos $\mathrm{X}$ permite obtener la posición relativa de los átomos en una muestra cristalizada, así como también permite inferir la naturaleza de los mismos. Las medidas fueron realizadas con un difractometro Oxford Xcalibur, Eos, Gemini CCD. La intensidad de difracción de rayos $X$ fue colectada, integrada y escalada con el paquete integrado de programas Crys Alis Pro. La estructura fue resuelta por el método directo con SHELXS-97 [4] y el modelo molecular de refinado de matriz completa de mínimos cuadrados sobre $\mathrm{F}^{2}$ con el programa SHELXL-97 [5]. La información cristalográfica suplementaria se encuentra en CCDC-813774.

\subsubsection{Espectroscopía infrarroja}

La técnica de espectroscopía infrarroja con transformada de Fourier (FTIR) permite obtener información acerca de la absorción de radiación electromagnética por una muestra en función de la longitud de onda de irradiación en la región del infrarrojo. Esta longitud de onda es fundamentalmente absorbida por los enlaces moleculares, permitiendo de este modo obtener información sobre la energía de los mismos. En particular en este trabajo de tesis esta técnica se utilizó para caracterizar los productos de síntesis. Los espectros fueron registrados con un equipo Nicolet 8700 Thermo Scientific instrument. La muestra fue depositada en forma de pastilla con $\mathrm{KBr}$ o en solución acuosa.

\subsubsection{Resonancia magnética nuclear}

La técnica de resonancia magnética nuclear (RMN) se basa en la absorción de radiación electromagnética en la zona de las radiofrecuencias por parte de los núcleos atómicos con número de espín fraccionario, con la posterior determinación de la energía liberada en el restablecimiento del estado basal. En particular, en esta tesis, se utilizaron mediciones sobre los isotopos ${ }^{1} \mathrm{H}\left({ }^{1} \mathrm{H}-\mathrm{RMN}\right)$ y ${ }^{13} \mathrm{C}\left({ }^{13} \mathrm{C}-\mathrm{RMN}\right)$. En ausencia de campo magnético estos espines se orientan al azar. Al aplicar un campo magnético externo, los núcleos con componente del momento magnético de espín positiva en la dirección del campo, se orientaran de forma paralela al campo externo (con mínima energía), mientras que los núcleos con componente del momento magnético de espín 
negativa en la dirección del campo se orientan en dirección anti-paralela con el campo magnético (en estado de mayor energía). La diferencia de energía entre estos dos estados depende de la fuerza del campo magnético aplicado, a mayor campo, mayor diferencia de energía entre los dos estados. Cuando una muestra es irradiada con radiación electromagnética de frecuencia apropiada, los núcleos absorben la radiación y pasan del estado de menor al de mayor energía. Así, los núcleos están en resonancia con el campo aplicado. Luego, debe restablecerse la condición de equilibrio entre los niveles de energía, es decir debe producirse la relajación. Este fenómeno es detectado por el equipo y las señales son registradas en un gráfico de frecuencias vs. intensidad. La frecuencia de las oscilaciones del campo electromagnético que es absorbida, depende fuertemente del entorno electrónico del núcleo. Los núcleos se encuentran rodeados de electrones que se mueven generando un campo magnético inducido que se opone al campo magnético externo. De esta manera, el campo magnético que realmente llega al núcleo es más débil que el campo externo aplicado y por lo tanto, se dice que el núcleo está protegido o apantallado. Esto hace que los protones con entornos electrónicos diferentes, que se encuentran desigualmente protegidos o apantallados, resuenen a distintas frecuencias, y por lo tanto, tengan distintos desplazamientos químicos $(\delta)$ los cuales se expresan en ppm. La asignación de los desplazamientos a los entornos electrónicos de los distintos grupos funcionales, se realiza por comparación utilizando tablas de corrimientos obtenidas de bibliografía. Los datos obtenidos de los espectros de RMN proveen valiosísima información sobre la estructura de la molécula estudiada. Los espectros ${ }^{1} \mathrm{H}-\mathrm{RMN}$ y ${ }^{13} \mathrm{C}-\mathrm{RMN}$ fueron registrados a $300 \mathrm{~K}$ con un espectrómetro Bruker AM-500 medido a $500 \mathrm{MHz}$. Como solvente se utilizó $\left[D_{6}\right]$ DMSO (Dimetil Sulfoxido deuterado) y los corrimientos químicos fueron referidos al $\left(\mathrm{CH}_{3}\right)_{2} \mathrm{SO}$ (DMSO) en $\left[\mathrm{D}_{6}\right] \mathrm{DMSO}(\delta=2.50 \mathrm{ppm})$. Las soluciones fueron introducidas en un tubo de $5 \mathrm{~mm}$ de diámetro con una concentración $10^{-4} \mathrm{M}$.

\subsubsection{Análisis elemental}

El análisis elemental es una técnica instrumental que permite determinar el contenido porcentual de carbono, nitrógeno e hidrógeno presente en una muestra homogénea. Esta técnica se basa en la oxidación completa de la muestra, que tiene lugar a $1000{ }^{\circ} \mathrm{C}$ en oxígeno puro u otro oxidante. Los productos que resultan de la combustión son 
separados y analizados por cromatografía gaseosa con detección de conductividad. El resultado se expresa como la cantidad porcentual de $\mathrm{C}, \mathrm{H}$ y N presente en la muestra.

\subsection{Equilibrios de protonación}

El estudio de los equilibrios acido base, requiere la estimación de la concentración de las distintas especies que coexisten en equilibrio a las distintas condiciones de acidez. La cuantificación de la concentración de especies se realiza por medio de técnicas espectrofotométricas. La metodología de esta técnica consiste en registrar los espectros de absorción de todas las condiciones de acidez dentro de un rango determinado. Luego con un análisis computacional se determina la cantidad de especies que contribuyen a la absorción con sus respectivos $\varepsilon$ y su perfil de concentración.

\subsubsection{Análisis de regresión bilineal.}

Aplicando el análisis de regresión bilineal a la matriz experimental de absorbancia (construida con los espectros de absorción obtenidos a los diferentes $\mathrm{pHs}$ ), es posible determinar el mínimo número de especies que participan del equilibrio, así como sus respectivos perfiles de concentración y espectros de absorción [6]. La absorbancia se escribe en forma matricial $[A]=[\varepsilon][c]$, donde $[A],[\varepsilon]$ y $[c]$ representan las matrices: absorbancia, coeficiente de absorción molar y concentración, respectivamente. $E(i \mathrm{Xj})$, es la matriz error, donde $\mathrm{i}$ y $\mathrm{j}$ representan el $\mathrm{pH}$ y la longitud de onda respectivamente.El procedimiento se basa en el cálculo de las matrices $[\varepsilon]$ y $[c]$ por regresiones lineales múltiples (utilizando la condición de cuadrados mínimos). Se realizan iteraciones sucesivas hasta que el sistema converge, o sea se minimizan los elementos de la matriz error, A partir de la matriz error se obtiene la matriz de absorbancia corregida $\left[A_{c}\right]$. El número de especies es seleccionada como el mínimo valor que permite una aproximación razonable entre $\left[A_{c}\right]$ y $[A]$. A partir de la intersección del perfil de concentración para las distintas especies, en función del pH, pueden obtenerse las constantes acido-base de estos procesos. 


\subsubsection{Descripción del instrumental}

El pH fue medido con un medidor de pH Adwa AD8000, las medidas de absorción se realizaron en un equipo UV-1800 Shimadzu, se utilizaron celdas de cuarzo de calidad óptica de dos ventanas transparentes, se trabajó con soluciones abiertas a la atmosfera.

\section{Técnicas fotofísicas, fotoquímicas y químicas}

Las propiedades fotofísicas y fotoquímicas se estudiaron mediante varias técnicas: espectroscopía UV-Visible en el estado basal, espectroscopía de emisión estacionaria y resuelta en el tiempo, espectroscopía optoacústica, y láser flash fotolisis. El estudio de las reacciones térmicas entre el complejo y diferentes especies (oxidantes y reductoras) fue llevado a cabo utilizando la técnica de radiólisis de pulso. Los fundamentos y materiales de estas técnicas se detallan en esta sección.

\subsection{Espectrofotometría de absorción UV-Visible}

Esta técnica de espectroscopía estacionaria en solución, se utiliza en el rango aproximado que comprende desde UV-C, hasta el rojo, (200 a $800 \mathrm{~nm}$ ), lo que representa un rango de energías entre los $2-2,5 \times 10^{-25} \mathrm{~J}$. En este rango de energías se encuentran comprendidos varios interesantes procesos, tales como los de transiciones electrónicas que ocurren en los orbitales moleculares de un compuesto o entre orbitales de diferentes moléculas.

La radiación electromagnética, de una determinada longitud de onda, cuando es absorbida por una molécula promueve un cambio en su estructura electrónica. Se modifica el ordenamiento de los electrones en los orbitales moleculares, desde la configuración electrónica de menor energía (estado basal) a una configuración de alta energía (estado excitado). Si la multiplicidad de espín del estado basal es unitaria (singlete), se lo denotará como $\mathrm{S}_{0}$, si en cambio su multiplicidad es tres (triplete), se denota $T_{0}$. 
A su vez, la intensidad de radiación monocromática que no es absorbida (transmitida) en comparación con la intensidad que es absorbida, resulta proporcional a la cantidad de moléculas que absorben la radiación y a un parámetro relacionado con la probabilidad de que la radiación sea absorbida $(\varepsilon)$. De este modo, conociendo $\varepsilon$, la cantidad de moléculas absorbentes puede relacionarse con la intensidad de luz absorbida. A este parámetro, $\varepsilon$, se lo denomina coeficiente de absortividad molar cuando se expresa con unidades de $\mathrm{M}^{-1} \mathrm{~cm}^{-1}(\mathrm{M}=\mathrm{mol} / \mathrm{L})$

En soluciones diluidas, por lo general se puede asumir que las características de absorción están determinadas por las moléculas individuales de soluto. La medida directa de la absorción de luz por parte de una muestra, puede expresarse en unidades de transmitancia $T\left(T=I_{t} / I_{0}\right)$, siendo esta cantidad matemáticamente convertible a unidades de absorbancia (Abs) (Ecuación 1).

$$
\text { Abs }=-\log \left(\frac{I_{t}}{I_{o}}\right)
$$

Donde, $I_{t}$ e $I_{0}$ representan la intensidad de luz transmitida e incidente respectivamente, a una determinada longitud de onda $(\lambda)$.

El valor adimensional de la absorbancia, a su vez, puede ser relacionado con la concentración de la especie absorbente utilizando la ley de Lambert y Beer (Ecuación 2), para lo que debe corregirse la absorción, restándole la propia del solvente a la misma longitud de onda.

$$
A b s=\varepsilon b c
$$

Donde b es el camino óptico que transita el haz de luz dentro de la muestra (el cual al tratarse de muestras liquidas, es definido por la celda empleada) y c es la concentración del analito en unidades de molaridad (M).

\subsubsection{Descripción del instrumental}

En este trabajo de tesis, se utilizó un espectrofotómetro UV-1800 Shimadzu de doble haz. Este equipo, básicamente se compone de, una lámpara deuterio y otra halógena, 
cuya luz emitida (190-1100 $\mathrm{nm}$ ) es colimada, y el haz resultante es monocromado con una red de difracción. Luego, el haz es dividido en dos, uno de los haces atraviesa la muestra, contenida en una celda de cuarzo y el otro se utiliza de referencia. Luego de atravesar la celda, se detecta la intensidad del haz de luz transmitida utilizando un fotodiodo. La intensidad detectada luego de atravesar la muestra, es contrastada punto a punto con la del haz de referencia (este equipo permite una resolución espectral de un nanómetro en un rango de 190-1100 nm). Con los programas adecuados se registran y almacenan los espectros. Las medidas, en esta tesis, se realizaron utilizando el solvente para fijar el cero de absorbancia. Se emplearon celdas de cuarzo (Hellma) 0,4 o 1,0 cm de camino óptico, de acuerdo a los requerimientos del experimento.

\subsubsection{Espectro de absorción}

Un espectro de absorción UV-Visible (UV-Vis) es la representación de la Abs en función de $\lambda$, para una muestra particular. También, suele graficarse el coeficiente $\varepsilon$ en lugar de la absorbancia cuando se busca interpretar características propias del analito y no las de la solución. El espectro de absorción contiene información sobre las transiciones electrónicas que ocurren en la molécula estudiada. Cuando un fotón y una molécula se encuentran cercanos se produce la interacción entre el campo eléctrico asociado a la molécula y el campo eléctrico asociado a la radiación. Esta perturbación puede conducir a un proceso en el cual el fotón transfiere su energía a la molécula dejando de existir y produce una variación en la estructura electrónica de la molécula. Esta variación se ve reflejada en una modificación de la ocupación de los orbitales moleculares. La configuración electrónica del estado fundamental cambia a un estado electrónicamente excitado. Las transiciones en las cuales se mantiene la misma multiplicidad de spin son completamente permitidas por la regla de selección de spin. De este modo, estas transiciones ocurren con una probabilidad mucho mayor que aquellas en las cuales si hay cambio de spin y que son no permitidas. Tanto los complejos de $\operatorname{Re}(\mathrm{l})$, que es un d6 de bajo espín, como los ligandos estudiados, poseen multiplicidad uno en su estado basal. Este estado fundamental se denominará $\mathrm{S}_{0}$. Los estados excitados poblados difieren en energía de acuerdo al nivel de energía molecular de los mismos, dando lugar a los estados excitados $S_{1}, S_{2} \ldots S_{n}$, donde $S_{1}$ es el 
estado excitado singlete de menor energía. Estos estados $S_{i}$ además poseen distintos sub-estados vibro-rotacionales. Las transiciones electrónicas de excitación ocurren en forma instantánea comparada con los movimientos nucleares (principio de FranckCondon), de modo que los estados generados conservan las coordenadas nucleares del estado basal. Así, se generan una serie de estados llamados estados de Franck-Condon. Entonces, un espectro de absorción refleja una superposición de todas las transiciones factibles, ponderadas de acuerdo a su probabilidad de ocurrir. Para lograr la asignación de una banda de absorción a una transición determinada (o a una combinación de ellas), pueden compararse los espectros obtenidos con los espectros de compuestos relacionados con transiciones ya asignadas. Otra herramienta muy útil para este fin son los cálculos computacionales, que utilizan la teoría del funcional de la densidad dependiente del tiempo (TD-DFT).

El entorno de solvatación del estado basal y el estado excitado, influye fuertemente en la estabilización de estos estados, por lo tanto los cambios en la constante dieléctrica del solvente se reflejan en cambios espectrales. Este efecto es particularmente importante en aquellas transiciones que involucran transferencias de carga, tales como las que ocurren entre el metal y el ligando.

En este trabajo, las medidas de absorción del estado basal se utilizaron para obtener información sobre la estructura electrónica y las transiciones en el soluto. Además esta técnica se utilizó para seguir y caracterizar: equilibrios acido-base, procesos químicos, reacciones de síntesis y fenómenos de interacción molecular. También, para determinar concentraciones y fijar la absorbancia de soluciones.

\subsection{Espectrofotometría de emisión}

La técnica de espectroscopía de emisión de radiación luminiscente, se basa en la cuantificación de la intensidad de luz emitida por una muestra. Esta cantidad es discriminada de acuerdo a la energía de los fotones emitidos. En esta técnica, la muestra se ilumina con radiación de una longitud de onda determinada, cubriendo un rango establecido. Luego de un corto periodo de tiempo (pocos nanosegundos) se detecta la intensidad de luz emitida. 
Los estados electrónicos excitados de una molécula, $S_{2}, S_{3} \ldots S_{n}$, generados por absorción de un fotón, decaen rápidamente al estado excitado más bajo, $\mathrm{S}_{1}$, mediante un proceso no radiativo llamado conversión interna $(\mathrm{Cl})$. Este estado, puede decaer al estado electrónico basal $\left(S_{1} \rightarrow S_{0}\right)$ mediante la emisión de un fotón (emisión luminiscente) o mediante una relajación no radiativa (RNR) (regla empírica de Kasha ${ }^{1}$ ). Los estados excitados, además poseen un exceso de energía vibro-rotacional. Este exceso se transfiere fácilmente a las moléculas del medio. A esta transformación se la denomina relajación vibracional $(\mathrm{RV})$. Los tiempos típicos para las transiciones entre y dentro de los estados excitados más altos ( $\mathrm{Cl}$ y RV) están en el orden de $10^{-12} \mathrm{~s}$. mientras que la RNR de $S_{1} \rightarrow S_{0}$ es mucho más lenta, típicamente del orden de $10^{-9} \mathrm{~s}$.

El cambio de un estado electrónico de singlete a triplete $(T)$, se da por un proceso denominado cruce inter-sistemas (CIS), que requiere un giro del espín o momento angular intrínseco de uno de los electrones. Estos procesos están altamente desfavorecidos en moléculas orgánicas. La transición $\mathrm{T}_{1} \rightarrow \mathrm{S}_{0}$ es mucho más lenta que $S_{1} \rightarrow T_{1}$. Sin embargo, existe una perturbación intra-molecular, llamada acoplamiento espín-órbita, que puede causar un cambio en la dirección del momento de espín de electrón durante las transiciones no radiativas y las transiciones radiativas. El acoplamiento espín-órbita es un efecto relativista que puede visualizarse como la acción de un campo magnético eficaz visto por los electrones, que orbitan alrededor de los núcleos cargados. Los efectos de acoplamiento espín-órbita en moléculas orgánicas, son generalmente débiles y como consecuencia hay poca mezcla entre los estados singlete y triplete. Sin embargo, los efectos se intensifican por la presencia de átomos pesados, conduciendo a CIS con constantes de velocidad varios órdenes de magnitud mayor.

\footnotetext{
${ }^{1}$ La regla de Kasha es un principio fotoquímico que postula que tras la absorción de un fotón por una molécula en su estado fundamental y la consiguiente población de estados electrónicos excitados, la emisión radiativa, tanto fluorescencia como fosforescencia, sucede desde el estado excitado de menor energía de la molécula. Se llama así por el espectroscopista estadounidense Michael Kasha (1920), que la propuso en 1950.
} 
Además de la fuerza de acoplamiento espín-órbita entre dos estados electrónicos, la brecha de energía electrónica entre ellos es el segundo factor importante que determina la velocidad de una transición no radiativa entre un estado singlete y un estado triplete, o viceversa. La ley de brecha de energía (energy gap law ${ }^{2}$ ) explica este comportamiento. Existen dos procesos de desexcitación radiativa. Uno que ocurre mediante transiciones sin cambio en el momento de spin, $\mathrm{S}_{1} \rightarrow \mathrm{S}_{0}$, conocido como fluorescencia, que siendo un proceso permitido se encuentra comúnmente en el orden de los nano segundos. El otro proceso, ocurre mediante transiciones $T_{1} \rightarrow S_{0}$, y se lo denomina fosforescencia. Este puede ocurrir en escalas de tiempo que van desde los cientos de nanosegundos y hasta las horas. Sin embargo cuando existe un efectivo acoplamiento spin orbita, con alto mezclado de estados triplete y singlete, es correcto referirse a este fenómeno como luminiscencia. En este caso, el rango de tiempos en los que ocurre la transición es altamente variable. Todos estos procesos se detallan en la figura 1 mediante un diagrama de Jablonsky modificado.

La emisión originada en un estado excitado de transferencia de carga metal ligando (MLCT) es sensible a la polaridad del solvente ya que las moléculas del mismo solvente se reorientan en función del momento dipolar generado por el estado excitado. Los solventes más polares tienen una mayor capacidad de reorientación generando una mayor estabilización en el estado excitado. Esto conduce a emisiones con máximos a menor energía. Para que esta dinámica tenga lugar, la redistribución del solvente debe ocurrir mucho más rápido que el decaimiento del estado excitado. Al enfriar una solución hasta $77 \mathrm{~K}$, esta se transforma en una matriz rígida de vidrio sin capacidad de reorientación y con menor capacidad de absorción de energía térmica. Esta condición modifica el máximo de emisión corriéndolo hacia el azul, efecto "rigidocrómico". Otro rasgo común de los espectros a baja temperatura es la observación de emisión estructurada.

\footnotetext{
${ }^{2}$ La ley de brecha de energía (EGL), indica que, menor será la constante de velocidad del proceso cuanto mayor sea la brecha de energía entre los niveles.
} 


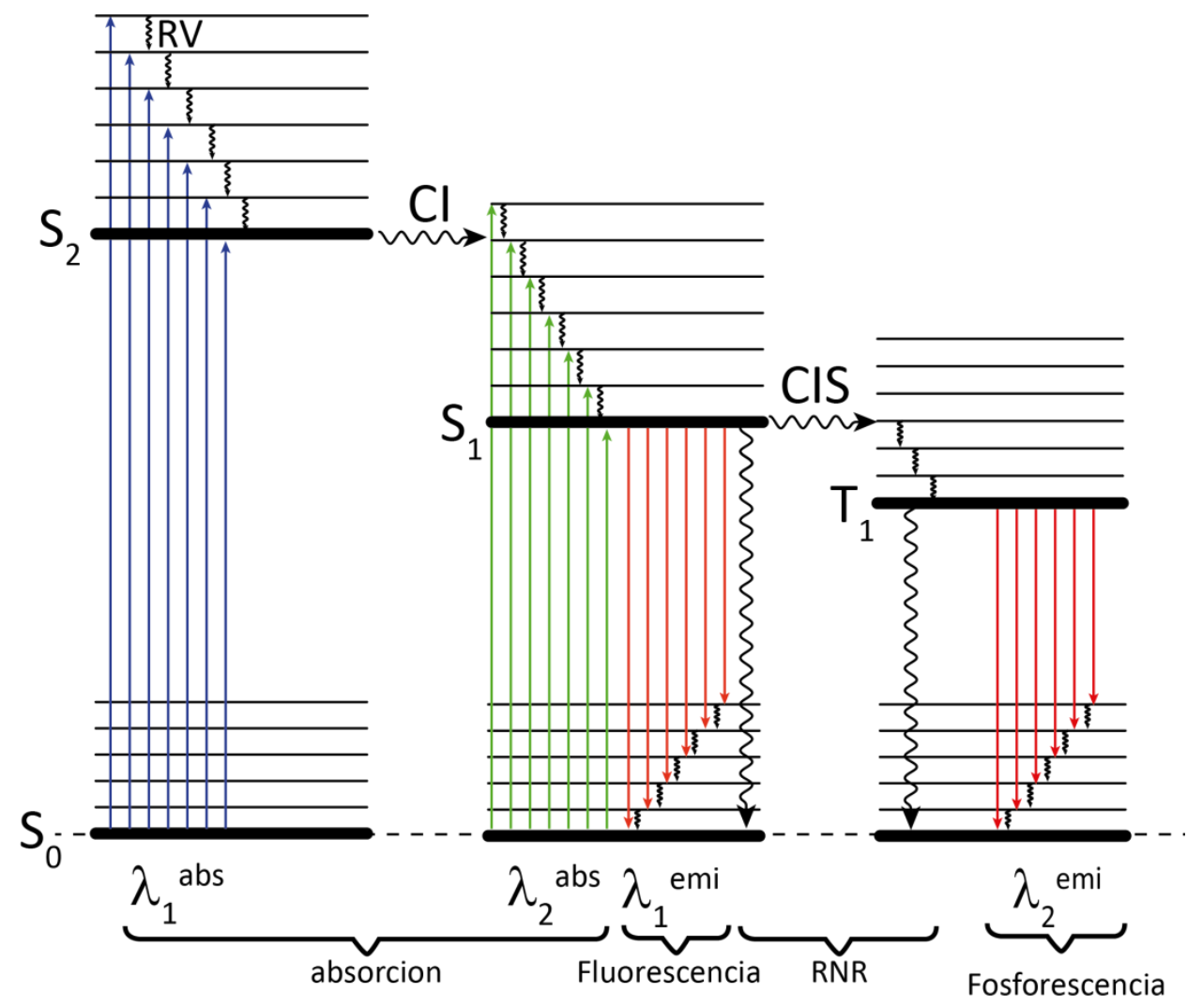

\section{Figura 1}

Diagrama de Jablonsky modificado para la absorción y emisión de un fluoróforo. Donde, RV: Relajación Vibracional, Cl: Conversión interna y CIS: Cruce Inter Sistemas, y RNR: relajación no radiativa.

\subsubsection{Descripción del instrumental}

Las medidas se realizaron a en un equipo FluoroMax 3, Horiba Jobin Yvon. Este equipo (figura 2) cuenta con dos fuentes de excitación, una lámpara de Xenón con un monocromador de excitación y un dispositivo de irradiación de nano LED. Posee rendijas de excitación y de emisión ajustables. La detección se realiza con un monocromador asociado a un detector que cuenta fotones individuales, utilizando un fotodiodo de referencia para corregir las señales. Los espectros de emisión se registran y son corregidos automáticamente por el equipo, tanto en la respuesta del fototubo como del monocromador de emisión. Las señales colectadas se analizaron con el programa propio del equipo FluorEssence ${ }^{\mathrm{TM}}$. Las medidas se realizaron a temperatura ambiente y a $77 \mathrm{~K}$. Se emplearon celdas de cuarzo de cuatro ventanas de calidad óptica de 0,4 y $1 \mathrm{~cm}$ de camino óptico. 


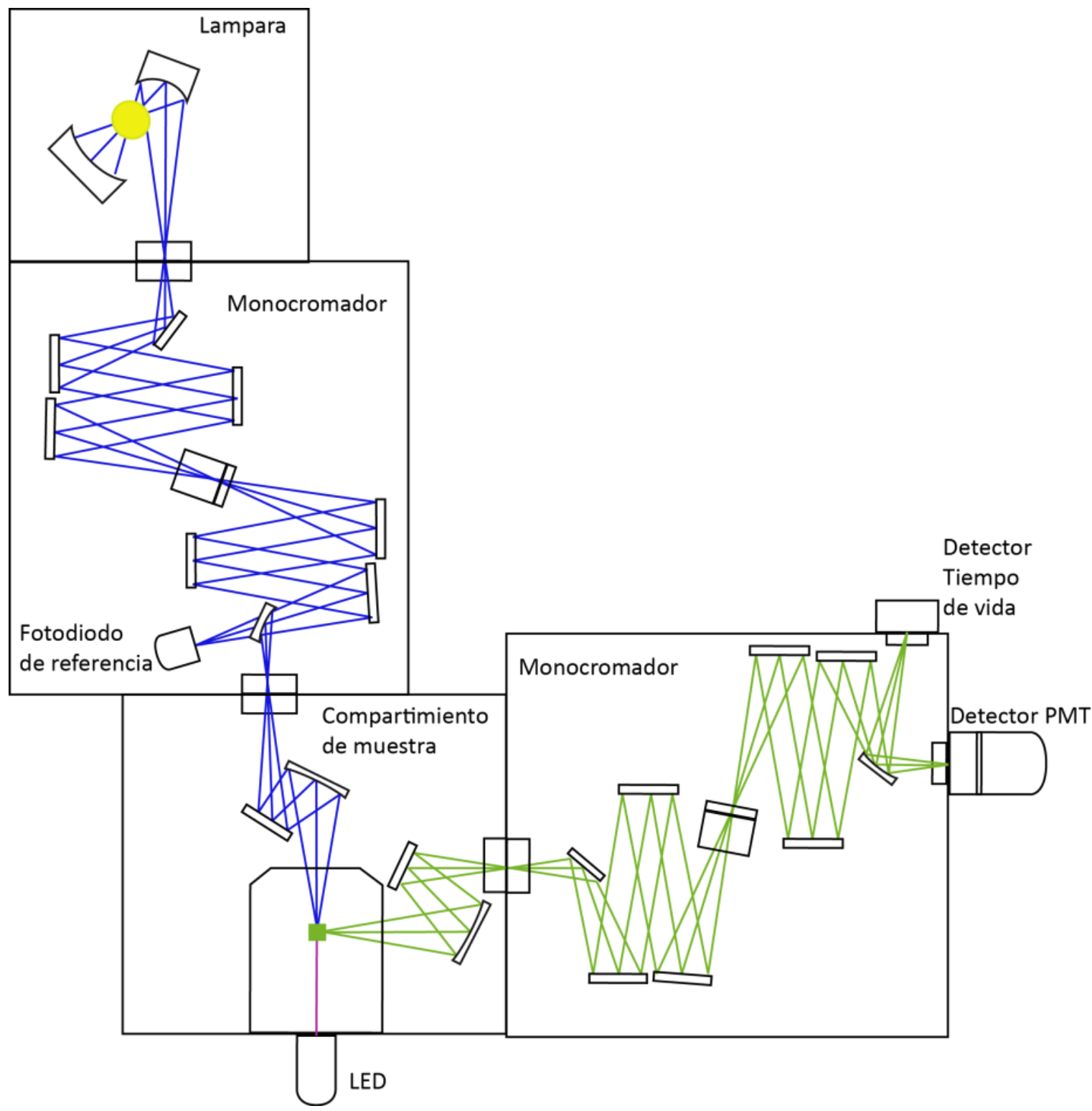

Figura 2

Esquema del espectrofluorómetro FluoroMax 3.

\subsubsection{Espectros de emisión}

El gráfico de la intensidad de luz emitida a cada longitud de onda, constituye el espectro de emisión de una sustancia. Al producirse la transición electrónica desde un estado excitado de alta energía a un estado de menor energía por una vía radiativa, se emite un fotón. La intensidad de luz emitida depende de la estructura química de la molécula y del solvente utilizado, por lo que es útil trabajar en distintos solventes y evaluar su influencia. Los espectros de emisión, dan información relacionada con los niveles de energía de los estados emisores. Con esta información es posible, estimar la 
diferencia de energía entre los estados electrónicos involucrados en una transición. Espectralmente, la luminiscencia aparece como una banda situada hacia el rojo de la primera banda de absorción y en forma aproximada de imagen especular de la banda de absorción. La mayor longitud de onda de la radiación emitida, con respecto a la radiación absorbida, se debe a una serie de fenómenos fisicoquímicos tales como: relajación vibracional, redistribución de electrones y reorientación en moléculas del solvente e interacciones entre la molécula absorbente y las moléculas del solvente. Este pérdida de energía se conoce como corrimiento de Stokes [7].

Experimentalmente es importante tener en cuenta determinadas situaciones. Cuando la solución medida tiene una alta absorbancia puede ocurrir que no toda la muestra absorba luz a lo largo del camino óptico modificando la intensidad de luz emitida. También puede ocurrir que parte de la luz emitida es reabsorbida por la muestra. Para evitar estos efectos de filtro interno, todas las medidas de fluorescencia se realizaron en soluciones acuosas con absorciones menores a 0,1 unidades de absorbancia a la longitud de onda de excitación.

\subsubsection{Rendimiento cuántico de emisión}

Los rendimientos cuánticos dan cuenta de la eficiencia de un proceso en términos de la cantidad de energía lumínica absorbida. El rendimiento cuántico de un proceso

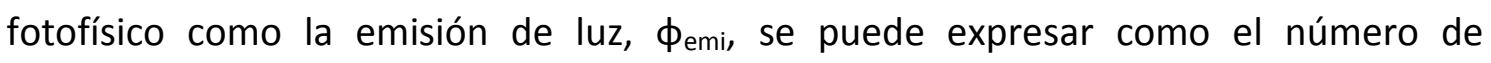
moléculas emisoras respecto del número de fotones absorbidos:

$$
\phi_{e m i}=N_{e m i} / N_{f o t}
$$

Donde $N_{\text {emi }}$ representa al número de moléculas emisoras por unidad de tiempo y por unidad de volumen y $N_{\text {fot }}$ indica el número de cuantos absorbidos por unidad de tiempo y por unidad de volumen. Como el número de fotones absorbidos es proporcional a la intensidad de la radiación absorbida, $I_{A b s}, y$ el número de fotones emitidos es proporcional a la intensidad de la radiación emitida, $l_{\text {emi, se }}$ puede considerar y escribir que: 


$$
\phi_{e m i}=I_{e m i} / I_{A b s}
$$

La expresión anterior es estrictamente válida cuando el estado excitado emisor es poblado en forma directa por la absorción de luz, es decir, cuando el rendimiento cuántico coincide con la eficiencia. Si el estado excitado emisor es poblado en forma indirecta siguiendo algún camino no radiativo, desde otro estado excitado que absorbió la luz, entonces el $\phi_{\text {emi }}$ se obtiene multiplicando la ecuación 4 por la eficiencia

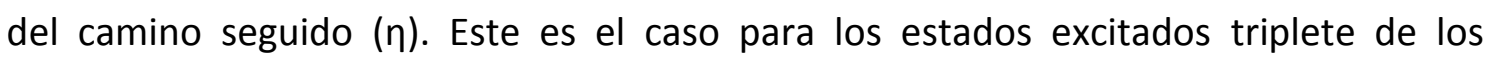
complejos y ligandos en estudio. Estos son poblados desde el correspondiente singlete a través de CIS. Por lo tanto, la expresión adecuada será:

$$
\phi_{e m i}=\eta_{c i s} I_{e m i} / I_{A b s}
$$

Cuando $\eta_{\text {cis }} \sim 1$ la ecuación anterior se vuelve a transformar en la expresión original. Experimentalmente, los rendimientos cuánticos de emisión de la solución, se determinan por comparación de la intensidad de la emisión, $l_{\text {emin }}$ tomada como el área bajo la curva del espectro de emisión, $A_{m}$, con el área bajo la curva de intensidad de emisión de una solución de referencia, $A_{r}$, de rendimiento cuántico conocido, medidas en iguales condiciones. La referencia a utilizar debe ser ópticamente comparable con la muestra (es decir, tener la misma densidad óptica y camino óptico y similar perfil de energía de emisión). Finalmente, tomando ambos espectros con el mismo equipo y en idénticas condiciones de temperatura, celda utilizada y abertura de las rendijas, los rendimientos cuánticos de emisión relativos pueden calcularse de acuerdo a la siguiente ecuación:

$$
\phi_{m}^{e m i}=\left(A_{r} I_{m} n_{m}^{2} / A_{m} I_{r} n_{r}^{2}\right) \phi_{r}^{e m i}
$$

Donde $n$ es el índice de refracción del solvente puro empleado en cada una de las soluciones. Estas medidas requieren, que las soluciones sean ópticamente diluidas 
$\left(A b s_{\lambda e x c} \leq 0,1\right)$ para evitar el efecto de filtro interno y permitiendo, además, despreciar las diferencias entre los $n$ del solvente puro y la solución.

\subsection{Espectroscopía de emisión resuelta en el tiempo}

Cuando una muestra es excitada por un pulso de luz corto, es posible observar el decaimiento de la luminiscencia en el tiempo. La técnica consiste en excitar la muestra con un pulso de luz muy corto de $\lambda$ apropiada y registrar el decaimiento de la emisión en función del tiempo. El pulso de luz genera un cierto número de moléculas en estado excitado $\left(\mathrm{N}^{*}\right)$. La velocidad con que decrece $\mathrm{N}^{*}$ puede describirse con la siguiente ecuación:

$$
\frac{\mathrm{d}\left(N^{*}\right)}{d t}=-k_{e m i} N^{*}
$$

Donde $k_{\text {emi }}$ es el coeficiente de velocidad de emisión espontánea, y es la sumatoria de todas las vías de decaimiento del estado emisor. Integrando la ecuación 7 con respecto al tiempo se obtiene:

$$
N^{*}(\mathrm{t})=\mathrm{N}_{0}^{*} \mathrm{e}^{-\left(\mathrm{t} k_{e m i}\right)}
$$

Donde $\mathrm{N}^{*}(\mathrm{t})$ y $\mathrm{N}_{0}^{*}$ son el número de moléculas en estado excitado a un tiempo t y 0 , respectivamente. Se espera que la intensidad de fluorescencia, que es proporcional al número de moléculas en el estado excitado, tenga un decaimiento exponencial. Se define entonces a $\tau_{\mathrm{emi}}$ como el tiempo requerido para que la intensidad de luminiscencia alcance 1/e de su valor inicial. [7] (Ecuación 9):

$$
\tau_{e m i}=\frac{1}{k_{e m i}}
$$

Realizando un ajuste de la curva de decaimiento con un exponencial es posible obtener el valor de la constante de decaimiento y el tiempo de vida de la especie emisora utilizando las ecuaciones 8 y 9. 
En caso de existir más de un estado emisor, con tiempos de vida lo suficientemente distintos, el ajuste puede hacerse con la suma de dos decaimientos exponenciales.

\subsubsection{Descripción del instrumental}

Para todas las medidas de emisión se utilizaron celdas de cuarzo de cuatro ventanas de calidad óptica, herméticas y equipadas con un robinete. Para los experimentos de luminiscencia resuelta en el tiempo se utilizaron dos tipos de equipamientos. Por un lado, un grupo de medidas de tiempo de vida fueron realizadas utilizando el tercer armónico $(355 \mathrm{~nm})$ de un láser pulsado Q-Switched Nd:YAG (7 ns FWHM) monitoreando la señal a diferentes longitudes de onda entre 500 y $600 \mathrm{~nm}$. Como detector para la emisión dispersada a través del monocromador, se utilizó un fotomultiplicador modificado 1 P28, con una respuesta temporal de 1 ns. La señal fue enviada a un osciloscopio de digitalización rápida (Rigol modelo DS1 102E).El tiempo de resolución total fue de 20 ns. El otro equipamiento utilizado, fue el Fluoromax 3 , antes descripto excitando con un nano-LED de $341 \mathrm{~nm}$ con un ancho de pulso de 0,2 $\mathrm{nm}$.

\subsection{Optoacústica}

La espectroscopía optoacústica resuelta en el tiempo inducida por láser (LIOAS), monitorea los pulsos de presión generados en una muestra líquida después de la excitación con un láser pulsado. La evolución en el tiempo del pulso de presión se detecta con un transductor piezoeléctrico rápido, colocado en un plano perpendicular a la dirección del haz de láser (figura 3). Los pulsos de presión en la muestra iluminada, surgen de los cambios de volumen producidos por, las vías de relajación no radiativa del estado excitado y por reordenamientos estructurales a nivel molecular $\left(\Delta \mathrm{V}_{\mathrm{e}}\right)$. Las vías de relajación no radiativa ( $R V$ y RNR), comprenden procesos de pérdida de energía de un estado vibracional excitado hacia el solvente. Generando así un aumento local en la temperatura del solvente inmediato a la molécula excitada. A este calor se lo denomina calor rápido. Este calor cedido al solvente induce una rápida expansión, que sumado a los cambios estructurales generan una onda de presión. El cambio de volumen estructural refleja el cambio de volumen propio de la molécula excitada y los 
movimientos en los alrededores en respuesta a eventos tales como el cambio momento dipolar, de transferencia de carga, etc.

La ecuación 10 representa una aproximación teórica que relaciona la amplitud de la primera onda optoacústica con la fracción de calor liberado en forma rápida $(\alpha)$, el cambio de volumen que produce la excitación y parámetros propios del solvente.

$$
\begin{gathered}
\mathrm{H}^{m}=\mathrm{k} n_{a b s}^{m}\left(\alpha \frac{\beta}{C_{p} \rho} E_{\lambda}+\Delta V_{e}\right) \\
n_{a b s}=\frac{n_{i}}{N A}\left(1-10^{-A b s}\right) \\
E_{\lambda}=\mathrm{NA} \frac{h c}{\lambda}
\end{gathered}
$$

Donde $\mathrm{n}_{\mathrm{abs}}$ representa en número de fotones absorbidos, $\mathrm{n}_{\mathrm{i}}$ el número de fotones incidentes, NA es el número de Avogadro. $\mathrm{H}$ representa la altura pico a pico de la primera onda acústica, Abs representa la absorbancia a la longitud de onda de excitación, $E_{\lambda}$ es la energía absorbida por mol de fotones. El término $\beta / C_{p} \rho$ representa las propiedades visco-elásticas del medio ( $\beta$ es el coeficiente de expansión isobárico, $C_{p}$ es la capacidad calorífica a presión constante y $\rho$ es la densidad) y $\mathrm{K}$ es una constante instrumental.

Por comparación de la señal obtenida para la muestra, con la de una referencia calorimétrica (libera toda la energía como calor rápido), es posible despejar las constantes de la ecuación, obteniendo:

$$
\frac{\mathrm{H}^{m}}{H^{r}}=\alpha+\frac{\Delta V_{e} C_{p} \rho}{\beta E_{\lambda}}
$$

Es posible que existan especies cuyo tiempo de vida supere a la ventana de tiempo en que se genera y detecta la onda optoacústica ( $5 \mu$ s en nuestro arreglo experimental) en cuyo caso esta energía no es detectada. Si parte del decaimiento de esta especie se superpone con la ventana de tiempo, se observará un corrimiento en la onda con 
respecto a la de la referencia y será necesario realizar un procedimiento matemático de deconvolución de la señal.

\subsubsection{Descripción del instrumento}

Las medidas de espectroscopía LIOAS fueron realizadas usando, como fuente de excitación un láser Q-Switched Nd:YAG (con 7 ns de ancho de pulso) operando a 355 nm. Para detectar las señales acústicas se usó un transductor cerámico de construcción casera PZT ( $4 \times 4 \mathrm{~mm})$ con un amplificador adecuado. La resolución temporal del experimento, determinada por esta configuración, fue de $\tau_{\mathrm{R}}=1 \mu \mathrm{s}$, generando una ventana de medida entre 0,2 y $5 \mu$ s. La configuración usada se presenta en la figura 3

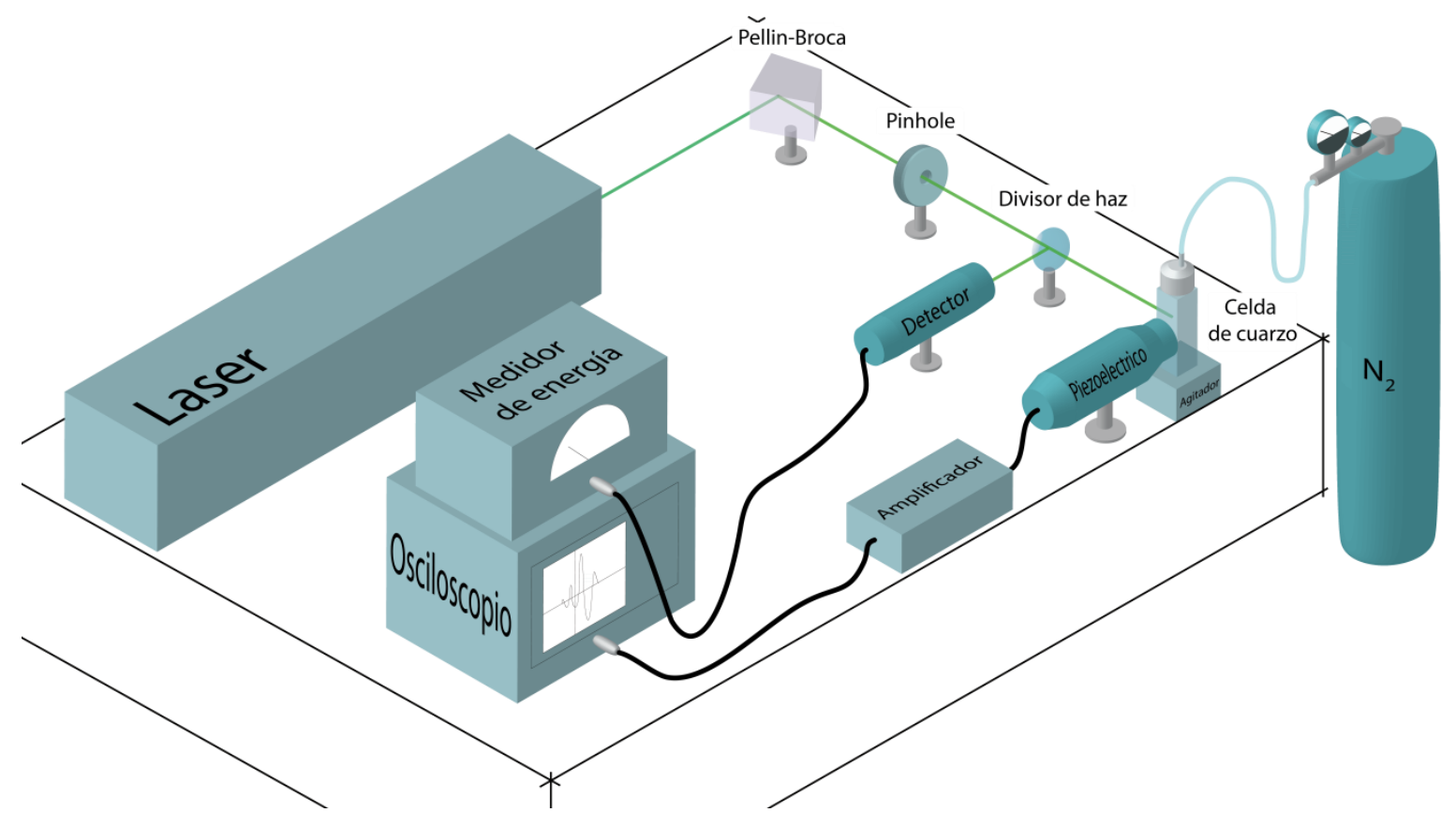

Figura 3

Representación de la configuración experimental usada para las mediciones por LIOAS

\subsection{Detección de ${ }^{1} \mathrm{O}_{2}$}

Luego del proceso de conversión interna que conduce a la formación del estado excitado $S_{1}$, se puebla el estado triplete $\left(T_{1}\right)$ por CIS. Como consecuencia de la colisión 
bimolecular entre $\mathrm{T}_{1}$ y oxígeno en su estado fundamental $\mathrm{O}_{2}\left({ }^{3} \Sigma_{\mathrm{g}}{ }^{-}\right)$se puede producir oxigeno singlete $\left(\mathrm{O}_{2}\left({ }^{1} \Delta_{\mathrm{g}}\right)\right)$ por transferencia de energía. Al estado excitado que transfiere energía a otra molécula se lo denominara fotosensibilizador o sensibilizador. Tal como se esquematiza en la figura 4, la generación fotoinducida de oxigeno singlete $\left({ }^{1} \mathrm{O}_{2}\right)$ consiste en la transferencia de energía desde una molécula electrónicamente excitada, en estado triplete, al $\mathrm{O}_{2}$. Como consecuencia de esta transferencia se regenera el sensibilizador en su estado basal y el $\mathrm{O}_{2}$ queda en su estado excitado singlete. El estado triplete del sensibilizador, es el que tiene la capacidad de transferir su energía al oxígeno molecular $\left({ }^{3} \mathrm{O}_{2}\right)$ disuelto en el medio, ya que en general posee un tiempo de vida lo suficientemente largo como para que el encuentro sea probable. Para que ocurra la transferencia, además, el triplete excitado debe tener un nivel de energía compatible con el estado basal del oxígeno. La técnica de detección de ${ }^{1} \mathrm{O}_{2}$ consiste en la irradiación de una muestra con pulsos cortos de láser para luego seguir la fosforescencia típica de oxigeno singlete a 1274 nm en función del tiempo.

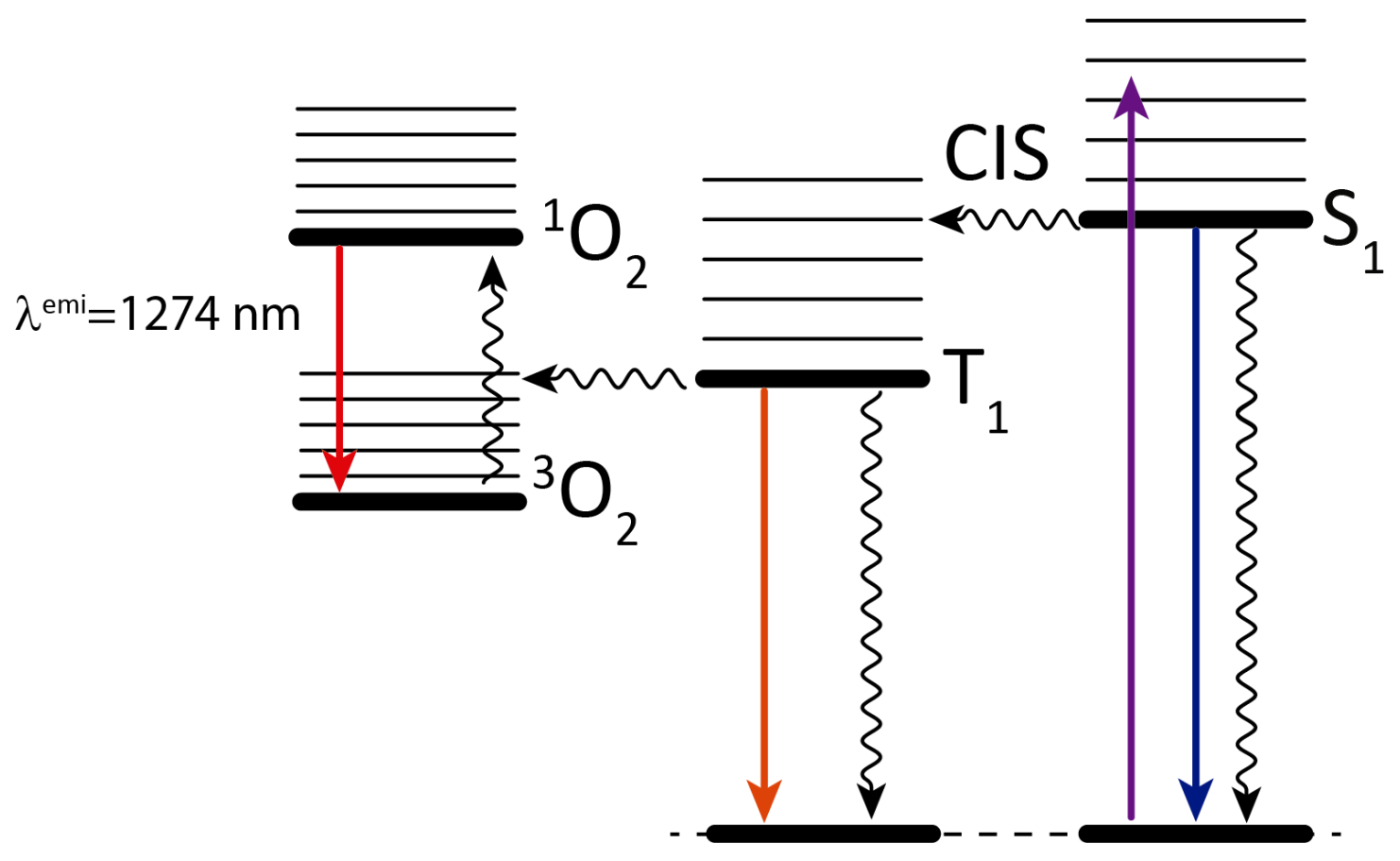

Figura 4

Diagrama de Jablonsky modificado en el que se representa la producción fotosensibilizada de oxígeno singlete. 


\subsubsection{Rendimiento cuántico de producción de ${ }^{1} \mathrm{O}_{2}$}

El rendimiento cuántico de producción de oxígeno singlete $\left(\phi_{\Delta}\right)$ se define como el número de moléculas de ${ }^{1} \mathrm{O}_{2}$ generadas por cada fotón absorbido por el fotosensibilizador. La producción de ${ }^{1} \mathrm{O}_{2}$ por fotosensibilización comienza con la absorción de la luz por el fotosensibilizador, que genera el estado triplete por ICS (el rendimiento cuántico de este proceso es la eficiencia de CIS ( $\left.\eta_{\text {CIS }}\right)$ o rendimiento cuántico de formación de triplete $\phi_{T}$ ). Luego, se produce la interacción entre el estado triplete excitado y el oxígeno molecular. Finalmente, ocurre la transferencia de energía desde el estado triplete al oxígeno molecular; la probabilidad de esta transferencia de energía es $\mathrm{P}_{\mathrm{T}}$. La fracción de triplete desactivado por $\mathrm{O}_{2}$ que conduce a la formación de ${ }^{1} \mathrm{O}_{2}$ se la denomina $f_{\mathrm{T}}$. De este modo la ecuación para la el rendimiento cuántico de oxigeno singlete resulta:

$$
\phi_{\Delta}=\phi_{T} \mathrm{P}_{\mathrm{T}} f_{T}
$$

Las mediciones de $\phi_{\Delta}$ se realizan utilizando una sustancia de referencia de $\phi_{\Delta}$ conocido. Como referencia, se utilizaron soluciones de fenalenona $\left(\phi_{\Delta}=0.98\right)$ [8] ópticamente ajustadas al valor de absorción de las muestras. Para las mediciones de este trabajo, se usó la detección de la fosforescencia del oxigeno singlete resuelta en el tiempo a 1270 $\mathrm{nm}$. Se realizó un análisis exponencial simple del decaimiento, excluyendo la primer parte de la señal. Luego, se graficó la intensidad de la señal del ${ }^{1} \mathrm{O}_{2}$ extrapolada a cero (factor pre-exponencial A), corregida por la fracción de luz absorbida y el tiempo de vida, en función de la energía del láser para la muestra y la referencia. La relación entre las pendientes de los ajustes lineales de estas curvas, es proporcional a la relación de los rendimientos cuánticos de producción de Oxigeno singlete. De esta relación se puede calcular el $\phi_{\Delta}$ de la muestra desconocida [9]. El rendimiento de formación de ${ }^{1} \mathrm{O}_{2}$, se determinó utilizando la ecuación 15.

$$
\phi_{\Delta}^{\mathrm{m}}=\frac{\mathrm{A}^{\mathrm{m}} \tau_{\Delta}^{\mathrm{r}}\left(1-10^{-\mathrm{Abs} \mathrm{r}}\right)}{\mathrm{A}^{\mathrm{r}} \tau_{\Delta}^{\mathrm{m}}\left(1-10^{-\mathrm{Abs} \mathrm{m}}\right)} \phi_{\Delta}^{\mathrm{r}}
$$


Donde, el superíndice $\mathbf{m}$ se refiere a la muestra del complejo en estudio y el superíndice $\mathbf{r}$ se refiere a la referencia. Siendo $\mathbf{A}$ y $\boldsymbol{\tau}$, el factor pre-exponencial y el tiempo de vida del ${ }^{1} \mathrm{O}_{2}$ en el solvente empleado respectivamente, obtenidos de la señal de emisión. $\phi_{\Delta}^{\mathrm{r}}$ es el rendimiento cuántico de producción de ${ }^{1} \mathrm{O}_{2}$ de la referencia.

El otro factor que está presente en la ecuación $15,\left[\left(1-10^{-A b s} r /\left(1-10^{-A b s} \mathrm{~m}\right)\right]\right.$, se origina por la diferencia entre la cantidad de fotones absorbidos por la muestra y por la referencia. Debido a que se trabajó con valores de absorbancia muy cercanos entre sí, este valor resultó cercano a 1.

\subsubsection{Descripción del instrumental}

Como fuente de excitación utilizó el segundo armónico de un láser Nd:YAG (Litron) con emisión a $532 \mathrm{~nm}$ ( $2 \mathrm{~ns}$ de ancho de pulso y $5 \mathrm{~mJ}$ por pulso). La radiación emitida fue detectada perpendicularmente a la dirección del láser, usando un detector de Germanio (Judson $11685 \mathrm{p}$, de $5 \mathrm{~mm}$ de diámetro) provisto de un sistema interno de filtros apropiados. La señal eléctrica proveniente del detector fue digitalizada por el osciloscopio (500 MHz Agilent Infiniium) y almacenada. Las señales se analizaron luego con el programa adecuado. Las soluciones se prepararon en $\mathrm{D}_{2} \mathrm{O}$ y $\mathrm{ACN}$ de modo de obtener valores del tiempo de vida de la muestra y de la referencia $\left(\tau_{\Delta}\right.$ y $\left.\tau_{\Delta}{ }^{0}\right)$ mucho mayores que el tiempo de resolución del detector empleado (1 $\mu \mathrm{s})$.

\subsection{Reactivos utilizados en las determinaciones fotofísicas}

Como referencia en el cálculo del rendimiento cuántico de emisión, se utilizó pterina comprada a ALDRICH. Los complejos $\operatorname{Re}(\mathrm{CO})_{3}(\mathrm{bpy}) \mathrm{CF}_{3} \mathrm{SO}_{3}, \operatorname{Re}(\mathrm{CO})_{3}($ phen $) \mathrm{CF}_{3} \mathrm{SO}_{3}$ y $\left.[\text { pyRe(CO) })_{3}(\mathrm{bpy})\right] \mathrm{CF}_{3} \mathrm{SO}_{3}$ fueron obtenidos de trabajos anteriores del grupo. Las soluciones saturadas en $\mathrm{N}_{2}$ y $\mathrm{O}_{2}$ se obtuvieron burbujeando estos gases ultra-puros.

\subsection{Laser flash fotólisis}

El método de flash fotólisis (LFF) es una poderosa herramienta para el estudio de las propiedades del estado excitado. Esta técnica utiliza un pulso corto de luz láser UV o 
visible para generar especies transientes, en cantidad suficiente como para observarlas espectroscópicamente. Esta técnica permite obtener los espectros de las especies excitadas y seguir su evolución en el tiempo. Como fuente de excitación se utiliza un láser pulsado, que permite el uso del método para detectar procesos desde los femto segundos, hasta nanosegundos. Los láseres de excímeros que se usan para excitar en la región UV emiten pulsos de luz de muy alta energía (35 a $200 \mathrm{~mJ} /$ pulso), están compuestos por una mezcla de un gas halógeno con un gas noble. La energía, ancho de pulso y frecuencia de emisión de este laser dependen de la composición de la mezcla gaseosa. Otro laser utilizado fue el láser Nd:YAG antes descripto.

Inicialmente la muestra tiene la configuración electrónica propia del estado fundamental $\left(\mathrm{S}_{0}\right)$. Al excitarla con el pulso de láser se genera una alta población de especies que conducen al estado excitado singlete $\left(S_{1}\right)$, que por CIS forman los estados excitados de tipo triplete $\left(T_{1}\right)$. Las moléculas en estado $T_{1}$ presentan un espectro de absorción (transiciones $T_{1} \rightarrow T_{n}$ ) diferente al observado para las moléculas en su estado fundamental (es decir, para la transición $S_{0} \rightarrow S_{1}$ ). Finalmente, el estado $T_{n}$ puede desactivarse decayendo al estado $S_{0} \circ$ al estado $T_{1}$ y luego a $S_{0}$. Todas estas vías ocurren en forma radiativa o no radiativa, generando una disminución en la absorción del estado triplete.

En cualquier instante de tiempo, la variación de la absorbancia con el tiempo se describe matemáticamente con la ecuación 16

$$
\Delta \operatorname{Abs}(\mathrm{t})=\log \left(\frac{I_{0}}{I_{t}}\right)
$$

Donde $\Delta A$ bs es la variación en la absorbancia, $I_{0}$ es la intensidad de luz medida antes del pulso del láser e $I_{t}$ representa la intensidad de luz medida por el fotomultiplicador a un cierto tiempo $t$ luego del pulso del láser. En la figura $\mathbf{5}$ se muestra una traza típica obtenida por este método. 


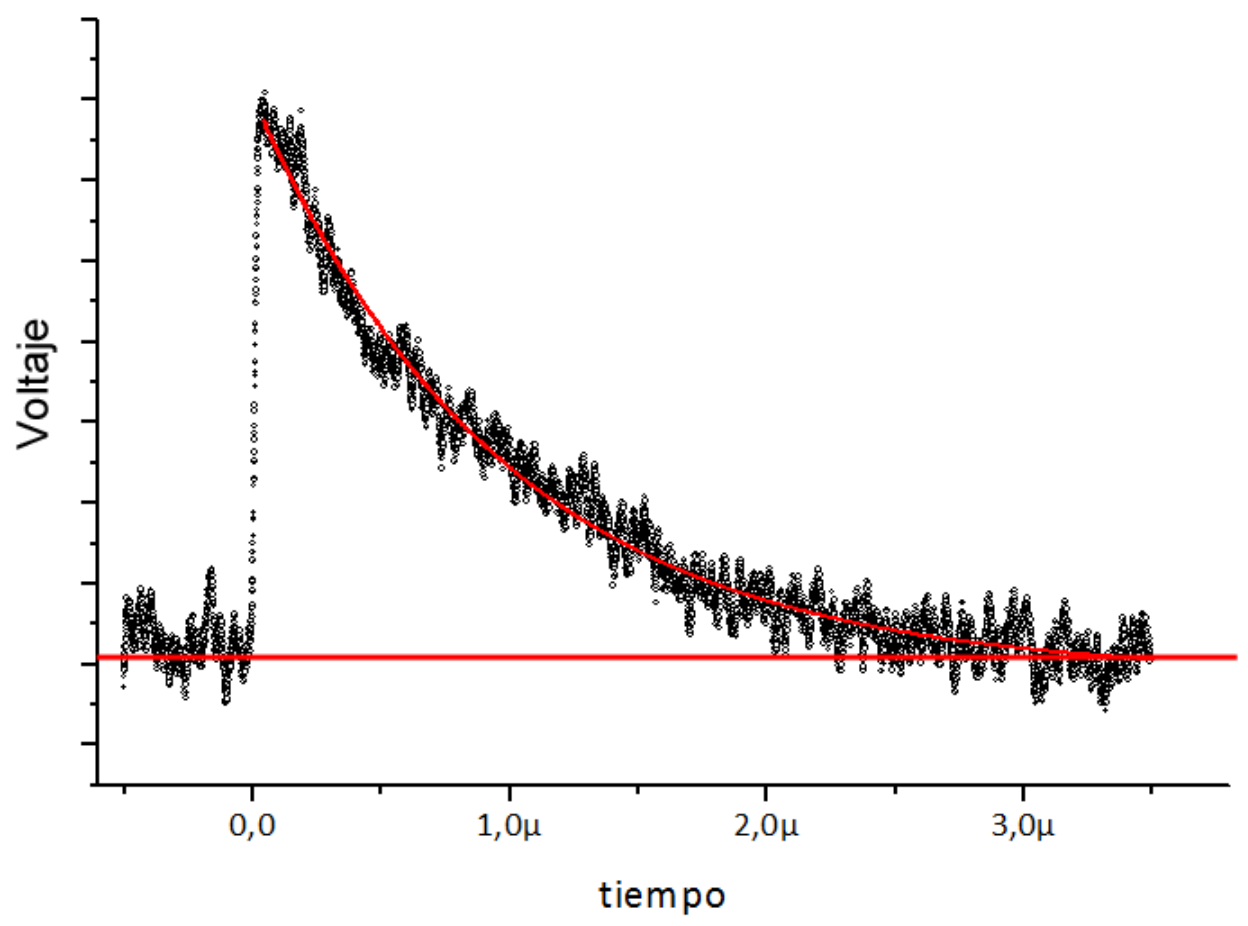

\section{Figura 5}

Esquema de una traza típica obtenida en un experimento de LFF, en línea continua se muestra un ajuste exponencial.

\subsubsection{Descripción del instrumental}

Para los experimentos presentados en este trabajo, se utilizaron celdas de emisión de cuarzo de calidad óptica $(1 \times 1 \times 4 \mathrm{~cm})$. En el extremo superior, la celda posee un robinete para permitir la deaireación de la solución antes, y/o durante, la medida. También se utilizaron celdas con sistema de flujo para refrescar la muestra. La fuente de la luz de análisis, fue una lámpara de arco de Xe con potencia de la luz emitida de 1 Kw. Esta luz de análisis es colimada y enfocada sobre la celda con la muestra, entrando por un pequeño orificio de $1 \mathrm{~mm}$. Los experimentos de LFF se realizaron en el laboratorio de radiación de la universidad de Notre Dame (Indiana EE.UU.), utilizando como fuente de excitación tercer armónico de un láser de $\mathrm{Nd}$ :YAG Litron (2 ns de ancho de pulso y $6 \mathrm{~mJ}$ por pulso a $355 \mathrm{~nm}$ ) y un láser de excímeros cargado con $\mathrm{Ne}, \mathrm{F}_{2}$ y Xe ( $351 \mathrm{~nm} / 20 \mathrm{~ns}$ ). El haz del láser se concentra sobre la celda incidiendo perpendicularmente a la luz de análisis, cubriendo totalmente el camino óptico del haz 
de análisis. El haz de salida de la celda se proyecta sobre la rendija de un monocromador. El detector consiste en un monocromador y un tubo fotomultiplicador, que envía la señal, previamente amplificada, a un osciloscopio digitalizador que convierte la señal a la forma digital y transfiere estos datos a una computadora para el posterior procesamiento. En la figura 6 se muestra un esquema del instrumental usado.

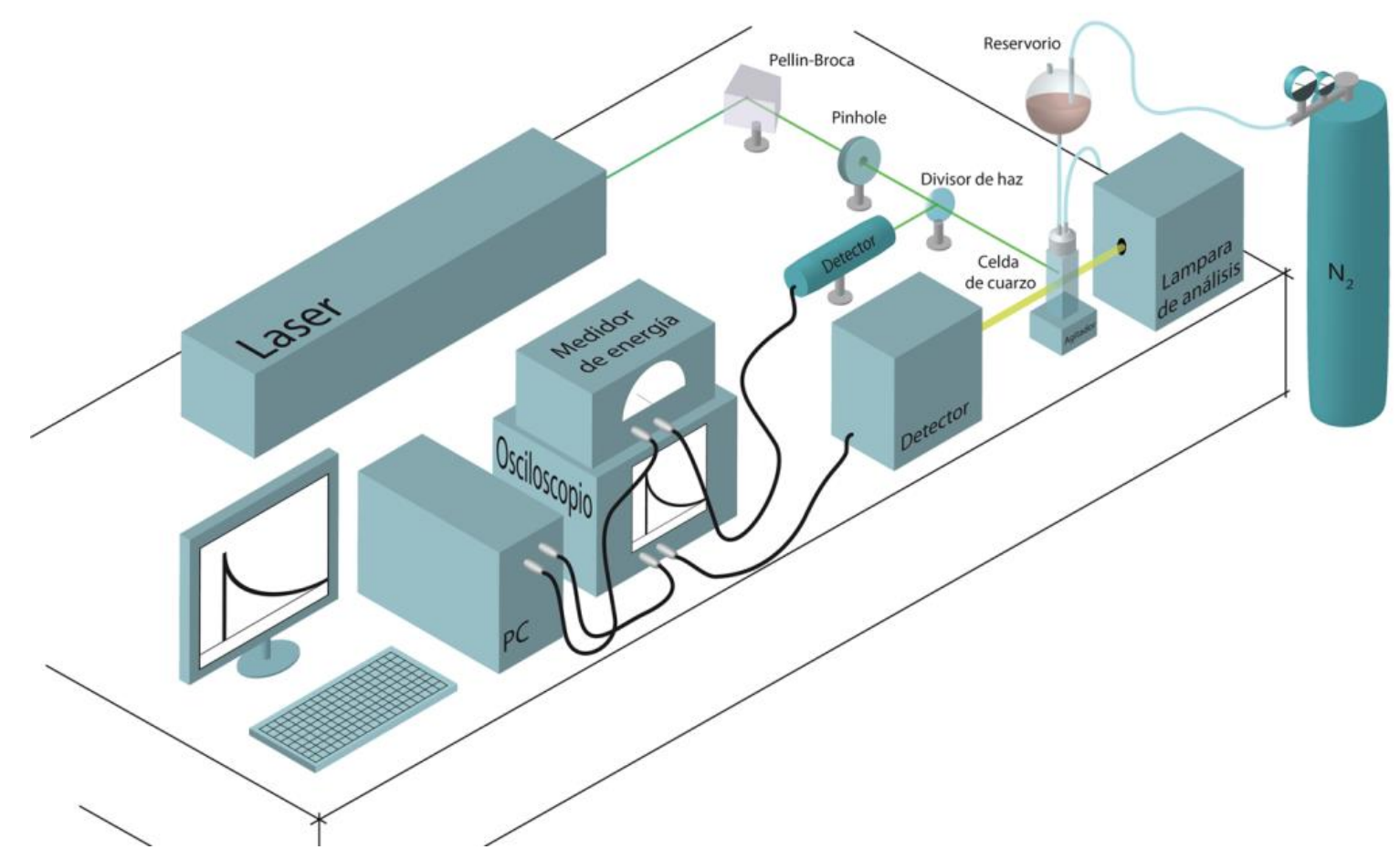

Figura 6

Representación de la configuración experimental usada para las mediciones por LFF

Se registran los cambios de absorción en función del tiempo, para las especies transitorias originadas por el pulso de luz, a una longitud de onda fija.

\subsection{Radiólisis de pulso}

Desde su invención por Boag y Hart y Keene, en la década del 60, la técnica de la radiólisis del pulso ha proporcionado un método poderoso para el estudio de especies inestables en solución acuosa. La técnica de radiólisis de pulso consiste en la irradiación de una muestra con un haz de electrones de muy alta energía, lo que genera la ionización del solvente. Los iones y electrones generados se recombinan 
rápidamente generando radicales $\left(10^{-6} \mathrm{M}\right)$. Los radicales libres reaccionan con las moléculas disueltas produciendo nuevas especies químicas. Estas especies son estudiadas en forma óptica siguiendo su espectro de absorción en el visible y ultravioleta cercano. En solución acuosa los radicales producidos mayormente son, el radical hidroxilo $\left(\mathrm{OH}^{\bullet}\right)$ el átomo de hidrogeno $(\mathrm{H})$ y el electrón solvatado $\left(\mathrm{e}_{\mathrm{sv}}{ }^{-}\right)$.

\subsubsection{Formación y detección de los radicales y sus productos}

\subsubsection{Radiólisis del agua}

Para lograr una apreciación completa de la utilidad de la técnica radiólisis de pulso en solución acuosa, se requiere un conocimiento básico de la química del agua luego de la irradiación.

Existen dos rasgos distintivos de la radiólisis de pulso: el primero es que en soluciones diluidas de la sustancia en estudio, la energía es absorbida principalmente por el agua; el segundo es la alta energía implicada, lo que resulta en la formación de iones y moléculas en estados excitados altos. La secuencia de eventos que sigue a la absorción de energía se resume en la figura 7.

La radiólisis del agua se completa en $10^{-7} \mathrm{~s}$, cuando las especies dejan de reaccionar, ya que en ese tiempo las moléculas excitadas por un mismo pulso están tan lejos que las posibilidades de reaccionar entre ellas son insignificantes [10].

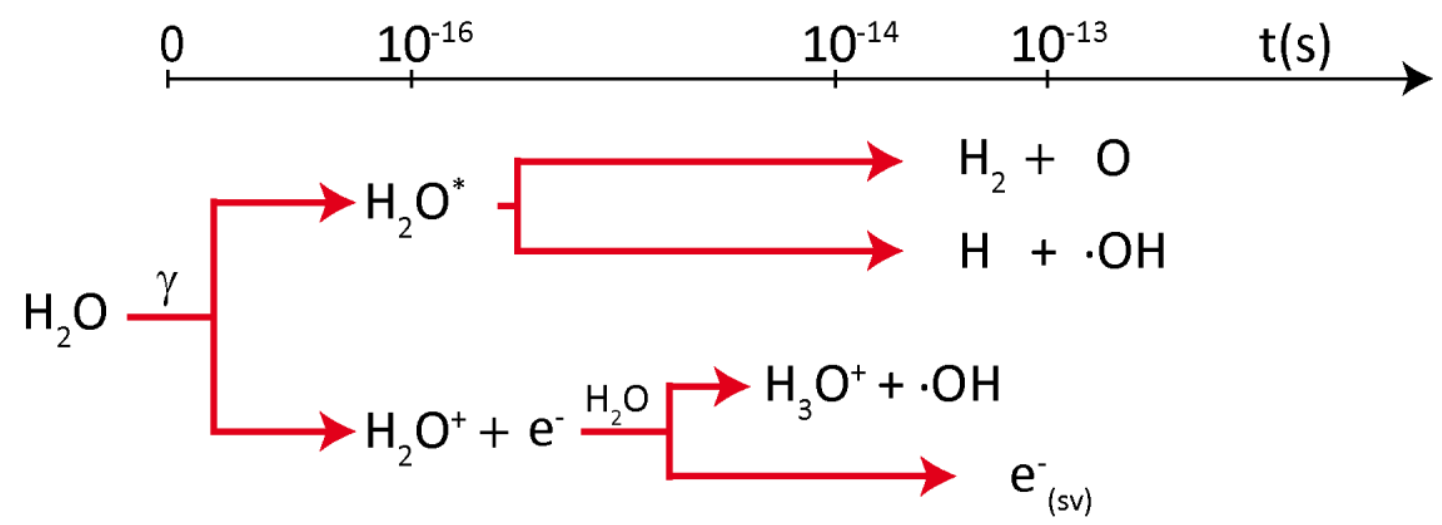

\section{Figura 7}

Formación de productos moleculares luego del pulso, con su escala temporal. 


\subsubsection{Propiedades de los radicales primarios}

El electrón solvatado $\left(e_{s v}^{-}\right)$es el más potente agente reductor. Reacciona como un nucleófilo en un proceso de transferencia de electrones que puede representar según la reacción 1

$$
e_{s v}^{-}+\mathrm{S}^{n} \rightarrow \mathrm{S}^{n-1}
$$

Donde $\mathrm{n}$ es la carga del soluto $\mathrm{S}$. Las constantes de velocidad para estas reacciones se detallan en la tabla 4. En solución acuosa el electrón solvatado suele denominarse electrón acuoso $\left(\mathrm{e}_{\mathrm{aq}}^{-}\right)$.

El átomo de hidrógeno es un radical reductor, que resulta poco importante en solución neutra, aunque, se convierte en el más significativo a pH ácido, se genera por la reacción 2

$$
e_{s v}^{-}+\mathrm{H}_{3} \mathrm{O}^{+} \rightarrow \mathrm{H}+\mathrm{H}_{2} \mathrm{O}
$$

El átomo de hidrogeno, $\mathrm{H}$, es un reductor ligeramente menos potente que el $\mathrm{e}_{s v}^{-}$, sin embargo en soluciones fuertemente ácidas puede actuar como oxidante.

El radical hidroxilo es un fuerte oxidante que oxida fácilmente iones inorgánicos. Puede reaccionar con otras moléculas según la reacción 3.

$$
\mathrm{OH}^{\bullet}+\mathrm{S}^{n} \rightarrow \mathrm{S}^{n+1}+\mathrm{OH}^{-}
$$

En la tabla 3 se indican las principales propiedades que gobiernan las reacciones de los radicales primarios, mientras que en la tabla $\mathbf{4}$ se indican las reacciones más relevantes en las que estos participan, junto con sus constantes de velocidad.

\section{Tabla 3}

Propiedades de radicales primarios en agua [10]

\begin{tabular}{|l|c|c|c|c|}
\hline Especie & $\mathbf{e}_{\mathrm{sv}}^{-}$ & $\mathbf{H}$ & $\mathbf{O H}^{\bullet}$ & $\mathbf{0}^{\bullet-}$ \\
\hline Coeficiente de difusión $\left(10^{-5} \mathrm{~cm}^{2} \mathrm{~s}^{-1}\right)$ & 4,9 & 8 & 2,2 & \\
\hline Potencial de reducción (V vs NHE) & $-2,9(\mathrm{pH} 7)$ & $-2,3(\mathrm{pH} 0)$ & $1,9(\mathrm{pH} 7) ; 2,79(\mathrm{pHO})$ & 1,77 \\
\hline
\end{tabular}




\section{Tabla 4}

Constantes de velocidad para las reacciones primarias que ocurren en la radiólisis del agua [10]

\begin{tabular}{|l|l|}
\hline Reacciones & k ( $\left.\mathbf{L ~ m o l}^{-1} \mathbf{s}^{-1}\right)$ \\
\hline $\mathrm{e}_{\mathrm{sv}}^{-}+\mathrm{H}_{2} \mathrm{O} \rightarrow \mathrm{H}+\mathrm{HO}^{-}$ & $1,9 \times 10^{1}$ \\
\hline $\mathrm{e}_{\mathrm{sv}}^{-}+\mathrm{HO}^{\bullet} \rightarrow \mathrm{HO}^{-}$ & $3,0 \times 10^{10}$ \\
\hline $\mathrm{e}_{\mathrm{sv}}^{-}+\mathrm{H}^{+} \rightarrow \mathrm{H}$ & $2,3 \times 10^{10}$ \\
\hline $\mathrm{e}_{\mathrm{sv}}^{-}+\mathrm{O}_{2} \rightarrow \mathrm{O}_{2}^{\bullet-}$ & $1,9 \times 10^{10}$ \\
\hline $\mathrm{H}^{+}+\mathrm{H}_{2} \mathrm{O} \rightarrow \mathrm{H}_{2}+\mathrm{HO}^{\bullet}$ & $10^{1}$ \\
\hline $\mathrm{H}+\mathrm{HO}^{-} \rightarrow \mathrm{e}_{\mathrm{sv}}^{-}$ & $2,2 \times 10^{7}$ \\
\hline $\mathrm{H}+\cdot \mathrm{H}^{-} \mathrm{H}_{2}$ & $2 \mathrm{k}=1,55 \times 10^{10}$ \\
\hline $\mathrm{H}+\mathrm{O}_{2} \rightarrow \mathrm{HO}_{2}^{\bullet}$ & $2,1 \times 10^{10}$ \\
\hline $\mathrm{HO}+\mathrm{HO}^{\bullet} \rightarrow \mathrm{H}_{2} \mathrm{O}_{2}$ & $2 \mathrm{k}=1,1 \times 10^{10}$ \\
\hline $\mathrm{HO}^{\bullet}+\mathrm{HO}^{-} \rightarrow \mathrm{O}^{\bullet}+\mathrm{H}_{2} \mathrm{O}$ & $1.3 \times 10^{10}$ \\
\hline $\mathrm{O}^{\bullet-}+\mathrm{H}_{2} \mathrm{O} \rightarrow \mathrm{HO}^{\bullet}+\mathrm{HO}^{-}$ & $10^{8}$ \\
\hline $\mathrm{O}^{\bullet-}+\mathrm{O}_{2} \rightarrow \mathrm{O}_{3}^{\bullet-}$ & $3,6 \times 10^{9}$ \\
\hline
\end{tabular}

\subsubsection{Formación de radicales secundarios}

La radiólisis del agua a $\mathrm{pH}$ neutro, genera el potente oxidante $\mathrm{OH}^{\bullet}$ y los potentes reductores $\mathrm{e}_{\text {sv. }}^{-}$y H. El tipo de radicales que quiera emplearse, puede seleccionarse por interconversión. La interconversión más común es la de $\mathrm{e}_{\mathrm{sv}}{ }^{-}$a $\mathrm{OH}^{\bullet}$ a través de reacciones 4 y 5 .

$$
\begin{gathered}
e_{s v}^{-}+\mathrm{N}_{2} \mathrm{O} \rightarrow \mathrm{N}_{2}+\mathrm{O}^{\bullet-} \\
\mathrm{O}^{\bullet-}+\mathrm{H}_{2} \mathrm{O} \rightarrow \mathrm{OH}^{\bullet}+\mathrm{OH}^{-}
\end{gathered}
$$

Saturando la solución con $\mathrm{N}_{2} \mathrm{O}$, puede despreciarse la reacción con $\mathrm{H}$, ya que comprende sólo el $10 \%$ de los radicales primarios en solución neutra y su reactividad con el $\mathrm{N}_{2} \mathrm{O}$ es menor.

El 2-propanol, genera un radical reductor menos potente que el $\mathrm{e}_{\mathrm{sv}}{ }^{-}$, este radical se genera según la reacción 6.

$$
\mathrm{OH}^{\bullet}+\left(\mathrm{CH}_{3}\right)_{2} \mathrm{COH} \rightarrow\left(\mathrm{CH}_{3}\right)_{2} \mathrm{COH}^{\bullet}
$$

También pueden generase radicales secundarios oxidantes, los mismos se producen por la reacción 7. 


$$
\mathrm{OH}^{\bullet}+\mathrm{X}^{-} \rightarrow \mathrm{X}^{\bullet}+\mathrm{OH}^{-}
$$

Como especie radical oxidante suele usarse la azida $\mathrm{N}_{3}{ }^{-}$cuya reacción con el $\mathrm{OH}^{\bullet}$ conduce a la formación del radical $\mathrm{N}_{3}{ }^{\circ}$.

El radical anión dióxido de carbono $\mathrm{CO}_{2}{ }^{\circ}$, es un eficiente agente reductor, que reduce rápidamente un gran número de iones y complejos metálicos acuosos. Esta especie puede generarse a partir de las reacciones 8 y 9 .

$$
\begin{gathered}
e_{s v}^{-}+\mathrm{CO}_{2} \rightarrow \mathrm{CO}_{2}^{\bullet-} \\
\mathrm{OH}^{\bullet}+\mathrm{HCO}_{2}^{-} \rightarrow \mathrm{CO}_{2}^{\bullet-}+\mathrm{H}_{2} \mathrm{O}
\end{gathered}
$$

Todos estos radicales son generados en forma controlada y pueden reaccionar con la molécula en estudio, conduciendo a distintos productos. Las especies transiente generadas inicialmente por reacción del radical con la molécula blanco pueden seguirse por absorción resuelta en el tiempo.

Un ejemplo muy bien documentado en literatura, de gran interés para realizar comparaciones con el complejo estudiado, es el del complejo $\mathrm{Ru}(\mathrm{bpy})_{3}{ }^{+2}$. Son conocidas las reacciones de este complejo con los radicales primarios y varios de los radicales secundarios de mayor interés. Además se conocen las constantes de velocidad para estos procesos. Esta información se resume en la tabla $\mathbf{5}$

\section{Tabla 5}

Constantes de velocidad para las reacciones entre radicales y $\mathrm{Ru}(\mathrm{bpy})_{3}{ }^{+2}[10]$

\begin{tabular}{|l|l|l|}
\hline Reacciones & pH & $\mathbf{k}\left(\mathbf{L ~ m o l}^{-1} \mathbf{s}^{-1}\right)$ \\
\hline $\mathrm{e}_{\mathrm{sV}}^{-}+\mathrm{Ru}(\mathrm{bpy})_{3}{ }^{+2} \rightarrow\left[\mathrm{Ru}^{\prime \prime}(\mathrm{bpy})_{2} \mathrm{bpy}^{-}\right]^{+}$ & 7 & $3,1 \times 10^{10}$ \\
\hline $\mathrm{H}+\mathrm{Ru}(\mathrm{bpy})_{3}{ }^{+2} \rightarrow\left[\mathrm{Ru}(\mathrm{bpy})_{3} \mathrm{H}\right]^{+2}$ & 2 & $9,5 \times 10^{9}$ \\
\hline $\mathrm{HO} 0^{\bullet}+\mathrm{Ru}(\mathrm{bpy})_{3}{ }^{+2} \rightarrow\left[\mathrm{Ru}(\mathrm{bpy})_{3} \mathrm{OH}\right]^{+2}$ & 7 & $6,8 \times 10^{9}$ \\
\hline $\mathrm{CO}_{2}{ }^{\bullet-}+\mathrm{Ru}(\mathrm{bpy})_{3}{ }^{+2} \rightarrow\left[\mathrm{Ru}^{\prime \prime}(\mathrm{bpy})_{2} \mathrm{bpy}^{\bullet-}\right]^{+}+\mathrm{CO}_{2}$ & $3-10$ & $6 \times 10^{7}$ \\
\hline$\left[\mathrm{Ru}^{\prime \prime}(\mathrm{bpy})_{2} \mathrm{bpy}^{\bullet}\right]^{+}+\mathrm{CO}_{2}{ }^{\bullet} \rightarrow \mathrm{Ru}^{\prime \prime}(\mathrm{bpy})_{2}\left(\mathrm{bpy}_{-} \mathrm{CO}_{2}{ }^{2-}\right)$ & & $1,7 \times 10^{9}$ \\
\hline $\mathrm{Ru}(\mathrm{bpy})_{3}{ }^{+2}+\mathrm{N}_{3}{ }^{\bullet} \rightarrow \mathrm{Ru}(\mathrm{bpy})_{3}{ }^{+3}+\mathrm{N}_{3}^{-}$ & 7 & $1,2 \times 10^{8}$ \\
\hline
\end{tabular}

Cuando se detecta la absorción de las especies generadas, muchas veces es necesario corregirla con la absorción típica de los radicales primarios. En la figura $\mathbf{8}$ se muestran los espectros correspondientes. 


\subsubsection{Descripción del instrumental}

Para los experimentos de radiólisis de pulso, se utilizaron celdas de cuarzo de calidad óptica de cuatro ventanas $(1 \times 1 \times 4 \mathrm{~cm})$ con un sistema de flujo para refrescar la muestra luego de cada serie de disparos. El burbujeo con los diferentes gases se realizó en el reservorio de muestras. La fuente de luz de análisis, fue una lámpara de arco de Xe con potencia de la luz emitida de $1 \mathrm{~kW}$. La fuente de irradiación es un acelerador lineal (LINAC) de $8 \mathrm{MeV}$ que puede emitir pulsos de electrones desde 2 ns hasta 1,5 $\mu \mathrm{s}$. La absorción de las especies generadas fue seguida en el tiempo por espectrofotometría resuelta en el tiempo, con un equipamiento similar al descripto para la técnica de LFF. La dosimetría, realizada para conocer el número de fotones absorbidos se realizó con una solución de $\mathrm{KSCN}$ de concentración conocida $\left(\varepsilon_{\mathrm{KSCN}}=7580\right.$ $\left.\mathrm{M}^{-1} \mathrm{~cm}^{-1}\right)[11]$.

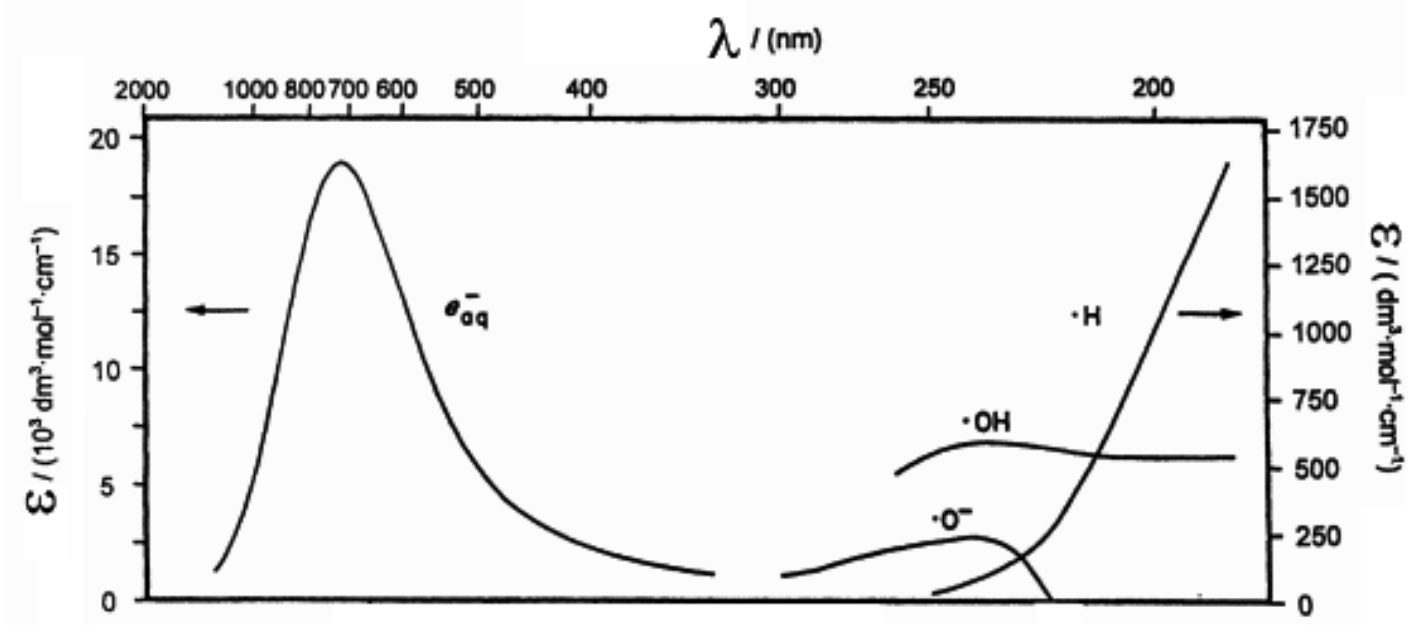

Figura 8

Espectro de absorción de los radicales primarios producidos en la radiólisis del agua.[10]

\subsection{Cromatografía liquida de alta performance}

Entre los ensayos implementados para identificar y caracterizar las especies presentes en solución, se utilizó la técnica de cromatografía liquida de alta performance (HPLC). El equipo utilizado fue un cromatógrafo Shimadzu Prominence LC-20A, este equipo cuenta con un sistema de detección formado por un detector con arreglo de diodo UV- 
Vis (SPD-M20A, Shimadzu), el cual permite hacer un monitoreo a todas las $\lambda$ entre 200 y $800 \mathrm{~nm}$. El equipo posee un programa de adquisición de datos (LC Solution) que permite registrar y analizar los espectros de absorción de cada uno de los analitos estudiados. La columna utilizada fue una C18.

\section{Ensayos bioquímicos}

Se realizaron una serie de experimentos para evaluar el comportamiento de distintos complejos tricarbonílicos de $\operatorname{Re}(\mathrm{I})$ con biopolímeros. Estos ensayos fueron, estudios de interacción de los complejos con ADN y con proteínas, seguidos por emisión. También se estudiaron los cambios inducidos en plásmidos por el estado basal y el estado excitado de complejos de $\operatorname{Re}(\mathrm{I})$. Estos cambios fueron seguidos por electroforesis $y$ microscopía AFM. A continuación se detallan la metodología y los materiales empleados.

\subsection{Ensayos con ADN}

En los ensayos bioquímicos se utilizaron tres tipos de polinucleótidos, plásmidos bacterianos, ADN eucariota y polinucleótidos sintéticos.

La molécula $A D N$ es, desde el punto de vista de la química, un polímero lineal de nucleótidos. Este se presenta en forma de doble hebra unida por interacciones hidrofóbicas y por puentes de hidrogeno entre las bases púricas y pirimidínicas de los nucleótidos (estructura primaria). La doble hebra se encuentra plegada sobre si misma adoptando una configuración de hélice levógira, dando lugar a distintos tipos de ADN $(A$ y $B$ ), existe también una configuración de hélice dextrógira denominada ADN Z. Estas estructuras difieren entre sí en la cantidad de vueltas por unidad de longitud y en la posición y profundidad de los surcos formados por el enrollamiento (estructura secundaria) (figura 9) [12]. En la superficie de estas moléculas se encuentran expuestos los grupos fosfatos de los nucleótidos, los cuales participan en la estabilización de la hélice. 
En la célula eucariota el ADN, metabólicamente inactivo, se encuentra en su forma BADN. Su conformación es aún más compleja que la expuesta aquí, con un plegamiento ultra compacto acompañado de proteínas. En este trabajo se utilizó ADN eucariota de timo de ternero libre de proteínas. El ADN bacteriano se encuentra de dos formas, como largas hebras enrolladas formando parte de la cromatina y en forma de pequeñas moléculas circulares de unos pocos kilo pares de bases (Kpb) llamadas plásmidos. Estos plásmidos poseen una conformación terciaria, superior a la doble hebra, que se presenta en forma de un superenrollamiento de la doble hebra sobre sí misma.

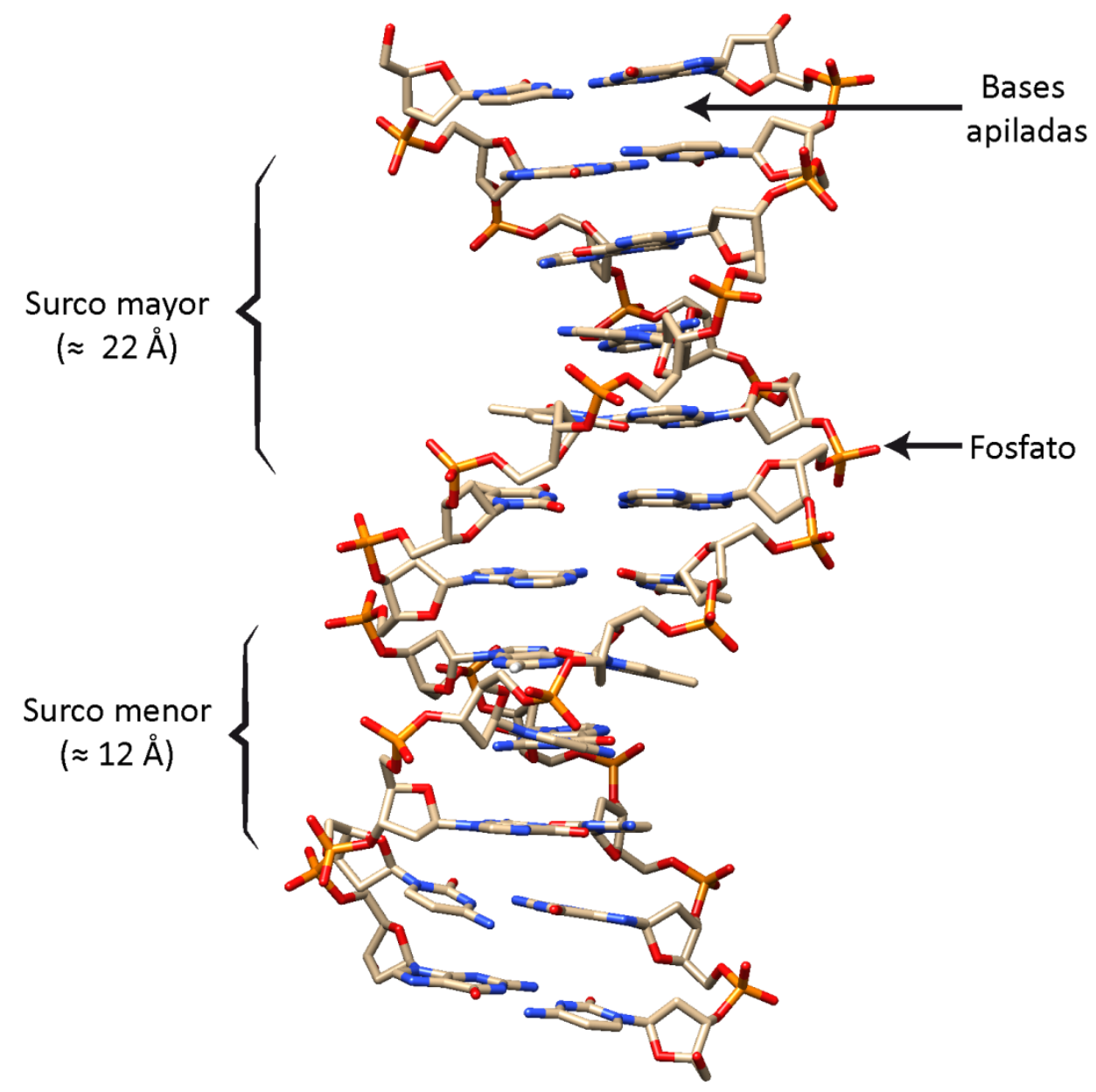

Figura 9

Estructura de la molécula de B-ADN 
Este superenrollamiento responde al relajamiento del exceso de tensión helicoidal que induce el enrollamiento de la doble hebra en esta molécula circular. Esta forma superenrollada es la forma natural en la que se encuentra dentro de la bacteria y es la misma con la que se trabajó en esta tesis. El grado se plegamiento del plásmido está estrechamente vinculado con la estructura secundaria de la molécula y cambios en esta estructura se ven reflejados en cambios en su conformación. Existen distintos procesos estudiados que conducen a una disminución en la tensión helicoidal y en el grado de superenrrollamiento. Estos procesos incluyen, la intercalación de moléculas entre los pares de bases; los cambios inducidos en la estabilidad electrostática de los fosfatos y el corte de una o ambas hebras.

\subsubsection{Materiales empleados}

Los plásmidos bacterianos empleados fueron: un plásmido de expresión del gen Gra7 de toxoplasma gondii (4,7 kpb) [13], Gra7-YFp y dos plásmidos comerciales, pRSET A $(2,9 \mathrm{kpb})$ y PTy $(3,1 \mathrm{kpb})$ comprados en Invitrogen, todos clonados y purificados por el grupo del Dr. Cabrerizo en el IIB-INTECH, según el siguiente protocolo:

- $\mathrm{S}_{1}:$ TRIS/HCL $50 \mathrm{mM}$ (TRIS = Tris-hidroximetilaminometano), $10 \mathrm{mM}$ EDTA (EDTA = ácido etilendiamino tetra-acético), $\mathrm{pH}=8$

- $\mathrm{S}_{2}$ : Sobre $10 \mathrm{ml}$ de $\mathrm{S}_{1}$ se agregan, 0,4 ml de $\mathrm{NaOH} 200 \mathrm{mM}, 1 \mathrm{ml}$ de SDS (SDS = Dodecil-sulfato sódico) $1 \%$ y $8,6 \mathrm{ml}$ de $\mathrm{H}_{2} \mathrm{O}$.

- $\mathrm{S}_{3}$ : Acetato de Potasio $3 \mathrm{M}, \mathrm{pH}=5,5$

1. Se cultiva una colonia de la cepa seleccionada en $50 \mathrm{ml}$ de medio LB (Medio de cultivo Luria Bertani) con los antibióticos adecuados a $37^{\circ} \mathrm{C} 12$ hs.

2. Se centrifuga una suspensión de las bacterias a 10000 RPM por $10 \mathrm{~min}$, se descarta el sobrenadante

3. Se resuspende el pellet completamente con $5 \mathrm{ml}$ de buffer $S_{1}$, con agregado de RNAsa.

4. Se agregan $5 \mathrm{ml}$ de buffer $\mathrm{S}_{2}$ y se mezcla invirtiendo de 6-8 veces, se incuba en hielo durante $5 \mathrm{~min}$. 
5. Se agregan $5 \mathrm{ml}$ de buffer $S_{3}$ y se mezcla invirtiendo de 6-8 veces, se incuba en hielo durante $5 \mathrm{~min}$.

6. Se centrifuga a 11000 RPM durante $30 \mathrm{~min}$ a temperatura ambiente.

7. Se transfiere el sobrenadante a un nuevo tubo y se agregan 0,7 volúmenes de isopropanol y se mezcla invirtiendo 6-8 veces. Se incuba en hielo por $5 \mathrm{~min}$.

8. Se centrifuga 50 minutos a 11000 RPM a $4{ }^{\circ} \mathrm{C}$. y se extrae el sobrenadante.

9. Se lava con $3 \mathrm{ml}$ de etanol $70 \%$ y se centrifuga a 11000 RPM durante $15 \mathrm{~min}$.

10. Se remueve el sobrenadante completamente. Se dejar secar el pellet.

11. Para redisolver, se agrega agua.

El ADN eucariota de timo de ternero fue comprado en SIGMA y utilizado sin posterior purificación. Se utilizaron también polinucleótidos sintéticos poly[dCdG $]_{2}$ y poly $[\mathrm{dAdT}]_{2}$. Estos polinucleótidos sintetizados artificialmente poseen en su estructura únicamente uno de los dos pares posibles de bases complementarias, los que se suceden en forma alternante (CG-GC-CG...). Estructuralmente no se diferencian del B$A D N$, lo que permite obtener información sobre las diferencias en la interacción nucleótido-específica. Estos polinucleótidos fueron comprados en SIGMA y utilizados sin posterior purificación. Todos los ácidos nucleicos mostraron una relación de absorción a 260/280 nm entre 1,8 y 2, confirmando con esto la ausencia de proteínas. Todos los experimentos se realizaron a temperatura ambiente y sin deaerear.

\subsection{Cambios conformacionales en plásmidos}

Un método experimental para determinar el grado de superenrollamiento de un plásmido, se basa en un descubrimiento hecho por Walter Keller de la Universidad de Heidelberg en 1974. Keller observó que si moléculas superenrolladas con números de enlace ligeramente diferentes se mueven a través de un gel de agarosa mediante electroforesis, no todos viajan a la misma velocidad, sino que las moléculas más compactas viajan más rápido creando un patrón de bandas discretas en el gel. Basado en esta propiedad de las moléculas circulares de ADN se evaluó el efecto de tres compuestos tricarbonílicos de $\operatorname{Re}(I)$ sobre la conformación de varios plásmidos. 


\subsubsection{Electroforesis en gel de agarosa}

La técnica de electroforesis se basa en la migración de partículas sobre un gel bajo la influencia de un campo eléctrico. Para realizar la electroforesis se colocan las macromoléculas en un gel de agarosa con pH adecuado. El gel se encuentra inmerso en un buffer contenido en una cuba con los electrodos sumergidos en ella. Al aplicar un campo eléctrico, la fuerza electromotriz mueve las macromoléculas hacia el ánodo o hacia el cátodo según posean carga negativa o positiva respectivamente.

En este trabajo de tesis se utilizó bromuro de etidio para el revelado del gel, el cual se fija al ADN y produce una fluorescencia característica al irradiarse con luz UV. Los geles se prepararon en solución reguladora TBE (Tris-Bórico-EDTA) con una concentración de $1 \%$ de agarosa. La unidad de alimentación utilizada fue una fuente continua que se operó a $60 \mathrm{~V}$. Los geles una vez corridos, se colocaron en un equipo fotográfico equipado con un transiluminador con luz UV y una cámara fotográfica digital y se fotografiaron. Con el fin de comparar las diferentes calles de un mismo gel, se adoptó como procedimiento de normalización, dividir la intensidad de cada banda por la suma de las intensidades de todas las bandas en el mismo carril. La menor intercalación del bromuro de etidio en el ADN superenrollado se tuvo en cuenta al dividir la intensidad correspondiente por 0,8 [14].

\subsubsection{Densitometría de bandas}

Las imágenes de los geles con las bandas reveladas se analizaron con el programa TotalLab de Nonlinear Dinamics, el cual permite obtener una curva de densidad óptica en función de la distancia. Integrando estas bandas de densidad se realizó el estudio cuantitativo de los cambios observados en los geles.

\subsubsection{Fotosensibilización}

El proceso de fotosensibilización consiste en la transferencia de energía desde el estado excitado del fotosensibilizador a una molécula blanco. En este trabajo se utilizaron complejos de $\operatorname{Re}(\mathrm{I})$ como fotosensibilizadores y plásmidos como blanco. La fuente de irradiación utilizada consiste en una lámpara Rayonet RPR (Southern N.E. Ultraviolet Co.) que presenta un máximo de emisión en 350 y un ancho de banda de alrededor de $20 \mathrm{~nm}$. 
Según el mecanismo, los procesos de fotosensibilización pueden ocurrir a través de transferencia de energía o transferencia de carga. La transferencia de energía provoca la formación de un estado excitado en la molécula blanco, mientras que el fotosensibilizador retorna al estado basal. Esta energía puede transferirse en forma radiativa o no radiativa. La transferencia de carga fotoinducida es un proceso redox que depende de los potenciales del estado excitado del sensibilizador y de la molécula blanco. En la figura 10 se muestra un esquema del equipamiento utilizado.

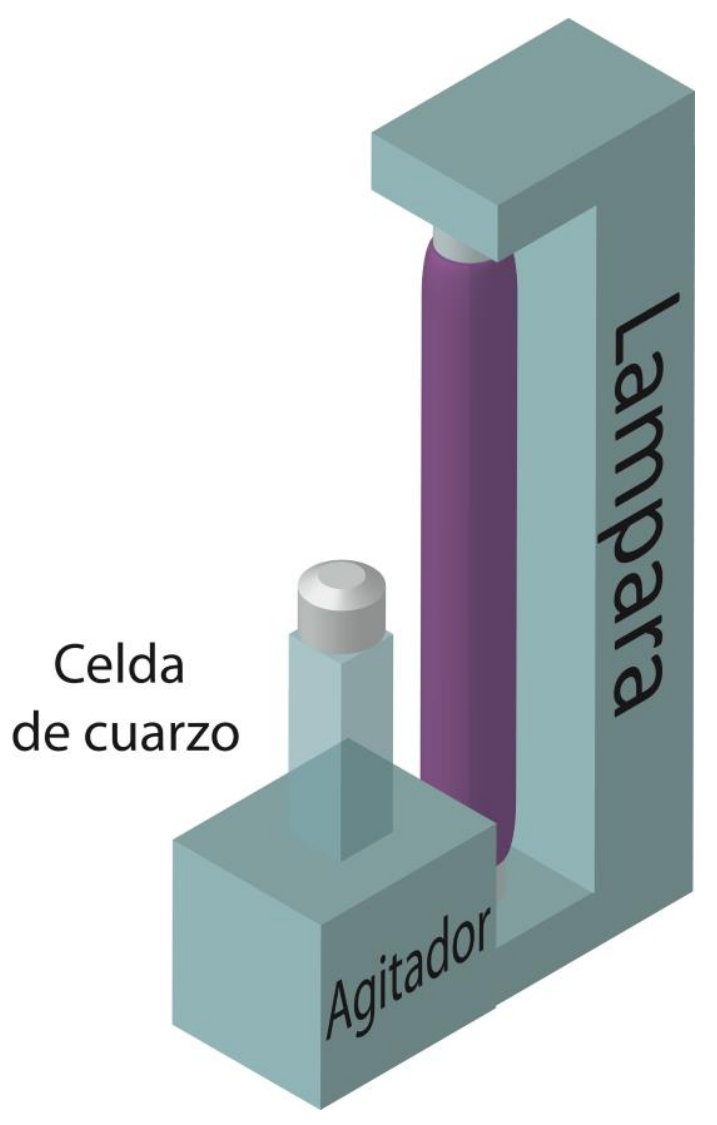

Figura 10

Esquema del arreglo instrumental utilizado para la fotosensibilización.

\subsubsection{Microscopía AFM}

Microscopía de fuerza atómica (AFM) [15]es un tipo microscopía de barrido de alta resolución. La resolución de esta técnica es del orden de fracciones de nanómetro, más de 1.000 veces mejor que el límite de difracción óptica. La técnica de AFM permite medir y manipular la materia a nanoescala. Se obtiene información por la interacción 
de la superficie a medir con una sonda mecánica. Los piezoeléctricos facilitan los movimientos minúsculos y exactos que, guiados por comandos electrónicos, permiten un escaneo muy preciso.

\subsubsection{Descripción del instrumental}

El microscopio AFM se compone de una placa flexible (cantiléver) con una punta afilada (sonda) en su extremo, que se utiliza para escanear la superficie de la muestra (figura 11). El cantiléver es típicamente de silicio o nitruro de silicio con un radio de curvatura de punta del orden de nanómetros. Cuando la punta se ubica en la proximidad de la superficie de la muestra, las fuerzas entre la punta y la muestra provocan una deflexión del cantiléver. La deflexión se mide utilizando un haz láser reflejado desde la superficie superior del cantiléver en un arreglo de fotodiodos. Las imágenes obtenidas fueron procesadas digitalmente, se corrigió la curvatura de la imagen y se ajustó el contraste de acuerdo a la intensidad de las imágenes del campo. Con las imágenes ya procesadas se realizaron mediciones de longitud y altura de las estructuras observadas.

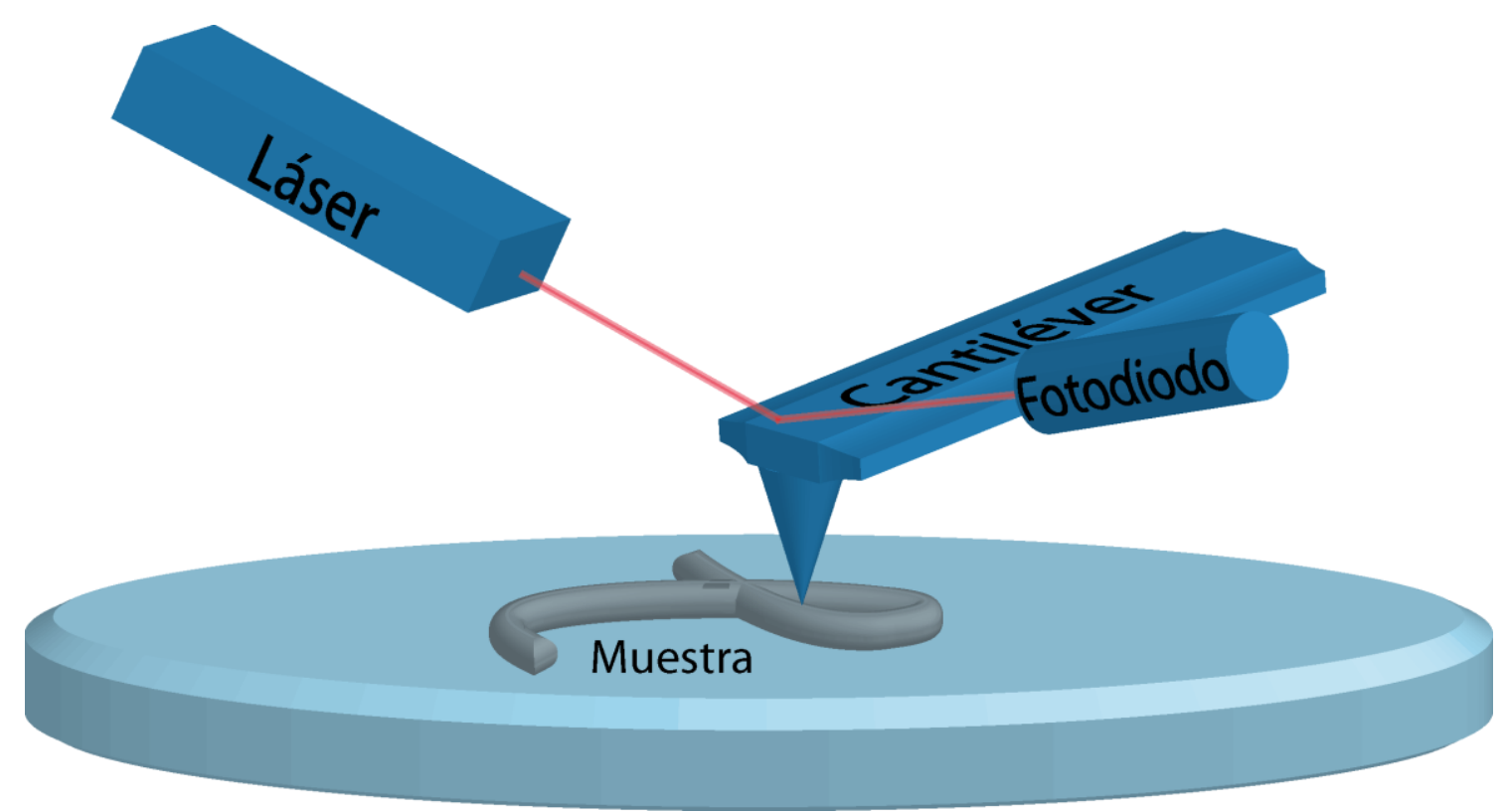

Figura 11

Esquema del funcionamiento del microscopio de AFM 


\subsection{Interacción polinucleótido-complejo}

La interacción entre los complejos estudiados y los distintos ácidos nucleicos, se estudió analizando los cambios que se inducen en los espectros de absorción y emisión del complejo al variar la concentración del ácido nucleico.

\subsubsection{Desactivación de la emisión}

La desactivación de la emisión del estado excitado de una molécula por un desactivador, puede ser el resultado de varios mecanismos. (e.g. reacciones de los estados excitados, transferencia de energía, formación de complejos y desactivación por colisiones.) En la ecuación 17 se representa la ecuación de velocidad de desactivación de un luminóforo excitado $\left(\mathrm{L}^{*}\right)$ por una molécula desactivadora $\mathrm{Q}$.

$$
\mathrm{v}_{q}=\mathrm{k}_{q}\left[L^{*}\right][Q]
$$

Donde $k_{\mathrm{q}}$ es la constante de velocidad bimolecular de desactivación. Los procesos de desactivación pueden clasificarse en dos grandes grupos: desactivación dinámica y desactivación estática.

\subsubsection{Desactivación dinámica}

Los procesos de desactivación dinámica, se dan por colisiones entre el luminóforo excitado y el desactivador. Es posible calcular la constante de velocidad del proceso de desactivación analizando los espectros de emisión del compuesto estudiado en presencia y ausencia de desactivador. Para ello se utiliza la ecuación de Stern-Volmer:

$$
\frac{\mathrm{I}_{e m i}^{0}}{\mathrm{I}_{e m i}}=1+\mathrm{K}_{S V}[Q]=1+\mathrm{k}_{q} \tau_{e m i}^{0}[Q]
$$

Donde $\mathrm{I}_{\mathrm{emi}}^{0}$ e $\mathrm{l}_{\mathrm{emi}}$ son las intensidades de emisión en ausencia y presencia del desactivador, respectivamente, $K_{\mathrm{SV}}$ es la constante de Stern-Volmer, [Q] es la concentración del desactivador, $k_{\mathrm{q}}$ es la constante bimolecular de desactivación y $\tau^{0}$ emi es el tiempo de vida de la especie emisora en ausencia de desactivador. Una gráfica de 
Stern-Volmer lineal generalmente indica la presencia de una sola especie emisora. Si la desactivación es de tipo dinámico el cociente de los tiempos de vida de emisión en ausencia y presencia de desactivador es igual al cociente de los correspondientes rendimientos cuánticos de luminiscencia.

$$
\frac{\mathrm{I}_{e m i}^{0}}{\mathrm{I}_{e m i}}=\frac{\tau_{e m i}^{0}}{\tau_{e m i}}=1+\mathrm{k}_{q} \tau_{e m i}^{0}[Q]
$$

Entre los tipos de desactivación dinámica tenemos el mecanismo de desactivación por transferencia de energía de resonancia de Förster (FRET). Este mecanismo es extremadamente dependiente de la distancia entre emisor y el desactivador y ocurre a distancias menores a $100 \AA$. El otro mecanismo de desactivación dinámica se conoce como transferencia de energía colisional, Dexter, y es un fenómeno de aun más corto alcance.

\subsubsection{Desactivación estática.}

Los procesos de desactivación pueden ocurrir como producto de la formación de aductos no emisivos entre los estados electrónicos basales del luminóforo (L) y el desactivador (Q). La relación de las intensidades de emisión con la concentración de desactivador, también cumple con la ecuación lineal de Stern-Volmer.

$$
\frac{\mathrm{I}_{e m i}^{0}}{\mathrm{I}_{e m i}}=\frac{\left[L^{0}\right]}{[\mathrm{L}]}=1+\mathrm{k}_{q} \tau_{e m i}^{0}[Q]
$$

Donde $[\mathrm{L}]$ es la concentración del luminóforo en el aducto y $\left[\mathrm{L}^{0}\right]$ es la concentración del luminóforo libre. Si existe una desactivación estática la fracción del compuesto emisor libre es la única fuente de emisión, por lo tanto su tiempo de vida no se ve alterado que $\left(\frac{\tau_{e m i}^{0}}{\tau_{e m i}}=1\right)$. De este modo puede diferenciarse de un mecanismo de desactivación dinámica. 


\subsubsection{Modelo de Scatchard modificado.}

La constante de asociación puede determinarse utilizando la ecuación de Scatchard modificada por McGhee-von Hippel [16] (Ecuaciones 21 y 22). El tratamiento de la asociación plantea el establecimiento de un equilibrio de asociación entre el complejo y el ADN con una constante de unión $k_{b}$.

$$
\begin{gathered}
\frac{r}{[\mathrm{C}]_{L}}=\mathrm{k}_{b}(1-n r)\left[\frac{1-n r}{1-(n-1) r}\right]^{(n-1)} \\
r=\frac{[C]_{U}}{[A D N]}
\end{gathered}
$$

Donde $n$ representa el número de sitios de unión del ADN que ocupa el complejo medido en pares de bases consecutivas Se considera que todos los sitios de unión son equivalentes y que el complejo interactúa de manera no-cooperativa.

En función de esta ecuación se realiza una gráfica de $r /[C]_{L}$ vs $r$ obteniéndose los parámetros $\mathrm{k}_{\mathrm{b}}$ y $\mathrm{n}$ por ajuste de los datos experimentales.

Los cálculos se realizan sobre los valores de intensidad de emisión medida para distintas soluciones del complejo con distinta concentración de ADN. La concentraciones del complejo libre, $[C]_{L}$, del complejo unido[C $]_{u}$, para cada una de las soluciones se calculan utilizando las ecuaciones 23 y 24 [17].

$$
\begin{gathered}
{[\mathrm{C}]_{L}=[\mathrm{C}]_{T} \frac{\left(A / A_{0}-{ }^{A_{\infty} / A_{0}}\right)}{\left(1-{ }^{A} / A_{0}\right)}} \\
{[\mathrm{C}]_{U}=[\mathrm{C}]_{T}-[\mathrm{C}]_{L}}
\end{gathered}
$$

Donde $\left[C_{T}\right]$ es la suma de las concentraciones del complejo libre y unido, $A$ y $A_{0}$ son las áreas en presencia y ausencia de $\operatorname{ADN}$ y $A_{\infty}$ es el área de los espectros de emisión cuando todo el complejo se encuentra unido al polinucleótido. 


\subsection{Estudios de interacción con albuminas}

Los ensayos de asociación del complejo RePtr a proteínas de transporte se realizaron empleando albuminas séricas humana (HSA) y bovina (BSA). Estas moléculas son de las más abundantes en el plasma sanguíneo, su principal función es transportar sustancias de muy diversa naturaleza en el torrente sanguíneo.

Los estudios de asociación entre el complejo RePtr y las seroalbúminas humana y bovina, HSA y BSA se realizaron, siguiendo la emisión fluorescente de la proteína al modificar la concentración del complejo. Se determinaron de este modo, las constantes y el modelo de asociación con sus parámetros termodinámicos y se analizó la transferencia de energía de resonancia entre el complejo y las proteínas. Finalmente se analizaron los cambios conformacionales inducidos en la proteína producto de la asociación con el complejo, realizando medidas de dicroísmo circular.

\subsubsection{Desactivación de la fluorescencia}

La fluorescencia en la albúmina se origina principalmente en dos tipos de fluoróforos: el triptófano (Trp) y la tirosina (Tyr). La BSA contiene dos residuos de Trp localizados en diferentes subdominios: el Trp-214, expuesto a un ambiente hidrofóbico en el subdominio IIA y el Trp-135, localizado en el subdominio IB en un entorno hidrofílico (figura 12). Por el contrario la HSA, solo posee un Trp ubicado en el subdominio IIA (Trp 214). Cuando se excita una solución de la proteína con luz de $\lambda_{\text {exc. }}=295 \mathrm{~nm}$, la fluorescencia de la albúmina proviene solo del Trp, mientras que si la $\lambda_{\text {exc. }}=280 \mathrm{~nm}$ la emisión proviene tanto del Trp como de la Tyr [18], [19]. De este modo, si no se observan diferencias al excitar a 280 y $295 \mathrm{~nm}$, es porque están involucrados ambos fluoróforos. 


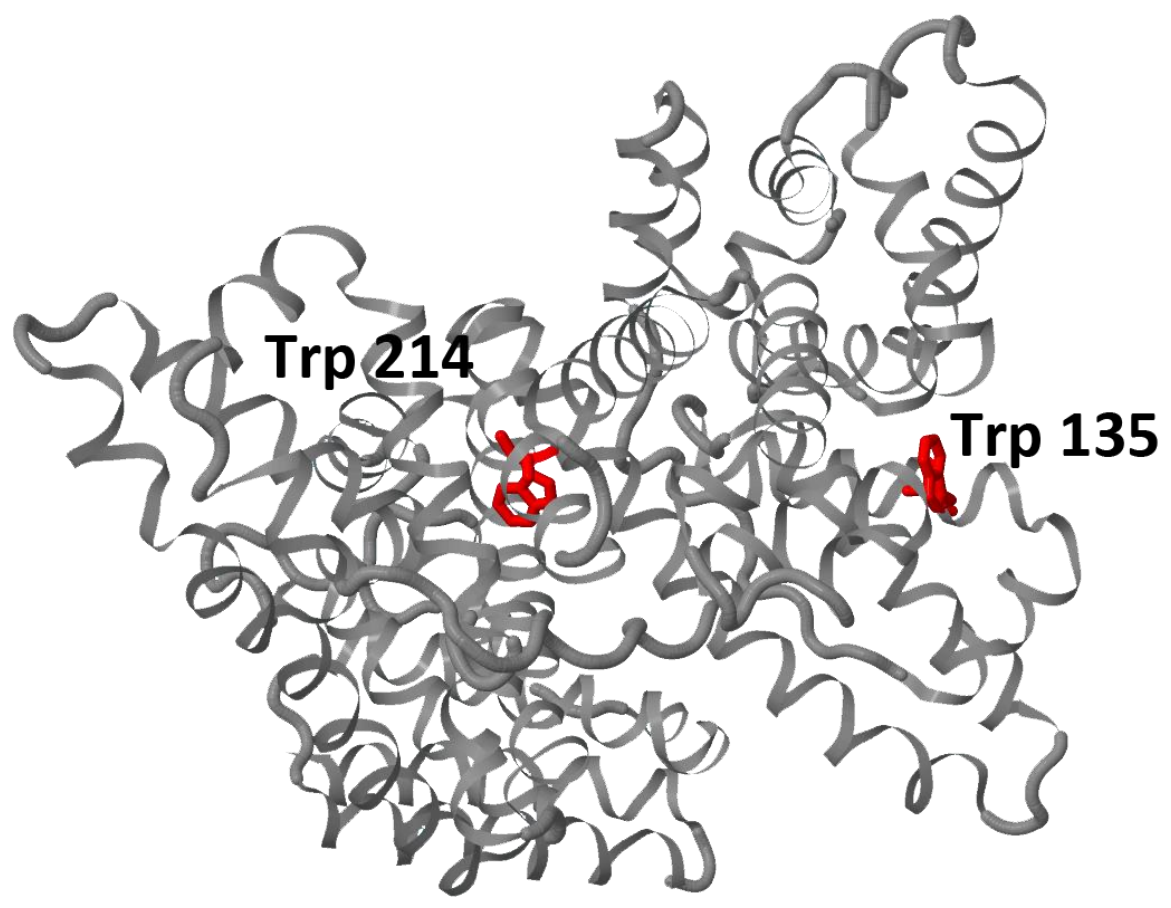

\section{Figura 12}

Representación de la molécula de BSA en la que se indica la posición de los dos residuos Trp.

La albuminas fueron compradas a SIGMA y se utilizaron sin posterior purificación. El buffer Tris se preparó con concentraciones 0,1 $\mathrm{M}$ de Tris y 0,1 $\mathrm{M}$ de $\mathrm{NaCl}$ y ajustando el $\mathrm{pH}$ a 7,4. Las soluciones se prepararon usando los coeficientes de extinción molar: $\varepsilon_{279}$ $=43.824 \mathrm{M}^{-1} \mathrm{~cm}^{-1}, \varepsilon_{280}=36.500 \mathrm{M}^{-1} \mathrm{~cm}^{-1}$ para la BSA y HSA respectivamente. LoS espectros de absorción UV-Vis se obtuvieron con un espectrofotómetro Agilent 8453 UV-Vis con detector PDA (Arreglo de fotodiodo), y resolución de $1 \mathrm{~nm}$, usando una celda de cuarzo de $1 \mathrm{~cm}$ de paso óptico. Las medidas de fluorescencia en estado estacionario, se realizaron en un espectrofluorómetro PTI (Photon Technology International) Quanta Master QM2 equipado con un detector de contador de fotones Hamamatsu R928. Las intensidades de fluorescencia fueron corregidas por filtro interno. 


\subsubsection{Constantes de asociación}

Las constantes de asociación se determinaron a partir del análisis de los cambios en la intensidad máxima de los espectros de emisión para las proteínas. Dicho análisis se realizó usando el modelo desarrollado por Bhattacharyya [20] (Ecuación 21).

$$
\frac{1}{\Delta I}=\frac{1}{\Delta I_{\max }}+\frac{1}{\Delta I_{\max } K_{b}[Q]}
$$

Donde $\Delta \mathrm{I}=\mathrm{I}_{\mathrm{\chi}}-\mathrm{I}_{0}$ y $\Delta \mathrm{I}_{\max }=\mathrm{I}_{\infty}-\mathrm{I}_{0}$, siendo $\mathrm{I}_{0}, \mathrm{I}_{\mathrm{\chi}}$ y $\mathrm{I}_{\infty}$ las intensidades de fluorescencia de la proteína en ausencia, en presencia de una concentración intermedia y a una concentración de saturación de complejo de $\operatorname{Re}(I)$, respectivamente; $K_{b}$ es la constante de asociación y $[Q]$ es la concentración de $\operatorname{Re}(I)$. La ecuación 21 predice linealidad cuando el proceso de asociación es 1:1. Este tratamiento ha sido utilizado para sistemas en los cuales se observó un incremento del valor de $K_{b}$ con el aumento de la temperatura.

\subsubsection{Modelo de asociación}

A fin de dilucidar la naturaleza de las fuerzas involucradas en el proceso de asociación proteína-complejo, las constantes de asociación se determinaron a diferentes temperaturas, y a partir de ellas se calcularon los parámetros termodinámicos. Suponiendo que el cambio de entalpía $(\Delta \mathrm{H})$ no varía significativamente en el rango de temperaturas estudiado $\left(\Delta T=15^{\circ} \mathrm{C}\right)$, tanto su valor como el del cambio de entropía $(\Delta S)$ pueden obtenerse desde la ecuación de Van'tHoff, (Ecuación 22).

$$
\ln K_{b}=-\frac{\Delta H}{R T}+\frac{\Delta \mathrm{S}}{R}
$$

Donde $K_{b}$ representa la constante de asociación, T la temperatura en $\mathrm{K}$ y $\mathrm{R}$ la constante de los gases. Los valores de $\Delta H$ y $\Delta S$ se calcularon a partir de la pendiente y la ordenada al origen, respectivamente, de la recta $\operatorname{lnK}_{b}$ vs. $1 / T$. Finalmente, los valores de cambio de energía libre $(\Delta G)$ a cada temperatura pueden obtenerse a partir de la ecuación de energía libre de Gibbs (Ecuación 23). 


$$
\Delta \mathrm{G}=\Delta H-T \Delta \mathrm{S}
$$

\subsubsection{FRET}

La eficiencia de la transferencia de energía entre el fluoróforo y el desactivador, se estudió de acuerdo con la teoría de la transferencia de energía de resonancia de Förster (FRET). En esta, la eficiencia de transferencia de energía, $\phi_{\mathrm{T}}$, se describe por la ecuación 24 [7].

$$
\phi_{T}=1-\frac{I}{I_{0}}=\left(\frac{R_{0}^{6}}{R_{0}^{6}+r^{6}}\right)
$$

Donde I y $\mathrm{I}_{0}$ son las intensidades de fluorescencia del fluoróforo (donor) en presencia y ausencia del desactivador (aceptor), $r$ es la distancia entre donante y aceptor, y $R_{0}$ es la distancia crítica (cuando la eficiencia de la transferencia es $50 \%$ ). $R_{0}$ se determina a partir de la ecuación 25.

$$
R_{0}^{6}=8,8 \times 10^{-25} \kappa^{2} \eta^{-4} \phi_{f} J
$$

Aquí, $\mathrm{k}^{2}$ es el factor de orientación espacial, que describe la orientación relativa en el espacio de los dipolos de transición del donor y el aceptor, $\eta$ es el índice de refracción del medio, $\Phi_{f}$ el rendimiento cuántico de fluorescencia del donor en ausencia del aceptor y J es la integral de solapamiento del espectro de emisión de fluorescencia del donor y el espectro de absorción del aceptor. J está dada por la ecuación 26

$$
J=\frac{\int_{0}^{\infty} F(\lambda) \varepsilon(\lambda) \lambda^{4} d \lambda}{\int_{0}^{\infty} F(\lambda) d \lambda}
$$

Donde $F(\lambda)$ es la intensidad de fluorescencia del donor en función de la longitud de onda (espectro de emisión normalizado con un área unitaria) y $\varepsilon(\lambda)$ es el coeficiente de absorción molar del aceptor a la longitud de onda $\lambda$ (espectro de absorción). De las 
relaciones anteriores, J y $\Phi_{T}$ se pueden obtener fácilmente; además, $R_{0}$ y $r$ se pueden calcular para la relación molar 1:1 entre el fluoróforo y el aceptor.

\subsection{Estudios de dicroísmo circular}

Los cambios conformacionales que puede inducir el complejo al asociarse a las albuminas fue determinado por espectroscopía de dicroísmo circular (DC).

Un rayo de luz polarizado en un plano puede considerarse formado por dos componentes polarizados circularmente, uno a la derecha y el otro a la izquierda. Estos componentes están en fase y son de la misma amplitud. Al pasar por un medio ópticamente activo, cada componente interactúa de manera diferente con los centros quirales de las moléculas presentes. La interacción de la radiación con la muestra induce un desfasaje y un cambio de magnitud diferenciales en ambos componentes circularmente polarizados de la luz. Estos fenómenos provocan una rotación del plano de polarización en un ángulo $\alpha$. La rotación del plano y la diferente absorción de los componentes circularmente polarizados varían de acuerdo con la longitud de onda, pudiéndose obtener espectros de estos fenómenos graficando esta rotación en función de la longitud de onda. Se trabajó en la región del ultravioleta cercano, en esta región, los cromóforos más importantes son los grupos aromáticos de las cadenas laterales de triptófano, tirosina, y fenilalanina. Ya que la asimetría en estos grupos químicos, se debe exclusivamente a su entorno y como los residuos aromáticos se encuentran distribuidos en toda la macromolécula, los espectros en esta región son un reflejo de la conformación global de la proteína.

Los resultados de esta técnica se expresan en función del residuo elíptico medio (MRE) en ${ }^{\circ} \mathrm{cm}^{2} \mathrm{dmol}^{-1}$ de acuerdo a la ecuación 27.

$$
M R E=\frac{\mathrm{DC}_{o b s}(m d e g)}{\left(10 C_{p} n l\right)}
$$

Donde $C_{p}$ es la concentración molar de la proteína ( $\left.M o l / L\right), n$ es el número de residuos de aminoácidos de la proteína y l es el camino óptico. 
La seroalbúmina humana (HSA $\approx 99 \%$, libre de ácidos grasos $(\approx 0,005 \%)$, libre de globulinas A3782) y la seroalbúmina bovina (BSA, 98\% A7906) fueron compradas a SIGMA. Y usadas sin posterior purificación. Sus pesos moleculares son 66.5 kDa y 66.0 kDa que corresponden a 585 y 583 residuos para la HSA y la BSA, respectivamente.

Se utilizaron celdas de cuarzo de calidad óptica de 4 ventanas con $0,2 \mathrm{~cm}$ de camino óptico. El espectropolarimetro usado fue un JASCO J-810. Las medidas se realizaron a temperatura ambiente y en atmosfera de $\mathrm{N}_{2}$. Se midió en el rango de 260-200 nm.

\section{Referencias bibliográficas}

\subsection{Bibliografía consultada}

- Química cuántica 5ta edición, Ira N. Levin.

- Principles of molecular photochemistry, Turro NJ, Scaiano JC, Ramamurthy V (2009).

- Molecular biology of the cell 4th edition, Bruce Alberts, Alexander Johnson, Julian Lewis, Martin Raff, Keith Roberts, and Peter Walter.

- Principios de Bioquímica, Segunda edición, A. L. Lehninger, D. L. Nelson, M. M. Cox, Omega (1995).

- Fundamentos de química analítica, Volumen 2, Douglas A. Skoog, Donald M. West, F. James Holler

- Principles of fluorescence spectroscopy, Third Edition, J. Lackowicz, (1983).

\subsection{Referencias}

[1] W. Henderson, B. Nickleson, and L. McCaffrey, "Applications of electrospray mass spectrometry inorganometallic chemistry," Polyhedron, vol. 17, no. 25, pp. 4291-4313, 1998.

[2] D. R. Goodlett, H. R. Udseth, and R. D. Smith, "Attomole Level Capillary Electrophoresis-Mass Spectrometric Protein Analysis Using 5-pm4 . d . Capillaries," no. 15, pp. 17-19, 1992. 
[3] H. Nonami, S. Fukui, and R. Erra-balsells, "b -Carboline Alkaloids as Matrices for Matrix-assisted Ultraviolet Laser Desorption Time-of-ýight Mass Spectrometry of Proteins and Sulfated Oligosaccharides: a Comparative Study Using Phenylcarbonyl Compounds , Carbazoles and Classical Matrices," J. mass Spectrom., vol. 32, no. November 1996, pp. 287-296, 1997.

[4] S. G. M., "Program for Crystal Structure Resolution, SHELXS-97." 1997.

[5] S. G. M., "Program for Crystal Structures, SHELXL-97." 1997.

[6] E. S. Roman and M. Gonzalez, "Analysis of spectrally resolved kinetic data and time-resolved spectra by bilinear regression," J. Phys. Chem., vol. 93, pp. 35323536, 1989.

[7] J. Lackowicz, Principles of fluorescence spectroscopy, vol. Third Edit. 1983.

[8] R. Schmidt, C. Tanielian, R. Dunsbach, and C. Wolff, "Phenalenone, a universal reference compound for the determination of quantum yields of singlet oxygen 102 sensitization," J. Photochem. Photobiol. A Chem., vol. 79, pp. 11-17, 1994.

[9] G. Valduga, S. Nonell, E. Reddi, G. Jori, and S. E. Braslavsky, "The production of singlet molecular oxygen by zinc ( i1 ) phthalocyanine in ethanol and in unilamellar vesicles . chemical quenching," Photochem. und Photobiol., vol. 48, no. 1, pp. 1-5, 1988.

[10] H. Richter wilkinson, "Radiation chemistry; principles and applications," in In Photochemistry and Radiation Chemistry, 1998, pp. 5-29.

[11] G. Hug, Y. Wang, and C. Schöneich, "Multiple time scales in pulse radiolysis. Application to bromide solutions and dipeptides," Radiat. Phys. Chem., vol. 54, pp. 559-566, 1999.

[12] B. Alberts, A. Johnson, J. Lewis, M. Raff, K. Roberts, and P. Walter, Biology of the Cell, 4th edition. 2002.

[13] T. Y. Shi, X. Y. Liu, L. L. Hao, J. D. Li, A. N. Gh, M. H. Abdille, and X. Suo, "Transfected Eimeria tenella could complete its endogenous development in vitro.," J. Parasitol., vol. 94, no. 4, pp. 978-980, 2008.

[14] W. Bauer and J. Vinograd, "The interaction of closed circular DNA with intercalative dyes. I. The superhelix density of SV40 DNA in the presence and absence of dye.," J. Mol. Biol., vol. 33, no. 1, pp. 141-71, Apr. 1968.

[15] G. Binnig and C. F. Quate, "Atomic Force Microscope," Phys. Rev. Lett., vol. 56, no. 9, pp. 930-933, 1986.

[16] J. D. McGhee and P. H. von Hippel, "Theoretical aspects of DNA-protein interactions: co-operative and non-co-operative binding of large ligands to a 
one-dimensional homogeneous lattice.," J. Mol. Biol., vol. 86, no. 2, pp. 469-89, Jun. 1974.

[17] V. W. Yam, K. K. Lo, K. Cheung, and R. Y. Kong, "Deoxyribonucleic acid binding and photocleavage studies of rhenium(I) dipyridophenazine complexes," J. Chem. Soc. Dalt. Trans., pp. 2067-2072, 1997.

[18] X. M. He and D. C. Carter, "Atomic structure and chemistry of human serum albumin.," Nature, vol. 358, pp. 209-215, 1992.

[19] N. Tayeh, T. Rungassamy, and J. R. Albani, "Fluorescence spectral resolution of tryptophan residues in bovine and human serum albumins.," J. Pharm. Biomed. Anal., vol. 50, pp. 107-116, 2009.

[20] J. Bhattacharyya, M. Bhattacharyya, a. S. Chakrabarty, U. Chaudhuri, and R. K. Poddar, "Interaction of chlorpromazine with myoglobin and hemoglobin: A comparative study," Biochem. Pharmacol., vol. 47, no. 1, pp. 2049-2053, 1994. 


\section{Capítulo II}

Estado del arte 


\section{Introducción}

La fotofísica y fotoquímica de complejos de metales de transición con configuración electrónica $d^{6}$, como Re (I), Ru (II), Os (II), y Rh (III), con ligandos aceptores de electrones, han sido ampliamente estudiadas durante cuatro décadas. Las características fotofísicas más útiles e interesantes de este tipo de complejos resultan:

- Sus altos rendimientos cuánticos para la formación de estados excitados tripletes, tanto de transferencia de carga del metal al ligando $\left({ }^{3} \mathrm{MLCT}\right)$ como $\pi \rightarrow \pi *$. Por lo general con valores cercanos a la unidad.

- Suelen ser complejos emisivos en solución a temperatura ambiente, y con largos tiempos de vida del estado excitado más bajo, típicamente de varios cientos de nanosegundos.

- Los estados excitados ${ }^{3}$ MLCT de estos complejos tienen un alto potencial de oxidación y/o reducción.

Este tipo de complejos se han utilizado en estudios de transferencia de electrones [1][3], conversión de energía solar y catálisis [4], [5]. Emergiendo también, posibles aplicaciones como sensores luminiscentes [6], [7], fotocatalizadores [4], materiales moleculares para óptica no lineal y conmutación óptica [8].

Por otra parte, existen potenciales aplicaciones técnicas y bioquímicas basadas en la formación de aductos entre los complejos tricarbonilicos de $\operatorname{Re}(\mathrm{I})$ y moléculas biológicas tales como ADN [9]-[14], pudiendo ser utilizados como marcadores biológicos y sondas no covalentes para biomoléculas [15]-[17].

En este capítulo se realiza una revisión de los trabajos publicados que puedan ser pertinentes al desarrollo de los temas abordados en este trabajo de tesis. Se comienza con una descripción de la estructura y fotofísica de los complejos tricarbonílicos de $\mathrm{Re}(\mathrm{I})$, luego utilizando los complejos del tipo $\mathrm{fac}-\mathrm{Re}(\mathrm{CO})_{3}$ diimina como modelo, se describen los estados excitados. El comportamiento fotoquímico de este tipo de complejos es ilustrado desde la fotoquímica del ligando para luego presentar las características más notables de complejos relacionados. 
Finalmente, se presentan los fundamentos básicos de la terapia fotodinámica detallando los avances que han tenido lugar en su desarrollo e investigación, utilizando complejos relacionados. 


\section{Índice}

\section{Capítulo II \\ Estado del arte}

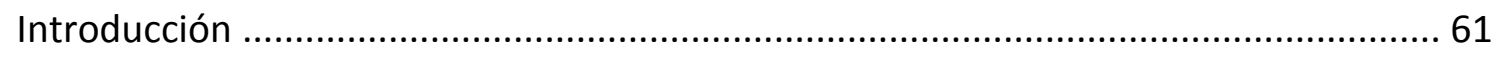

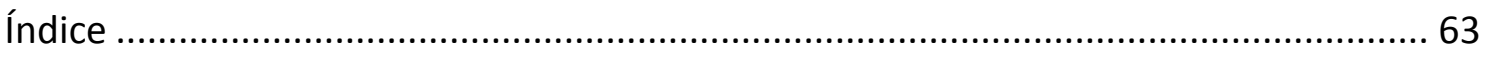

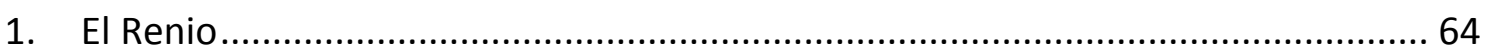

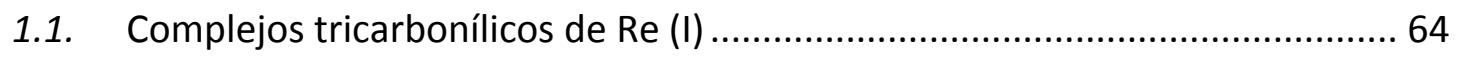

1.2. Complejos tricarbonílicos de $\operatorname{Re}(\mathrm{I})$ con ligandos diimina................................. 66

1.3. Complejos con estados excitados de menor energía del tipo MLCT...............68 68

1.4. Complejos con estados excitados de menor energía del tipo IL ....................69

1.5. Complejos con estados excitados de menor energía del tipo LLCT ................ 70

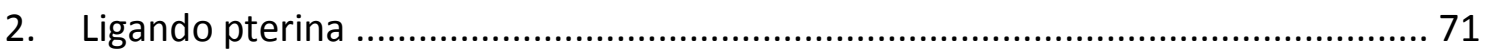

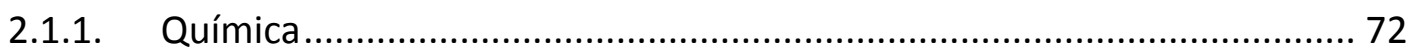

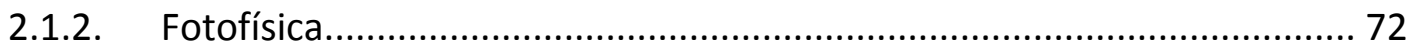

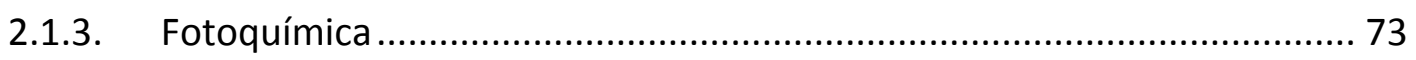

2.1.4. Reacción del triplete de la pterina con el solvente .............................. 74

2.1.5. Transiente de la pterina semireducida................................................ 74

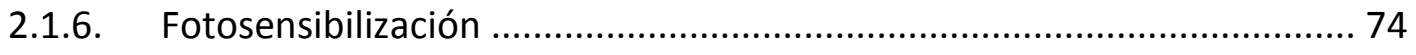

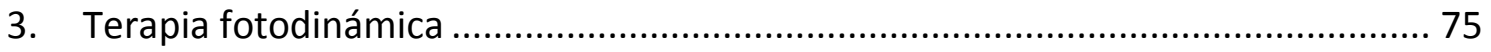

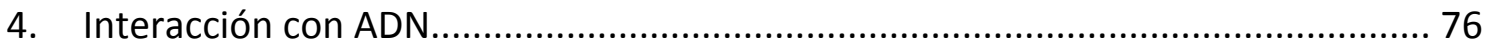

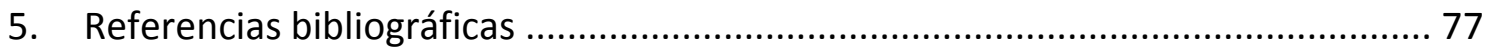




\section{El Renio}

El Renio (Re) es un elemento de transición del tercer periodo con una electronegatividad, en su estado elemental, similar a la del hidrogeno. Su radio covalente es de $159 \mathrm{pm}$. Naturalmente se presenta en un amplio rango de estados de oxidación $(-1,+1,+2,+3,+4,+5,+6,+7)$. Sus dos isotopos estables más abundantes son ${ }^{187} \operatorname{Re}$ y ${ }^{185} \mathrm{Re}$, con abundancias relativas de 62,6 y $37,4 \%$ respectivamente. En su estado elemental posee 75 electrones, cuya configuración electrónica es $[X e] 4 f^{14} 5 d^{5} 6 s^{2}$.

La primera energía de ionización es $760 \mathrm{KJ} / \mathrm{mol}$, necesaria para generar el estado de oxidación +1 . Aunque este estado de oxidación es uno de los menos estables, la coordinación con distintos ligandos logra compuestos altamente estables. En el estado de oxidación +1 la configuración electrónica es $[X e] 4 f^{14} 5 d^{6}$, en la cual los seis electrones de la última capa se encuentran en los cinco orbitales degenerados $5 \mathrm{~d}$. Estos orbitales $5 \mathrm{~d}$ degenerados del metal, en un entorno de coordinación octaédrico, se diferencian en energía. Esta diferenciación ocurre como producto de su diferente simetría, la cual es generada por la repulsión ejercida por los ligandos. De este modo se obtienen dos tipos de orbitales, $e_{g} y$ tres $t_{2 g}$. Los electrones $5 d$, en el $\operatorname{Re}(I)$, se ubican apareados en estos tres orbitales degenerados $t_{2 g}$ con multiplicidad de spin igual a 1 (estado singlete).

\subsection{Complejos tricarbonílicos de $\operatorname{Re}($ I)}

Durante mucho tiempo, la química organometálica fue predominantemente restringida a medios no acuosos. Sin embargo, debido a las significativas ventajas químicas y bioquímicas de utilizar el agua como solvente, la química acuosa de los complejos organometálicos ha recibido notable atención. El complejo $\left[\operatorname{Re}(\mathrm{CO})_{3}\left(\mathrm{H}_{2} \mathrm{O}\right)_{3}\right]^{+}$ posee una elevada solubilidad y estabilidad en medio acuoso y su interesante química de reemplazo de ligandos ha sido estudiado extensamente [18]-[23].

La coordinación entre el metal y el carbonilo posee propiedades particulares. El CO libre posee una distribución de electrones en la cual el orbital de simetría sigma 
antienlazante centrado sobre el carbono $\left(\sigma^{*} \mathrm{co}\right)$ se encuentra ocupado por un par de electrones. Este par de electrones participa en el enlace con el metal (figura 1), ocupando el orbital molecular formado por el $\sigma^{*}$ co y un orbital vacío (s,p o d) del metal.
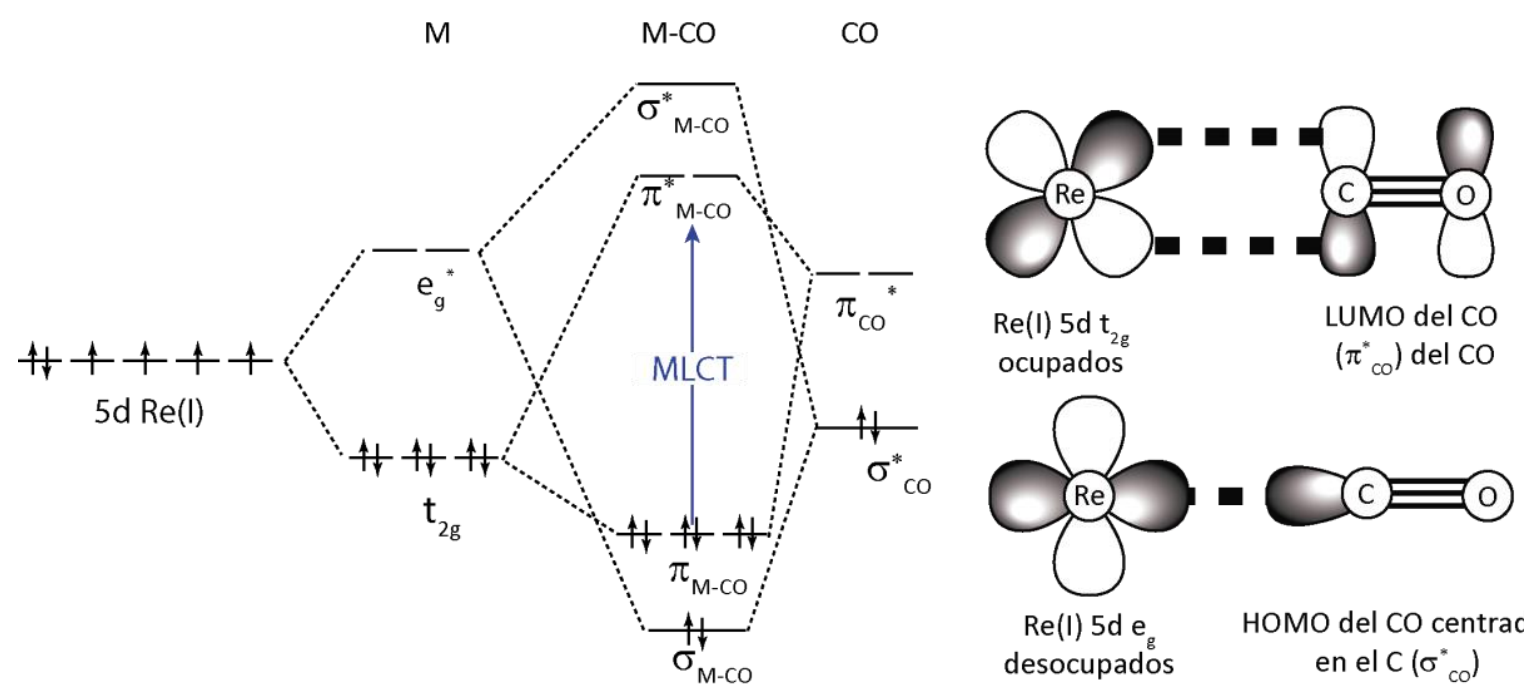

$\operatorname{Re}(\mathrm{I}) 5 \mathrm{~d} \mathrm{e}$ desocupados

HOMO del CO centrado en el $C\left(\sigma^{*}{ }_{\text {co }}\right)$

\section{Figura 1}

Diagrama de orbitales para la coordinación entre el átomo de renio en un entorno octaédrico con un $\mathrm{CO}$.

El orbital de simetría $\pi$ antienlazante del $\mathrm{CO}\left(\pi^{*} \mathrm{co}\right)$ forma, junto al $t_{2 \mathrm{~g}}$ del Re, el orbital $\pi^{*} \mathrm{M}$-co. Este enlace puede resumirse como una donación $\sigma$ del par libre alojado sobre el $C$ al orbital libre del $\operatorname{Re}(I)$ y una retro-donación $\pi$ hacia el CO. La transición MLCT que ocurre es una transición Re-d $\pi \rightarrow \mathrm{CO}-\pi^{*}$. Este enlace sinérgico estabiliza al Re en su estado de oxidación +1 [24].

Los sistemas formados por un núcleo $f a c-\operatorname{Re}^{\prime}(\mathrm{CO})_{3}$ coordinado a un ligando diimina (L) componen una familia de compuestos con extensas e interesantes características fotofísicas y fotoquímicas. Esto ha generado un gran interés científico, reflejado en numerosas publicaciones [7], [25]-[48]. Se ha logrado un profundo conocimiento sobre sus propiedades. Es por ello, que se eligió a los complejos $f a c-X \mathrm{Re}^{\prime}(\mathrm{CO})_{3}($ diimina) como modelo para entender la fotofísica y fotoquímica de los complejos que son evaluados en este trabajo de tesis. 


\subsection{Complejos tricarbonílicos de $\operatorname{Re}(\mathrm{I})$ con ligandos diimina.}

Los estudios sistemáticos de las propiedades fotofísicas y fotoquímicas de este grupo de complejos fac-XRe'(CO) ${ }_{3} \mathrm{~L}$ fueron iniciados en la década del 70' por Wrighton y sus colaboradores. Desde entonces, los complejos tricarbonílicos de Renio (I) han jugado un muy importante rol en la comprensión de la fotofísica de la transferencia de electrones inducida por la luz y de la transferencia de energía electrónica [2], [3], [49]. En la literatura científica, han aparecido un gran número de investigaciones basadas en complejos del tipo $f a c-x \mathrm{Re}^{\prime}(\mathrm{CO})_{3} \mathrm{~L}$. Estos trabajos informan sobre la dependencia de sus propiedades fotofísicas con el medio [50], las propiedades fotofísicas de los estados excitados de transferencia de carga del metal al ligando (MLCT) [51], y sobre procesos fisicoquímicos inducidos por la asociación del cromóforo con un desactivador [52].

La conveniente y sencilla síntesis de los complejos $f a c-\operatorname{Re}^{\prime}(\mathrm{CO})_{3}$ diimina y la simple modificación en la estructura química de estos ligandos hacen más fácil la sintonización sistemática y el estudio de las propiedades electrónicas de estos complejos [53], [54]. Por otra parte, el tiempo de vida de los estados excitados de más baja energía de estos complejos suele ser lo suficientemente largo como para permitir procesos de transferencia de electrones o de energía a los componentes cercanos, siempre que se cumplan las condiciones energéticas y electrónicas adecuadas [52]. En general, las diversas propiedades del estado excitado de los complejos tricarbonílicos de Renio (I) con un ligando diimina, están relacionadas a sus estados excitados triplete de más baja energía. Esto es debido, a que en estos complejos existe una rápida relajación vibracional y un efectivo cruce entre sistemas (CIS) desde los niveles de energía superiores [3]. Los ligandos diimina, aceptores de electrones, juegan un papel decisivo en la determinación de las propiedades fotofísicas y fotoquímicas. La naturaleza de los estados excitados que en estos se generan, depende de la relación entre los niveles de energía de los orbitales del metal y del ligando, así como también, del grado de interacción que existe entre ellos. 


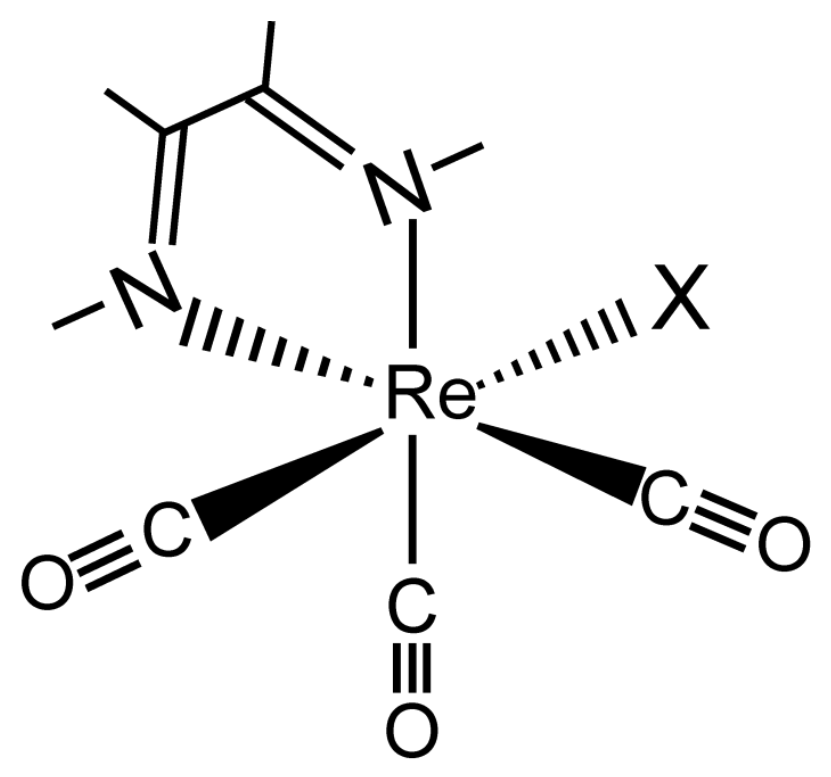

Figura 2

Representación general del complejo $\mathrm{fac}_{-}\left[\mathrm{XRe}^{\prime}(\mathrm{CO})_{3} \mathrm{~L}\right]$, donde $\mathrm{L}$ Representa un ligando neutro diimina y $\mathrm{X}$ un ligando espectador.

Los ligandos del tipo diimina coordinan por dos grupos imina $\left(R^{1} R^{2} C=N R^{3}\right)$. Poseen orbitales moleculares del tipo $n, \pi$ y $\pi^{*}$ capaces de interaccionar con los orbitales $5 \mathrm{~d}$ del metal. En la figura 3 se ilustra el diagrama de orbitales moleculares resultante de la combinación de los orbitales $5 \mathrm{~d}$ del $\operatorname{Re}(\mathrm{I})$ y orbitales de un ligando del tipo diimina.

Los cálculos teóricos realizados usando la teoría del funcional de densidad dependiente del tiempo (TD-DFT) para la familia de complejos del tipo fac$\mathrm{XRe}(\mathrm{CO})_{3}$ (diimina), muestran que la banda ubicada a alta energía corresponde a transiciones $\pi \rightarrow \pi^{*}$ centradas en el ligando diimina, mientras que a energías menores se ubica una banda asociada a una mezcla entre transiciones ligando-ligando LLCT y MLCT [25]. 


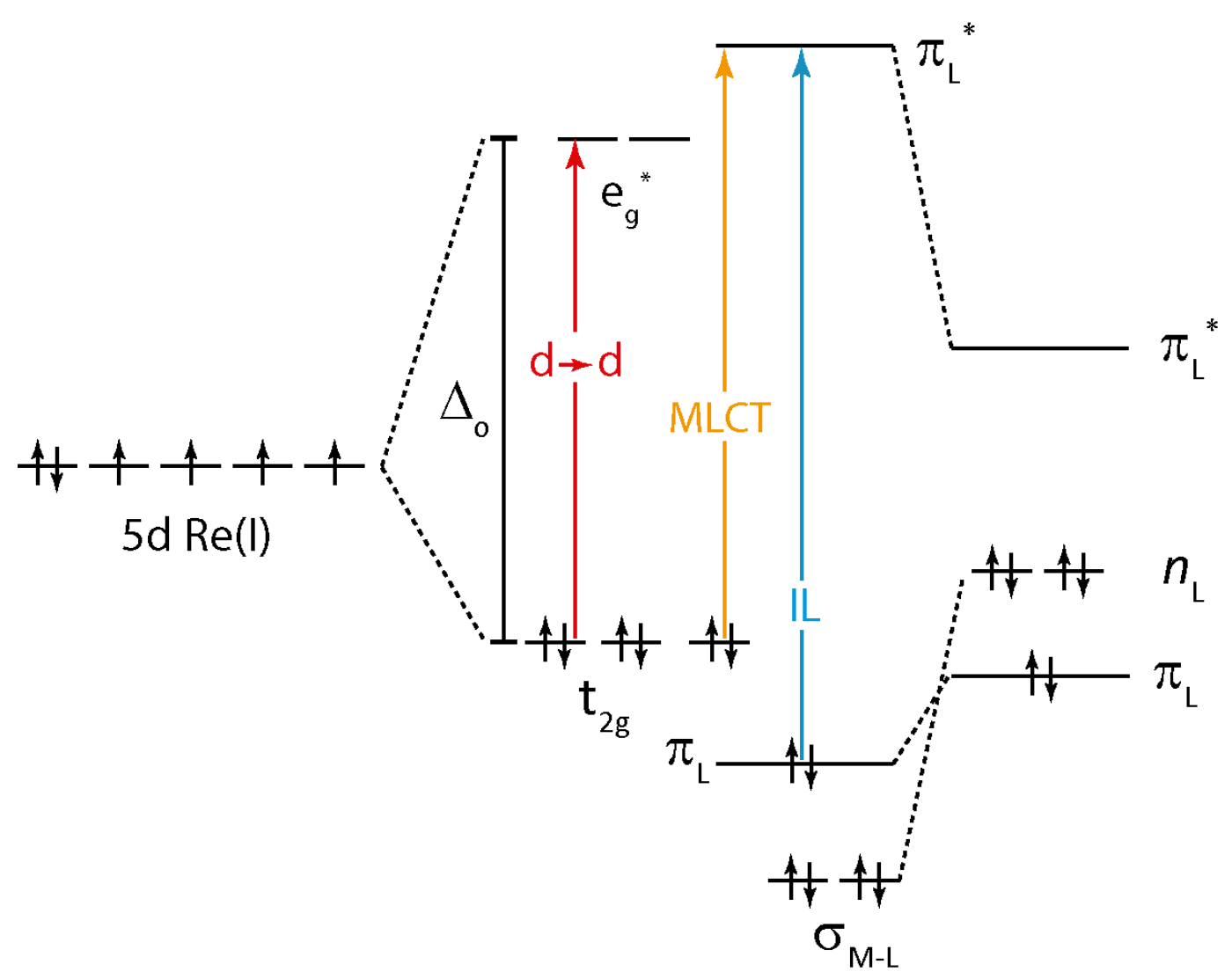

Orbitales del Renio

\section{Figura 3}

Diagrama de orbitales moleculares simplificado obtenidos por combinación los orbitales d del $\mathrm{Re}^{\prime}$ y los propios de la diimina. Las flechas representan las transiciones electrónicas más probables luego de la absorción de luz.

\subsection{Complejos con estados excitados de menor energía del tipo MLCT}

La banda de absorción MLCT de este tipo de complejos fac-XRe'(CO) ${ }_{3} \mathrm{~L}$, se encuentra a energías más bajas y superpuesta con la cola de la banda de transición intraligando (IL) $\pi \rightarrow \pi^{*}$; por lo tanto, los niveles ${ }^{1} \mathrm{MLCT}$ y ${ }^{1} \mathrm{IL}$ en general se pueblan simultáneamente. Estos complejos, presentan un notable efecto de metal pesado ejercido por el átomo de Renio, que conduce a una efectiva mezcla de estados singlete-triplete. Los tripletes ${ }^{3} \mathrm{MLCT}$ e ${ }^{3} \mathrm{IL}$, generados por CIS, varían en energía uno con respecto al otro. En consecuencia, se observa frecuentemente distintos tipos de espectros de emisión. Unos centrados cerca de los $500 \mathrm{~nm}$ con una estructura vibracional consistente con 
una contribución importante del estado excitado triplete centrado en el ligando ( $\left.{ }^{3} \mathrm{IL}\right)$. Otro tipo de espectros observados, poseen una emisión centrada en los $600 \mathrm{~nm}$, la misma suele ser no estructurada y puede ser asignada al estado ${ }^{3}$ MLCT. Sin embargo, como la banda del espectro de emisión centrada en el ligando diimina coordinado está desplazada hacia el rojo con respecto a la del ligando libre, a menudo se utiliza la combinación de los estados ${ }^{3} \mathrm{LC}$ y ${ }^{3} \mathrm{MLCT}$ para describir el comportamiento de la emisión de estos complejos. Estas bandas muestran un efecto batocrómico, revelado por un corrimiento a menores energías cuando se cambia a solventes menos polares [1][3][55]. Esta dirección del corrimiento del máximo con el solvente se asocia al cambio en el momento dipolar en el estado excitado MLCT. Las bandas son típicamente anchas y sin estructura y exhiben a menudo un efecto rigidocrómico [55][3]. Tanto los rendimientos cuánticos de emisión como los tiempos de vida se incrementan significativamente al enfriar la solución a $77 \mathrm{~K}$, lo que implica que la vías de relajación radiativa se ven favorecidas en un medio más rígido [35]. Los tiempos de vida del estado emisor en general están gobernados por la ley de la brecha de energía (EGL) [54][56], la cual establece que la constante de velocidad de transferencia de energía intramolecular disminuye al aumentar la brecha de energía entre los estados. La estructura electrónica del estado MLCT excitado de complejos $\operatorname{Re}^{\prime}(\mathrm{CO})_{3}($ diimina) puede interpretarse como una especie en la cual existe una separación de cargas, $\left[\operatorname{Re}^{\prime \prime}(\mathrm{CO})_{3}\left(\text { diimina }^{*-}\right)\right]^{*}$, con un centro metálico oxidado y un ligando diimina reducido. El estado excitado MLCT presenta una disminución en la longitud de la unión Re-CO por retrodonación $\pi$, respecto de la distancia de enlace en el estado fundamental. Este efecto puede verificarse fácilmente por espectroscopia IR resuelta en el tiempo [57].

\subsection{Complejos con estados excitados de menor energía del tipo IL}

Los sistemas con estados excitados de menor energía del tipo IL usualmente se encuentran en los complejos que contienen ligandos con conjugación extendida, donde el electrón se excita principalmente desde los orbitales basales $n$ o $\pi$ del ligando. Las características típicas de las emisiones ${ }^{3} \mathrm{IL}$, son sus perfiles estructurados y los largos tiempos de vida de la emisión, en comparación con las transiciones ${ }^{3} \mathrm{MLCT}$ 
[58]-[60]. El caso del complejo $\mathrm{fac}_{-}\left[\mathrm{ClRe}(\mathrm{CO})_{3}(\mathrm{dppz})\right]$ es un ejemplo interesante, sobre el que aun hoy no se logra consenso. Por espectroscopia Raman de resonancia resuelta en el tiempo, se determinó que el estado excitado de menor energía era el estado excitado ${ }^{3} \pi \pi^{*}$, aunque la emisión se origina, en el estado excitado ${ }^{3}$ MLCT. Este complejo con cloro es un emisor del tipo MLCT a temperatura ambiente pero es un emisor $\pi \pi^{*}$ a $77 \mathrm{~K}$. El reemplazo de $\mathrm{Cl}$ por $\mathrm{PPh}_{3}$ (tri-fenilfosfina) produce emisiones procedentes del estado ${ }^{3} \pi \pi^{*}$ a temperatura ambiente [61].
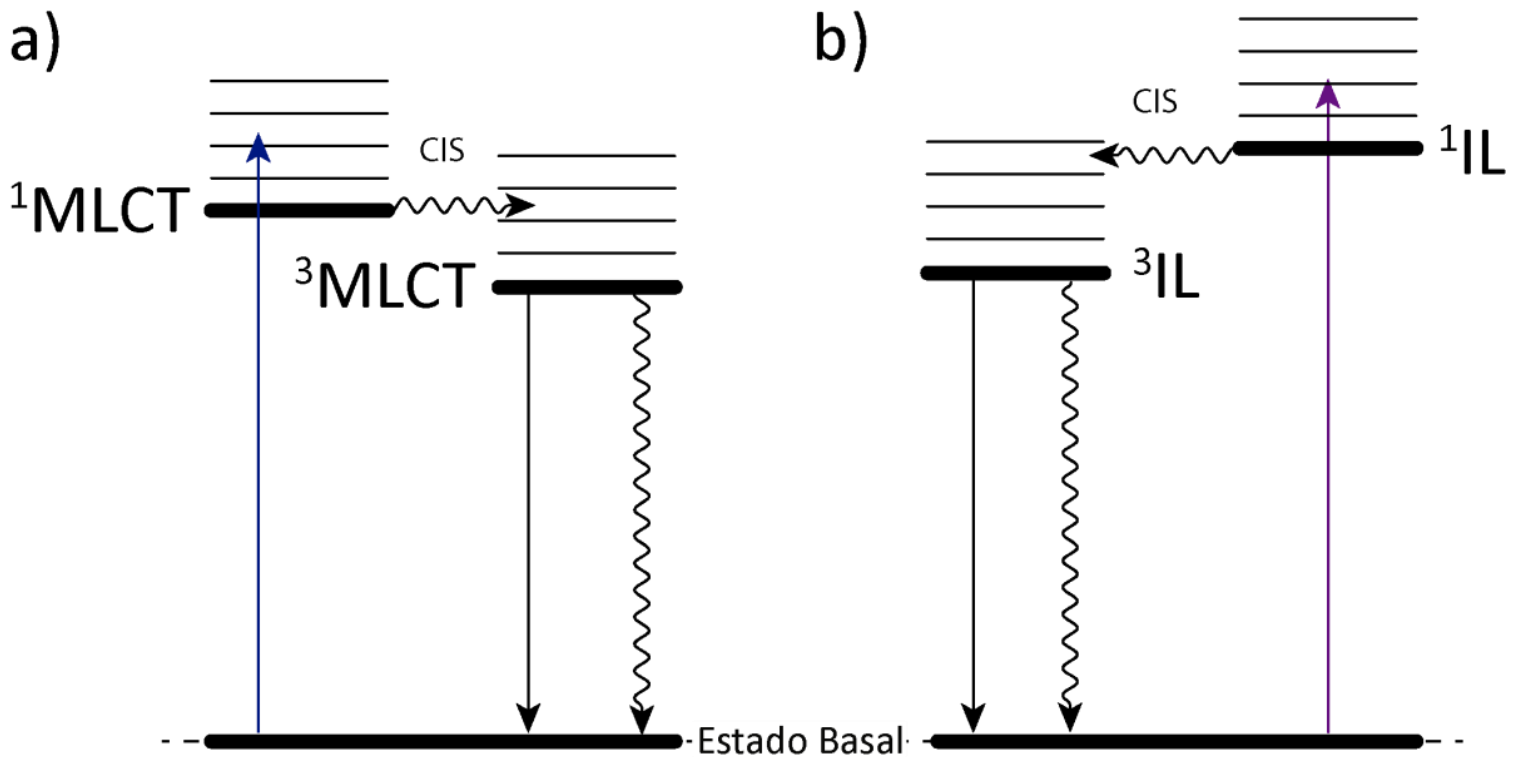

\section{Figura 4}

Diagrama de Jablonski modificado para complejos del tipo $\left[\operatorname{Re}(\operatorname{diimina})(\mathrm{CO})_{3} \mathrm{~L}\right](\mathrm{a})$ modelo MLCT, (b) IL.

\subsection{Complejos con estados excitados de menor energía del tipo LLCT}

En complejos con ligandos reductores y oxidantes, pueden surgir estados excitados que son el resultado de la transferencia de carga de un ligando (donor) a otro ligando (aceptor)[62][53]. Debido a la muy débil interacción electrónica entre el donor y el aceptor, los coeficientes de extinción para las bandas LLCT suelen ser muy bajos. Sin embargo, el estado LLCT puede poblarse indirectamente por excitación del MLCT por $\mathrm{CIS}$, seguido por una transferencia de electrones intramolecular. Por lo general, los parámetros de decaimiento no radiativos de los estados excitados LLCT en estos complejos, siguen la EGL. Debido a la naturaleza generalmente no emisiva del estado 
LLCT, sus propiedades en estado excitado sólo pueden ser estudiadas por espectroscopia de absorción del transiente, o indirectamente analizando su efecto en los tiempos vida del estado excitado MLCT de los cromóforos emisivos. Sin embargo, si el ligando donor de electrones no es estable a la oxidación, pueden ocurrir reacciones fotoquímicas posteriores.

\section{Ligando pterina}

Como se ha mencionado, la naturaleza y las características fotofísicas y fotoquímicas del ligando son determinantes en las propiedades del estado excitado del complejo. Por lo tanto es importante señalar aquí las principales características del ligando pterina.

La pterina (Ptr) (figura 5) es una molécula natural, miembro de la extensa familia de las pteridinas (las que comúnmente se hallan sustituidas en los C6 y C7). Esta familia de compuestos heterocíclicos se encuentra ampliamente distribuida, en el reino animal y vegetal. Las pteridinas se encuentran involucradas en varios procesos fotobiológicos y se las encuentra en vías metabólicas en mamíferos, órganos sensitivos de vertebrados e invertebrados y pigmentos en artrópodos [63].

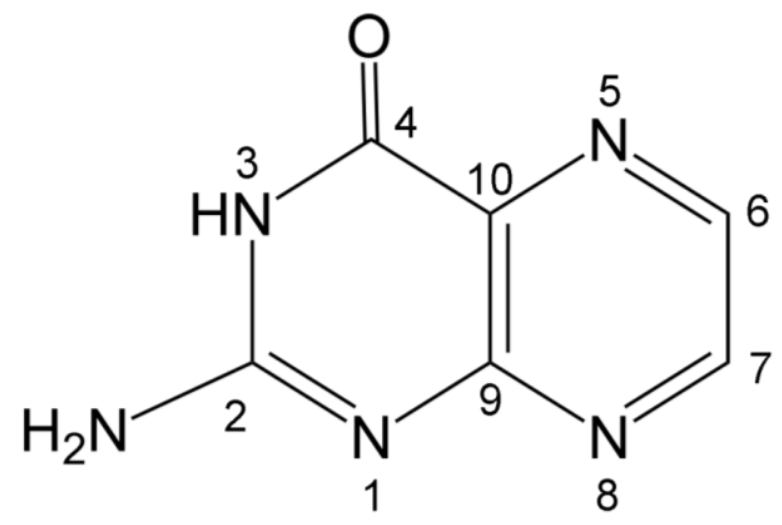

\section{Figura 5}

Representación de la molécula de pterina en su forma ceto con la numeración que se utiliza en esta tesis 


\subsubsection{Química}

Químicamente es un compuesto hetero-aromático deficiente en electrones $\pi$, capaz de formar puentes de hidrogeno. Los átomos de nitrógeno le confieren a la molécula un carácter básico, aunque débil, debido a la participación de los pares de electrones no enlazantes de los nitrógenos, $n$, en los sistemas $\pi$.

El estado basal de la pterina, en solución acuosa, se presenta en tres formas de acuerdo al pH (figura 6), siendo los $\mathrm{pK}_{\mathrm{a}}$ de los equilibrios entre estas especies 2,3 y 7,9 [64], [65]. El compuesto neutro (Ptr), mayoritario a pH 5,5, sufre la protonación del N1 al bajar el pH hasta 1, dando lugar a la formación del catión $\left(\mathbf{P t r H}^{+}\right)$(forma acida de la pterina). Cuando se alcaliniza la solución hasta pH cercano a 12, la especie mayoritaria es la forma aniónica pterinato (Pto`) que ha perdido el protón del N3.<smiles></smiles>

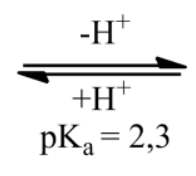<smiles>Nc1nc2nccnc2c(=O)[nH]1</smiles>

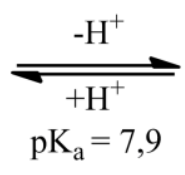<smiles>Nc1nc([O-])c2nccnc2n1</smiles>

\section{Figura 6}

Equilibrio entre formas acida, neutra y alcalina de la pterina.

El espectro de absorción de la pterina en solución acuosa presenta dos bandas de absorción. Una banda ubicada a alta energía, con máximo entre 220 y 290 nm y la otra, de menor energía, con un máximo cercano a $350 \mathrm{~nm}$ [66]. Estas bandas varían de acuerdo al pH. La forma neutra (especie mayoritaria entre los pHs 3 y 7) presenta dos máximos de absorción, uno centrado en $280 \mathrm{~nm}$ y otro en $340 \mathrm{~nm}$, aproximadamente. La forma aniónica presenta dos bandas, una con un máximo centrado en $255 \mathrm{~nm}$ y otro en $370 \mathrm{~nm}$. Las bandas de absorción de mayor energía de ambas especies fue asignada a la transición So $\rightarrow$ S2. Mientras que, la banda de menor energía se asignó a la transición So $\rightarrow$ S1 [66].

\subsubsection{Fotofísica.}

Se encontró en literatura, que el $\mathrm{pK}_{\mathrm{a}}{ }^{*}$ del equilibrio entre el estado singlete excitado de las formas neutra $\left({ }^{1} \mathrm{Ptr}^{*}\right)$ y aniónica $\left({ }^{1} \mathrm{Pto}^{-*}\right)$ es prácticamente igual al del estado 
basal [67]. También, que la desactivación de ${ }^{1} \mathrm{Ptr}^{*}$ es mucho más rápida que su desprotonación. Los valores de los parámetros de absorción y emisión se resumen en la tabla 1. La disminución en el rendimiento cuántico de fluorescencia $\phi_{\mathrm{f}}$ a $\mathrm{pH}$ alcalino se asigna a la desactivación del estado excitado por el $\mathrm{OH}^{-}[67]$.

\section{Tabla 1.}

Parámetros fotofísicos de absorción y emisión para la pterina, en condiciones de $\mathrm{pH}=$ 12,6 y 1. Los $\phi_{f}$ en $\mathrm{O}_{2}$ y $\mathrm{N}_{2}$ tienen los mismos valores que en aire. $\left(\lambda_{\text {exc }}=350 \mathrm{~nm}\right.$ ) [67], [68]

\begin{tabular}{|l|l|l|l|l|l|l|}
\hline Iones & $\boldsymbol{\lambda}_{\text {Abs }}(\mathbf{n m})$ & $\boldsymbol{\lambda}_{\mathbf{f}}(\mathbf{n m})$ & $\boldsymbol{\phi}_{\mathbf{f}}($ aire) & $\boldsymbol{\tau}_{\mathbf{f}}(\mathbf{n s})$ & $\boldsymbol{\lambda}_{\mathbf{p}}(\mathbf{n m})(\mathbf{a}$ 77K) & $\boldsymbol{\tau}_{\mathbf{p}}(\mathbf{s})(\mathbf{a}$ 77K) \\
\hline $\operatorname{PtrH}^{+}$ & 270,320 & 465 & $\mathrm{~N} / \mathrm{D}$ & $\mathrm{N} / \mathrm{D}$ & 431 & 1,1 \\
\hline Ptr & 270,342 & 440 & 0,33 & 7,6 & 434,472 & $\mathrm{~N} / \mathrm{D}$ \\
\hline Pto $^{-}$ & 253,360 & 456 & 0,27 & 5,0 & 495 & 0,9 \\
\hline
\end{tabular}

La emisión observada a 77K, presenta un corrimiento de Stokes menor que el observado temperatura ambiente. Esto se debe a la existencia de un reacomodamiento de la esfera solvatación en el cromóforo excitado, inducida por el cambio en el momento dipolar del estado ${ }^{1} \mathrm{Ptr}^{*}$. Además, la intensidad de fluorescencia es menor a temperatura ambiente que a $77 \mathrm{~K}$, indicando un importante proceso de desactivación no radiativo al encontrarse en solución a temperatura ambiente [64].

\subsubsection{Fotoquímica}

Los espectros de excitación de fluorescencia y fosforescencia reportados para la pterina, resultan coincidentes, hecho que indica que el estado excitado que se puebla inicialmente es el mismo para los dos procesos. El espectro de fosforescencia a 77K de la especie neutra exhibe dos emisiones distintas. Esto sugiere que posee dos estados triplete de naturaleza $\pi \rightarrow \pi^{*}$ [69], pudiendo corresponder a las dos formas tautomericas (amida-fenolato) de la pterina.

Se han reportado resultados de estudios de LFF realizados sobre la pterina en medio alcalino [67], donde se informa la existencia de dos transientes de absorción, uno cuyo espectro muestra dos bandas a 400 y $550 \mathrm{~nm}$, y decae con un tiempo de vida de 2,3 $\mu \mathrm{s}$. Y otro transiente, de vida más corta (ca. 300 ns) con máximos de absorción a 415 nm y a $600 \mathrm{~nm}$. Estas especies transientes, se postula que correspondan a la fosforescencia 
dual observada a 77K. Los datos publicados sobre la evolución del tiempo de vida del triplete con el pH, sugieren que tiene lugar la desprotonación del triplete neutro [67]. El aumento de la velocidad de decaimiento observado en presencia de $\mathrm{O}_{2}$ o sustratos oxidables, sugiere la naturaleza de tipo triplete de este transiente (la constante de velocidad de reacción bimolecular para la desactivación por oxigeno es $1,3 \times 10^{9} \mathrm{M}^{-1} \mathrm{~s}^{-}$

$\left.{ }^{1}\right)$. La energía encontrada para el triplete $\left(22000 \mathrm{~cm}^{-1}\right)$ es mucho más grande que la energía de los niveles 13800 y $7700 \mathrm{~cm}^{-1}$ correspondientes al ${ }^{1} \Sigma_{\mathrm{g}}{ }^{+}$y al ${ }^{1} \Delta_{\mathrm{g}}$ del oxígeno singlete, lo que da lugar a la posibilidad de producir oxígeno singlete por transferencia de energía desde el estado excitado triplete de la pterina hacia el oxígeno molecular. Además, la energía del triplete de la pterina es suficiente como para reaccionar con donores de hidrogeno mediante reacciones de abstracción [70].

\subsubsection{Reacción del triplete de la pterina con el solvente}

Ha sido reportada la formación de la especie semireducida (·HPtr) por reacción entre el triplete de la pterina y el solvente (Reacción 1) [71].

$$
\left[{ }^{3} \mathrm{Ptr}^{*}\right]+\mathrm{H}_{2} \mathrm{O} \stackrel{k_{s}}{\rightarrow} \mathrm{Ptr} H \cdot+\cdot \mathrm{OH}
$$

\subsubsection{Transiente de la pterina semireducida}

Se encuentran reportados en bibliografía los espectros de la especie semireducida de la pterina obtenida en distintas condiciones por la técnica de radiólisis de pulso [72]. El espectro del transiente generados, presenta un máximo en la región visible centrado en torno a los $480 \mathrm{~nm}$.

\subsubsection{Fotosensibilización}

Cuando se irradia a la pterina en la banda de absorción de menor energía, esta puede fotosensibilizar la oxidación de importantes biomoléculas, aminoácidos y bases púricas [63], [73], [74]. En particular, se han descripto estudios de fotosensibilización con luz UV-A del plásmido pUC18, usando Ptr como fotosensibilizador [73], [75]. Cuando se irradia el plásmido en presencia de Ptr, este sufre cortes al azar en sus hebras. Estos cortes conducen a la relajación del topoisómero superenrollado. La acumulación de 
estos cortes genera, en una segunda etapa, un corte en la doble hebra con la consiguiente transformación del plásmido circular en una molécula lineal. Los autores encontraron que la reacción de fotosensibilización ocurre tanto en presencia como en ausencia de $\mathrm{O}_{2}$.

\section{Terapia fotodinámica}

En el año 1893 Niels Ryberg Finsen utilizó por primera vez luz roja para tratamiento de viruela. En el mismo sentido, desarrolló la lámpara de arco voltaico para el tratamiento del lupus tuberculoso. Este desarrollo le valió el premio Nobel de medicina en el año 1903. Comenzando el siglo XX, en el año 1900 Oscar Rabb observó la disminución en la viabilidad de paramecios tratados con naranja de acridina al ser expuestos a la luz, siendo ésta la primera observación científica del efecto microbicida de la luz utilizando un fotosensibilizador. En 1905, Von Tappeiner utilizó una técnica, a la que llamó terapia fotodinámica (TFD), para el tratamiento de cáncer y otras afecciones cutáneas usando luz blanca y eosina como sensibilizador. Hasta fines del siglo XX, se utilizaron porfirinas como sensibilizadores para el tratamiento fotodinámico de diversos carcinomas y patologías cutáneas [76]. Ya en 1999 la FDA aprobó el uso de ALA (ácido amino levulínico, precursor de las porfirinas) para el tratamiento de queratosis y recientemente se probó su efectividad para el tratamiento de la enfermedad de Bowen (carcinoma de piel)[77].

Recientemente se han utilizado con éxito complejos metálicos en el tratamiento de tumores [9], [10], [78]-[80], de ellos el primero fue el Cisplatino [81]. En particular, es importante destacar los estudios sobre tricarbonilos de renio coordinados a diiminas con actividad antitumoral fotoinducida [82], [83].

La TFD básicamente consiste en la utilización de un fotosensibilizador de localización intracelular, el cual luego de absorber luz genera un estado excitado, que reacciona con las macromoléculas dentro de la célula. Estas reacciones introducen cambios que pueden conducir a la muerte de la célula o del microorganismo blanco. La TFD utilizada en el tratamiento de cáncer requiere la administración del fotosensibilizador, en forma intravenosa o local. Si la distribución del sensibilizador se realiza por sangre, 
este deberá asociarse a alguna de las proteínas de transporte. El siguiente paso es la incorporación a la célula, mecanismo mediado por difusión o facilitado por receptores de membrana. Una vez dentro de la célula es necesario irradiar, de modo de generar suficientes moléculas del fotosensibilizador en estado excitado como para inducir los cambios que conducen a la desactivación de la célula. Todos estos procesos constituyen sendos campos de investigación en los estudios con complejos metálicos.

\section{Interacción con ADN}

Existen diversos mecanismos por los cuales moléculas pequeñas pueden interaccionar con el ADN. Una clasificación muy básica consiste en dividir entre interacciones reversibles e interacciones irreversibles. Dentro de las interacciones reversibles se pueden encontrar varios subtipos:

- Agentes intercalantes: Estos ligandos se disponen entre los pares de bases apilados, sus interacciones con las bases nitrogenadas son de tipo electrostático o de Van der Waals y en ocasiones mediante la formación de puentes de hidrógeno.

- Agentes que se unen a un surco: la disposición en doble hélice de las cadenas de DNA hace que se formen unas hendiduras a lo largo del exterior de la hélice donde residen los grupos fosfato de los nucleótidos. Estos surcos, debido a su diferente estructura, muestran preferencia por determinados ligandos.

- Rompedores de hebra: Este tipo de agentes interaccionan con el DNA de forma que rompen la doble hélice imposibilitando su replicación.

Las interacciones irreversibles, son típicas en algunos antitumorales como el Cisplatino [81].

Existen ensayos de asociación que permiten monitorizar la interacción con el ADN. Estos ensayos se basan en el seguimiento de los cambios en las propiedades fotofísicas del cromóforo, tales como su emisión y absorción. Utilizando este tipo de ensayos, se ha estudiado la capacidad de unirse e inducir cambios en el ADN de numerosos complejos metálicos [28], [34], [80], [84]-[88]. Los efectos, inducidos por los complejos organometálicos, sobre la conformación de distintos plásmidos, han sido 
extensamente estudiados, tanto en sus estados basales como en estados fotoexcitados [89]-[93]. Dentro de los complejos estudiados, nos resultan interesantes los complejos tricarbonilicos de Renio $f a c-\operatorname{Re}^{\prime}(\mathrm{CO})_{3}$, debido a su interesante fotofísica antes descripta. Es importante notar los trabajos que en particular informan sobre los cambios conformacionales inducidos en plásmidos por parte de este tipo de complejos [28], [86].

En particular, se ha informado sobre la capacidad de intercalar entre las bases de la molécula de $A D N$ que tienen algunos complejos tricarbonílicos de $\operatorname{Re}(I)$ coordinando al dppz [29], [88], [94]-[96]. También se ha estudiado su capacidad de actuar como fotosensibilizadores en procesos de transferencia de electrones o de energía [97].

\section{Referencias bibliográficas}

[1] G. L. Geoffroy and M. S. Wrighton, Organometallic Photochemistry. 1979.

[2] J. Luong, R. A. Faltynek, and M. S. Wrighton, "Ground-and excited-state oxidation-reduction chemistry of (triphenyltin)-and (triphenylgermanium) tricarbonyl (1, 10-phenanthroline) rhenium and related compounds," J. Am. Chem. SOC, vol. 3, no. 102, pp. 7892-7900, 1980.

[3] A. Lees, "Luminescence Properties of Organometallic Complexes," Chem. Rev., vol. 87, pp. 711-743, 1987.

[4] R. Staehle, L. Tong, L. Wang, L. Duan, A. Fischer, M. S. G. Ahlquist, L. Sun, and S. Rau, "Water oxidation catalyzed by mononuclear ruthenium complexes with a 2,2'-bipyridine-6,6'-dicarboxylate (bda) ligand: how ligand environment influences the catalytic behavior.," Inorg. Chem., vol. 53, no. 3, pp. 1307-19, Mar. 2014.

[5] R. Díaz, O. Reyes, A. Francois, A. Leiva, and B. Loeb, "Synthesis of a new polypyridinic highly conjugated ligand with electron-acceptor properties," Tetrahedron Lett., vol. 42, pp. 6463-6467, 2001.

[6] B. Higgins, B. a DeGraff, and J. N. Demas, "Luminescent transition metal complexes as sensors: structural effects on pH response.," Inorg. Chem., vol. 44, no. 19, pp. 6662-9, Sep. 2005.

[7] M. Cattaneo, F. Fagalde, C. D. Borsarelli, and N. E. Katz, "Improvement of the dynamic range of $\mathrm{pH}$ sensing by using a luminescent tricarbonylpolypyridylrhenium(l) complex with three different protonation sites.," Inorg. Chem., vol. 48, no. 7, pp. 3012-7, Apr. 2009. 
[8] O. Briel, K. Sünkel, I. Krossing, H. Nöth, E. Schmälzlin, K. Meerholz, C. Bräuchle, and W. Beck, "Synthesis and Nonlinear Optical Properties of Carbonylrhenium Bromide Complexes with Conjugated Pyridines," Eur. J. Inorg. Chem., pp. 483490, 1999.

[9] R. S. Kumar, S. Arunachalam, V. S. Periasamy, C. P. Preethy, a. Riyasdeen, and M. a. Akbarsha, "Synthesis, DNA binding and antitumor activities of some novel polymer-cobalt(III) complexes containing 1,10-phenanthroline ligand," Polyhedron, vol. 27, no. 3, pp. 1111-1120, Feb. 2008.

[10] N. Busto and B. García, "Anticancer Activity and DNA Binding of a Bifunctional $\mathrm{Ru}$ (II) Arene Aqua-Complex with the 2, 4-Diamino-6-(2-pyridyl)-1, 3, 5-triazine Ligand," Inorg. Chem., vol. 52, 2013.

[11] S. R. Dalton, S. Glazier, B. Leung, S. Win, C. Megatulski, and S. J. N. Burgmayer, "DNA binding by Ru(II)-bis(bipyridine)-pteridinyl complexes.," J. Biol. Inorg. Chem., vol. 13, no. 7, pp. 1133-48, Sep. 2008.

[12] E. Gicquel, J.-P. Souchard, F. Magnusson, J. Chemaly, P. Calsou, and P. Vicendo, "Role of intercalation and redox potential in DNA photosensitization by ruthenium(II) polypyridyl complexes: assessment using DNA repair protein tests.," Photochem. Photobiol. Sci., vol. 12, no. 8, pp. 1517-26, Aug. 2013.

[13] S. Swavey and K. J. Brewer, "Visible light induced photocleavage of DNA by a mixed-metal supramolecular complex: [[(bpy)(2)Ru(dpp)](2)RhCl2]5+.," Inorg. Chem., vol. 41, no. 24, pp. 6196-8, Dec. 2002.

[14] K. D. Barker, B. R. Benoit, J. a Bordelon, R. J. Davis, A. S. Delmas, O. V Mytykh, J. T. Petty, J. F. Wheeler, and N. a. . Kane-Maguire, "Intercalative binding and photoredox behavior of [Cr(phen)2(dppz)]3+ with B-DNA," Inorganica Chim. Acta, vol. 322, no. 1-2, pp. 74-78, Oct. 2001.

[15] R. Hartshorn and J. Barton, "Novel dipyridophenazine complexes of ruthenium (II): exploring luminescent reporters of DNA," J. Am. Chem. Soc., no. 1, pp. 59195925, 1992.

[16] F. Li, W. Chen, C. Tang, and S. Zhang, "Recent development of interaction of transition metal complexes with DNA based on biosensor and its applications.," Talanta, vol. 77, no. 1, pp. 1-8, Oct. 2008.

[17] E. D. Olmon, M. G. Hill, and J. K. Barton, "Using metal complex reduced states to monitor the oxidation of DNA.," Inorg. Chem., vol. 50, no. 23, pp. 12034-44, Dec. 2011.

[18] A. Roger, A. Egli, U. Abram, C. K. Hegetschweiler, V. Gramlich, and P. A. Schubiger, "Synthesis and Reactivity of [ NEt4]2[ ReBr,( CO),]. Formation and Structural Characterization of the Clusters by [N Et4] [Re3 ( u3- OH ( u-OH 
)3(CO)9] and [N Et4][Re2(u-OH)3(CO)6] by alkaline titration," J. Chem. Soc. Dalt. Trans., no. 1, pp. 2815-2820, 1994.

[19] B. Salignac, P. V Grundler, S. Cayemittes, U. Frey, R. Scopelliti, A. E. Merbach, R. Hedinger, K. Hegetschweiler, R. Alberto, U. Prinz, G. Raabe, U. Kölle, and S. Hall, "Reactivity of the organometallic fac-[(CO)3Rel( $(\mathrm{H} 2 \mathrm{O}) 3]+$ aquaion. Kinetic and thermodynamic properties of $\mathrm{H} 2 \mathrm{O}$ substitution.," Inorg. Chem., vol. 42, no. 11, pp. 3516-26, Jun. 2003.

[20] L. Helm, "Ligand exchange and complex formation kinetics studied by NMR exemplified on fac-[(CO)3M(H2O)]+ (M=Mn, Tc, Re)," Coord. Chem. Rev., vol. 252, no. 21-22, pp. 2346-2361, Nov. 2008.

[21] K. Adams and L. Marzilli, "fac-[Re(CO)3(H2O)3]+ Nucleoside Monophosphate Adducts Investigated in Aqueous Solution by Multinuclear NMR Spectroscopy," Inorg. Chem., vol. xx, no. xx, pp. 15833-15842, 2007.

[22] N. Lazarova, S. James, J. Babich, and J. Zubieta, "A convenient synthesis, chemical characterization and reactivity of $[\operatorname{Re}(\mathrm{CO}) 3(\mathrm{H} 2 \mathrm{O}) 3] \mathrm{Br}$ : the crystal and molecular structure of $[\mathrm{Re}(\mathrm{CO}) 3(\mathrm{CH} 3 \mathrm{CN}) 2 \mathrm{Br}]$," Inorg. Chem. Commun., vol. 7, no. 9, pp. 1023-1026, Sep. 2004.

[23] A. Egli, K. Hegetschweiler, and R. Alberto, "Hydrolysis of the Organometallic Aqua Ion fac-Triaquatricarbonylrhenium (I). Mechanism, $\mathrm{p} \mathrm{K}$ a, and Formation Constants of the Polynuclear Hydrolysis Products," Organometallics, vol. 7333, no. I, pp. 1833-1840, 1997.

[24] R. Alberto, R. Schibli, and R. Waibel, "Basic aqueous chemistry of $+(M=R e, T c)$ directed towards radiopharmaceutical application," Coord. Chem. ..., vol. 192, pp. 901-919, 1999.

[25] M. V Werrett, D. Chartrand, J. D. Gale, G. S. Hanan, J. G. MacLellan, M. Massi, S. Muzzioli, P. Raiteri, B. W. Skelton, M. Silberstein, and S. Stagni, "Synthesis, structural, and photophysical investigation of diimine triscarbonyl $\operatorname{Re}(\mathrm{I})$ tetrazolato complexes.," Inorg. Chem., vol. 50, no. 4, pp. 1229-41, Feb. 2011.

[26] M. R. Feliz, G. Ruiz, and E. Wolcan, "Photophysical properties of Re ( CO ) $3 \mathrm{~L} \neq 3$ ( $L$ ` monoazine ) complexes Electronic delocalization effect in metal-to-ligand charge transfer excited states," J. Photochem. Photobiol. A Chem., vol. 117, 1998.

[27] L. Rodríguez, M. Ferrer, O. Rossell, F. J. S. Duarte, a. Gil Santos, and J. C. Lima, "Solvent effects on the absorption and emission of $[\operatorname{Re}(\mathrm{R} 2 \mathrm{bpy})(\mathrm{CO}) 3 \mathrm{X}]$ complexes and their sensitivity to $\mathrm{CO} 2$ in solution," J. Photochem. Photobiol. A Chem., vol. 204, no. 2-3, pp. 174-182, May 2009. 
[28] F. Zobi, B. Spingler, and R. Alberto, "Guanine and plasmid DNA binding of monoand trinuclear fac- $[\operatorname{Re}(\mathrm{CO}) 3]+$ complexes with amino acid ligands.," Chembiochem, vol. 6, no. 8, pp. 1397-405, Aug. 2005.

[29] E. D. Olmon, P. a Sontz, A. M. Blanco-Rodríguez, M. Towrie, I. P. Clark, A. Vlček, and J. K. Barton, "Charge photoinjection in intercalated and covalently bound $[\operatorname{Re}(\mathrm{CO}) 3(\mathrm{dppz})(\mathrm{py})]+-\mathrm{DNA}$ constructs monitored by time-resolved visible and infrared spectroscopy.," J. Am. Chem. Soc., vol. 133, no. 34, pp. 13718-30, Aug. 2011.

[30] A. El Nahhas, C. Consani, A. M. Blanco-Rodríguez, K. M. Lancaster, O. Braem, A. Cannizzo, M. Towrie, I. P. Clark, S. Zális, M. Chergui, and A. Vlcek, "Ultrafast excited-state dynamics of rhenium(l) photosensitizers $[\operatorname{Re}(\mathrm{Cl})(\mathrm{CO}) 3(\mathrm{~N}, \mathrm{~N})]$ and [Re(imidazole)(CO)3(N,N)]+: diimine effects.," Inorg. Chem., vol. 50, no. 7, pp. 2932-43, Apr. 2011.

[31] H. van der Salm, M. G. Fraser, R. Horvath, S. a Cameron, J. E. Barnsley, X.-Z. Sun, M. W. George, and K. C. Gordon, "Re(I) Complexes of Substituted dppz: A Computational and Spectroscopic Study.," Inorg. Chem., no. I, Feb. 2014.

[32] F. Ragone, H. H. Martinez Saavedra, P. M. David Gara, G. T. Ruiz, and E. Wolcan, "Photosensitized generation of singlet oxygen from $\operatorname{Re}(\mathrm{I})$ complexes: a photophysical study using LIOAS and luminescence techniques.," J. Phys. Chem. A, vol. 117, no. 21, pp. 4428-35, May 2013.

[33] W. Kaim, H. Kramer, C. Vogler, and J. Rieker, "Synthesis, electrochemistry and emission spectroscopy in fluid solution of four isomeric ( $\alpha$-diimine) Re (CO) $3 \mathrm{Hal}$ complexes," J. Organomet. ..., vol. 367, pp. 107-115, 1989.

[34] G. T. Ruiz, M. P. Juliarena, R. O. Lezna, E. Wolcan, M. R. Feliz, and G. Ferraudi, "Intercalation of fac-[(4,4'-bpy)Rel(CO)3(dppz)]+, dppz = dipyridyl[3,2-a:2'3'c]phenazine, in polynucleotides. On the UV-vis photophysics of the $\operatorname{Re}(I)$ intercalator and the redox reactions with pulse radiolysis-generated radicals.," Dalton Trans., vol. 3, no. 20, pp. 2020-9, May 2007.

[35] J. M. Villegas, S. R. Stoyanov, W. Huang, and D. P. Rillema, "Photophysical, spectroscopic, and computational studies of a series of $\operatorname{Re}(\mathrm{I})$ tricarbonyl complexes containing 2,6-dimethylphenylisocyanide and 5- and 6-derivatized phenanthroline ligands," Inorg. Chem., vol. 44, no. 7, pp. 2297-2309, 2005.

[36] E. Wolcan, "On the origins of the absorption spectroscopy of pterin and $\operatorname{Re}(\mathrm{CO}) 3$ (pterin)(H2O) aqueous solutions. A combined theoretical and experimental study.," Spectrochim. Acta. A. Mol. Biomol. Spectrosc., vol. 129, pp. 173-83, Aug. 2014.

[37] E. Wolcan and M. R. Feliz, "Temperature and medium effects on the photophysical properties of $\operatorname{Re}(\mathrm{CO}) 3\left(2,2^{\prime}\right.$-bipyridine) pendant chromophores 
coordinated to a poly(4-vinylpyridine) backbone," Photochem. Photobiol. Sci., vol. 2, no. 4, p. 412, 2003.

[38] M. Schutte, G. Kemp, H. G. Visser, and A. Roodt, "Tuning the reactivity in classic low-spin $\mathrm{d} 6$ rhenium(I) tricarbonyl radiopharmaceutical synthon by selective bidentate ligand variation ( $L, L^{\prime}-B i d ; L^{\prime} L^{\prime}=N, N^{\prime}, N, O$, and $O, O^{\prime}$ donor atom sets) in fac-[Re(CO)3(L,L'-Bid)(MeOH)]n complexes.," Inorg. Chem., vol. 50, no. 24, pp. 12486-98, Dec. 2011.

[39] J. Dyer, W. J. Blau, C. G. Coates, C. M. Creely, J. D. Gavey, M. W. George, D. C. Grills, S. Hudson, J. M. Kelly, P. Matousek, J. J. McGarvey, J. McMaster, A. W. Parker, M. Towrie, and J. a. Weinstein, "The photophysics of fac$[\operatorname{Re}(\mathrm{CO}) 3(\mathrm{dppz})(\mathrm{py})]+$ in $\mathrm{CH} 3 \mathrm{CN}$ : a comparative picosecond flash photolysis, transient infrared, transient resonance Raman and density functional theoretical studyDedicated to the memory of Nobel Laureate, Lord George Porter FRSC FRS ," Photochem. Photobiol. Sci., vol. 2, no. 5, p. 542, 2003.

[40] P. Natarajan and M. Schmittel, "ON-OFF luminescence signaling of hybrid organic-inorganic switches.," Inorg. Chem., vol. 52, no. 15, pp. 8579-90, Aug. 2013.

[41] A. Cannizzo, A. M. Blanco-Rodríguez, A. El Nahhas, J. Sebera, S. Zális, A. Vlcek, and M. Chergui, "Femtosecond fluorescence and intersystem crossing in rhenium(I) carbonyl-bipyridine complexes.," J. Am. Chem. Soc., vol. 130, no. 28, pp. 8967-74, Jul. 2008.

[42] J. Shaw and R. Schmehl, "Photophysical properties of rhenium (I) diimine complexes: observation of room-temperature intraligand phosphorescence," J. Am. Chem. Soc., vol. 113, no. 2, pp. 389-394, 1991.

[43] T. M. McLean, J. L. Moody, M. R. Waterland, and S. G. Telfer, "Luminescent rhenium(I)-dipyrrinato complexes.," Inorg. Chem., vol. 51, no. 1, pp. 446-55, Jan. 2012.

[44] a El Nahhas, R. M. van der Veen, T. J. Penfold, V. T. Pham, F. a Lima, R. Abela, a M. Blanco-Rodriguez, S. Záliš, a Vlček, I. Tavernelli, U. Rothlisberger, C. J. Milne, and M. Chergui, "X-ray absorption spectroscopy of ground and excited rheniumcarbonyl-diimine complexes: evidence for a two-center electron transfer.," J. Phys. Chem. A, vol. 117, no. 2, pp. 361-9, Jan. 2013.

[45] A. Cannizzo, A. M. Blanco-rodrı, and A. El Nahhas, "Femtosecond Fluorescence and Intersystem Crossing in Rhenium ( I ) Carbonyl-Bipyridine Complexes," no. I, pp. 8967-8974, 2008.

[46] A. Klein, T. Scheiring, and W. Kaim, "Molecular and Crystal Structure of an Organoplatinum (II) Complex with Dipyrido phenazine (dppz)," Zeitschrift fur Anorg. und ..., vol. 625, pp. 1177-1180, 1999. 
[47] T. O. Chem and S. B. Heidelberg, "Ultrafast Excited-State Processes in Re ( I ) Carbonyl-Diimine Complexes: From Excitation to Photochemistry," no. May 2009, pp. 73-114, 2010.

[48] A. Kumar, S. Sun, and A. J. Lees, "Photophysics and Photochemistry of Organometallic Rhenium Diimine Complexes," Top Organomet Chem, no. June 2009, pp. 1-35, 2010.

[49] C. Bronner and O. S. Wenger, "Proton-coupled electron transfer between 4cyanophenol and photoexcited rhenium(I) complexes with different protonatable sites.," Inorg. Chem., vol. 51, no. 15, pp. 8275-83, Aug. 2012.

[50] P. Chen and T. J. Meyer, "Medium Effects on Charge Transfer in Metal Complexes.," Chem. Rev., vol. 98, no. 4, pp. 1439-1478, Jun. 1998.

[51] A. Vogler and H. Kunkely, "Excited state properties of organometallic compounds of rhenium in high and low oxidation states," Coord. Chem. Rev., vol. 200-202, pp. 991-1008, May 2000.

[52] V. Balzani, A. Juris, M. Venturi, S. Campagna, and S. Serroni, "Luminescent and Redox-Active Polynuclear Transition Metal Complexes.," Chem. Rev., vol. 96, pp. 759-834, 1996.

[53] K. S. Schanze, D. Brent MacQueen, T. a Perkins, and L. a Cabana, "Studies of intramolecular electron and energy transfer using the fac-(diimine)Rel(CO)3 chromophore," Coord. Chem. Rev., vol. 122, pp. 63-89, 1993.

[54] L. a. Worl, R. Duesing, P. Chen, L. Della Ciana, and T. J. Meyer, "Photophysical properties of polypyridyl carbonyl complexes of rhenium (I)," J. Chem. Soc. Dalt. Trans., pp. 849-858, 1991.

[55] D. J. Stufkens, "The Remarkable Properties of $\alpha$-Diimine Rhenium Tricarbonyl Complexes in Their Metal-to-Ligand Charge-Transfer (MLCT) Excited States," Comments Inorg. Chem., vol. 13, no. October 2014, pp. 359-385, 1992.

[56] J. Caspar and T. Meyer, "Application of the Energy Gap Law to Nonradiatlve, Excited-State Decay," J. Phiys. Chem, vol. 6, no. 1, pp. 952-957, 1983.

[57] J. M. Butler, M. W. George, J. R. Schoonover, D. M. Dattelbaum, and T. J. Meyer, "Application of transient infrared and near infrared spectroscopy to transition metal complex excited states and intermediates," Coord. Chem. Rev., vol. 251, no. 3-4, pp. 492-514, Feb. 2007.

[58] L. Wallace and D. Rillema, "Photophysical properties of rhenium (I) tricarbonyl complexes containing alkyl-and aryl-substituted phenanthrolines as ligands," Inorg. Chem., vol. 32, no. 18, pp. 3836-3843, 1993. 
[59] P. J. Giordano, S. M. Fredricks, M. S. Wrighton, and D. L. Morse, "fac-XRe(C0)3(3benzoylpyridine)2:," J. Am. Chem. Soc., vol. 100, no. 1977, p. 2257, 1978.

[60] R. M. Leasure, L. Sacksteder, D. Nesselrodt, G. a. Reitz, J. N. Demas, and B. a. DeGraff, "Excited-state acid-base chemistry of (.alpha.diimine)cyanotricarbonylrhenium(I) complexes," Inorg. Chem., vol. 30, pp. 3722-3728, 1991.

[61] J. R. Schoonover, W. D. Bates, and T. J. Meyer, "Application of Resonance Raman Spectroscopy to Electronic Structure in Metal Complex Excited States. ExcitedState Ordering and Electron Delocalization in Dipyrido[3,2-a:2',3'-c]phenazine (dppz): Complexes of Re(I) and Ru(II)," Inorg. Chem., vol. 34, pp. 6421-6422, 1995.

[62] P. M. W. R. D. P. W. C. Shaver R.J., "Structure, physical and photophysical properties, and charge separation studies of $\operatorname{Re}(\mathrm{bpm})(\mathrm{CO}) 3 \mathrm{Ln}+$ complexes $(\mathrm{L}=$ CH3CN, py, MeQ+, py-PTZ)," Inorg. Chem., vol. 34, no. 12, pp. 5446-5454, 1995.

[63] J. Berg, J. Tymoczko, and L. Stryer, Biochemistry, 5th edition. 2002.

[64] W. Pfleiderer, E. LIEDE, P. H. M. Lohmant, and M. Rukwied, "On the structure of the pterin," Chem. Ber., vol. 93, no. 9, pp. 2015-2024, 1960.

[65] R. De Wit, "Determination of proton dissociation constants by ion-exchange high-performance liquid chromatography," Anal. Biochem., vol. 123, pp. 285290, 1982.

[66] C. Lorente and A. H. Thomas, "Photophysics and photochemistry of pterins in aqueous solution.," Acc. Chem. Res., vol. 39, no. 6, pp. 395-402, Jun. 2006.

[67] C. Chahidi and M. Aubailly, "Photophysical and photosensitizing properties of 2amino-4 pteridinone: a natural pigment," Photochem. Photobiol., vol. 33, pp. 641-649, 1981.

[68] A. Thomas and C. Lorente, "Fluorescence of pterin, 6-formylpterin, 6carboxypterin and folic acid in aqueous solution: pH effects," Photochem. Photobiol. Sci., vol. 1, pp. 421-426, 2002.

[69] K. Neverov, E. Mironov, and T. Lyudnikova, "Phosphorescence analysis of the triplet state of pterins in connection with their photoreceptor function in biochemical systems," Biochem., vol. 61, no. 9, pp. 1149-1155, 1996.

[70] K. Gollnick, In Radiation Research: Biochemical, Chemical and Physical Perspectives, 2013th ed. Elsevier, 1975.

[71] L. I. Grossweiner, "In Photophysiology," in Photophysiology, vol. 5, A. Giese, Ed. Academic Press. N.Y, 1970, pp. 1-30. 
[72] P. Moorthy and E. Hayon, "One-electron redox reactions of water-soluble vitamins. II. Pterin and folic acid," J. Org. Chem., vol. 41, no. 9, pp. 1607-1613, 1976.

[73] C. Lorente, A. H. Thomas, L. Villata, D. Hozbor, A. Lagares, and A. L. Capparelli, "Photoinduced cleavage of plasmid DNA in the presence of pterin," Pteridines, vol. 11, pp. 100-105, 2000.

[74] G. Petroselli, M. L. Dantola, F. M. Cabrerizo, A. L. Capparelli, C. Lorente, E. Oliveros, and $\mathrm{H}$. Thomas, "Oxidation of 2'-Deoxyguanosine 5'MonophosphatePhotoinduced by Pterin: Type I versus Type II Mechanism," J. Am. Chem. Soc., no. 130, pp. 3001-3011, 2008.

[75] C. Lorente, "Fotofísica y propiedades fotosensibilizadoras de pterinas en solución acuosa," Tesis, 2001.

[76] M. G. Kotoula, E. E. Tsironi, C. H. Karabatsas, and D. Z. Chatzoulis, "Photodynamic therapy.," J. Natl. cancer Inst., vol. 90, no. 12, pp. 889-905, 1998.

[77] J. C. Kennedy, R. H. Pottier, and D. C. Pross, "Photodynamic therapy with endogenous protoporphyrin IX: basic principles and present clinical experience.," J. Photochem. Photobiol. B., vol. 6, pp. 143-148, 1990.

[78] L. Ronconi and P. J. Sadler, "Using coordination chemistry to design new medicines," Coord. Chem. Rev., vol. 251, no. 13-14, pp. 1633-1648, Jul. 2007.

[79] K. D. Mjos and C. Orvig, "Metallodrugs in Medicinal Inorganic Chemistry.," Chem. Rev., Jan. 2014.

[80] R. K. Gupta, R. Pandey, G. Sharma, R. Prasad, B. Koch, S. Srikrishna, P.-Z. Li, Q. $\mathrm{Xu}$, and D. S. Pandey, "DNA binding and anti-cancer activity of redox-active heteroleptic piano-stool Ru(II), Rh(III), and $\operatorname{Ir}(\mathrm{III})$ complexes containing 4-(2methoxypyridyl)phenyldipyrromethene.," Inorg. Chem., vol. 52, no. 7, pp. 368798, Apr. 2013.

[81] S. Dasari and P. Bernard Tchounwou, "Cisplatin in Cancer therapy: Molecular mechanisms of action.," Eur. J. Pharmacol., vol. 740, pp. 364-378, 2014.

[82] K. Wähler, A. Ludewig, P. Szabo, K. Harms, and E. Meggers, "Rhenium complexes with red-light-induced anticancer activity," Eur. J. Inorg. Chem., no. I, pp. 807811, 2014.

[83] A. Leonidova, V. Pierroz, R. Rubbiani, J. Heier, S. Ferrari, and G. Gasser, "Towards cancer cell-specific phototoxic organometallic rhenium(I) complexes," Dalton Trans., vol. 43, pp. 4287-94, 2014. 
[84] L. J. Boerner and J. M. Zaleski, "Metal complex-DNA interactions: from transcription inhibition to photoactivated cleavage.," Curr. Opin. Chem. Biol., vol. 9, no. 2, pp. 135-44, Apr. 2005.

[85] G. Sathyaraj, M. Kiruthika, T. Weyhermüller, and B. Unni Nair, “Oxidative Cleavage of DNA by Ruthenium(II) Complexes Containing a Ferrocene/NonFerrocene Conjugated Imidazole Phenol Ligand," Organometallics, vol. 31, no. 19, pp. 6980-6987, Oct. 2012.

[86] V. W. Yam, K. K. Lo, K. Cheung, and R. Y. Kong, "Deoxyribonucleic acid binding and photocleavage studies of rhenium(I) dipyridophenazine complexes," J. Chem. Soc. Dalt. Trans., pp. 2067-2072, 1997.

[87] S. Delaney, M. Pascaly, P. K. Bhattacharya, K. Han, and J. K. Barton, "Oxidative damage by ruthenium complexes containing the dipyridophenazine ligand or its derivatives: a focus on intercalation.," Inorg. Chem., vol. 41, no. 7, pp. 1966-74, Apr. 2002.

[88] A. J. McConnell, M. H. Lim, E. D. Olmon, H. Song, E. E. Dervan, and J. K. Barton, "Luminescent Properties of Ruthenium(II) Complexes with Sterically Expansive Ligands Bound to DNA Defects.," Inorg. Chem., vol. 51, no. 22, pp. 12511-20, Nov. 2012.

[89] B. R. Williams, S. R. Dalton, M. Skiba, S. E. Kim, A. Shatz, P. J. Carroll, and S. J. N. Burgmayer, "Pteridine cleavage facilitates DNA photocleavage by $\mathrm{Ru}(\mathrm{II})$ polypyridyl compounds.," Inorg. Chem., vol. 51, no. 23, pp. 12669-81, Dec. 2012.

[90] S. L. H. Higgins, T. a White, B. S. J. Winkel, and K. J. Brewer, "Redox, spectroscopic, and photophysical properties of Ru-Pt mixed-metal complexes incorporating 4,7-diphenyl-1,10-phenanthroline as efficient DNA binding and photocleaving agents.," Inorg. Chem., vol. 50, no. 2, pp. 463-70, Jan. 2011.

[91] A. M. Angeles-Boza, P. M. Bradley, P. K.-L. Fu, M. Shatruk, M. G. Hilfiger, K. R. Dunbar, and C. Turro, "Photocytotoxicity of a new Rh2(II,II) complex: increase in cytotoxicity upon irradiation similar to that of PDT agent hematoporphyrin.," Inorg. Chem., vol. 44, no. 21, pp. 7262-4, Oct. 2005.

[92] N. Deepika, Y. P. Kumar, C. Shobha Devi, P. V. Reddy, A. Srishailam, and S. Satyanarayana, "Synthesis, characterization, and DNA binding, photocleavage, cytotoxicity, cellular uptake, apoptosis, and on-off light switching studies of $\mathrm{Ru}(\mathrm{II})$ mixed-ligand complexes containing 7-fluorodipyrido[3,2-a:2', 3'c]phenazine.," J. Biol. Inorg. Chem. JBIC a, vol. 18, no. 7, pp. 751-66, Oct. 2013.

[93] S. J. Burya, A. M. Palmer, J. C. Gallucci, and C. Turro, "Photoinduced ligand exchange and covalent DNA binding by two new dirhodium bis-amidato complexes.," Inorg. Chem., vol. 51, no. 21, pp. 11882-90, Nov. 2012. 
[94] K. K. Lo, "Exploitation of Luminescent Organometallic Rhenium ( I ) and Iridium ( III ) Complexes in Biological Studies," no. May 2009, pp. 115-158, 2010.

[95] T. Phillips, I. Haq, A. J. H. M. Meijer, H. Adams, I. Soutar, L. Swanson, M. J. Sykes, and J. a Thomas, "DNA binding of an organic dppz-based intercalator.," Biochemistry, vol. 43, no. 43, pp. 13657-65, Nov. 2004.

[96] A. J. McConnell, H. Song, and J. K. Barton, "Luminescence of [Ru(bpy)2(dppz)]2+ bound to RNA mismatches.," Inorg. Chem., vol. 52, no. 17, pp. 10131-6, Sep. 2013.

[97] G. T. Ruiz, G. Ferraudi, E. Wolcan, and M. R. Feliz, "On the elusive, non-emissive yet reactive, upper excited states of [(4,40-bpy)Rel(CO)3(dppz)]PF6 (dppz = dipyridil[3,2-a:2030-c]phenazine)," Inorg. Chem. Acta, no. 363, pp. 1615-1618, 2010. 


\section{Segunda parte}

Resultados 



\title{
Capítulo III
}

Síntesis y caracterización del complejo

\author{
fac-Re'(CO) $)_{3}$ (pterina) $\left(\mathrm{H}_{2} \mathrm{O}\right)$
}




\section{Introducción}

En esta parte del trabajo se presenta la síntesis y caracterización de un nuevo complejo tricarbonilico de Re (I) coordinando un ligando orgánico del tipo pterina (Ptr). Además se analizan los equilibrios que se establecen en solución acuosa con distintas condiciones de acidez.

Las pterinas son compuestos heterocíclicos poliimina ampliamente distribuidos en la naturaleza, sus derivados sustituidos en la posición 6 se encuentran, usualmente, en los sistemas biológicos como pigmentos, cofactores de transferencia de un carbono y cofactores redox. Esta relevancia biológica atrae el interés sobre el estudio de sus propiedades y reactividad tanto in vivo como in vitro [1], [2]. La unión del fragmento $\operatorname{Re}(\mathrm{CO})_{3}{ }^{+}$a estos heterociclos se da usualmente a través de los sitios quelantes O4 y N5 [3]. Esto también se ha verificado para un gran número de complejos pterina con $\mathrm{Cu}(\mathrm{II})$ [4], [5], Zn(II), Ru(II) [6], Co(II) [7], Ni(II) [8], Fe(II)[9], Mo(VI) [10], Ir(III) [11] y otros [12]. En la mayoría de los ejemplos que pueden encontrarse en la literatura, relacionados a complejos metálicos de pterina, se observa una baja solubilidad debida a la presencia de múltiples puentes de hidrogeno intermoleculares. La mayoría de las estructuras de rayos $\mathrm{X}$ reportadas, son de complejos metálicos con ligandos derivados de pterina tales como 2-(dimetilamino)-4-oxo-3H-pterina [9] o de lumazina metilada [3], [11], [13], estos ligandos resultaron ser más solubles que la pterina, en agua y/o solventes orgánicos y también más adecuados para obtener mono-cristales. Sin embargo, recientemente, se ha sintetizado un nuevo complejo con buena solubilidad en agua, $\mathrm{Ni}$-(etilendiamina)(pterina) 2 , y su estructura fue determinada mediante difracción de rayos $X[14]$. Hasta el momento de realización de este trabajo de tesis, no hay ejemplos de complejos del tipo $\mathrm{XRe}(\mathrm{CO})_{3} \mathrm{~L}$ con ligandos pterina.

Este nuevo complejo de $\operatorname{Re}(I)$ sintetizado, fue caracterizado usando espectroscopía de resonancia magnética nuclear de hidrogeno y carbono $\left({ }^{1} \mathrm{H} R M N,{ }^{13} \mathrm{C} R M N\right)$, espectroscopía infrarroja con transformada de Fourier (FTIR) y una combinación de tres técnicas de espectrometría de masa (MS): Desorción/ionización láser asistida por matriz (MALDI); ionización por electro-spray (ESI) y sonda de ionización por electrospray (PESI). A pesar de que la técnica de MS en el campo de la química 
organometálica está ampliamente desarrollada [15], [16], la aplicación de la técnica PESI-MS para el análisis de compuestos organometálicos es de reciente aplicación [17]. 


\section{Índice}

\section{Capítulo III}

\section{Síntesis y caracterización del complejo fac-Re'(CO) ${ }_{3}($ pterina $)\left(\mathrm{H}_{2} \mathrm{O}\right)$}

Introducción

Índice

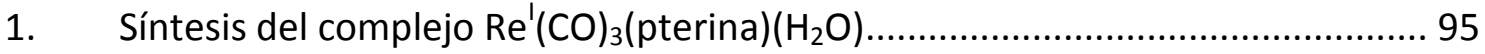

1.1. Síntesis del complejo fac- $\operatorname{Re}^{\prime}(\mathrm{CO})_{3}$ (pterina) $\left(\mathrm{H}_{2} \mathrm{O}\right)$ a partir de $\mathrm{ClRe}^{\prime}(\mathrm{CO})_{5} \ldots \ldots . . . .95$

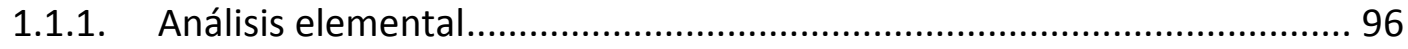

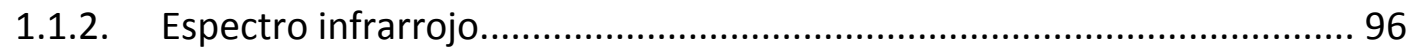

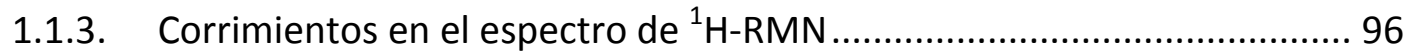

1.2. Síntesis del complejo fac- $\mathrm{Re}^{\prime}(\mathrm{CO})_{3}($ pterina $)\left(\mathrm{H}_{2} \mathrm{O}\right)$ utilizando $\operatorname{Re}^{\prime}(\mathrm{CO})_{3}\left(\mathrm{H}_{2} \mathrm{O}\right)_{3}{ }^{+} .97$

1.2.1. Síntesis del precursor $\operatorname{Re}^{\prime}(\mathrm{CO})_{3}\left(\mathrm{H}_{2} \mathrm{O}\right)_{3}{ }^{+}$ 97

1.2.2. Espectro UV-Vis del complejo $\operatorname{Re}^{\prime}(\mathrm{CO})_{3}\left(\mathrm{H}_{2} \mathrm{O}\right)_{3}{ }^{+}$................................. 97

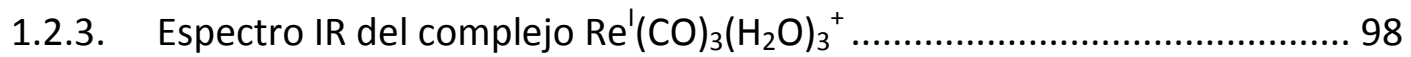

1.2.4. Síntesis del complejo $\operatorname{Re}^{\prime}(\mathrm{CO})_{3}($ pterina $)\left(\mathrm{H}_{2} \mathrm{O}\right)$ a partir del precursor

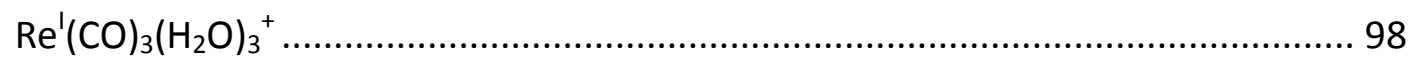

2. Caracterización del complejo $\mathrm{Re}^{\prime}(\mathrm{CO})_{3}\left(\mathrm{H}_{2} \mathrm{O}\right)$ (pterina) ...................................... 99

2.1. Caracterización espectroscópica del complejo RePtr................................. 100

2.1.1. Espectro de absorción UV-Vis ....................................................... 100

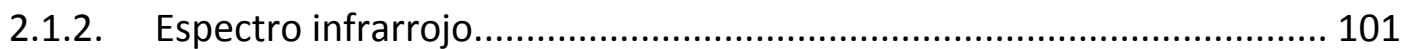

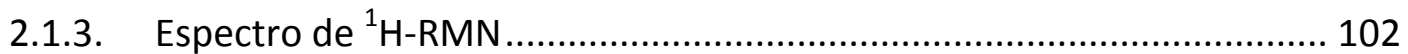

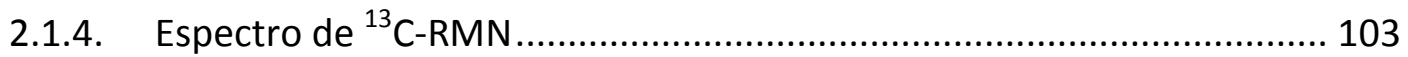

2.1.5. Espectrometría de masas (MS) ................................................... 104

2.2. Obtención de la estructura cristalina por difracción de rayos X................. 109 


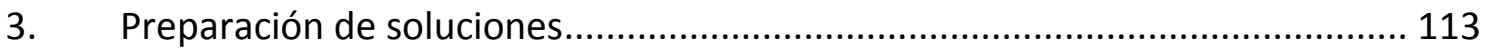

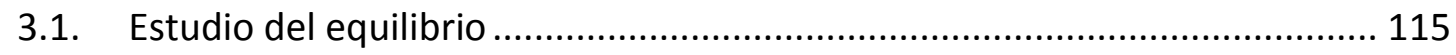

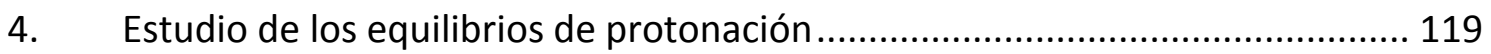

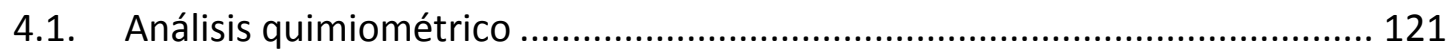

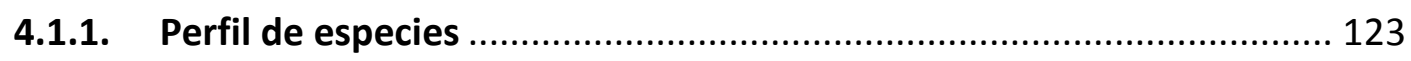

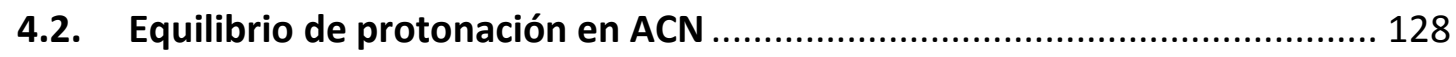

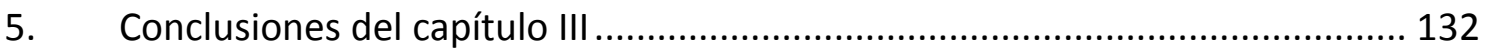

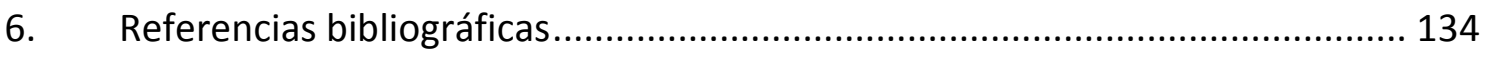




\section{Síntesis del complejo $\operatorname{Re}^{\prime}(\mathrm{CO})_{3}($ pterina $)\left(\mathrm{H}_{2} \mathrm{O}\right)$}

\subsection{Síntesis del complejo fac- $\operatorname{Re}^{\prime}(\mathrm{CO})_{3}($ pterina $)\left(\mathrm{H}_{2} \mathrm{O}\right)$ a partir de $\mathrm{ClRe}^{\prime}(\mathrm{CO})_{5}$.}

El complejo RePtr, fue preparado siguiendo dos vías de síntesis distintas. En la primera, se utilizó una modificación del procedimiento reportado para otros complejos de Renio similares [3], [11], [13] [12]. Se preparó una solución acuosa de pterina (181 mg; $1,1 \times 10^{-3}$ moles) en un balón. Luego, se agregaron lentamente $75 \mathrm{ml}$ de una solución etanólica de $\mathrm{CIRe}^{\prime}(\mathrm{CO})_{5}\left(362 \mathrm{mg} ; 1,0 \times 10^{-3} \mathrm{~mol}\right)$, manteniendo a la mezcla de reacción en agitación y a reflujo por 7 hs. en atmosfera de $N_{2}$. Rápidamente, la mezcla se tornó de un intenso color naranja. Se removió un pequeño exceso de un sólido blanco insoluble por filtración, identificado como pterina en exceso, lo que es consistente con el exceso agregado de $10 \%$ del ligando con respecto al pentacarbonilo de $\operatorname{Re}$ en la mezcla. La solución fue enfriada a temperatura ambiente y se evaporaron los solventes hasta sequedad utilizando un rotavapor a $60{ }^{\circ} \mathrm{C}$. El sólido resultante se disolvió en el mínimo volumen de diclorometano, y el complejo fue precipitado con el agregado lento de iso-octano frío.

El proceso de recristalización se repitió hasta lograr un valor constante del coeficiente de absorción molar. El sólido naranja obtenido se secó en vacío. En la figura $\mathbf{2}$ se muestra un esquema de la síntesis del complejo.

Este proceso de síntesis se lleva a cabo en medio acuoso neutro. En estas condiciones cercanas al pKa de la pterina existen cantidades comparables del ion pterinato y de la pterina neutra. Dado que el anión pterinato por su carga negativa es un mejor nucleófilo, es razonable pensar que será éste quien sea coordinado, de este modo el equilibrio será desplazado a medida que el anión coordine con el catión carbonilo de $\operatorname{Re}(I)$. Se han reportados complejos de pterina que co-cristalizan con moléculas de solvente [3], en nuestro caso, luego de la recristalización con $\mathrm{CH}_{2} \mathrm{Cl}_{2}$, el análisis elemental mostró la presencia de 2,5 moléculas de solvente co-cristalizadas por cada molécula de complejo. El rendimiento total de la síntesis fue de $334 \mathrm{mg}$ (70\%). Las determinaciones realizadas a fin de verificar la identidad del sólido obtenido 
se detallan a continuación.

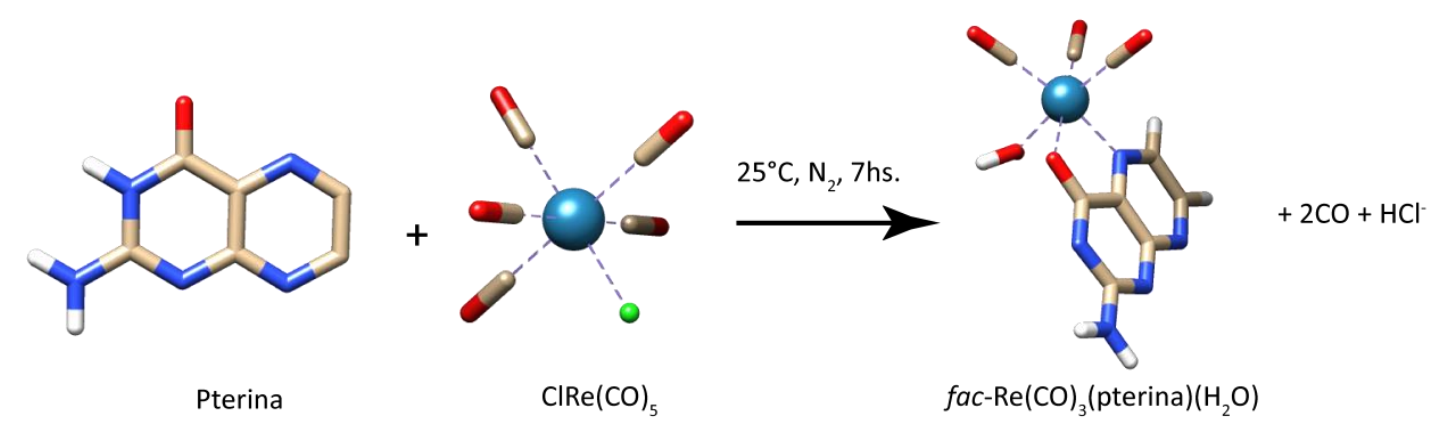

Figura 2

Esquema de la reacción de síntesis del complejo $f a c-\mathrm{Re}^{\prime}(\mathrm{CO})_{3}$ (pterina) $\left(\mathrm{H}_{2} \mathrm{O}\right)$

\subsubsection{Análisis elemental}

Se realizó un análisis elemental del sólido obtenido cuyos resultados para la fórmula $\operatorname{Re}^{\prime}(\mathrm{CO})_{3}$ (pterina) $\left(\mathrm{H}_{2} \mathrm{O}\right) \cdot 2,5 \mathrm{CH}_{2} \mathrm{Cl}_{2}$ fueron:

Valores calculados: \%H 1,3; \%C 20,8; \%N 10,5.

Valores encontrados: \%H 1.4; \%C 20,4; \%N 10,8.

\subsubsection{Espectro infrarrojo}

Se realizó el espectro de absorción de luz infrarroja con transformada de Fourier (FTIR), en una pastilla con $\mathrm{KBr}$, las frecuencias encontradas más representativas fueron:

$\tilde{v}=1602,1623,1653,1900,1940$ (hombro), 2029, $3500(-\mathrm{OH}) \mathrm{cm}^{-1}$.

Los números de onda relevantes para la pterina libre son:

$\tilde{v}=1619,1692$ y $1726 \mathrm{~cm}^{-1}$.

\subsubsection{Corrimientos en el espectro de ${ }^{1} \mathrm{H}-\mathrm{RMN}$}

Se registró el espectro de corrimientos de la señal de ${ }^{1} \mathrm{H}$ RMN operando a $500 \mathrm{MHz}$. En d6 DMSO. Los resultados para el complejo en estudio fueron:

$\delta=8,93(d, J=2.5 \mathrm{~Hz}, 7-\mathrm{H}) ; 8,79(\mathrm{~d}, J=2,5 \mathrm{~Hz}, 6-\mathrm{H}) ; 7,56(\mathrm{~s}, \mathrm{C} 2-\mathrm{NH} 2) \mathrm{ppm}$.

Y para pterina libre: 
$\delta=8,79(\mathrm{~d}, J=2.5 \mathrm{~Hz}, 7-\mathrm{H}), 8,70(\mathrm{~d}, J=2.5 \mathrm{~Hz}, 6-\mathrm{H}), 8,52$ (s, C4-OH), 8,35 (s,C2-NH2) ppm.

No se observó la señal de ${ }^{1} \mathrm{H}-\mathrm{NMR}$ de N3-H, en el complejo, ni en la pterina libre.

\subsection{Síntesis del complejo $f a c-\operatorname{Re}^{\prime}(\mathrm{CO})_{3}($ pterina $)\left(\mathrm{H}_{2} \mathrm{O}\right)$ utilizando $\operatorname{Re}^{\prime}(\mathrm{CO})_{3}\left(\mathrm{H}_{2} \mathrm{O}\right)_{3}^{+}$}

En recientes publicaciones, se informa sobre la síntesis y caracterización de nuevos complejos de $\operatorname{Re}(\mathrm{I})$, en las que se ha utilizado el precursor soluble $\operatorname{Re}^{\prime}(\mathrm{CO})_{3}\left(\mathrm{H}_{2} \mathrm{O}\right)_{3}{ }^{+}$en lugar del tradicional $\mathrm{CIRe}^{\prime}(\mathrm{CO})_{5}[18]-[22]$. Basándonos en las ventajas que supone la solubilidad en agua del precursor, así como la ausencia de solventes distintos al agua en los pasos de síntesis, se ensayó esta nueva ruta de síntesis. Este nuevo método comienza con la síntesis del precursor $\operatorname{Re}^{\prime}(\mathrm{CO})_{3}\left(\mathrm{H}_{2} \mathrm{O}\right)_{3}{ }^{+}$, el cual se obtiene manteniendo en reflujo cloruro de $\mathrm{ClRe}^{\prime}(\mathrm{CO})_{5}$ en agua. El tricarbonilo obtenido de este modo, se utiliza luego como reactivo para sintetizar el complejo $\operatorname{Re}^{\prime}(\mathrm{CO})_{3}$ (pterina) $\left(\mathrm{H}_{2} \mathrm{O}\right)$ haciéndolo reaccionar con el ligando pterina a reflujo en agua.

\subsubsection{Síntesis del precursor $\operatorname{Re}^{\prime}(\mathrm{CO})_{3}\left(\mathrm{H}_{2} \mathrm{O}\right)_{3}{ }^{+}$}

Se pesaron $0.0989 \mathrm{~g}$ de $\mathrm{CIRe}^{\prime}(\mathrm{CO})_{5}$ con los que se preparó una suspensión en agua. Se mantuvo en reflujo durante 20 hs. en atmosfera de $N_{2}$. Pasadas las 20 hs se obtuvo una solución incolora. Se eliminó el solvente por rotavaporación a sequedad obteniéndose un sólido de color verde muy claro. El sólido obtenido se caracterizó por espectroscopía de absorción Uv-visible e IR. Este compuesto se utilizó sin posterior purificación.

\subsubsection{Espectro UV-Vis del complejo $\operatorname{Re}^{\prime}(\mathrm{CO})_{3}\left(\mathrm{H}_{2} \mathrm{O}\right)_{3}{ }^{+}$}

Se registró el espectro Uv-Visible de una solución acuosa del complejo, los resultados se muestran en la figura 3. En el espectro se observan, un máximo alrededor de los $260 \mathrm{~nm}$ y la continuación de una banda de mayor energía a $200 \mathrm{~nm}$ con un hombro en $\operatorname{los} 210 \mathrm{~nm}$. 


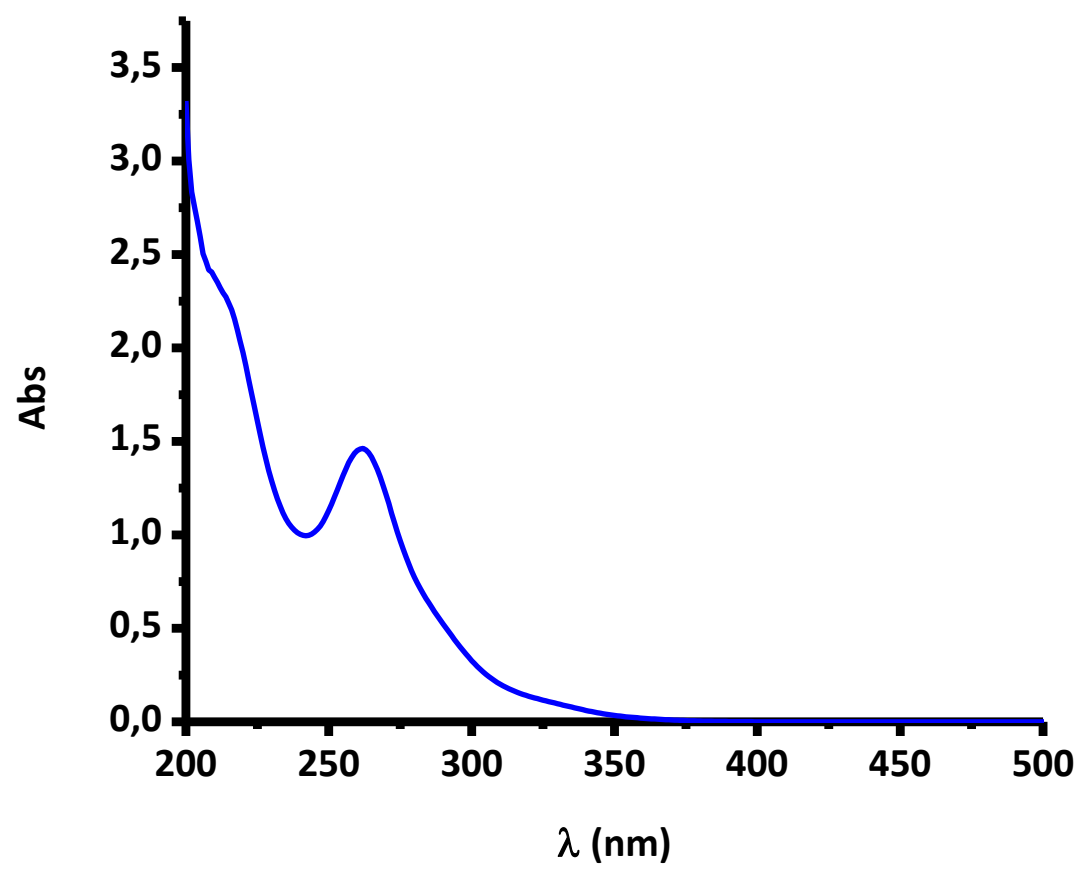

Figura 3

Espectro UV-Visible de una solución acuosa del complejo $\operatorname{Re}^{\prime}(\mathrm{CO})_{3}\left(\mathrm{H}_{2} \mathrm{O}\right)_{3}{ }^{+}$.

\subsubsection{Espectro IR del complejo $\operatorname{Re}^{\prime}(\mathrm{CO})_{3}\left(\mathrm{H}_{2} \mathrm{O}\right)_{3}{ }^{+}$}

Se realizaron medidas de absorción FTIR de una solución acuosa del complejo RePtr (figura 4). Los máximos en el espectro muestran dos bandas centradas en 1918 y 2028 (c/hombro a los 2036) $\mathrm{cm}^{-1}$. Estos valores coinciden con los ya publicados para $\operatorname{BrRe}^{\prime}(\mathrm{CO})_{3}\left(\mathrm{H}_{2} \mathrm{O}\right)_{3}$ en agua $\left(1916\right.$ y $\left.2036 \mathrm{~cm}^{-1}\right)[18]$.

\subsubsection{Síntesis del complejo $\operatorname{Re}^{\prime}(\mathrm{CO})_{3}($ pterina $)\left(\mathrm{H}_{2} \mathrm{O}\right)$ a partir del precursor $\operatorname{Re}^{\prime}(\mathrm{CO})_{3}\left(\mathrm{H}_{2} \mathrm{O}\right)_{3}{ }^{+}$}

Se preparó una solución acuosa del ligando pterina a la cual se le agregó gota a gota una solución acuosa del complejo $\operatorname{Re}^{\prime}(\mathrm{CO})_{3}\left(\mathrm{H}_{2} \mathrm{O}\right)_{3}{ }^{+}$, con una relación final en la mezcla equimolar para ambos compuestos. Se mantuvo la mezcla en reflujo con atmosfera inerte de $\mathrm{N}_{2}$ durante 6 hs. La solución se tornó rápidamente de un intenso color naranja-rojizo similar al de la solución del complejo preparada por el método tradicional. La solución fue enfriada a temperatura ambiente y se rotavaporó el agua hasta sequedad utilizando un rotavapor a $60{ }^{\circ} \mathrm{C}$. El sólido obtenido, color naranja ladrillo fue purificado por cromatografía en columna utilizando como fase móvil agua y 
sílica gel 60 como fase fija. El complejo obtenido por este nuevo método de síntesis se caracterizó por espectroscopía UV-Visible, FTIR y espectrometría ESI. Todos los resultados obtenidos fueron coincidentes con los obtenidos para el complejo sintetizado por el método tradicional. Lo que nos permite afirmar que el producto final obtenido es el mismo.

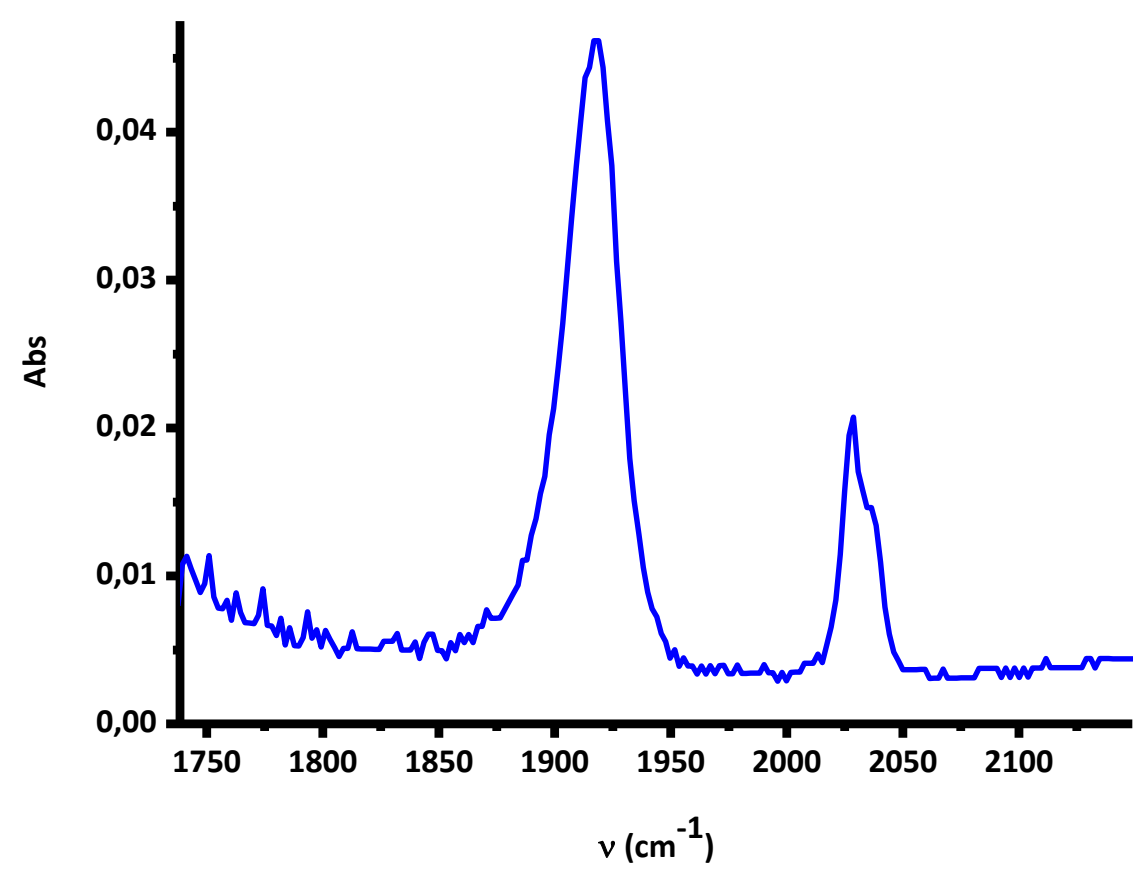

\section{Figura 4}

Espectro FTIR en la región del estiramiento de los carbonilos de una solución acuosa del complejo $\operatorname{Re}^{\prime}(\mathrm{CO})_{3}\left(\mathrm{H}_{2} \mathrm{O}\right)_{3}{ }^{+}$

\section{Caracterización del complejo $\operatorname{Re}^{\prime}(\mathrm{CO})_{3}\left(\mathrm{H}_{2} \mathrm{O}\right)$ (pterina)}

El complejo RePtr fue obtenido con un buen rendimiento (70\%) por los dos métodos antes descriptos. Sus características espectroscópicas y estructurales se determinaron utilizando las técnicas de: análisis elemental, espectroscopía Uv-Vis, FTIR; ${ }^{1} H$ RMN; ${ }^{13} \mathrm{C}$ RMN, espectrometría de masa MALDI; ESI y PESI y difracción de rayos X. 


\subsection{Caracterización espectroscópica del complejo RePtr}

\subsubsection{Espectro de absorción UV-Vis}

Se registró el espectro del complejo RePtr en solución acuosa neutra, barriendo el espectro entre 200 y $800 \mathrm{~nm}$. Este se comparó con el espectro correspondiente al ligando libre (figura 5).

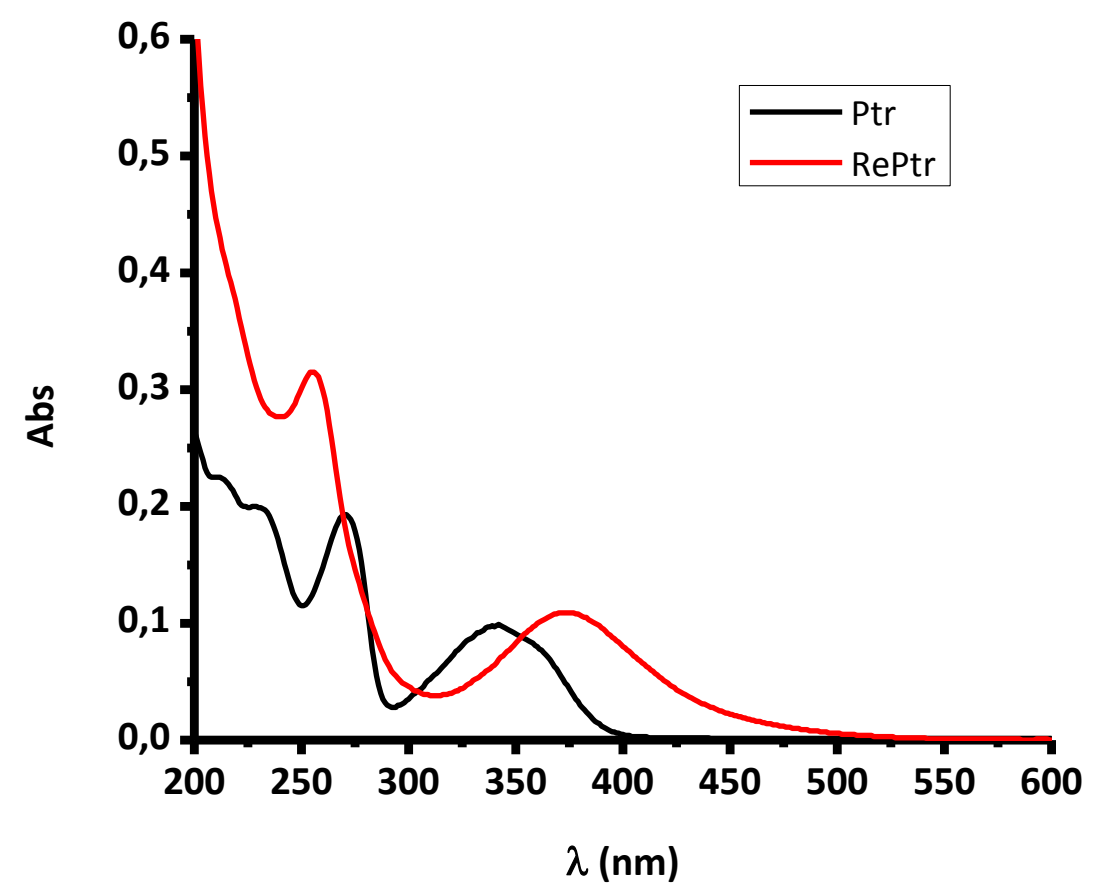

Figura 5

Espectros de absorción del complejo RePtr y de su ligando pterina obtenidos en solución acuosa a pH 7.

En el espectro del complejo puede observarse una banda de absorción desplazada hacia el visible con respecto a la del ligando. Las características fisicoquímicas que pueden inferirse del análisis de los espectros de absorción UV-Vis se analizarán en detalle en el siguiente capítulo. Sin embargo es pertinente indicar, que este tipo de desplazamiento se observa comúnmente para este tipo de complejos tricarbonilicos asociado a la aparición de una nueva transición de menor energía de naturaleza MLCT. 


\subsubsection{Espectro infrarrojo}

El espectro de absorción IR obtenido para solido del complejo RePtr dispersado en pastillas de $\mathrm{KBr}$, es consistente tanto con la configuración facial ( $f a c$ ) de los carbonilos coordinados como con la simetría $C_{s}$ del complejo, puesto esto en evidencia por la presencia de dos intensas bandas de absorción en la región de $2050-1880 \mathrm{~cm}^{-1}$. De acuerdo con lo reportado previamente para compuestos similares, la banda aguda a alta frecuencia (ca. $2029 \mathrm{~cm}^{-1}$ ) es atribuida al modo $A^{\prime}$ (estiramiento totalmente simétrico y en fase de tres ligandos $\mathrm{CO}$ ), mientras que las dos bandas restantes a frecuencias intermedia y baja (1901 con hombro a $1941 \mathrm{~cm}^{-1}$ ), se asigna al modo $\mathrm{A}_{2}$ (estiramiento totalmente simétrico fuera de fase de los ligandos $\mathrm{CO}$ ) y al modo $\mathrm{A}^{\prime \prime}$ (estiramiento asimétrico de ligandos ecuatoriales CO) [23], [24]. Del mismo modo que con otros complejos del tipo $\mathrm{fac} \mathrm{Re}(\mathrm{CO})_{3}$ [14], en el caso del complejo RePtr, las bandas $A^{\prime}{ }_{2}$ y $A^{\prime \prime}$ se encuentran superpuestas en un única banda ancha e intensa, observándose una fuerte banda centrada a $1901 \mathrm{~cm}^{-1}$. Este patrón está de acuerdo con la baja simetría esperada alrededor del metal central del complejo.

Comparado con el ligando pterina libre (con estiramientos C4=04 a 1619, 1692 y 1726 $\mathrm{cm}^{-1}$ ), el complejo muestra un significativo corrimiento a bajas frecuencias en la región de $1600-1800 \mathrm{~cm}^{-1}$ (figura 6). Estos son rasgos típicos que indican la desprotonación del átomo N3 de la pterina y la coordinación a través del O4 y N5 [14]. 


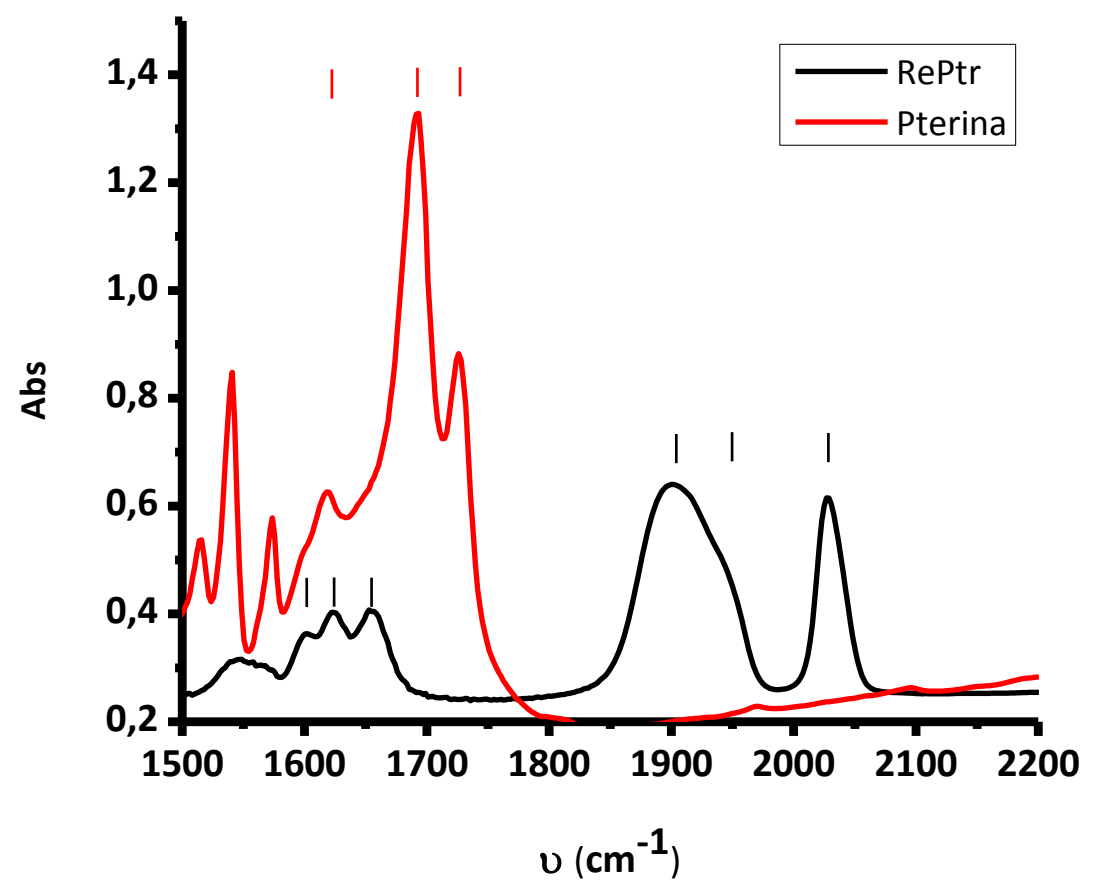

\section{Figura 6}

Espectro de absorción IR, la línea negra corresponde al complejo RePtr, mientras que la línea roja corresponde al ligando pterina. Con las marcas rojas se indican los 3 picos más significativos de la pterina a 1619, 1692 y $1726 \mathrm{~cm}^{-1}$, mientras que las marcas negras de menor energía indican las bandas correspondientes a la pterina coordinada $\left(1602,1623,1653 \mathrm{~cm}^{-1}\right)$ y las de mayor energía las bandas de los CO (1901 con hombro a 1941 y $2029 \mathrm{~cm}^{-1}$ )

\subsubsection{Espectro de ${ }^{1} \mathrm{H}-\mathrm{RMN}$}

En el espectro ${ }^{1} \mathrm{H}-\mathrm{RMN}$ del complejo en d6-DMSO (dimetilsulfoxido deuterado) (figura 7), se observan dos dobletes de señales que corresponden a los protones $\mathrm{C} 6-\mathrm{H}$ y al C7$H$ que están desplazadas $(\delta)$ a campos menores con respecto a las señales de la pterina libre. Esto es debido al efecto de átomo pesado ejercido por el átomo Renio. Este efecto en el corrimiento $\delta$ debido a la coordinación, fue observado previamente en complejos de pteridina relacionados [3]. Sin embargo la coordinación a través del 04 y N5 desplaza la señal singlete $\mathrm{C} 2-\mathrm{NH}_{2}$ a campos más altos. También se observó una señal doblete de 7,21 ppm. Cuando se agregan gotas de $\mathrm{D}_{2} \mathrm{O}$ a la solución del complejo en d6-DMSO, tanto la señal del $\mathrm{C} 2-\mathrm{NH}_{2}$ como la de 7,21 ppm desaparecen. En el caso de la señal de $\mathrm{C} 2-\mathrm{NH}_{2}$ el efecto del agregado de $\mathrm{D}_{2} \mathrm{O}$, se debe a la naturaleza 
intercambiable de este protón, mientras que en el caso de la señal 7,21 ppm el efecto puede ser asignado al intercambio de $\mathrm{H}_{2} \mathrm{O}$ coordinada por $\mathrm{D}_{2} \mathrm{O}$. La ausencia de señal de ${ }^{1} \mathrm{H}$ NMR para el protón N3-H en el complejo de Re es indicativa de la coordinación a través del $\mathrm{O} 4$ y N5.

COMPLEJO Re-PT - $1 \mathrm{H}$

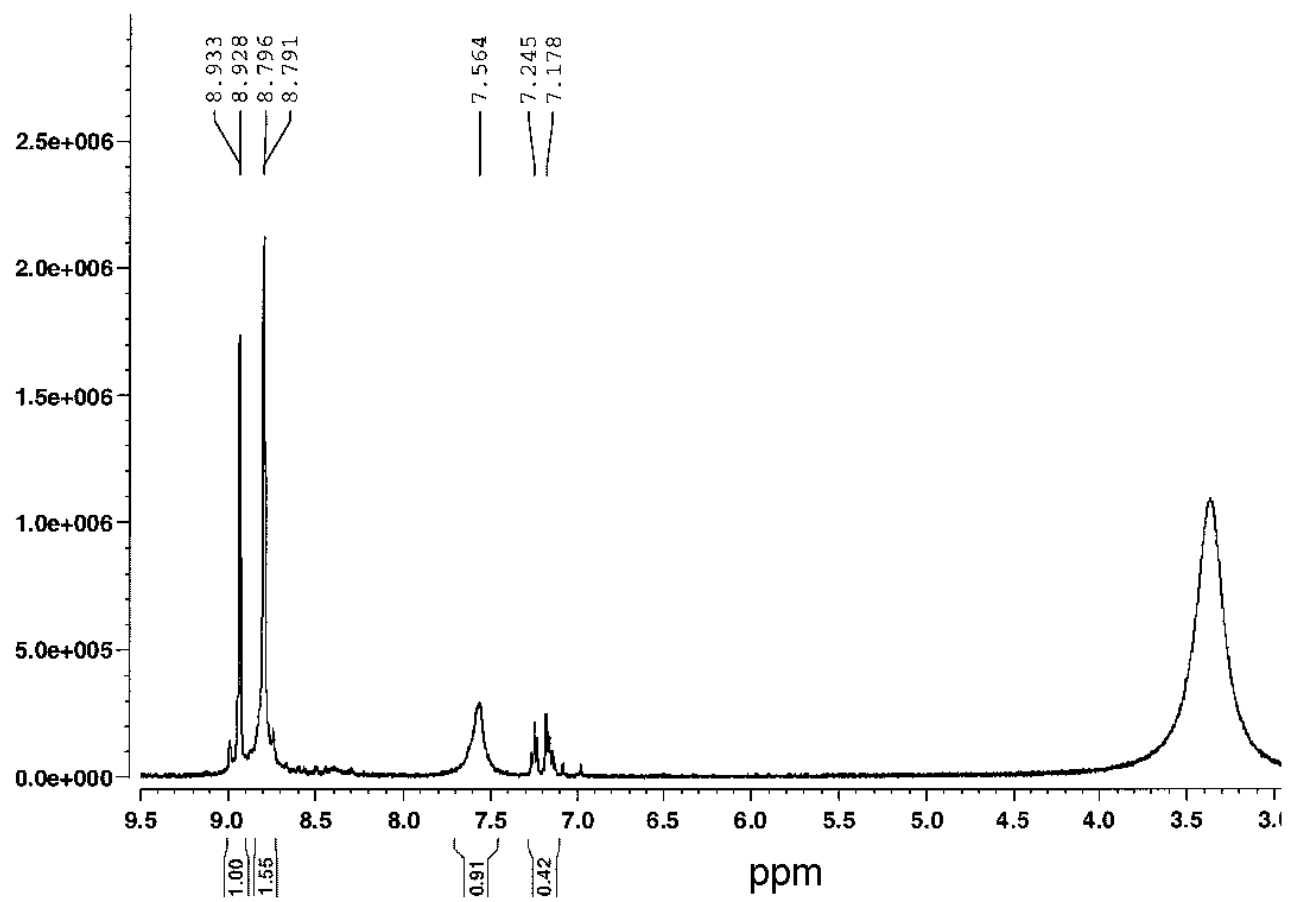

Figura 7

Espectro de ${ }^{1} \mathrm{H}-\mathrm{RMN}$ para el complejo RePtr en d6-DMSO

\subsubsection{Espectro de ${ }^{13} \mathrm{C}-\mathrm{RMN}$}

Se registró el espectro ${ }^{13} \mathrm{C}-\mathrm{RMN}$ del complejo medido en d6-DMSO (figura 8). En este espectro se observan dos grupos de señales, un grupo atribuible al complejo y otro al solvente. El primer grupo contiene cinco picos que se encuentran entre los 190 y 200 ppm, los que pueden asignarse a los CO basándonos en los valores encontrados en bibliografía para otros complejos $f a c-\operatorname{Re}(\mathrm{CO})_{3}$ [25]. El segundo grupo, compuesto por seis señales, entre los 180 y 120 ppm, se asignaron a los corrimientos propios de los anillos pterínicos [26] (C2=158,7; C4 = 152; C6 = 143,7; C7 = 151,6; C9 = 147,6; C10 = 126) asignándose los $C$ del complejo, $(C 2=157 ; C 4=177 ; C 6=141 ; C 7=152 ; C 9=152$; 
$C 10=126)$. La señal asignada al C4 muestra una diferencia significativa con respecto a la misma señal del ligando libre. Este corrimiento de mayor magnitud, puede atribuirse al efecto de desapantallamiento que ejerce el átomo de Renio sobre este carbono.

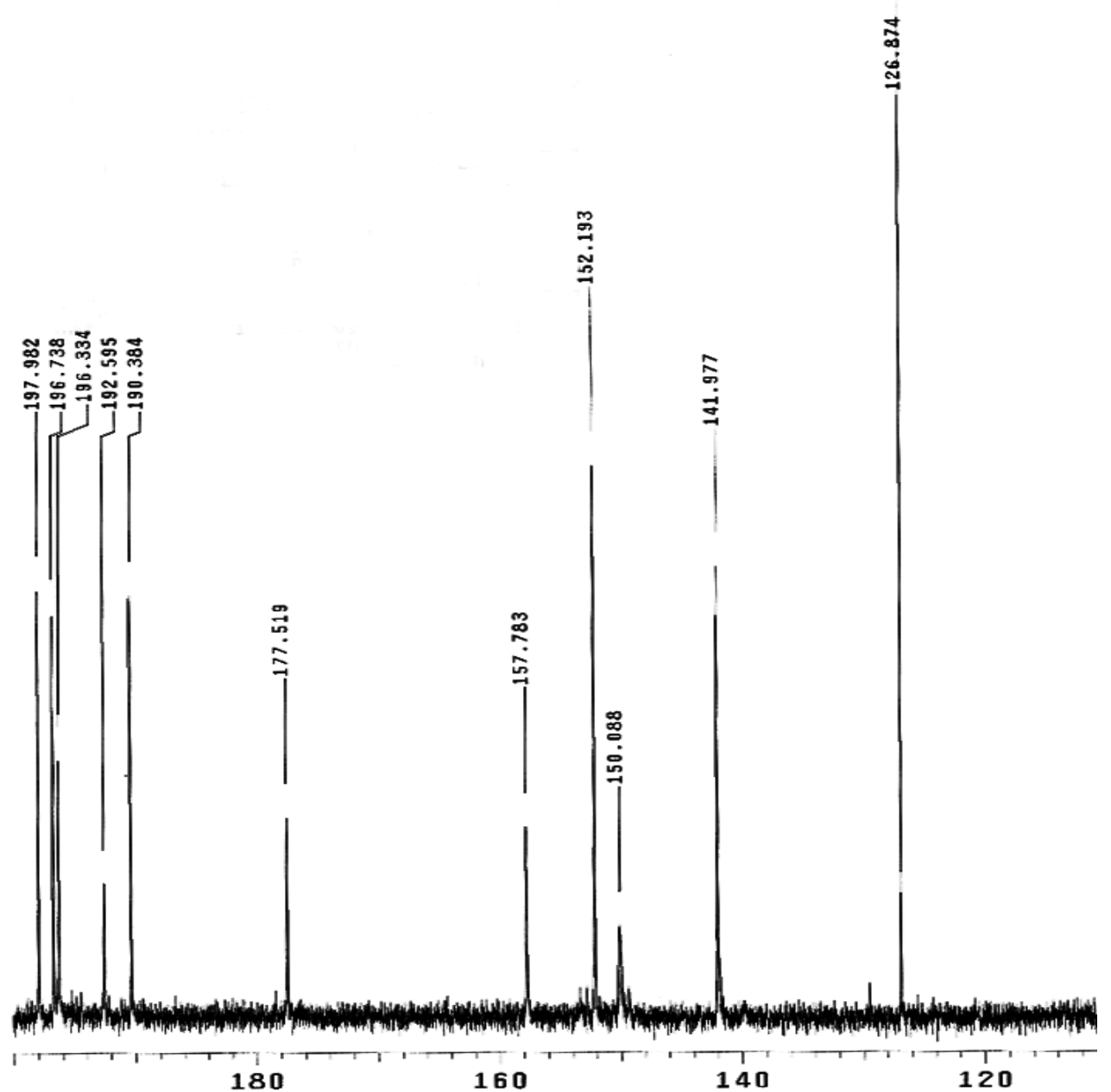

Figura 8

Espectro de corrimientos de la señal de ${ }^{13} \mathrm{C}-\mathrm{RMN}$ para el complejo RePtr en DMSO, no se muestra la region correspondiente al corrimiento del solvente

\subsubsection{Espectrometría de masas (MS)}

Las soluciones stock del complejo fueron preparadas en metanol con una concentración $10^{-4} \mathrm{M}$. Se utilizaron diluciones de la solución stock. Cada experimento fue repetido al menos tres veces para garantizar su reproducibilidad 


\subsubsection{Espectrometría de masas ESI}

Se utilizó la técnica de ionización de electro-spray ESI, de alto flujo, asistida por matriz, con descarga en corona (HF-ESI-CD).

En la figura 9 a se muestra el espectro de masas de HF-ESI-CD en modo positivo del complejo estudiado. Se observó la señal del ion molecular intacto [M] $]^{+}$con $\mathrm{m} / \mathrm{z}=$ 451,04, como así también el fragmento formado cuando se pierde una molécula de agua coordinada $\left[\mathrm{M}-\mathrm{H}_{2} \mathrm{O}+\mathrm{H}\right]^{+}$con $m / z=434,07$. En el espectro pueden observarse claramente las contribuciones de los isotopos ${ }^{187} \mathrm{Re} y{ }^{185} \mathrm{Re}$, con una relación de picos acorde a su abundancia natural, 62,6 y 37,4\% respectivamente, tanto en el ion molecular como en el fragmento con la pérdida de un agua, siendo las correspondientes señales de ambos isotopos $m / z=451,04$ y 449,03 para $[\mathrm{M}]^{+}$y $\mathrm{m} / \mathrm{z}$ $=434,07$ y 432,08 para el fragmento $\left[\mathrm{M}-\mathrm{H}_{2} \mathrm{O}+\mathrm{H}\right]^{+}$, respectivamente.

La figura 9 b muestra el espectro masa/masa (MS/MS) obtenido con el modo de disociación inducida por colisión $Q(P Q D)$. Las señales observadas corresponden al fragmento $\left[\mathrm{M}-\mathrm{H}_{2} \mathrm{O}+\mathrm{H}\right]^{+}$con $\mathrm{m} / z=434,07 ;[\mathrm{M}-\mathrm{CO}]^{+}$con $\mathrm{m} / \mathrm{z}=423,04 ;\left[\mathrm{M}-\mathrm{H}_{2} \mathrm{O}-\right.$ $\mathrm{CO}+\mathrm{H}]^{+} \operatorname{con} m / z=406,04 ;[\mathrm{M}-2(\mathrm{CO})]^{+} \operatorname{con} m / z=395,07 ;\left[\mathrm{M}-\mathrm{H}_{2} \mathrm{O}-2(\mathrm{CO})+\mathrm{H}\right]^{+}$con $m / z=378,11 ;[\mathrm{M}-3(\mathrm{CO})]^{+} \operatorname{con} m / z=367,05 ; \mathrm{y}\left[\mathrm{M}-\mathrm{H}_{2} \mathrm{O} 3(\mathrm{CO})+\mathrm{H}\right]^{+}$con $\mathrm{m} / \mathrm{z}=$ 350,18 .

En modo negativo, cuando se usó HF-ESI-CD, se observó que la principal señal corresponde a $\left[\mathrm{M}-\mathrm{H}_{2} \mathrm{O}-\mathrm{H}\right]^{-}$con $m / z=432,15$; el cual puede ser usado como un testigo señal/fragmento.

\subsubsection{Espectrometría de masas PESI}

La figura 9 c muestra el espectro de masas PESI del complejo RePtr. Se observan, el ion molecular intacto $[\mathrm{M}+\mathrm{H}]^{+}$con $\mathrm{m} / \mathrm{z}=452,00$, el fragmento formado por la pérdida de una molécula de agua $\left[\mathrm{M}-\mathrm{H}_{2} \mathrm{O}+\mathrm{H}\right]^{+}$con $m / z=434,00$, y un fragmento formado por la pérdida de tres $\mathrm{CO}[\mathrm{M}-3(\mathrm{CO})+\mathrm{H}]^{+}$con $m / z=368,17$. Cuando se realizó el análisis $\mathrm{MS} / \mathrm{MS}$ se observaron otro dos fragmentos $[\mathrm{M}-\mathrm{CO}+\mathrm{H}]^{+}$con $m / z=424,00$ y $\left[\mathrm{M}-\mathrm{H}_{2} \mathrm{O}\right.$

$-\mathrm{CO}+\mathrm{H}^{+}$con $\mathrm{m} / \mathrm{z}=406,08$ (figura $10 \mathrm{~d}$ ). Ambos métodos de ionización usados permitieron detectar el ion molecular intacto, sin embargo la más alta relación señal ruido se observó al usar PESI en lugar de HF-ESI-CD-MS. 

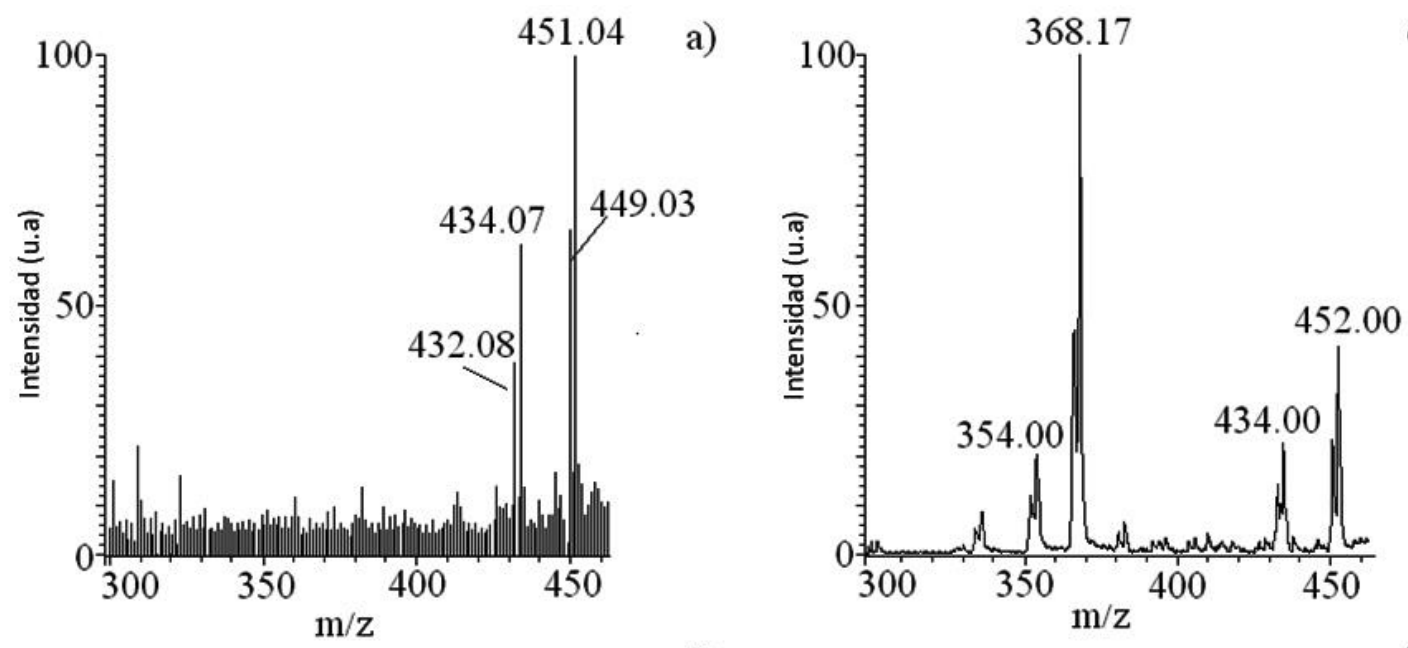

c)

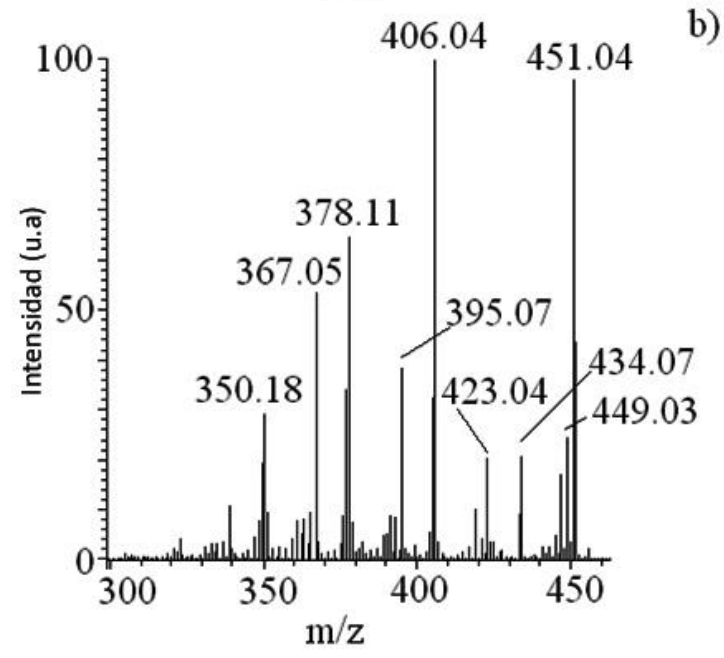

b)

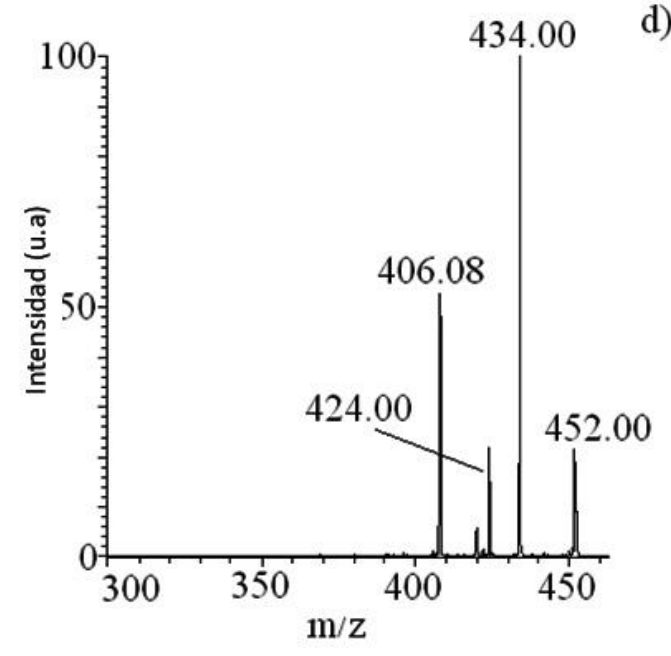

\section{Figura 9}

Espectro de masas en modo ion positivo del complejo $\operatorname{Re}^{\prime}(\mathrm{CO})_{3}($ Pterina $)\left(\mathrm{H}_{2} \mathrm{O}\right)$ a) HF-ESI-CD b) HF-ESI-CD-MS/MS c) PESI d) PESI-MS/MS.

\subsubsection{Espectrometría de masas LDI}

Dado que el complejo RePtr muestra una fuerte absorción en la región UV-Vis particularmente a $355 \mathrm{~nm}$, se utilizó el método de desorción/ionización laser (LDI) MS, sin la presencia de una molécula secundaria como fotosensibilizador o matriz en la muestra. Como se muestra en la figura 10 a y 10 d, no pudo detectarse el ion molecular intacto de este complejo en modo positivo ni en modo negativo. Sin embargo, se obtuvo información sobre la estructura del complejo del análisis de las señales. En modo ion positivo se detectaron las señales $\left[\mathrm{M}-\mathrm{H}_{2} \mathrm{O}-2(\mathrm{CO})+\mathrm{H}\right]^{+}$con $\mathrm{m} / \mathrm{z}$ 
$=378,20,[\mathrm{M}-3(\mathrm{CO})+\mathrm{H}]^{+}$con $m / z=368,05$ y $\left[\mathrm{M}-\mathrm{H}_{2} \mathrm{O}-3(\mathrm{CO})+\mathrm{H}\right]^{+}$con $m / z=$ 350,25 ; mientras que en modo ion negativo se observó una señal $\left[\mathrm{M}-\mathrm{H}_{2} \mathrm{O}-\mathrm{H}\right]^{-}$con $m / z=432,27$.

\subsubsection{Espectrometría de masas MALDI}

El espectro de masas MALDI del complejo RePtr fue registrado usando norharmano (nHo) y 2-[(2E)-3-(4-tertbutilfenil)-2-metilprop-2-enildieno] malononitrilo (MCTB) como matrices. Ambas matrices fueron usadas con anterioridad para el análisis de complejos de Re [17][27] permitiendo su detección, en algunos casos con muy baja intensidad, del ion molecular intacto. Sin embargo, para este complejo en particular, el ion molecular no pudo ser detectado con ninguna de las matrices ni en modo positivo ni en modo negativo. Como se muestra en la figura 10 b y 10 c, para el modo ion positivo, se observan al menos algunos fragmentos característicos. La señal más intensa corresponde a $\left[\mathrm{M}-\mathrm{H}_{2} \mathrm{O}-\mathrm{H}\right]^{-}$con $m / z=432,27$. A pesar de que MALDI es un método de ionización más suave que LDI-MS, no fue posible detectar el ion molecular intacto del complejo estudiado, solo se detectaron fragmentos producidos por la pérdida de uno o más ligandos. La obvia razón fue que este analito absorbe parte de los fotones del láser, lo que conduce a la fotólisis del mismo, y como consecuencia, es casi imposible encontrar una matriz apropiada. 

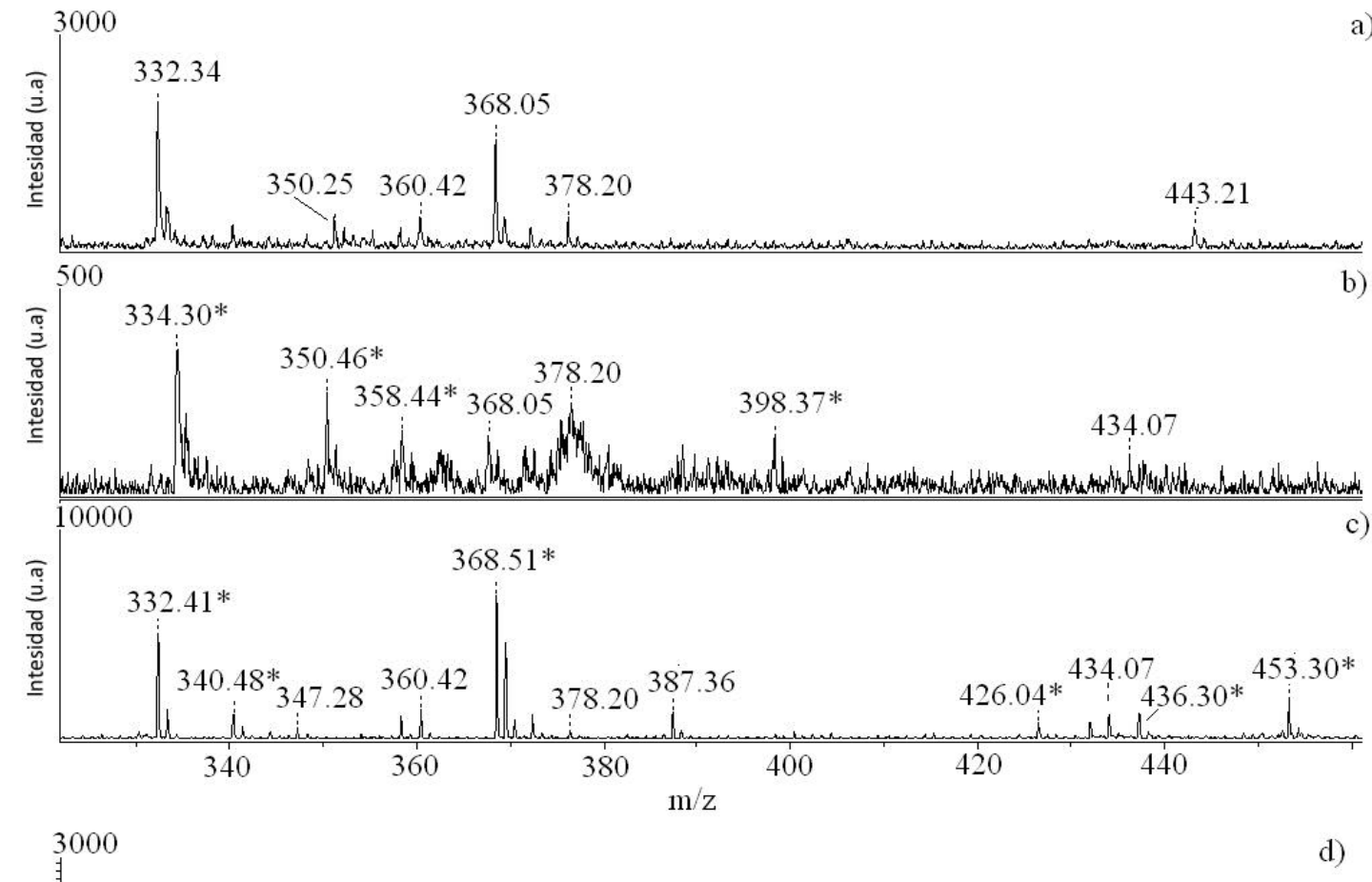

d)

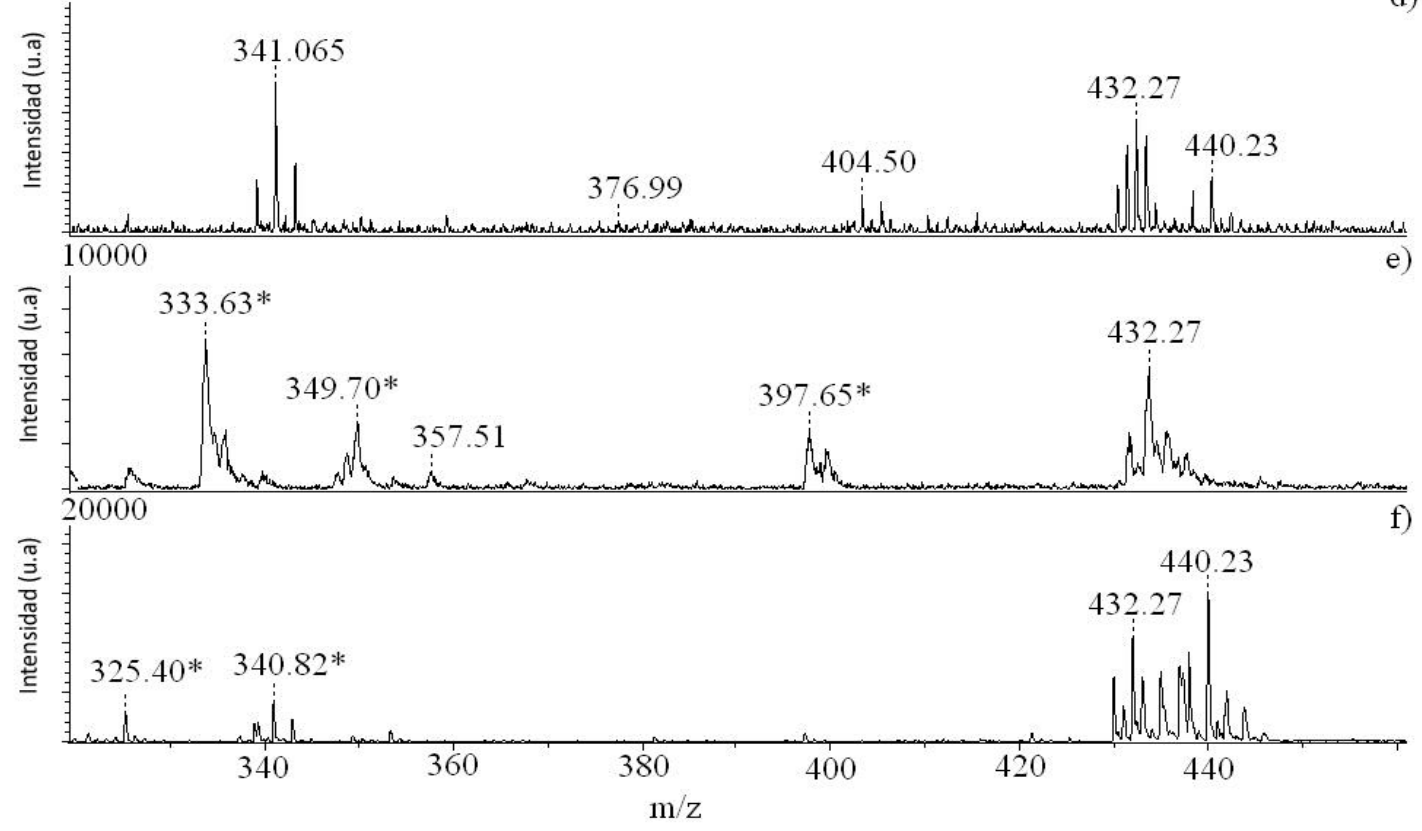

Figura 10

Espectros de masas del complejo $\operatorname{Re}^{\prime}(\mathrm{CO})_{3}$ (pterina) $\left(\mathrm{H}_{2} \mathrm{O}\right)$

En modo ion positivo:

a) Espectro de masas LDI, b) Espectro de masas MALDI obtenido con nHo como matriz,

c) Espectro de masas MALDI obtenido con DCTB como matriz

En modo ion negativo:

d) Espectro de masas LDI, e) Espectro de masas MALDI obtenido con nHo como matriz, f) Espectro de masas MALDI obtenido con DCTB como matriz.

* Picos que corresponden a los clúster de la matriz. 


\subsection{Obtención de la estructura cristalina por difracción de rayos $X$.}

Los monocristales del complejo fac-Re' $(\mathrm{CO})_{3}$ (pterina) $\left(\mathrm{H}_{2} \mathrm{O}\right) \cdot 2\left(\mathrm{H}_{2} \mathrm{O}\right)$ se obtuvieron por evaporación lenta de una solución concentrada del complejo en agua sobre una capa de diclorometano (DCM). Se obtuvo un cristal de buen tamaño (figura 11).

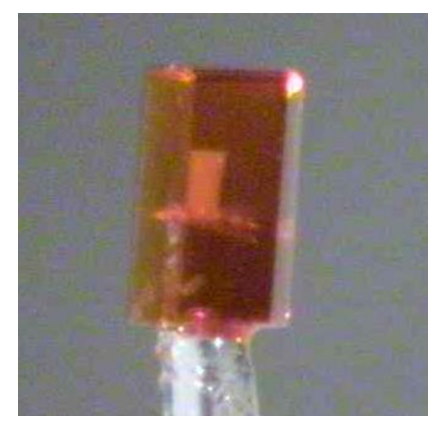

\section{Figura 11.}

Fotografía del monocristal del complejo RePtr utilizado para la determinación de la estructura cristalina por de difracción de rayos $X$.

La figura 12 muestra el grafico ORTEP [28] obtenido del análisis de los datos para el complejo RePtr. Los datos del cristal y los resultados del refinamiento estructural están resumidos en la tabla 1. La longitud de los puentes intermoleculares y los ángulos en torno al metal se encuentran en la tabla 2. El ion $\operatorname{Re}(\mathrm{I})$ se encuentra en un entorno octaédrico levemente distorsionado. El anión pterinato coordinado con el metal define el plano ecuatorial (la desviación cuadrática media de los átomos al plano es de 0.012 Å) y actúa como un ligando bidentado por medio del oxígeno del carbonilo y el átomo de $\mathrm{N}\left[d(\operatorname{Re}-\mathrm{O}) 2.162(3) \AA, d(\operatorname{Re}-\mathrm{N}) 2.186(3) \AA ̊(\mathrm{O}-\mathrm{Re}-\mathrm{N}) 76.6(1)^{\circ}\right]$. Dos de los grupos CO se encuentran en las posiciones cis prácticamente en el plano $[d(\operatorname{Re}-C) 1.896(6)$ y 1.920(5) Å]. Las posiciones apicales del octaedro están ocupados por un tercer grupo CO $[d(\operatorname{Re}-C) 1.889(5) \AA ̊$ y por una molécula de agua $[d(\operatorname{Re}-O w) 2.190(3) \AA ̊]$. Los enlaces Re-(CO) son prácticamente perpendiculares entre sí, los ángulos OC-Re-CO están en el rango de $88.9(2)$ a $89.1(2)^{\circ}$. Producto de la coordinación al ion $\operatorname{Re}(\mathrm{I})$, la molécula neutra de pterina pierde el protón del N3 para convertirse en un ligando aniónico. Como consecuencia de esto, la estructura de la unión -(N3H)-C4=04 cambia formalmente, de un enlace simple y uno doble a dos dobles $-\mathrm{N} 3=\mathrm{C} 4=\mathrm{O}$. 
a)

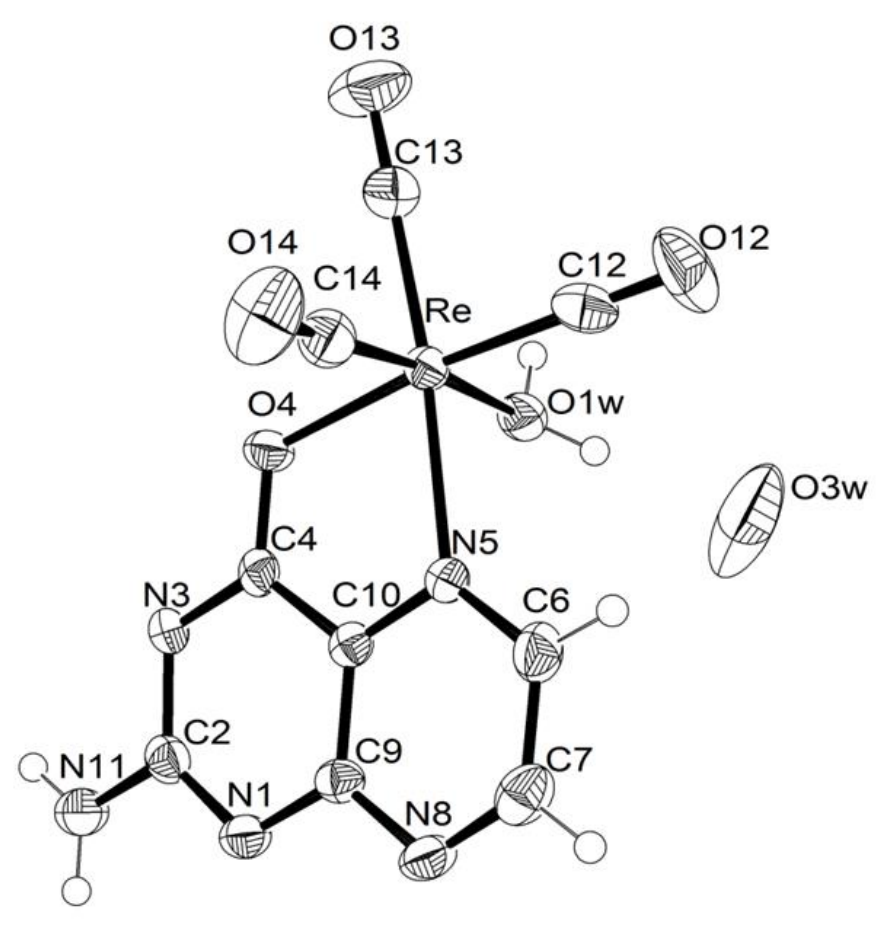

b)

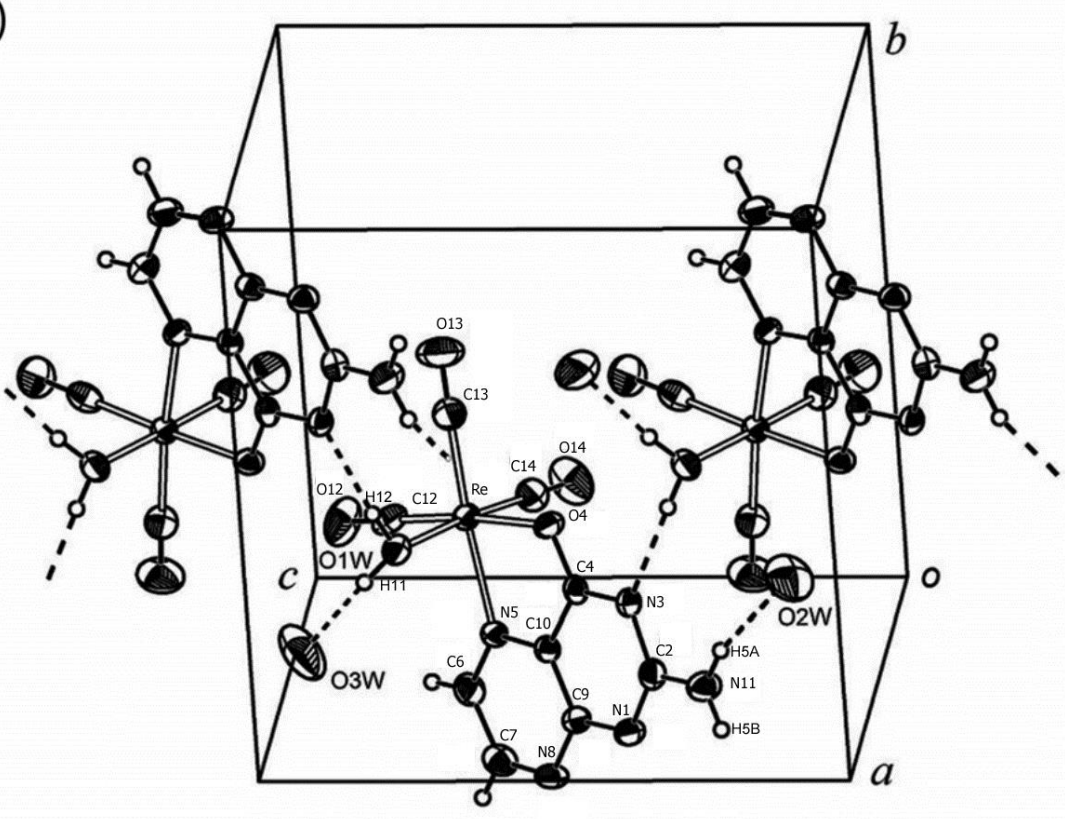

\section{Figura 12}

a) Vista de la molécula de RePtr con el etiquetado de los átomos distintos de $\mathrm{H}$ y sus desplazamientos elipsoides con nivel de probabilidad del $50 \%$. Los enlaces metalligando se indican mediante líneas llenas y los puentes de $\mathrm{H}$ por líneas de trazos.

b) Proyección que muestra el empaquetamiento cristalino. La figura muestra los puentes de $\mathrm{H}$ que enlazan las moléculas RePtr vecinas en el polímero a lo largo del eje c. 
El enlace N3-C4 se acorta, pasando de las distancias habituales N-C (1,35 a 1,37 ̊̊) a un valor de 1,326 (6) $\AA$ y se produce un alargamiento correspondiente del enlace C4=O4 (normalmente en el rango 1,20-1,24 $\AA$ ) a un valor de 1,283 (5) $\AA$; este efecto se ve reforzado por la Interacción Re-O4.

La conformación del complejo RePtr se asemeja con la del complejo relacionado Re(6$\mathrm{ATML})(\mathrm{CO})_{3} \mathrm{Cl}[3]$, en el cual el ion pterinato es reemplazado por el ligando neutro 6ATML (6-acetil-1,3,7 trimetil-lumazina) y el agua coordinada por un $\mathrm{Cl}$.

Como era de esperar, la longitud de los enlaces $\mathrm{Re}-\mathrm{O}$ y $\mathrm{Re}-\mathrm{N}$ en nuestro complejo son levemente más cortas comparadas con las de este último $(0.027(4)$ y $0.037(4) \AA$ respectivamente). Los complejos RePtr vecinos en el mismo plano cristalográfico se encuentran enlazados entre sí por fuertes puentes de hidrogeno $\mathrm{Ow}-\mathrm{H} \cdot \cdots \mathrm{N}\left[d\left(\mathrm{Ow} \cdots \mathrm{N} 3^{\prime}\right)\right.$ $\left.=2.826 \AA, \angle\left(\mathrm{O} w-\mathrm{H} \cdot \cdots \mathrm{N} 3^{\prime}\right)=166.7^{\circ}\right]$, dando lugar a una arreglo polimérico que se extiende a través del eje cristalográfico $c$ (figura 12 b). Otro puente de hidrogeno se encuentra entre el átomo de hidrogeno del grupo amino del N11 y el átomo de oxigeno del agua de cristalización. Este puente de hidrogeno intermolecular torna más negativo al átomo de nitrógeno del grupo amino debido a la polarización del enlace $\mathrm{N}$ $\mathrm{H}$ del grupo amino, resultando en la estabilización de la estructura resonante con forma quinonoide (R2 sobre R1 en la figura 13), lo que da un carácter de doble enlace a la unión C2-N11.

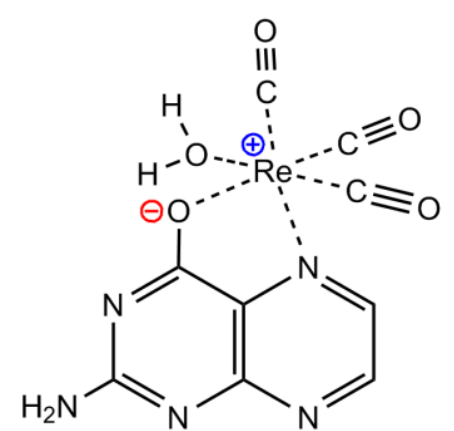

R1

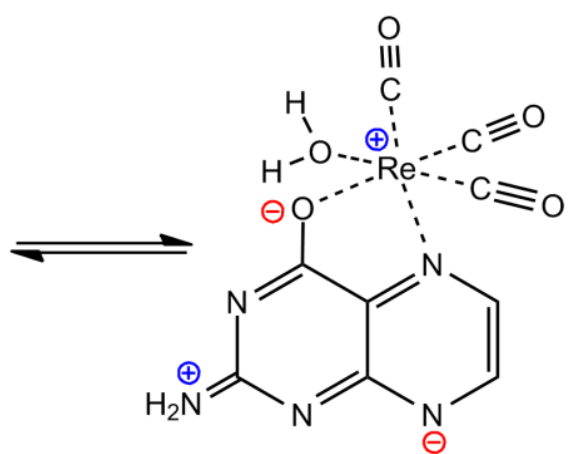

R2

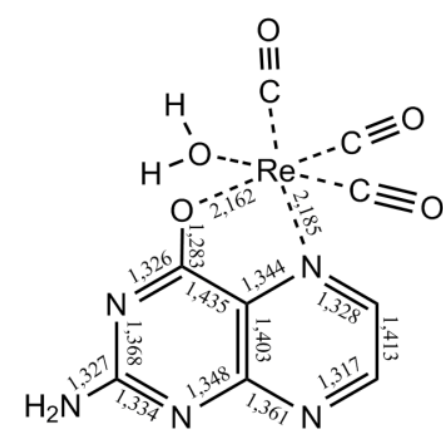

\section{Figura 13}

Estructuras resonantes contribuyentes del complejo RePtr, en el esquema de la derecha se indican las longitudes de los enlaces expresados en $\AA$. 
Esta estabilización de la estructura resonante con carácter quinonoide ha sido observada previamente en un complejo Ru(II)-Pterina [6]. Además, la distancia C2-N11 (1.327 ̊̊) es muy similar a la distancia C4-N3 (1.326 ̊̊), la cual tiene carácter de doble enlace. En efecto, la distancia C4-N3 está cerca de la distancia más corta C-N encontrada en anillo de pterina.

Tabla 1

Datos del cristal y resultados de refinamiento de la estructura para el complejo $\operatorname{Re}(\mathrm{CO})_{3}$ (pterina) $\left(\mathrm{H}_{2} \mathrm{O}\right) \cdot 2 \mathrm{H}_{2} \mathrm{O}$.

\begin{tabular}{|c|c|}
\hline Formula empírica & $\mathrm{C}_{9} \mathrm{H}_{10} \mathrm{~N}_{5} \mathrm{O}_{7} \mathrm{Re}$ \\
\hline Peso Molecular & 486.42 \\
\hline Temperatura & $295(2) \mathrm{K}$ \\
\hline Longitud de onda & 0.71073 \\
\hline Sistema cristalino & monoclínico \\
\hline Grupo espacial & $\mathrm{P} 2{ }_{1} / c$ \\
\hline \multirow[t]{4}{*}{ Dimensiones de la celda unidad } & $a=11.9165(5) \AA$ \\
\hline & $b=10.5694(4) \AA$ \\
\hline & $c=11.0357(4) \AA$ \\
\hline & $\beta=96.423(4)^{\circ}$ \\
\hline Volumen & $1381.22(9) \AA^{3}$ \\
\hline Z, densidad (calculada) & $4,2339 \mathrm{mg} / \mathrm{m}^{3}$ \\
\hline Coeficiente de absorción & $8,843 \mathrm{~mm}^{-1}$ \\
\hline$F(000)$ & 920 \\
\hline Tamaño del cristal & $0,34 \times 0,21 \times 0,11 \mathrm{~mm}$ \\
\hline$\theta$ rango para la recolección de datos & 3.07 a $25.99^{\circ}$ \\
\hline Rangos de índices & $-14 \leq \mathrm{h} \leq 8,-13 \leq \mathrm{k} \leq 6, \quad-11 \leq, \mathrm{I} \leq 13$ \\
\hline Reflexiones colectadas & 5045 \\
\hline Reflexiones independientes & $2709[\mathrm{R}$ (int) $=0.0202]$ \\
\hline Reflexiones observadas & 2188 \\
\hline Cumplimiento de $\theta=25.99^{\circ}$ & $99.80 \%$ \\
\hline Transmisión máxima y mínima & 0.4485 у 0.1540 \\
\hline Método de refinamiento & Matriz completa de mínimos cuadrados sobre \\
\hline Datos / Ataduras / parámetros & $\mathrm{F}^{2}$ \\
\hline Bondad del ajuste en $\mathrm{F}^{2}$ & $2709 / 3 / 207$ \\
\hline Índices $R$ finales $[I>2 \sigma(I)]$ & 0.953 \\
\hline índices R (todos los datos) ${ }^{[a],[b]}$ & $\mathrm{R} 1=0.0223, w \mathrm{R} 2=0.0502$ \\
\hline \multirow[t]{2}{*}{ Mayor diferencia entre pico y agujero } & $\mathrm{R} 1=0.0303, w \mathrm{R} 2=0.0514$ \\
\hline & 0.817 y $-0.866 \mathrm{e}^{-3}$ \\
\hline
\end{tabular}




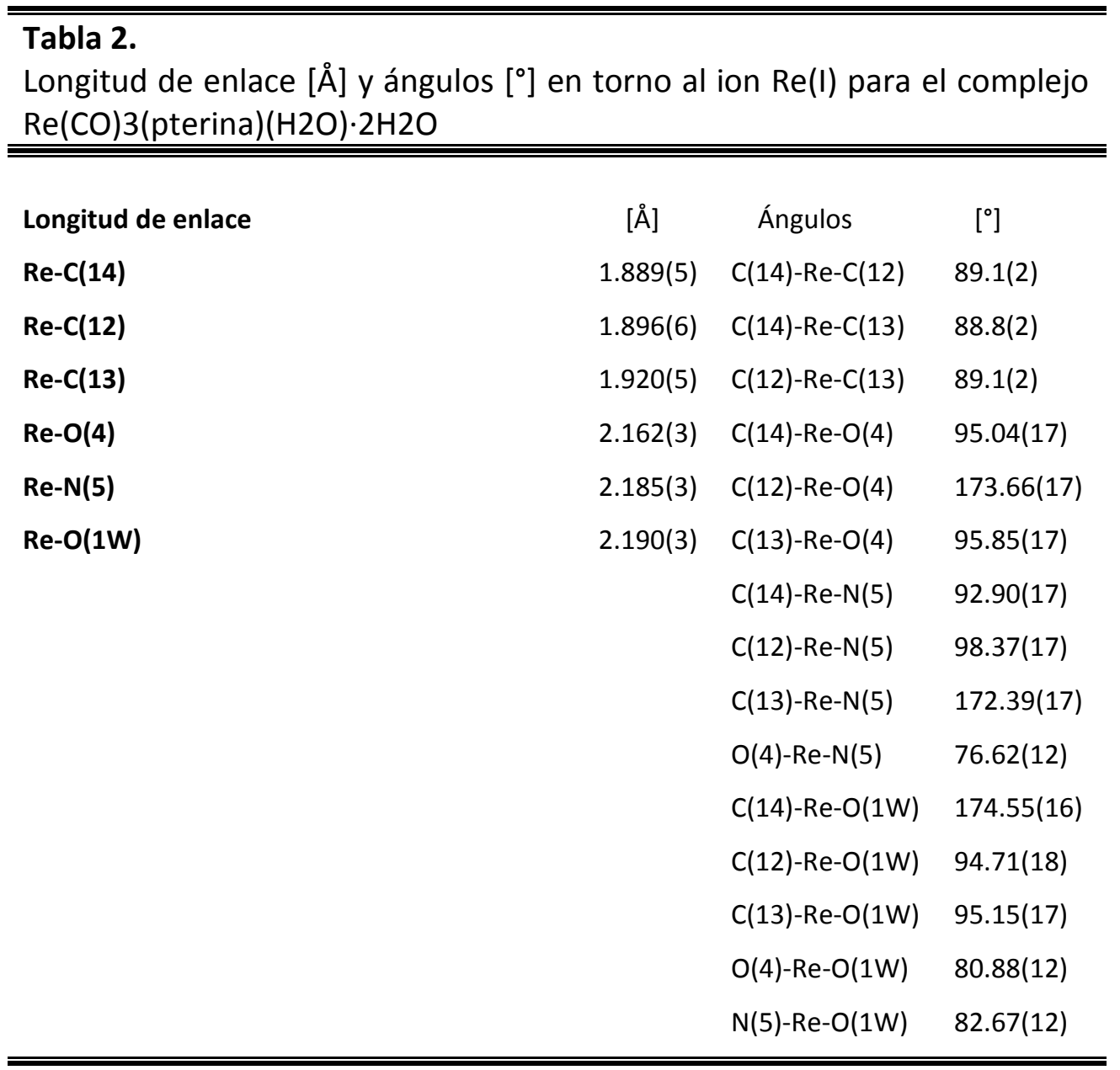

\section{Preparación de soluciones}

Cuando se preparó una solución del complejo RePtr, se observó un rápido cambio en la coloración de la misma, pasando de un color naranja rojizo a un color amarillo que permanece sin cambios.

Este fenómeno se observa en todos los solventes utilizados. A fin de caracterizar el proceso que ocurre, se realizaron una serie de determinaciones que incluyen medidas de absorción UV-Vis, emisión estacionaria, corridas cromatograficas de HPLC y determinaciones de espectrometría ESI-MS.

En la figura 14 se presentan espectros de absorción tomados a distintos tiempos, comenzando 15 minutos luego de preparar la solución. 


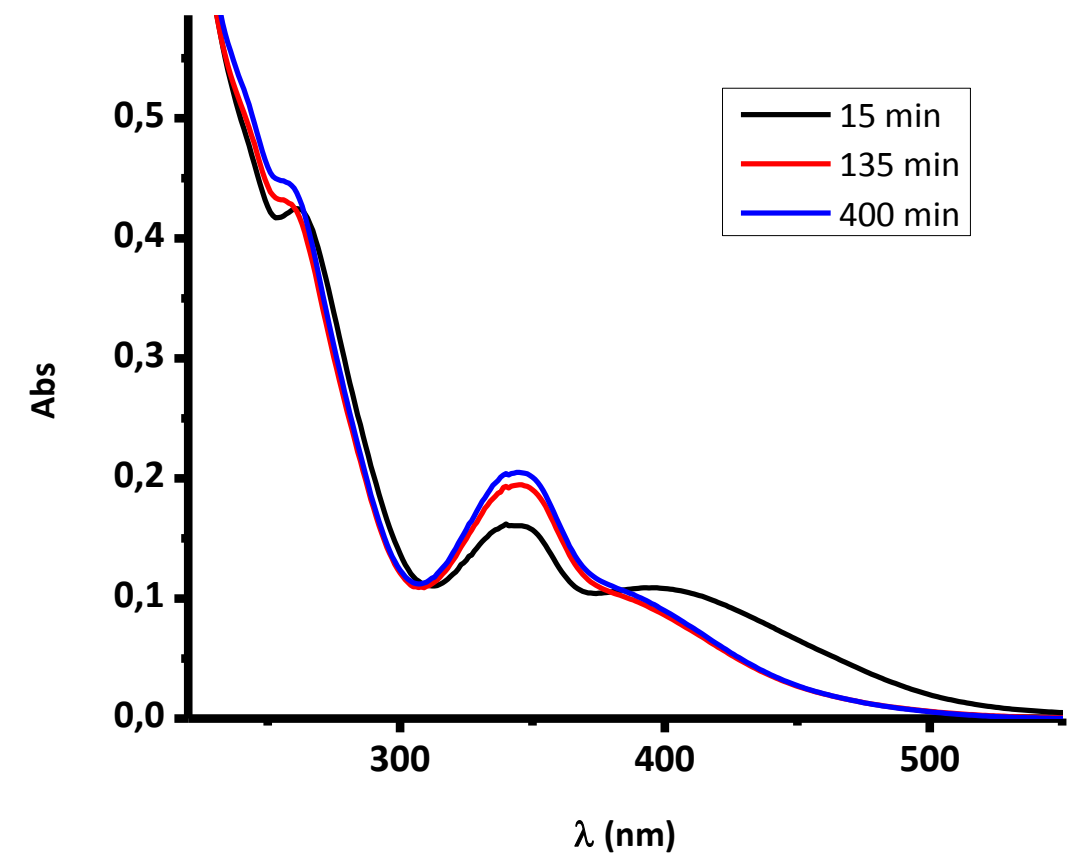

\section{Figura 14}

Espectros de absorción del complejo RePtr tomados a distintos tiempos en solución acuosa de $\mathrm{pH} 3$.

Se registraron los espectros de emisión de una solución acuosa a pH 3 del complejo RePtr. En estos., se observó un aumento sostenido en la intensidad de emisión hasta las 12 hs. después de haber sido preparada la solución. El espectro final obtenido muestra un corrimiento en el máximo de emisión desde los $434 \mathrm{~nm}$ (solución a los 15 minutos de ser preparada) a $441 \mathrm{~nm}$ de la solución final (figura 15). 


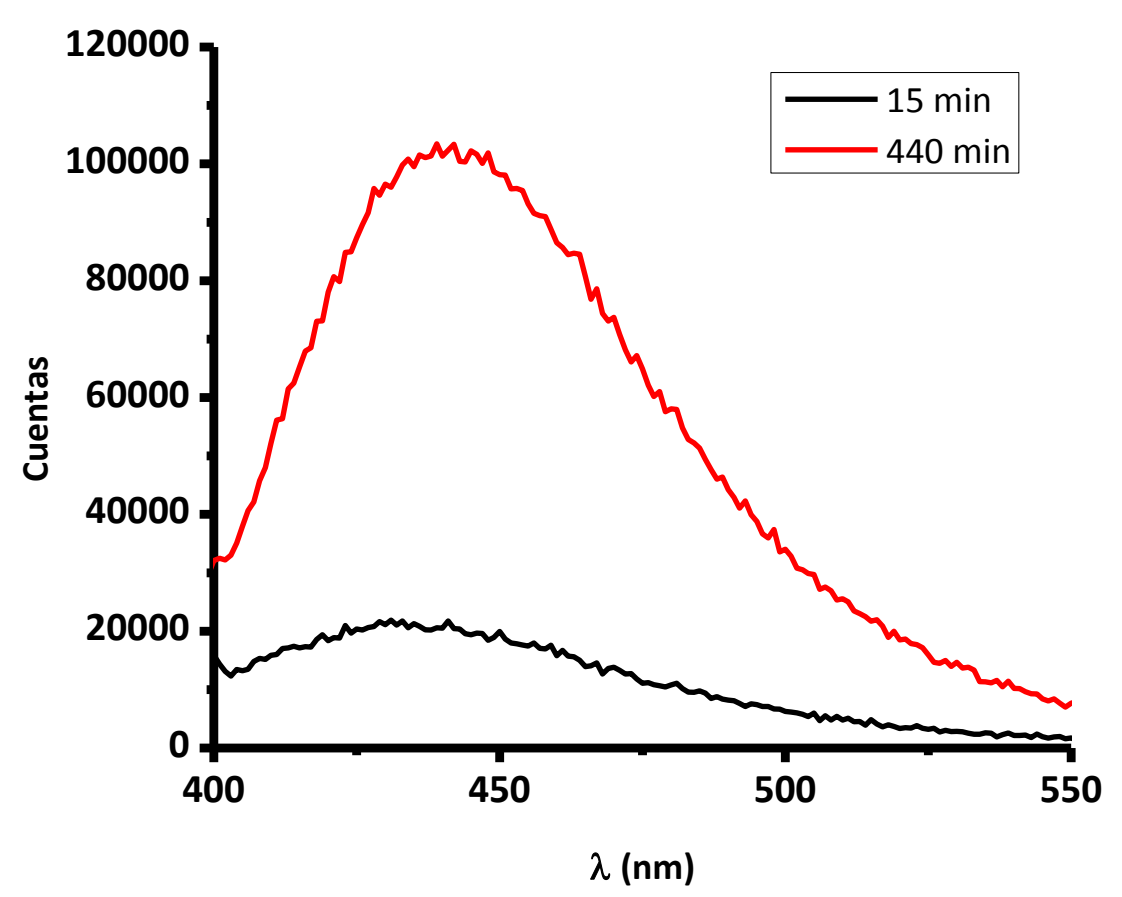

Figura 15

Espectros de emisión del complejo RePtr registrados a tiempos 14 y 240 minutos de preparada la solución. Se trabajó en solución acuosa de pH 3. $\lambda_{\text {exc }}=350 \mathrm{~nm}$.

\subsection{Estudio del equilibrio}

Se utilizaron técnicas quimiométricas [29] para obtener los perfiles de concentración y el número de especies presentes en el equilibrio. La matriz experimental se construyó con los espectros de absorción de una solución del complejo RePtr en agua obtenidos en un periodo de cuatro horas (figura 16). Se observó un muy buen ajuste para dos especies. Los perfiles de concentración obtenidos se muestran en la figura 17.

Para estudiar si estos procesos están asociados a la descomposición térmica del complejo, se realizaron estudios cromatográficos para analizar la naturaleza de los cambios registrados. El equipo usado fue un HPLC-UV-Vis Shimadzu Prominence LC$20 \mathrm{~A}$ con una columna C-18 con un detector de arreglo de diodos en la salida de la columna. 


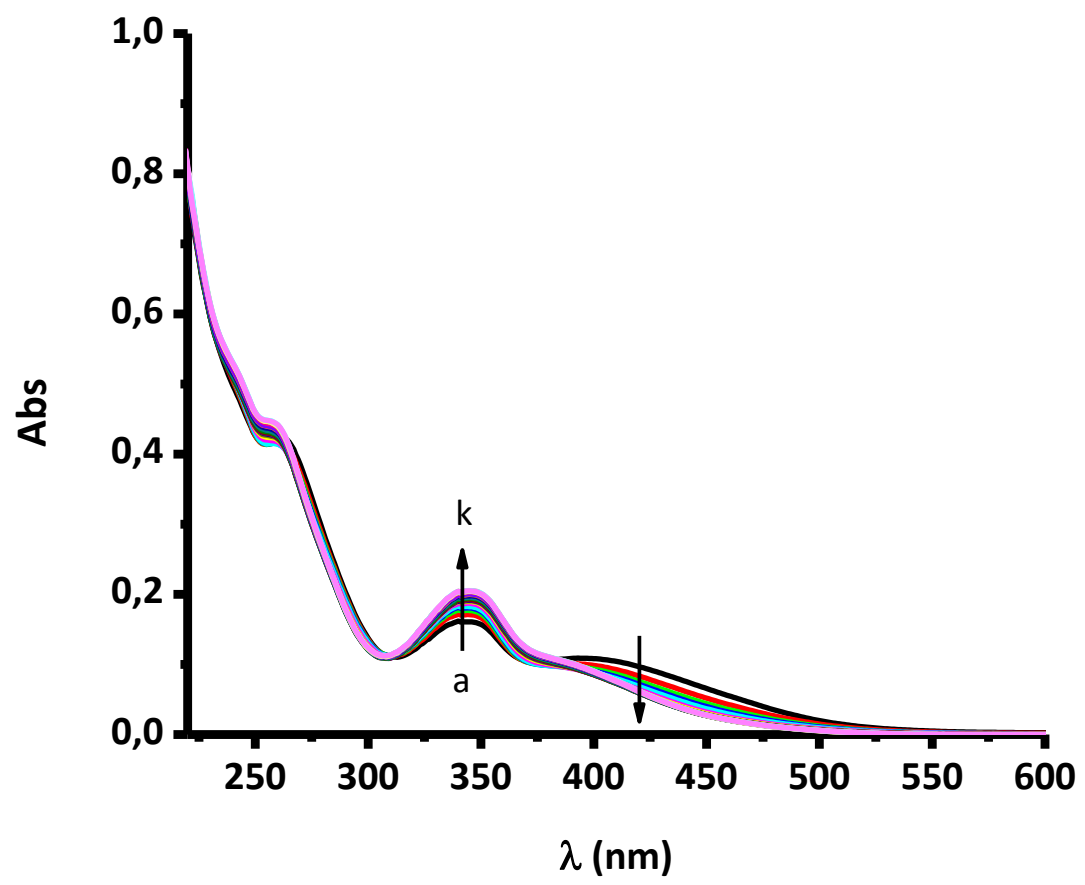

Figura 16

Espectros de absorción del complejo RePtr registrados a tiempos ( $a=15 \mathrm{~min}, \mathrm{k}=450$ min. de preparada la solución). Se trabajó en solución acuosa de pH 3.

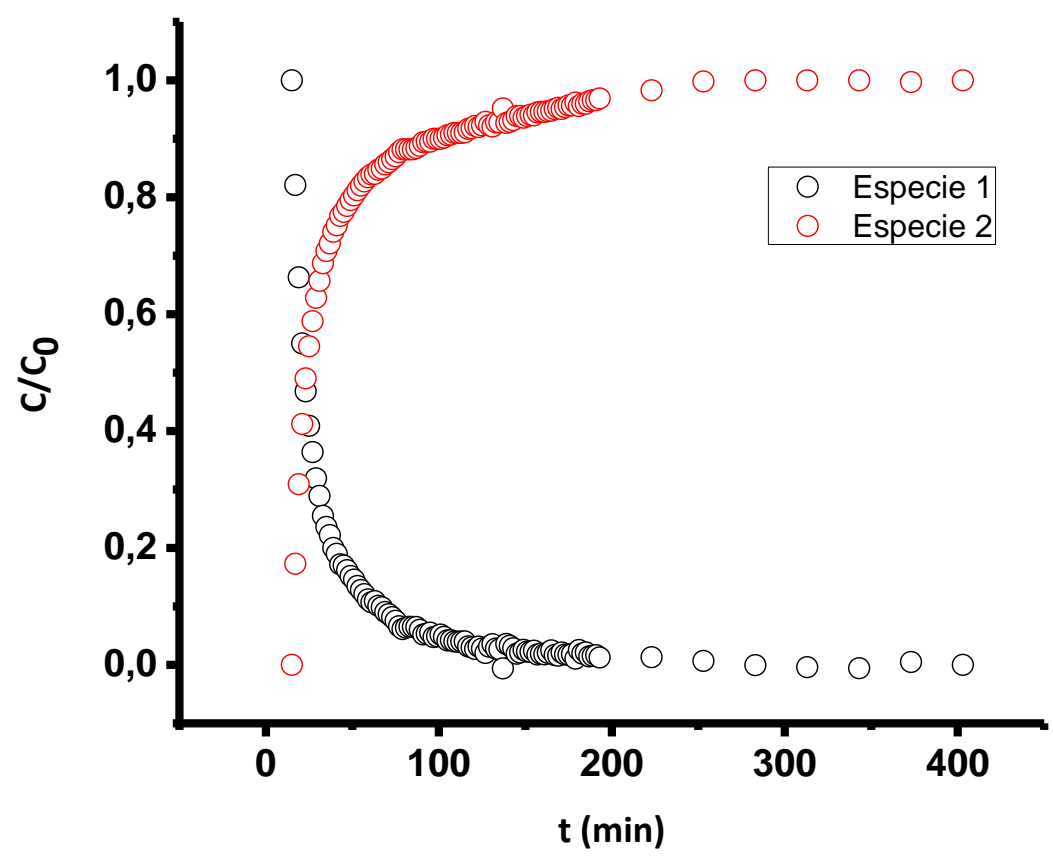

Figura 17.

Perfil de concentración para las especies presentes en el proceso estudiado. 
Se realizaron corridas de HPLC de una solución recién preparada del complejo RePtr en una mezcla Metanol-buffer 50:50, con buffer fórmico a pH 3. No se observó el pico que aparece al tiempo de elución correspondiente a la pterina ( $3 \mathrm{~min}$ en las mismas condiciones). Pudieron distinguirse claramente dos picos con espectros similares entre sí, con tiempos de elución $t_{\text {elu }}=7,9$ y 5,5 min. Se realizaron inyecciones de una solución a los 10 minutos de preparada la muestra hasta las 2 horas, cada 30 minutos. También se inyectaron muestras de la misma solución luego de 24 hs y a los 7 días. Las corridas se realizaron en las mismas condiciones. Los cromatogramas obtenidos a distintos tiempos, con los espectros correspondientes a cada pico se muestran en la figura 18. En los cromatogramas correspondientes a las corridas de soluciones con tiempo luego de la preparación creciente, puede observarse la disminución del pico con tiempo de elución $t_{\text {elu }}=7,9$ min y el crecimiento del pico con $t_{e l u}=5,5$ min. En los cromatogramas obtenidos con la solución del complejo RePtr con 24 hs y 7 días de preparada, se observa un único pico con $\mathrm{t}_{\text {elu }}=5,5$.

Con el fin de identificar inequívocamente la naturaleza de las especies a las que corresponden los picos en los cromatogramas, se realizó una corrida en un HPLC acoplado a un detector de masas con ionización ESI. La técnica se utilizó en modo positivo. El correspondiente cromatograma junto con el análisis de masas se muestra en la figura 19. La muestra se inyectó a los 30 minutos de haber sido preparada y 1 hora después en las mismas condiciones que en el experimento realizado con el HPLCUV-Vis. Se observó el mismo comportamiento en los cromatogramas que en el experimento anterior.

Del análisis de los pesos del ion molecular que arroja el análisis de HPLC-masa, puede concluirse que, el segundo pico $\left(t_{\text {elu }}=7,9 \mathrm{~min}\right)$, puede asignarse a un dímero $(\operatorname{RePtr})_{2}{ }^{+}$ (PM: 901) mientras que el pico con $t_{\text {elu }}=5,5 \mathrm{~min}$ corresponde al monómero del complejo (RePtr) ${ }^{+}(\mathrm{PM}: 450)$. Con toda la evidencia presentada puede afirmarse la existencia de un proceso en el cual el dímero (RePtr) ${ }_{2}$ se hidroliza dando lugar, al monómero RePtr estable (Ecuación 1). El monómero permanece sin alteraciones en su espectro de absorción y espectro de emisión. Tampoco se ve modificado el tiempo de elución en HPLC ni su espectro correspondiente. 


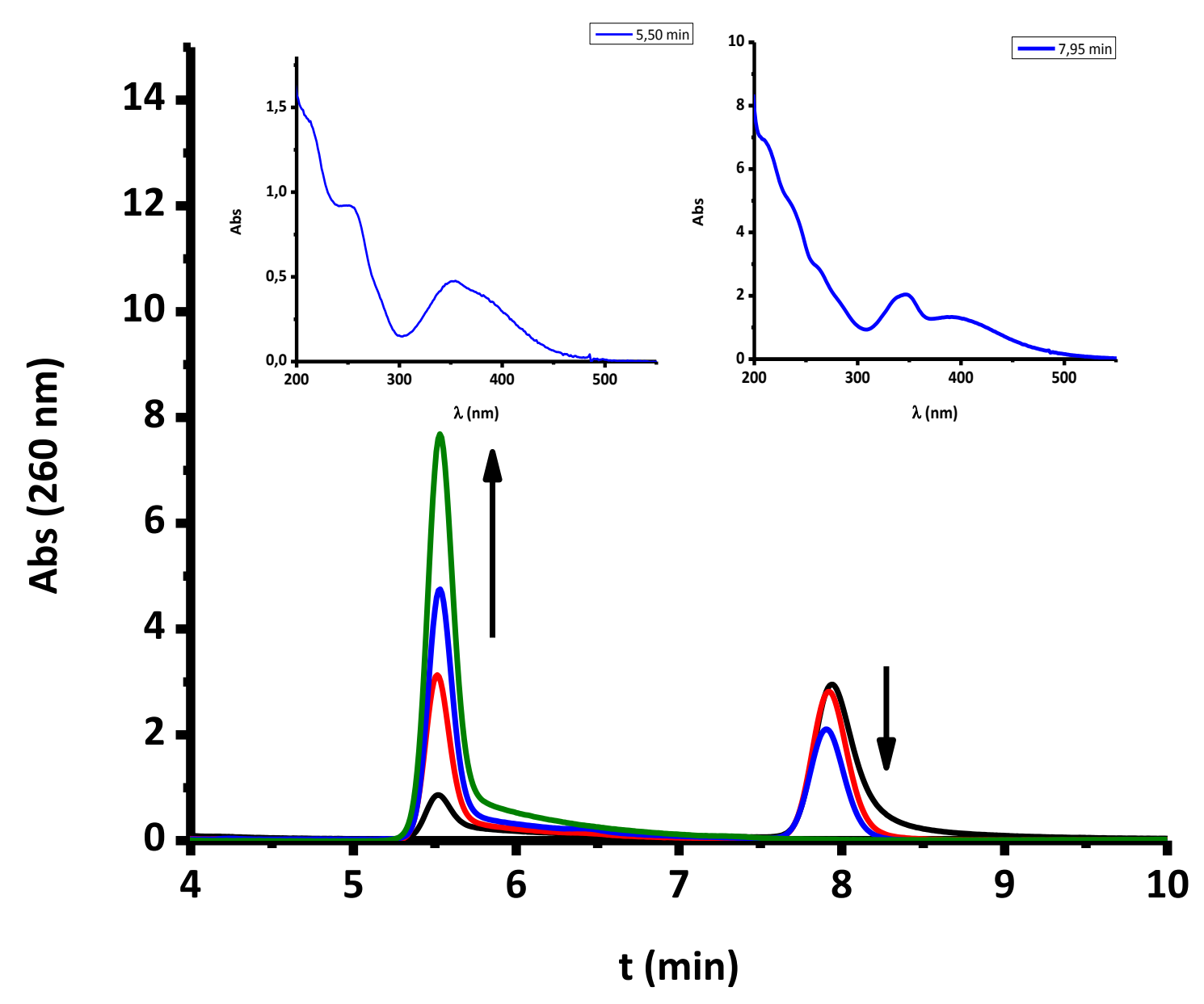

Figura 18

Cromatogramas de una solución de RePtr a tiempos 10, 30, 120 min y 24 hs luego de preparadas, los espectros en los insertos corresponden a cada pico. Se trabajó en solución $\mathrm{MeOH} / \mathrm{H}_{2} \mathrm{O}$ a pH 3 . 

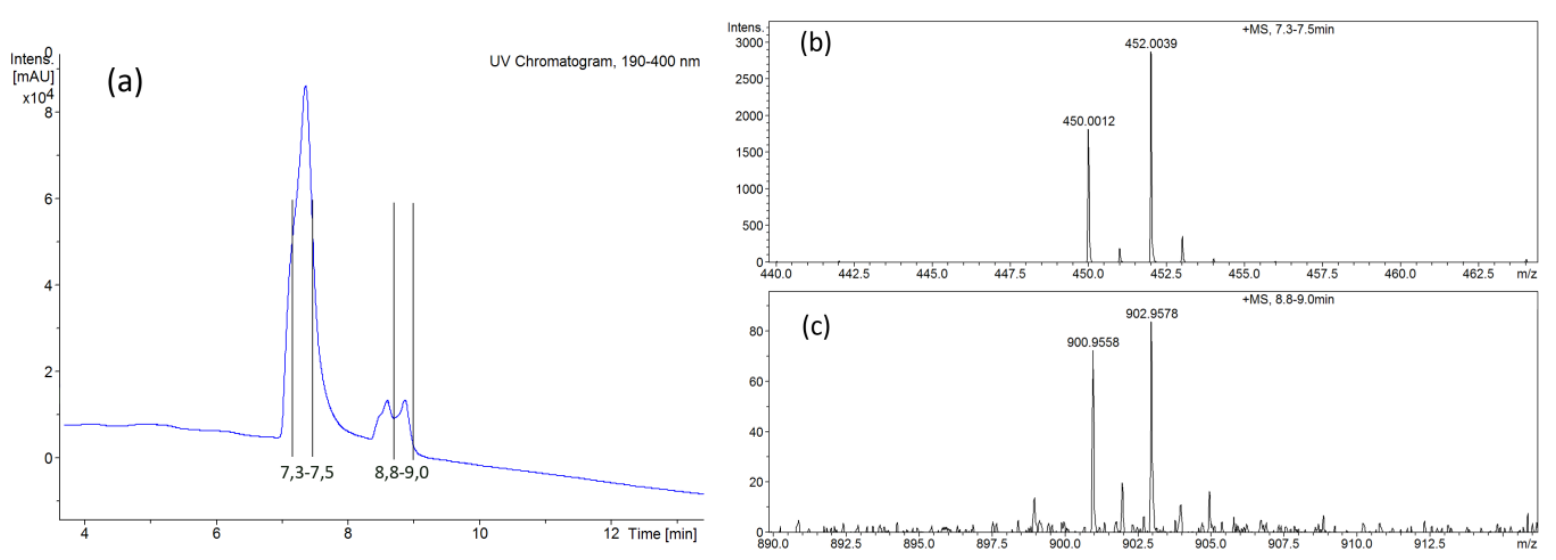

\section{Figura 19}

(a) Cromatograma de una solución de RePtr. (b) Resultados del ESI para el primer pico (7,3-7,5 min). (c) Resultados del ESI para el segundo pico (8,8-9,0 min). 30 minutos luego de preparada.

Con la información experimental obtenida, se propone que durante el proceso de evaporación del solvente, el complejo RePtr sufre un proceso de dimerización, este proceso se revierte al solubilizar al complejo. Una vez completa la disociación el complejo permanece estable, en todos los solventes ensayados, al menos hasta 7 días. Este proceso de disociación del dímero se observó en todos los solventes utilizados. En solventes menos polares este proceso se completa rápidamente, alcanzándose espectros de absorción y emisión invariantes antes de la hora de preparada la solución. En medio acuoso la cinética de disociación es más rápida al aumentar la acidez.

Para asegurar que los ensayos presentados en este trabajo reflejan las propiedades del monómero RePtr se trabajó siempre con soluciones de al menos 24 hs de preparadas. Este tiempo es el necesario para asegurar que el proceso de disociación llegó a su fin en el caso de trabajar a pH3, que es la condición en la cual este proceso es más lento.

\section{Estudio de los equilibrios de protonación}

En esta sección se presenta una detallada descripción de los equilibrios acido-base en una solución acuosa del complejo fac-Re'(CO) $)_{3}$ (pterina) $\left(\mathrm{H}_{2} \mathrm{O}\right)(\mathrm{RePtr})$. En la figura 20 se muestra una representación optimizada del complejo con la numeración utilizada en este trabajo. 
Se registraron los espectros de absorción en el estado basal de soluciones del complejo RePtr ajustadas a los pH 11, 6 y 2. El espectro de absorción del complejo RePtr en medio alcalino a pH 11, consiste en una banda de absorción intensa $\left(\varepsilon \approx 2 \times 10^{4} \mathrm{M}^{-1} \mathrm{~cm}^{-}\right.$ ${ }^{1}$ ) centrada a $\lambda_{\max }=255 \mathrm{~nm}$ y una banda de absorción de mediana intensidad ( $\varepsilon \approx 4 \mathrm{x}$ $10^{3} \mathrm{M}^{-1} \mathrm{~cm}^{-1}$ ) centrada a $\lambda_{\max }=373 \mathrm{~nm}$. En solución con acidez cercana a la neutralidad ( $\mathrm{pH}$ 6), el máximo de la banda de más alta energía permanece en su posición pero con menor intensidad, mientras que la banda de menor energía presenta un corrimiento a $\lambda_{\max }=366 \mathrm{~nm}$. En medio acido $(\mathrm{pH} 2)$ pueden observarse por lo menos tres bandas que se superponen en la región entre 220 y $300 \mathrm{~nm}$. Se distinguen dos inflexiones en 260 y $240 \mathrm{~nm}$. En la región entre 300 y $500 \mathrm{~nm}$, se observan dos bandas, la primera con $\lambda_{\max }$ $=344 \mathrm{~nm}$, y la segunda aparece como un hombro ancho con $\lambda_{\max } 400 \mathrm{~nm}$. En la figura 21 se muestran los espectros en las tres condiciones de para el complejo RePtr.

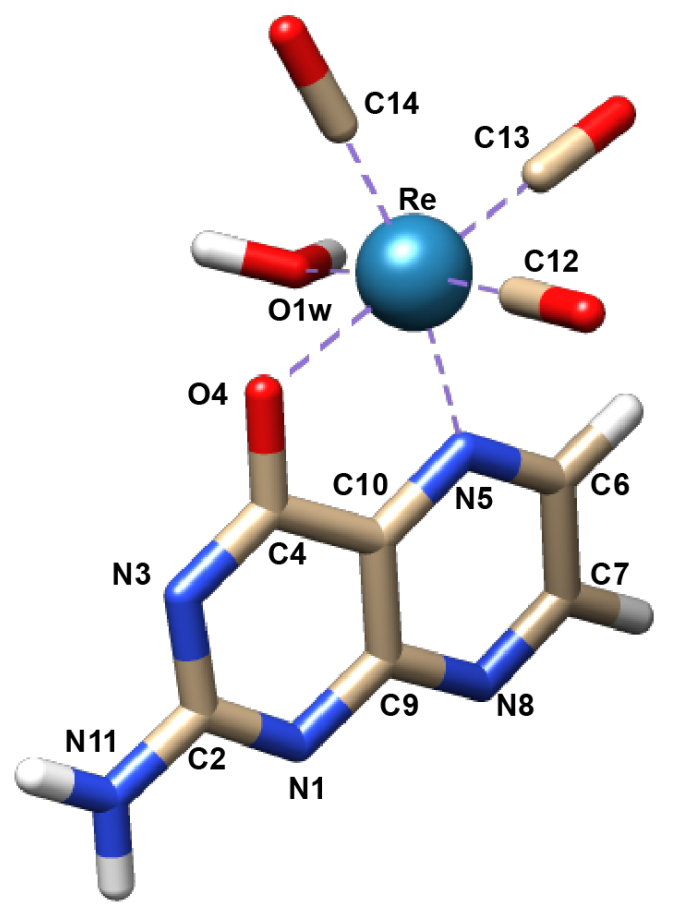

Figura 20

Representación del complejo RePtr con la numeración utilizada a lo largo de la tesis. 


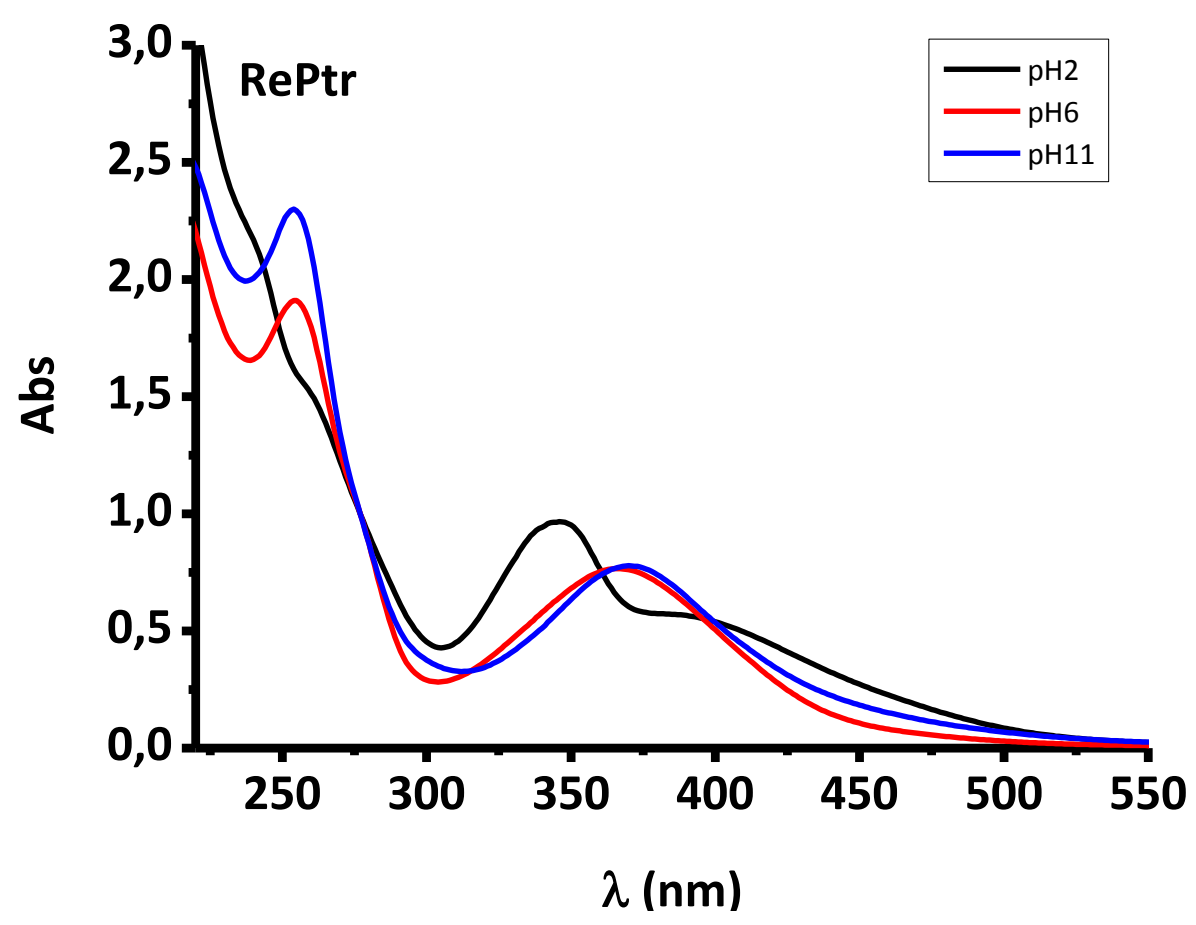

Figura 21

Comparación de los espectros de absorción UV-Vis del complejo RePtr en sus tres formas acido-base a los $\mathrm{pH} 2,6$ y 11.

\subsection{Análisis quimiométrico}

El estudio de los equilibrios de protonación se realizó, midiendo los espectros de absorción cada 0,5 unidades de pH a una solución acuosa del complejo RePtr. Como solvente, se utilizó una solución del buffer Britton y Robinson (una mezcla de ácidos: acético, perclórico fosfórico y bórico $0.04 \mathrm{M}$ cada uno). En cada experimento, a $25 \mathrm{~mL}$ de una solución del complejo RePtr $\left(9.4 \times 10^{-5} \mathrm{M}\right.$ o $\left.2.7 \times 10^{-5} \mathrm{M}\right)$, inicialmente a pH 1,9; se le agregó $\mathrm{NaOH} 3 \mathrm{M}$ hasta llegar a pH12. A continuación se aumentó la acidez gradualmente por adición de alícuotas de 50-100 $\mu \mathrm{L}$ de $\mathrm{HClO}_{4}$. Luego de cada agregado, se registró el espectro de absorción de una alícuota de la solución. El procedimiento fue repetido revirtiendo el pH de 1,9 a 12 por adición porciones de 50$100 \mu \mathrm{L}$ de una solución de $\mathrm{NaOH}$. Cuando fue necesario, la absorbancia final se corrigió por dilución. En la figura $\mathbf{2 2}$ se muestran los espectros obtenidos 

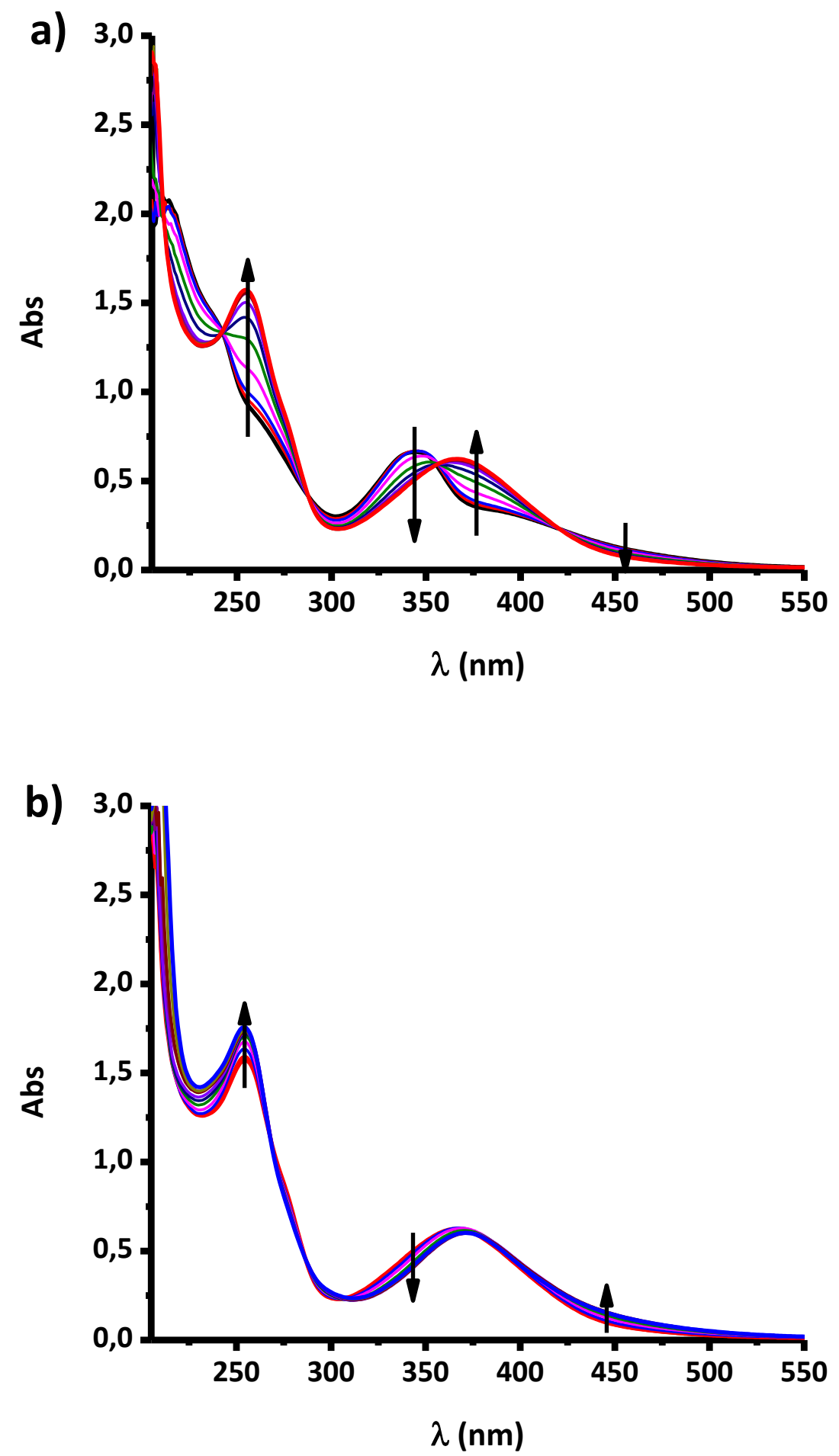

Figura 22

Cambios espectrales UV-Vis exhibidos por el complejo RePtr en los estudios de protonación. a) Cambios espectrales en el rango de $\mathrm{pH} 2-7$, (puntos isosbésticos a 243, 287, 355 y $422 \mathrm{~nm}$ ) b) Cambios espectrales en el rango de $\mathrm{pH} \mathrm{7-11.} \mathrm{(puntos}$ isosbésticos a 270,285 y 307) $\mathrm{nm}$ Las flechas indican el sentido en que se dan los cambios al alcalinizar la solución 
La invariancia del espectro UV-Vis cuando se va de pH 2 a 11 y se vuelve a pH 2 sugiere que no ocurre una disociación del ligando asociada al cambio de acidez y que el complejo es estable en el rango de pH en que se trabajó. Por ello, podemos afirmar que cuando el pH se cambia entre 2 y 11 ocurre una protonación reversible.

\subsubsection{Perfil de especies}

Se utilizaron técnicas quimiométricas [29] para obtener los perfiles de concentración y los espectros de cada especie contribuyente a la matriz de absorbancia [30], [31]. Al aplicar estos métodos a los datos de espectroscopía del proceso químico (figuras 22 a y b) se obtuvo información sobre los cambios en la composición del sistema. Se usó el algoritmo de mínimos cuadrados alternante (ALS) para estimar simultáneamente la concentración y los perfiles espectrales [32]. Se aplicó el análisis de factores y la descomposición en valores singulares a la matriz experimental para la estimación del valor $n$. (cantidad de especies) encontrándose que con $n=3$ se logra una adecuada reproducción de la matriz experimental.

Para obtener una estimación inicial de los espectros contribuyentes se empleó el método de la proyección ortogonal [33]. Para reducir las ambigüedades rotacionales, se utilizaron restricciones químicas relevantes [34] (e.g. no negatividad, finalización, selectividad y unimodalidad). Además, se usó la estrategia de aumento de la matriz para obtener simultáneamente los perfiles de concentración correspondientes a diferentes condiciones experimentales.

La formas se las curvas se obtuvieron mediante resolución multivariada empleando el método de los mínimos cuadrados alternantes (MCR-ALS) cuyos resultados se muestran en la figura 23. En la figura $\mathbf{2 4}$ se muestran las funciones de distribución para tres especies en todo el rango de $\mathrm{pH}$, de esta figura se desprenden dos valores de $\mathrm{pKa}$ 3,9 y 8,8, calculados como la intersección de las funciones de distribución para las tres especies. 


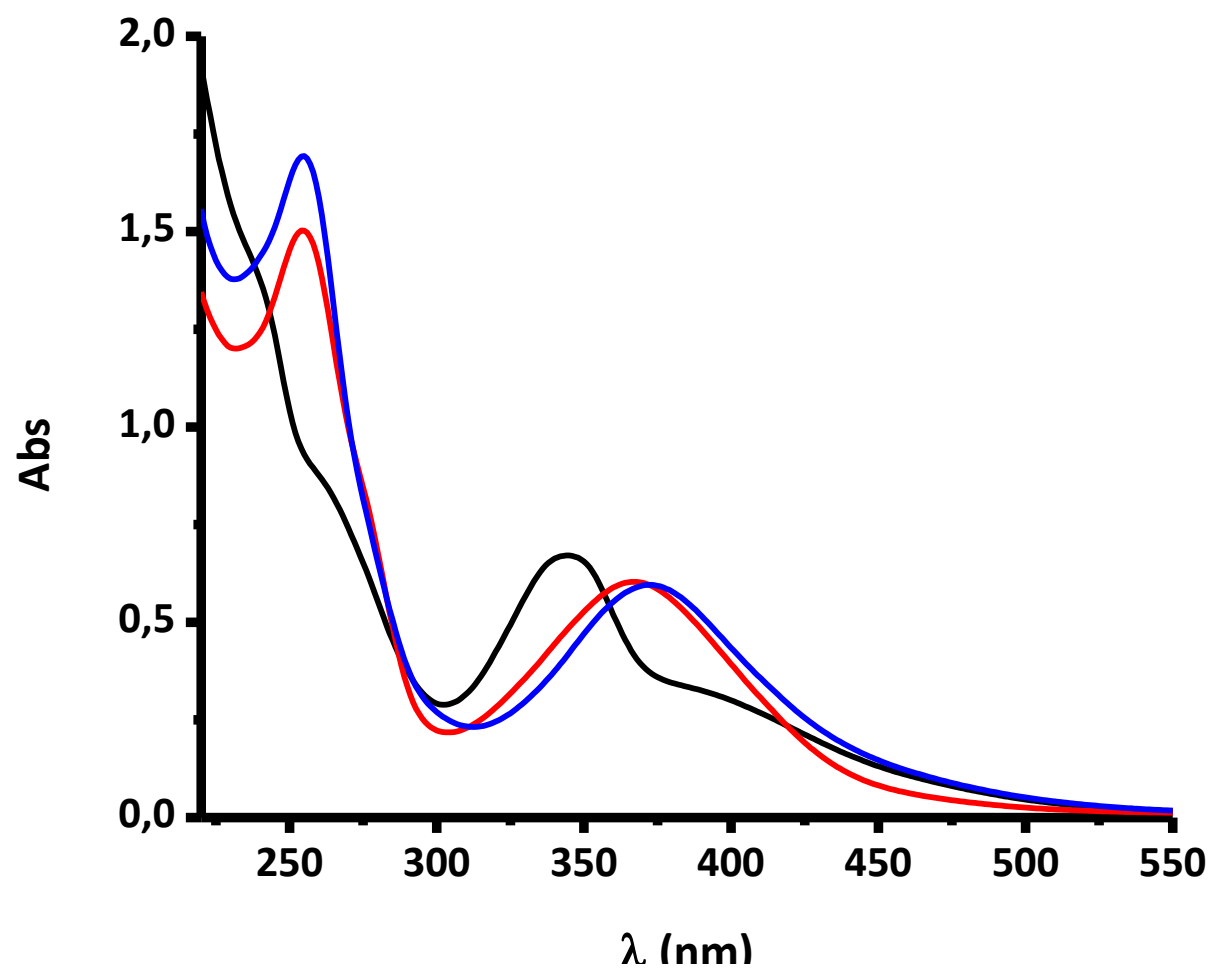

Figura 23

Espectros calculados, mediante el análisis quimiométrico, de las tres especies. Negro especie 1 (acida), rojo especie 2 (neutra) y Azul especie 3 (alcalina).

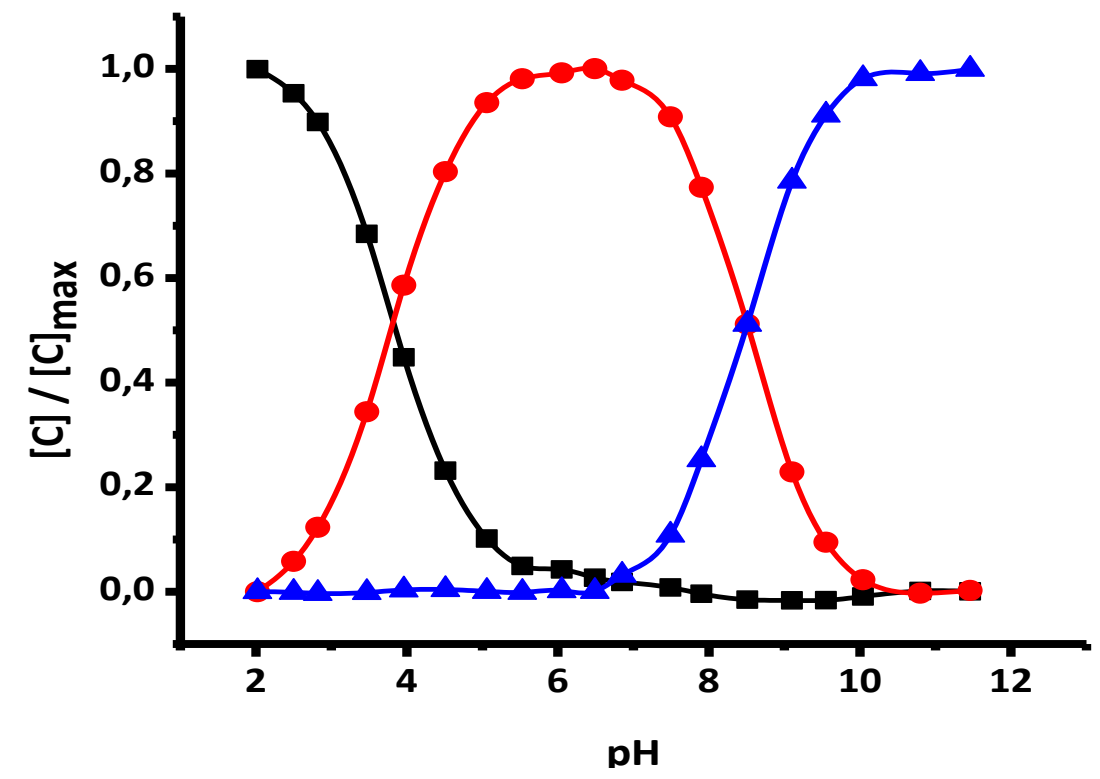

Figura 24

Funciones de distribución obtenidas por análisis quimiométrico del complejo RePtr en los estudios de protonación. Negro especie 1, rojo especie 2 y azul especie 3. 
Los valores de pKa determinados son el promedio de los valores para los estudios de protonación usando soluciones del complejo de $\operatorname{Re}(I)$ a las dos concentraciones antes mencionadas.

El equilibrio ácido-base del ligando libre ya fue presentado en detalle en el capítulo II. Brevemente, el estado basal de la pterina, en solución acuosa, se presenta en tres formas de acuerdo a la acidez, una especie catiónica $\left(\mathrm{PtrH}^{+}\right)$a $\mathrm{pH}$ menor a 2, una especie neutra (Ptr) a pH entre 2 y 8 y una especie aniónica (Pto ${ }^{-}$) por encima de $\mathrm{pH} 8$, los $\mathrm{pK}_{\mathrm{a}}$ de estos equilibrios son 2,3 y 7,9 [2][35][36] (figura 25).

Las bandas observadas en los espectros del ligando libre (figura 26) fueron asignadas a transiciones $S_{0} \rightarrow S_{1}, S_{2}, S_{3}$. Se utilizaron cálculos teóricos usando la teoría del funcional de densidad dependiente del tiempo TD-DFT [37] para las especies neutra y catiónica de la pterina. Los resultados de estos cálculos reproducen con gran precisión los datos experimentales. Además, muestran que para la forma neutra, la banda de mayor energía se encuentra centrada en $340 \mathrm{~nm}$ y corresponde a una transición desde el orbital ocupado de más alta energía (HOMO) al orbital desocupado de más baja energía (LUMO). Esta transición puede ser vista como una mezcla entre transiciones $\pi$ $\rightarrow \pi^{*}, \mathrm{n} \rightarrow \pi^{*}$ y $\mathrm{n} \rightarrow \mathrm{n}^{*}$.<smiles>Nc1[nH]c(=O)c2nccnc2[nH+]1</smiles><smiles>Nc1nc2nccnc2c(=O)[nH]1</smiles>

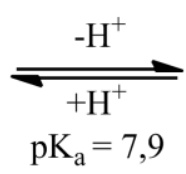<smiles>Nc1nc([O-])c2nccnc2n1</smiles>

\section{Figura 25}

Equilibrio entre las formas ácida, neutra y alcalina de la pterina. 


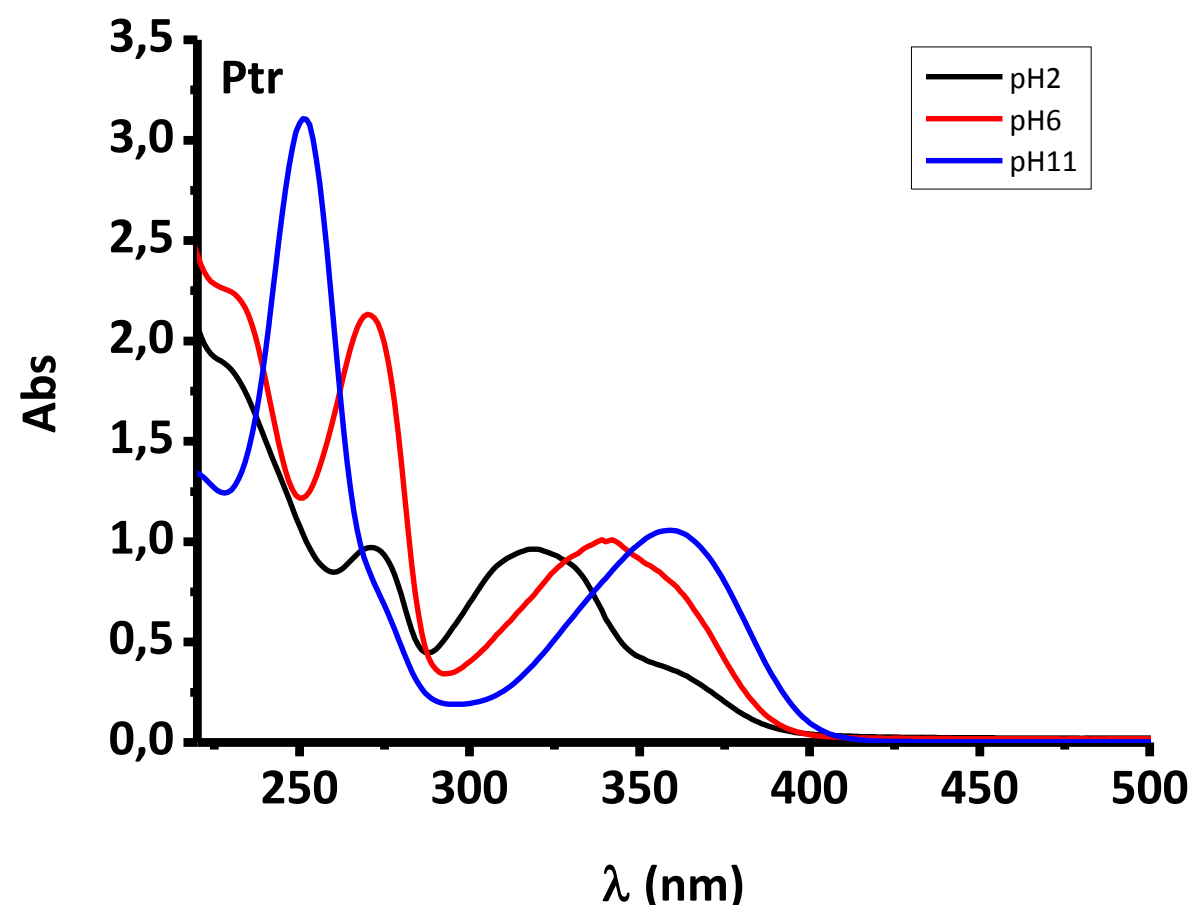

Figura 26

Comparación de los espectros de absorción UV-Vis del ligando libre pterina en sus tres formas acido-base a los $\mathrm{pH}$ 2, 6 y 11.

Los cálculos de TD-DFT para el complejo RePtr, realizados en el grupo [37], muestran que los orbitales involucrados en las transiciones electrónicas de mayor intensidad son los H-7, H-5, H-3, H-2, H-1, HOMO, LUMO, L+1, L+2 y L+3. La banda de menor energía para las tres especies acido-base del complejo está principalmente definida por las transiciones de los orbitales $\mathrm{H}-3, \mathrm{H}-2$ y $\mathrm{H}-1$ al LUMO. Los orbitales $\mathrm{H}-3, \mathrm{H}-2$ y $\mathrm{H}-1$ poseen una contribución aproximada de un $50 \%$ del $\operatorname{Re}(\mathrm{I})$ un $25 \%$ de los $\mathrm{CO}$ y otro tanto de la pterina. Mientras que el LUMO posee una contribución casi exclusiva de los orbitales de la pterina. Debido a esto, las transiciones que tienen mayor contribución a esta banda pueden describirse como transferencias de carga metal-ligando al ligando $(M L L C T)$ y puede resumirse como una transferencia de carga desde la porción $\operatorname{Re}(C O)_{3}$ al ligando pterina. En la figura $\mathbf{2 7}$ puede apreciarse una representación de los orbitales del complejo que tienen mayor contribución de una de las transiciones que define la banda de menor energía, en esta puede notarse el carácter MLLCT de la transición. 


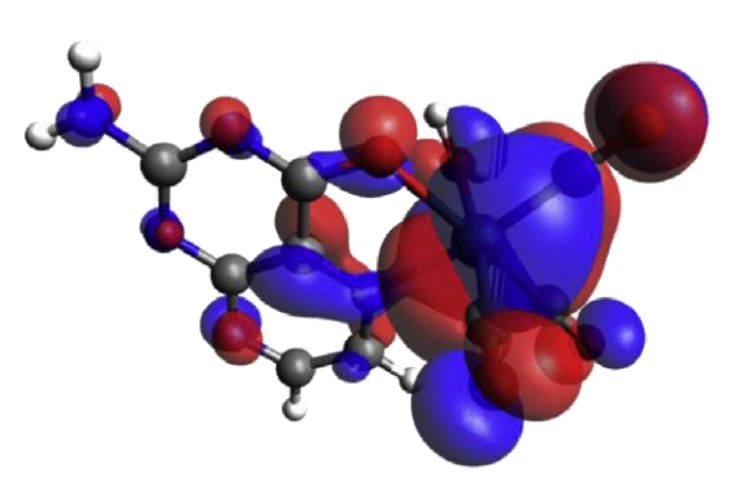

HOMO-2

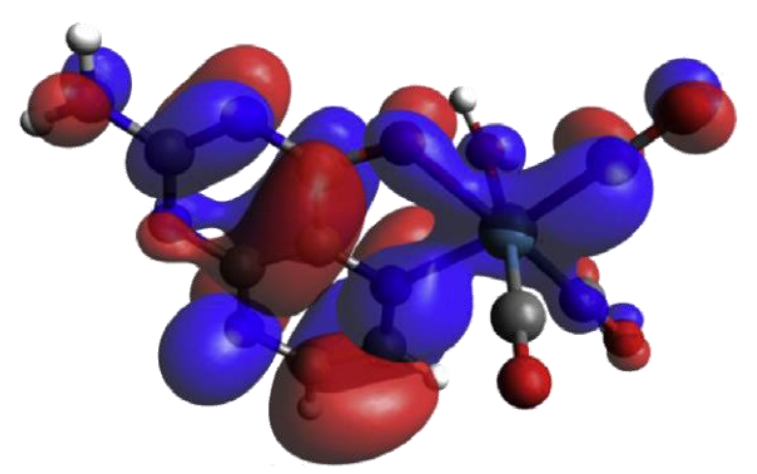

LUMO

Figura 27

Representación de los orbitales HOMO-2 y LUMO del complejo RePtr obtenidos mediante cálculos de TD-DFT. Los diagramas fueron tomados del la referencia [39]

Las bandas de más alta energía en el complejo de $\operatorname{Re}(I)$ se identificaron como la combinación de las transiciones MLLCT, intraligando de la pterina IL y transiciones LLMCT desde la pterina a los carbonilos.

Considerando la evidencia experimental expuesta hasta este punto, sabemos que en la coordinación de la pterina por el $\operatorname{Re}(\mathrm{I})$, intervienen el oxígeno y el N5. En solución acuosa neutra el N3 se halla desprotonado. La especie del complejo RePtr mayoritaria en una solución acuosa neutra, posee la fracción $\operatorname{Re}(\mathrm{CO})_{3}$ coordinando un pterinato.

El espectro que se obtiene de una solución neutra presenta bandas centradas a $\lambda_{\max }$ 255 y $370 \mathrm{~nm}$. Comparando este espectro con el del Pto ${ }^{-}\left(\lambda_{\max }=250\right.$ y $\left.360 \mathrm{~nm}\right) \mathrm{se}$ observa una notable coincidencia en la posición de la banda de mayor energía. Esto resulta razonable teniendo en cuenta la mayor contribución de las transiciones centradas en el ligando que se asignaron a esta banda. También se observa, en el espectro del complejo, un ensanchamiento hacia el rojo en la banda de mayor energía. Este último rasgo es esperable teniendo en cuenta la participación de transiciones MLCT de menor energía en esta banda. El espectro del complejo en medio ácido presenta dos inflexiones en la zona de alta energía a 240 y $260 \mathrm{~nm}$ y una banda ancha en la zona de menor energía con dos máximos a 346 y $400 \mathrm{~nm}$. Mientras que el ligando libre a pH 6 presenta una banda con $\lambda_{\max }=270 \mathrm{~nm}$ y una banda de baja energía centrada en $\lambda_{\max }=340 \mathrm{~nm}$. La aparición de la banda en $346 \mathrm{~nm}$ coincide con la observada en el ligando. Estos rasgos espectrales están de acuerdo con los obtenidos por cálculos computacionales, que interpretan a estas transiciones como una mezcla 
de transiciones $\pi \rightarrow \pi^{*}$ dentro de los anillos del ligando mas transiciones electrónicas de carácter MLLCT. Estas últimas pueden ser responsables del máximo centrado en los $400 \mathrm{~nm}$. La forma aniónica del complejo no tiene referencia en las especies acido-base del ligando. Esta especie se asoció con la pérdida del protón del agua coordinada, que da lugar a un hidroxo-complejo. El espectro del complejo en medio alcalino muestra pequeños cambios con respecto al espectro medido en medio neutro, sin presentar cambios espectrales en la zona de alta energía. Se observa un ensanchamiento y un corrimiento de la banda de menor energía hacia el rojo. La presencia de la carga del oxidrilo sobre el renio podría explicar la disminución en energía de las bandas de transferencia de carga del metal al ligando que son las de mayor influencia en la zona de menor energía.

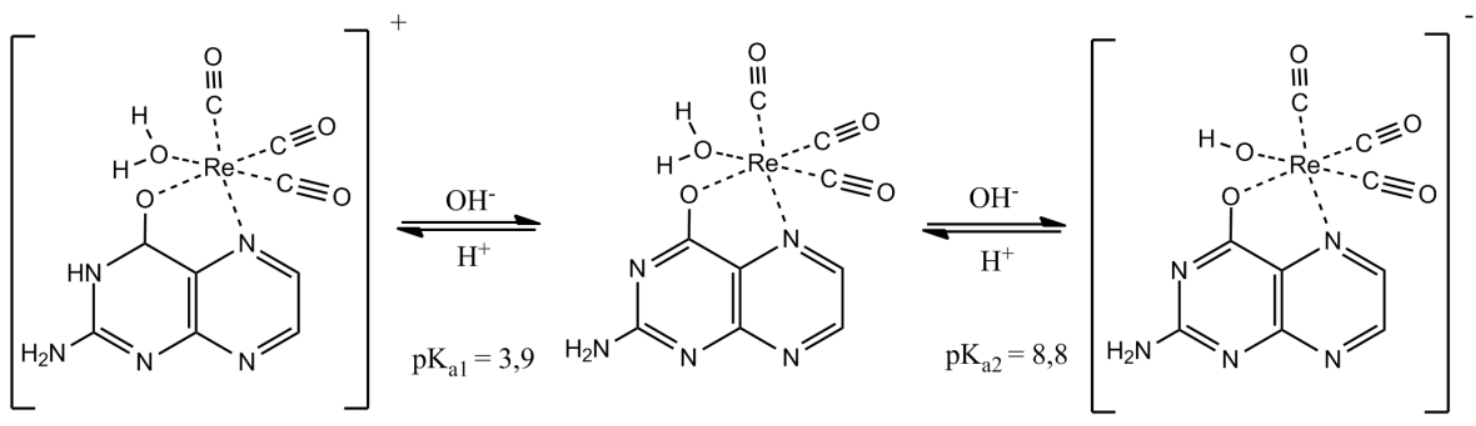

\section{Figura 28}

Representación de las tres especies propuestas para el equilibrio ácido-base del complejo RePtr en medio acuoso.

\subsection{Equilibrio de protonación en $\mathrm{ACN}$}

Varios autores han observado que cuando se disuelven complejos del tipo fac$\mathrm{XRe}(\mathrm{CO})_{3} \mathrm{~L}$ en distintos solventes nucleofilicos, entre ellos $\mathrm{ACN}$, se reemplaza la posición X por una molécula de solvente [18], [38]. Al disolver el complejo RePtr en $\mathrm{ACN}$ se observaron cambios espectrales compatibles con este comportamiento (figura 29). Estos cambios se atribuyen al reemplazo de la molécula de agua coordinada por una de ACN (figura 30). Luego de 30 min no se observan cambios en los espectros de absorción. 


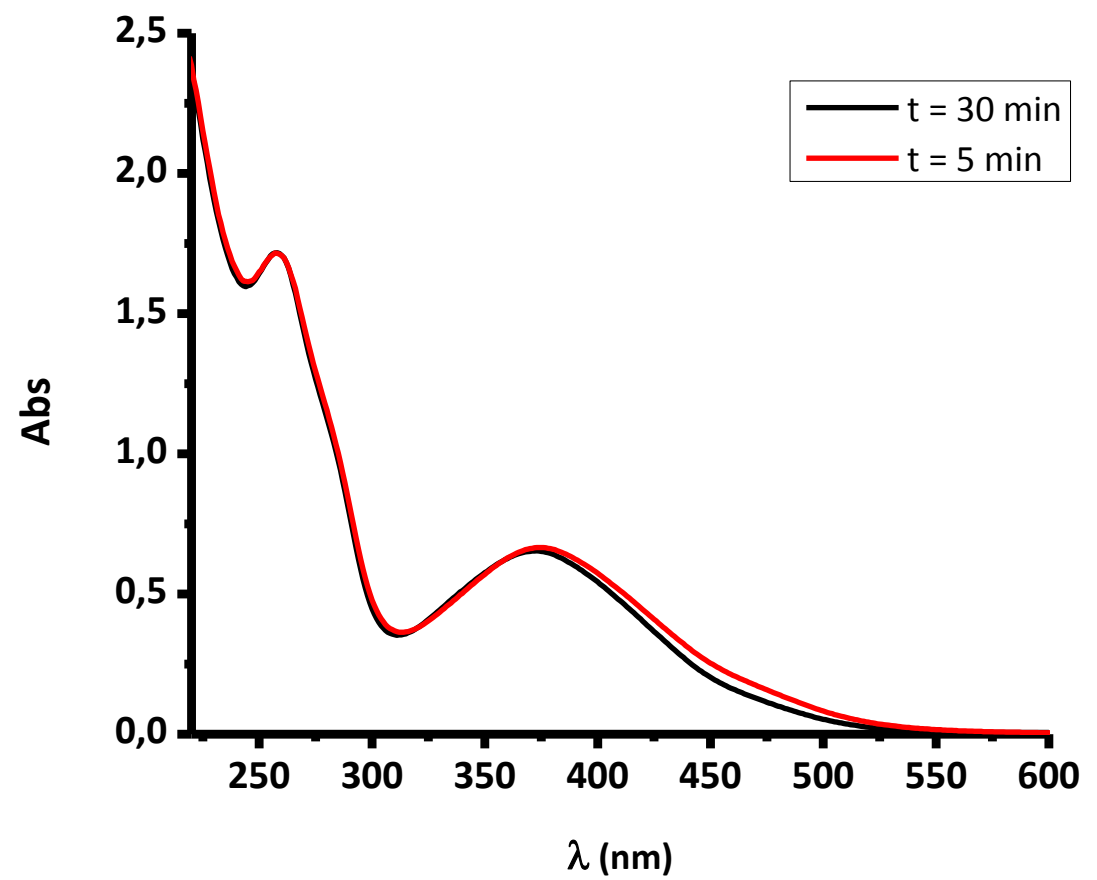

Figura 29

Espectros del complejo RePtr en ACN medidos a los 5 y 30 minutos de preparada la solución.

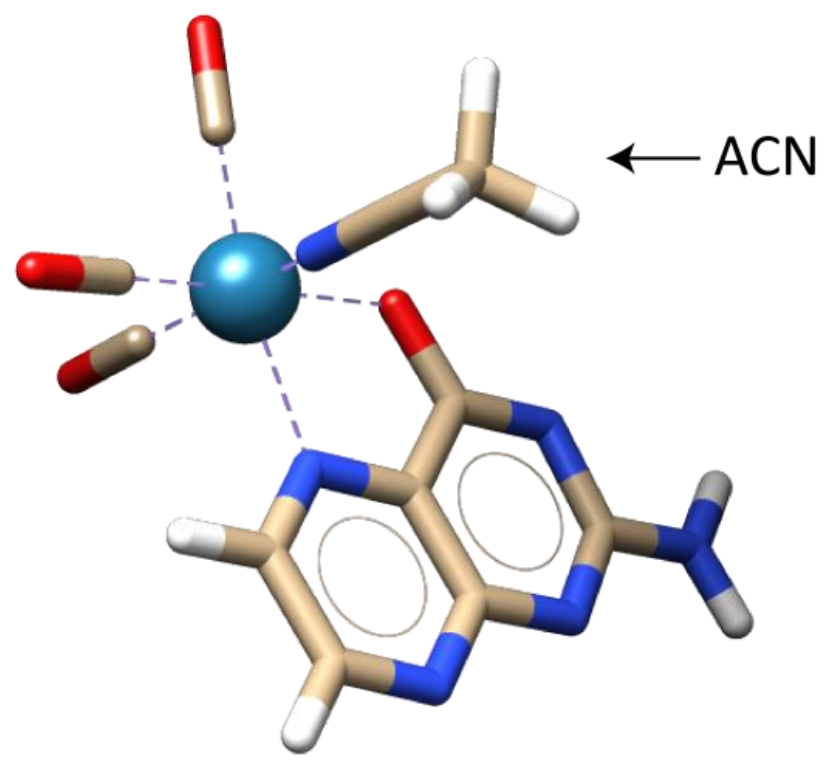

Figura 30

Representación de la molécula complejo RePtr-ACN. 
Se midió el espectro de absorción del complejo RePtr en ACN. Este espectro presenta una banda ancha de baja energía centrada en $370 \mathrm{~nm}$, y una banda más intensa centrada en $254 \mathrm{~nm}$. Se registraron los espectros de absorción de una solución del complejo RePtr en $\mathrm{ACN}$ a la que se le realizaron agregados sucesivos de $\mathrm{HClO}_{4}$ hasta una concentración $10^{-4} \mathrm{M}$. El espectro final obtenido presenta dos bandas a baja energía superpuestas parcialmente, de las cuales la de mayor energía es una banda angosta centrada a $342 \mathrm{~nm}$ y la de menor energía es una banda ancha centrada en 400 $\mathrm{nm}$. El espectro entre los 220 y $300 \mathrm{~nm}$ presenta una superposición de bandas sin un máximo definido. Además, se registró el espectro de absorción de una solución del complejo en $\mathrm{ACN}$ con agregado de $\mathrm{KOH}$. No se observaron cambios significativos de este espectro con respecto al espectro en ACN. Los coeficientes de absorción de las bandas de menor energía en todas las condiciones se encuentran entre los 2000 y $4000 \mathrm{M}^{-1} \mathrm{~cm}^{-1}$ (estos espectros se detallan en el capítulo IV).

El espectro del complejo en ACN presenta una forma similar al espectro del complejo en medio acuoso neutro. Al agregar $\mathrm{HClO}_{4}$ a la solución del complejo, ocurren cambios espectrales que también se correlacionan con los observados al acidificar la solución en medio acuoso. La banda centrada en $370 \mathrm{~nm}$ decrece en intensidad, aparece una nueva banda centrada en $340 \mathrm{~nm}$ y disminuye en intensidad la banda centrada en 254 nm. Así también, se observan puntos isosbésticos situados en 227, 293, 342 y 445 nm similares a los observados en medio acuoso acido. Estos cambios se presentan en la figura 31. 


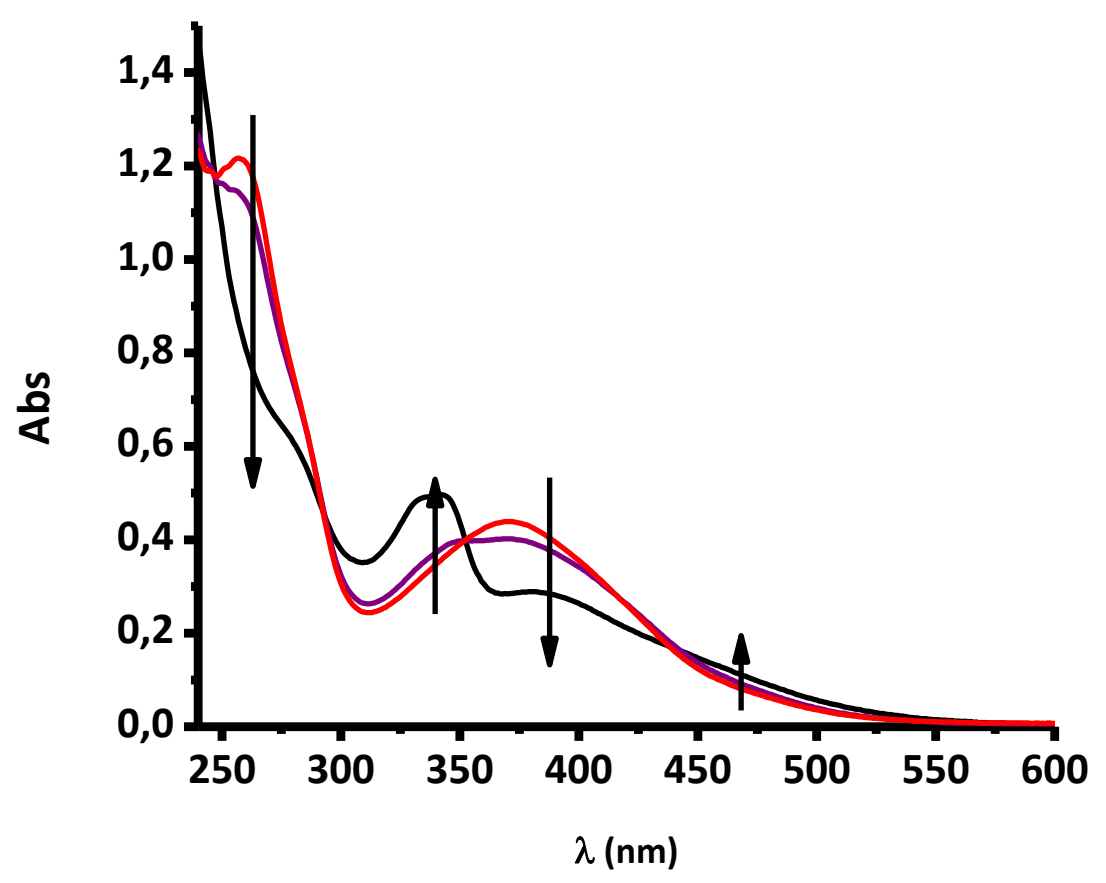

Figura 31

Cambios espectrales en el complejo RePtr. (-) En ACN. (-) Al agregar $\mathrm{HClO}_{4}$ hasta concentración $2 \times 10^{-5} \mathrm{M}$ y $(-) 10^{-4} \mathrm{M}$. Las flechas indican los cambios que se observan al acidificar la solución.

Al agregar trietil amina (TEA) que es una base con un $\mathrm{pKa}_{\mathrm{ACN}}=18,2$ [39], los cambios espectrales observados son mínimos, solo observándose una disminución en la intensidad de la banda de menor energía a concentraciones del orden de $10^{-1} \mathrm{M}$ de la base. Los cambios espectrales en medio acuoso al pasar de medio neutro a alcalino fueron asociados a la pérdida del protón del agua coordinada. En ACN esta molécula de agua fue reemplazada por el solvente. De este modo no sorprende el hecho de que no se observan cambios espectrales en ACN al alcalinizar el medio. En todos los casos los cambios espectrales resultaron reversibles e inmediatos.

En base a las similitudes espectrales y al reemplazo de la molécula de agua coordinada por una de solvente, podemos asumir que los cambios espectrales observados en ACN, se deben a un equilibrio acido base. Puede entonces, plantearse la existencia de dos especies que coexisten en un equilibrio de protonación (figura 32). Considerando que el $\mathrm{HClO}_{4}$ se encuentra totalmente disociado en $\mathrm{ACN}$ [40], el rango de concentraciones 
de $\mathrm{H}^{+}$(agregados) entre las que se establece el equilibrio se encuentra entre $10^{-5}$ y $10^{-}$ ${ }^{4} \mathrm{M}$.

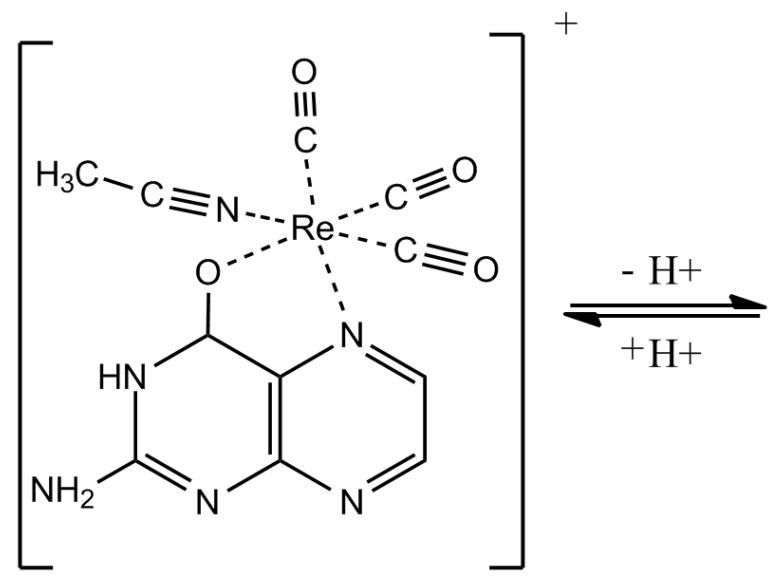<smiles></smiles>

\section{Figura 32}

Estructuras propuestas para las especies que participan del equilibrio acido-base del complejo RePtr en ACN. Donde la estructura de la izquierda representa a la especie ácida y la de la derecha la especie neutra.

\section{Conclusiones del capítulo III}

Se sintetizó un nuevo complejo de coordinación de $\operatorname{Re}(I)$ que incluye al ligando pterina, fac-Re'(CO) $)_{3}$ (pterina) $\left(\mathrm{H}_{2} \mathrm{O}\right)$ utilizando dos métodos distintos de síntesis. Utilizando el método tradicional se obtuvo un buen rendimiento. Sin embargo el nuevo procedimiento de síntesis, utilizando $\operatorname{Re}(\mathrm{CO})_{3}{ }^{+}$como precursor, resulto ser un método más limpio y también con un buen rendimiento. Este último método es aplicable a complejos tricarbonilicos de $\operatorname{Re}(\mathrm{I})$ solubles en agua, y permite obtener un producto sin restos de solvente ni otros iones. Se obtuvo evidencia de la coordinación del ligando pterina a través de los átomos $\mathrm{O} 4$ y N5 utilizando espectroscopía ${ }^{1} \mathrm{H} N \mathrm{NMR},{ }^{13} \mathrm{C} N \mathrm{NM}$ y FTIR. La caracterización estructural por difracción de rayos $X$ confirmó el modo de unión de la pterina y además mostró la configuración facial de los tres carbonilos coordinados al Re. La coordinación octaédrica del metal central se completa con una molécula de agua. El análisis de la estructura cristalina mostró, la presencia de dos moléculas de agua de cristalización adicionales. Estas están involucradas en la red 
cristalina formando puentes de hidrogeno que se extiende a lo largo del cristal y conecta complejos vecinos en la forma cristalina del complejo.

El análisis estructural fue profundizado por el uso comparativo de tres técnicas de espectrometría de masas. En general se observó una fragmentación más eficiente del analito cuando se emplea la técnica de desorción-ionización laser (LDI y MALDI). Utilizando el método ESI, que es el más usado en el campo de la química organometálica, se observó el ion molecular intacto aportando evidencia también sobre los fragmentos. Además, hemos demostrado por primera vez, que la técnica de ionización PESI, recientemente desarrollada, es apta para el estudio de complejos de pterina coordinada con Re. Ambos métodos ESI usados permitieron detectar el ion molecular intacto, sin embargo, se obtuvo una mejor relación señal- ruido, cuando se utilizó PESI en lugar de ESI. Mediante la técnica ESI se pudo obtener evidencia adicional sobre la estructura del complejo. Las más interesantes características encontradas en este particular complejo RePtr, fueron, su relativamente alta solubilidad en agua y su marcada estabilidad. Siendo estas importantes características en relación a su aplicabilidad en ambientes fisiológicos [41].

Las tres especies presentes en los dos equilibrios acido base de este complejo RePtr, presentaron notables cambios espectrales, en particular entre las especies relacionadas al primer equilibrio. Estos cambios en la posición e intensidad de los máximos de absorción puede resultar de utilidad en campos de estudio tales como como el del estudio de nuevos biosensores de pH [42]. Las bandas de absorción pudieron ser asignadas a contribuciones de los estados individuales del ligando, transiciones entre los ligandos, y transiciones de transferencia de carga MLLCT. Se reportaron dos equilibrios acido-base del complejo RePtr. El pKa = 3.9 fue asignado al equilibrio de protonación de la pterina en el complejo en el N3 y el pKa = 8.8 se asignó a la desprotonación de la molécula de agua coordinada al complejo. Fue posible proponer un par de especies responsables de los cambios espectrales observados en ACN al variar la $\left[\mathrm{H}^{+}\right]$. 


\section{Referencias bibliográficas}

[1] T. Kojima, T. Sakamoto, Y. Matsuda, K. Ohkubo, and S. Fukuzumi, "A ruthenium pterin complex showing proton-coupled electron transfer: synthesis and characterization.," Angew. Chem. Int. Ed. Engl., vol. 42, no. 40, pp. 4951-4, Oct. 2003.

[2] C. Lorente and A. H. Thomas, "Photophysics and photochemistry of pterins in aqueous solution.," Acc. Chem. Res., vol. 39, no. 6, pp. 395-402, Jun. 2006.

[3] S. B. Jimenez Pulido, M. Sieger, A. Kno, O. Heilmann, M. Wanner, B. Schwederski, J. Fiedler, M. N. Moreno Carretero, and W. Kaim, "Rhenium ( I ) coordinated lumazine and pterin derivatives : structure and spectroelectrochemistry of reversibly reducible ( 6-ATML) Re ( CO ) $3 \mathrm{Cl}$ ( 6ATML = 6-acetyl-1 , 3 , 7-trimethyllumazine )," Inorganica Chim. Acta, vol. 325, pp. 65-72, 2001.

[4] A. Odani, O. Yamauchi, H. Masuda, K. Inukai, and O. Yamamuchi, "PteridineContaining Ternary and Quaternary Complexes as Models for MetalloenzymePterin Cofactor-Substrate Association. Structure of Ternary Copper( 11)-2,2'Bipyridine-Lumazine Complex and Successful Equilibrium Study of a Quaternary Copper( 11) System," J. Am. Chem. SOC, vol. 114, no. 114, pp. 6294-6300, 1992.

[5] M. Mitsumi, J. Toyoda, and K. Nakasuji, "Metal-pteridine complexes having three-dimensional hydrogen-bonded networks," Inorg. Chem., vol. 34, pp. 3367-3370, 1995.

[6] S. Miyazaki, T. Kojima, T. Sakamoto, T. Matsumoto, K. Ohkubo, and S. Fukuzumi, "Proton-coupled electron transfer in ruthenium(II)-pterin complexes: formation of ruthenium-coordinated pterin radicals and their electronic structures.," Inorg. Chem., vol. 47, no. 1, pp. 333-43, Jan. 2008.

[7] S. Burgmayer, E. Stiefel, C. It, W. Oh, and B. Ni, "Transition-Metal Pteridine Complexes. Preparation and Characterization" Am. Chem. Soc., vol. 27, no. 22, pp. 4059-4065, 1988.

[8] J. Perkinson, S. Brodie, K. Yoon, K. Mosny, P. J. Carroll, T. V. Morgan, and S. J. Nieter, "Preparations and Properties of Transition-Metal Pterin Complexes . Models for the," Inorg. Chem., vol. 30, no. 4, pp. 719-727, 1991.

[9] Y. Funahashi, Y. Hara, H. Masuda, and O. Yamauchi, "Structures and Spectral Properties of Iron ( II ), Cobalt ( II ), and Copper ( II ) Complexes Involving 2- ( Dimethylamino ) -4 ( 3 H ) -pteridinone," Inorg. Chem., vol. 4, no. li, pp. 38693875, 1997. 
[10] P. Basu and S. J. N. Burgmayer, "Pterin chemistry and its relationship to the molybdenum cofactor.," Coord. Chem. Rev., vol. 255, no. 9-10, pp. 1016-1038, May 2011.

[11] O. Heilmann, F. M. Hornung, J. Fiedler, and W. Kaim, "Organometallic iridium(III) and rhenium(I) complexes with lumazine, alloxazine and pterin derivatives," $J$. Organomet. Chem., vol. 589, no. 1, pp. 2-10, Oct. 1999.

[12] W. Kaim, B. Schwederski, O. Heilmann, and F. M. Hornung, "Coordination compounds of pteridine, alloxazine and flavin ligands: structures and properties," Coord. Chem. Rev., vol. 182, no. 1, pp. 323-342, Feb. 1999.

[13] C. Bessenbacher, C. Vogler, and W. Kaim, "Stabilization of biochemically interesting intermediates by metal coordination. 6 . Charge transfer in complexes of 1, 3-dimethyllumazine with low-valent metals," Inorg. Chem., vol. 3, no. Table V, pp. 4645-4648, 1989.

[14] A. Crispini, D. Pucci, A. Bellusci, G. Barberio, M. La Deda, A. Cataldi, and M. Ghedini, "Complexes : Synthesis and Characterization of Derivatives 2005," Cryst. Growth Des., vol. 5, no. 4, pp. 1597-1601, 2005.

[15] W. Henderson, B. Nickleson, and L. McCaffrey, "Applications of electrospray mass spectrometry inorganometallic chemistry," Polyhedron, vol. 17, no. 25, pp. 4291-4313, 1998.

[16] J. Traeger, "Electrospray mass spectrometry of organometallic compounds," Int. J. Mass Spectrom., vol. 200, no. June, pp. 387-401, 2000.

[17] G. Petroselli, M. K. Mandal, L. C. Chen, G. T. Ruiz, E. Wolcan, K. Hiraoka, H. Nonami, and R. Erra-Balsells, "Mass spectrometry of rhenium complexes: a comparative study by using LDI-MS, MALDI-MS, PESI-MS and ESI-MS.," J. Mass Spectrom., vol. 47, no. 3, pp. 313-21, Mar. 2012.

[18] N. Lazarova, S. James, J. Babich, and J. Zubieta, "A convenient synthesis, chemical characterization and reactivity of $[\operatorname{Re}(\mathrm{CO}) 3(\mathrm{H} 2 \mathrm{O}) 3] \mathrm{Br}$ : the crystal and molecular structure of $[\operatorname{Re}(\mathrm{CO}) 3(\mathrm{CH} 3 \mathrm{CN}) 2 \mathrm{Br}]$," Inorg. Chem. Commun., vol. 7, no. 9, pp. 1023-1026, Sep. 2004.

[19] R. S. Herrick, C. J. Ziegler, J. Lopez, N. V. Barone, A. Gambella, and C. Masi, "Complexes formed from reactions of $\operatorname{Re}(\mathrm{CO}) 3(\mathrm{H} 2 \mathrm{O}) 3+$ with amines used for biological buffering," J. Organomet. Chem., vol. 700, pp. 160-165, Mar. 2012.

[20] B. R. Franklin, R. S. Herrick, C. J. Ziegler, C. Anıl, N. Barone, and L. R. Condon, "Reactions of the Re ( CO ) 3 ( H 2 O ) 3 + Synthon with Monodentate Ligands under Aqueous Conditions," vol. 47, no. 13, pp. 5902-5909, 2008.

[21] H. He, M. Lipowska, X. Xu, A. T. Taylor, M. Carlone, and L. G. Marzilli, “Re(CO)(3) complexes synthesized via an improved preparation of aqueous fac- 
$[\operatorname{Re}(\mathrm{CO})(3)(\mathrm{H}(2) \mathrm{O})(3)](+)$ as an aid in assessing $(99 \mathrm{~m}) \mathrm{Tc}$ imaging agents.

Structural characterization and solution behavior of complexes with thioetherbearing amino acids as trident," Inorg. Chem., vol. 44, no. 15, pp. 5437-46, Jul. 2005.

[22] R. Schibli, R. Schwarzbach, R. Alberto, K. Ortner, H. Schmalle, C. Dumas, A. Egli, and P. A. Schubiger, "Steps toward high specific activity labeling of biomolecules for therapeutic application: preparation of precursor $[(188) \operatorname{Re}(\mathrm{H}(2) \mathrm{O})(3)(\mathrm{CO})(3)](+)$ and synthesis of tailor-made bifunctional ligand systems.," Bioconjug. Chem., vol. 13, no. 4, pp. 750-6, 2002.

[23] U. N. Fagioli, F. S. García Einschlag, C. J. Cobos, G. T. Ruiz, M. R. Féliz, and E. Wolcan, "On the mechanism of $\operatorname{Re}(\mathrm{I})$-carboxylate bond cleavage by perchloric acid: a kinetic and spectroscopic study.," J. Phys. Chem. A, vol. 115, no. 40, pp. 10979-87, Oct. 2011.

[24] M. V Werrett, D. Chartrand, J. D. Gale, G. S. Hanan, J. G. MacLellan, M. Massi, S. Muzzioli, P. Raiteri, B. W. Skelton, M. Silberstein, and S. Stagni, "Synthesis, structural, and photophysical investigation of diimine triscarbonyl Re(I) tetrazolato complexes.," Inorg. Chem., vol. 50, no. 4, pp. 1229-41, Feb. 2011.

[25] D. K. Nayak, K. K. Halder, R. Baishya, T. Sen, P. Mitra, and M. C. Debnath, "Tricarbonyltechnetium(I) and tricarbonylrhenium(I) complexes of amino acids: crystal and molecular structure of a novel cyclic dimeric $\operatorname{Re}(\mathrm{CO}) 3$-amino acid complex comprised of the OON donor atom set of the tridentate ligand.," Dalton Trans., vol. 42, no. 37, pp. 13565-75, Oct. 2013.

[26] G. Müller and W. Philipsborn, "13C-NMR. Spectra of Pteridines," Helv. Chim. Acta, vol. 56, no. 273,1973

[27] M. F. Wyatt, B. K. Stein, and A. G. Brenton, "Characterization of Various Analytes Using Matrix-Assisted Laser Desorption / Ionization Time-of-Flight Mass Spectrometry and enylidene ] malononitrile Matrix," vol. 78, no. 1, pp. 199-206, 2006.

[28] C. K. Johnson, "ORTEP-II. A Fortran Thermal-Ellipsoid Plot Program." Oak Ridge National Laboratory, Tennessee, USA, USA, p. Report ORNL-5318, 1976.

[29] F. S. García Einschlag, "Kinesim, multipurpose program for kinetics and photochemistry," Copyright No. 395814. 2005.

[30] C. Ruckebusch, S. Aloïse, L. Blanchet, J. P. Huvenne, and G. Buntinx, "Reliable multivariate curve resolution of femtosecond transient absorption spectra," Chemom. Intell. Lab. Syst., vol. 91, no. 1, pp. 17-27, Mar. 2008.

[31] R. Tauler, "Multivariate curve resolution applied to second order data," Chemom. Intell. Lab. Syst., vol. 30, pp. 133-146, 1995. 
[32] I. Sartorius, "Photo-CIDNP Investigation of the Deprotonation of Aminium Cations," no. 17, pp. 11123-11133, 1993.

[33] A. G. Frenich, D. Pic, J. L. Mart, and M. Mart, "Resolution ( and quantitation ) of mixtures with overlapped spectra by orthogonal projection approach and alternating least squares," vol. 449, pp. 143-155, 2001.

[34] P. J. Gemperline and E. Cash, "Advantages of soft versus hard constraints in selfmodeling curve resolution problems. Alternating least squares with penalty functions.," Anal. Chem., vol. 75, no. 16, pp. 4236-43, 2003.

[35] W. Pfleiderer, E. LIEDE, P. H. M. Lohmant, and M. Rukwied, "On the structure of the pterin," Chem. Ber., vol. 93, no. 9, pp. 2015-2024, 1960.

[36] R. De Wit, "Determination of proton dissociation constants by ion-exchange high-performance liquid chromatography," Anal. Biochem., vol. 123, pp. 285290, 1982.

[37] E. Wolcan, "On the origins of the absorption spectroscopy of pterin and $\mathrm{Re}(\mathrm{CO}) 3$ (pterin)(H2O) aqueous solutions. A combined theoretical and experimental study.," Spectrochim. Acta. A. Mol. Biomol. Spectrosc., vol. 129, pp. 173-83, Aug. 2014.

[38] B. Salignac, P. V Grundler, S. Cayemittes, U. Frey, R. Scopelliti, A. E. Merbach, R. Hedinger, K. Hegetschweiler, R. Alberto, U. Prinz, G. Raabe, U. Kölle, and S. Hall, "Reactivity of the organometallic fac-[(CO)3Rel(H2O)3]+ aquaion. Kinetic and thermodynamic properties of $\mathrm{H} 2 \mathrm{O}$ substitution.," Inorg. Chem., vol. 42, no. 11, pp. 3516-26, Jun. 2003.

[39] I. Kaljurand, A. Ku, and L. Soova, "Extension of the Self-Consistent Spectrophotometric Basicity Scale in Acetonitrile to a Full Span of $28 \mathrm{p} \mathrm{K} \mathrm{a}$ Units : Unification of Different Basicity Scales," J. Org. Chem., vol. 70, no. 4, pp. 1019-1028, 2005.

[40] I. Kolthoff, "Acid-Base Equilibria in Acetonitrile. Spectrophotometric and Conductometric Determination of the Dissociation of Various Acids," J. Am. Chem. Soc., vol. 83, no. 3, pp. 3927-3935, 1961.

[41] R. Alberto, R. Schibli, and R. Waibel, "Basic aqueous chemistry of +(M= Re, Tc) directed towards radiopharmaceutical application," Coord. Chem. ..., vol. 192, pp. 901-919, 1999.

[42] B. Higgins, B. a DeGraff, and J. N. Demas, "Luminescent transition metal complexes as sensors: structural effects on pH response.," Inorg. Chem., vol. 44, no. 19, pp. 6662-9, Sep. 2005. 


\section{Capítulo IV}

Estudio de las propiedades

fotofísicas y fotoquímicas de

complejos tricarbonílicos de $\operatorname{Re}(\mathrm{I})$ 


\section{Introducción}

Los complejos tricarbonílicos de $\operatorname{Re}(I)$ coordinados con ligandos orgánicos pertenecen a una familia con un extenso e interesante repertorio de características fotofísicas y fotoquímicas. Es por esto que se los ha empleado ampliamente tanto en investigación como en aplicaciones médicas e industriales. En el capítulo anterior se presentó la síntesis y caracterización de un nuevo complejo fac- $\operatorname{Re}^{\prime}(\mathrm{CO})_{3}($ pterina $)\left(\mathrm{H}_{2} \mathrm{O}\right)$. Sus interesantes características, tales como su marcada solubilidad en agua y la presencia de dos equilibrios de protonación abren un amplio campo de potenciales aplicaciones, tales como su utilización como biosensores, y como agentes fotosensiblilizadores en terapia fotodinámica. En función de esto surgieron muchas interrogantes sobre la naturaleza de sus estados excitados. Es destacable que no existan aún trabajos que den cuenta de las propiedades fotofísicas de complejos de Renio con pterina. Buscando aportar evidencia en este campo intentamos resolver varias interrogantes. En particular, conocer como ocurre el poblamiento los estados excitados, en distintos solventes y en distintas condiciones de acidez. Así también, atrajo nuestro interés el esclarecer las distintas vías de desexcitación de estos estados excitados. Es por esto, que entre los objetivos que nos planteamos para desarrollar este trabajo, destaca el de encontrar evidencia sobre las características de las transiciones electrónicas que ocurren en el complejo luego de la absorción de un fotón. En este sentido se realizaron diversas medidas fotofísicas y fotoquímicas, las cuales se presentan en este capítulo. Se realizaron medidas de absorción en distintos solventes. Éstas, junto con los resultados de los cálculos computacionales, nos permiten establecer la naturaleza de las transiciones que pueblan el estado excitado. Las medidas de luminiscencia y optoacústica nos permiten avanzar sobre el esclarecimiento de las vías de desexcitación y la naturaleza de los estados excitados de menor energía. Las propiedades del estado excitado se estudiaron con la técnica de láser flash fotólisis (LFF), cuyos resultados fueron complementados con los resultados obtenidos utilizando la técnica de radiólisis de pulso (PR).

La producción fotoinducida de oxígeno singlete $\left({ }^{1} \mathrm{O}_{2}\right)$ es un área de interés común a muchas disciplinas. La utilidad de esta especie excitada de oxígeno se extiende desde 
la terapia fotodinámica a la degradación de contaminantes. En particular la producción de ${ }^{1} \mathrm{O}_{2}$ ocurre a partir de la interacción del triplete de una molécula excitada con estado triplete del oxígeno. La coordinación, de los ligandos orgánicos, por el renio modifica la características de los estados tripletes del ligando y da lugar a nuevos tripletes del tipo MLCT. Sin embargo, la capacidad de estos estados excitados para generar oxígeno singlete en complejos de $\operatorname{Re}(\mathrm{I})$ ha sido poco explorada. Buscando avanzar en este sentido, se realizaron estudios sobre otros tres complejos

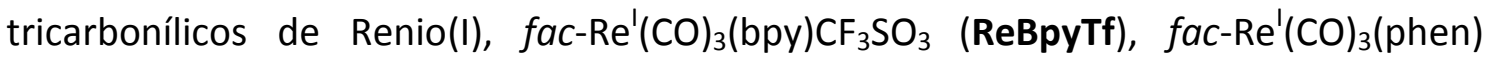
$\mathrm{CF}_{3} \mathrm{SO}_{3}$ (RePhen) y $\left.[\text { fac-Re'(CO) })_{3}(\mathrm{bpy})(\mathrm{py})\right] \mathrm{CF}_{3} \mathrm{SO}_{3}$ (ReBpyPy) (Figura 1), además del RePtr. Estos complejos, ReBpyTf, RePhen y, ReBpyPy, pertenecen a los muchos compuestos de Renio sintetizados y caracterizados en el grupo [1], [2].

El instrumental utilizado para desarrollar estas técnicas y sus respectivos fundamentos se encuentran detallados en el capítulo I.
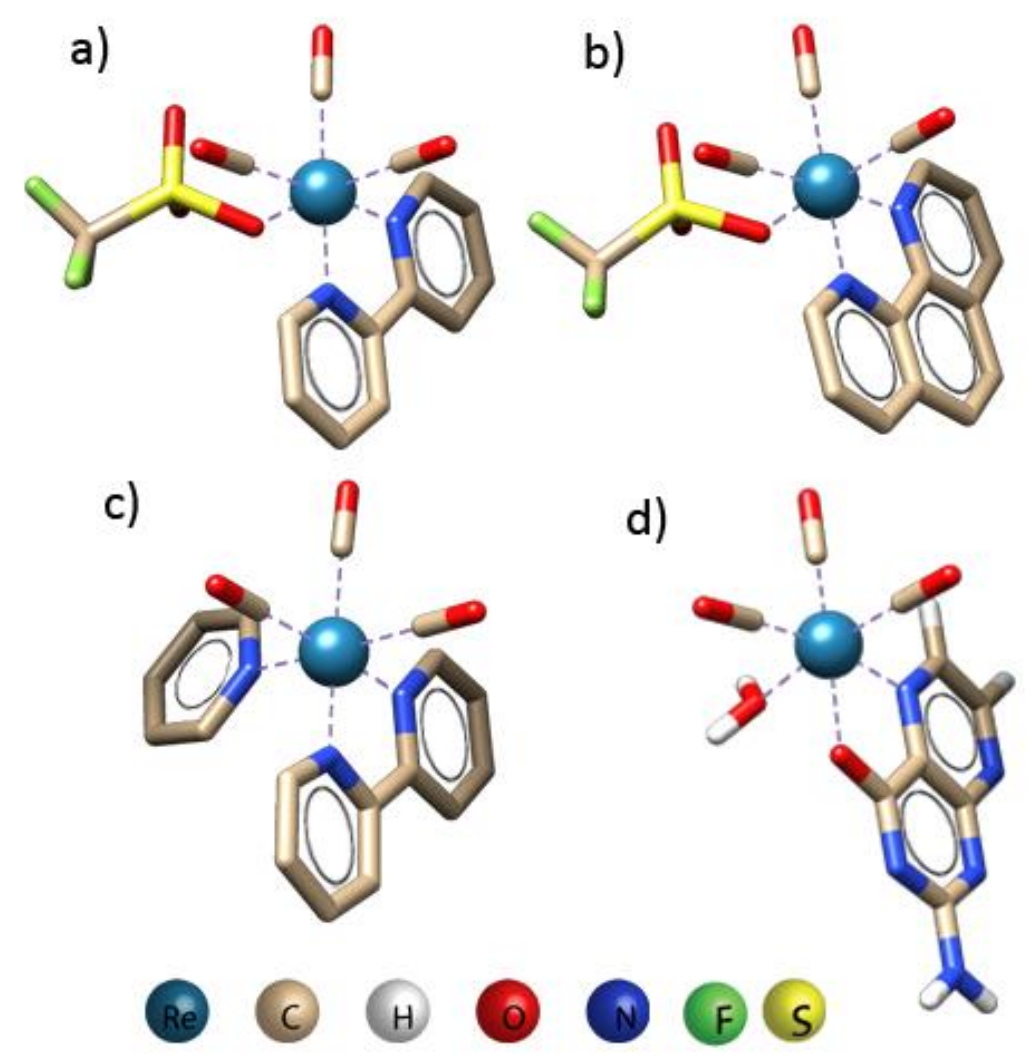

\section{Figura 1}

Geometría optimizada de los complejos estudiados.

a) ReBpyTf, b) RePhenTf, c) ReBpyPy, d) RePtr. 


\section{Índice}

\section{Capítulo IV \\ Estudio de las propiedades fotofísicas y fotoquímicas de complejos tricarbonílicos de $\operatorname{Re}(I)$}

Introducción 141

Índice 143

1. Fotofísica del complejo $\operatorname{Re}^{\prime}(\mathrm{CO})_{3}($ pterina $)\left(\mathrm{H}_{2} \mathrm{O}\right)$ 145

1.1. Espectroscopíade absorción UV-Visible 145

1.2. Emisión luminiscente del complejo RePtr 148

1.2.1. Espectros de emisión luminiscente en estado estacionario 148

1.2.2. Calculo de los rendimientos cuánticos de emisión 153

1.2.3. Emisión resuelta en el tiempo 154

1.2.4. Constante bimolecular de desactivación por Oxígeno. 156

1.3. Rendimiento cuántico de generación de Oxígeno singlete. 158

1.4. Medidas de espectroscopia optoacústica LIOAS. 158

2. Fotofísica de los complejos ReBpyTf, RePhenTf y ReBpyPy. 161

2.1. Espectroscopíade absorción UV-Visible 161

2.2. Emisión luminiscente en estado estacionario 162

2.3. Experimentos LIOAS. 164

2.4. Rendimiento cuántico de generación de Oxígeno singlete. 164

2.5. Balance de energía 165

2.6. Evaluación de las vías de generación de ${ }^{1} \mathrm{O}_{2}$ 166

3. Estudios de reacciones térmicas y fotoquímicas del complejo fac$\operatorname{Re}^{\prime}(\mathrm{CO})_{3}$ (pterina) $\left(\mathrm{H}_{2} \mathrm{O}\right)$

3.1. Espectroscopia LFF 172 
3.1.1. Transientes de absorción.............................................................. 172

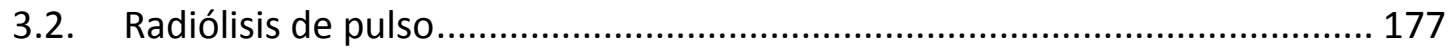

3.2.1. Reacciones con especies reductoras .............................................. 177

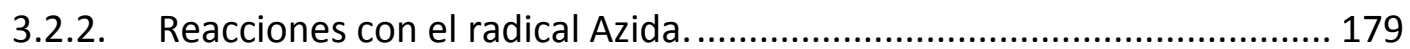

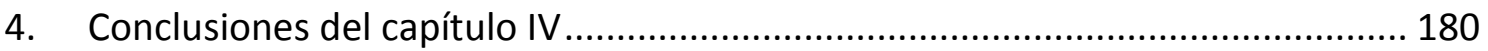

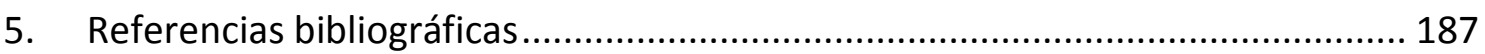




\section{Fotofísica del complejo $\operatorname{Re}^{\prime}(\mathrm{CO})_{3}($ pterina $)\left(\mathrm{H}_{2} \mathrm{O}\right)$}

\subsection{Espectroscopíade absorción UV-Visible}

Se realizaron medidas de absorción de luz en el rango de los 220 a 600 nm, utilizando soluciones de concentración conocida y adecuada para cumplir con la linealidad de la ley de Lambert-Beer en todo el rango de medición. Se obtuvieron los espectros UVvisible graficando los valores del coeficiente de absortividad molar $(\varepsilon)$ en función de la longitud de onda.

Las medidas de absorción de las soluciones se realizaron en los siguientes solventes: Acetonitrilo (ACN), Etanol (EtOH), Acetona y Agua. La tabla 1 muestra la constante dieléctrica de los solventes utilizados y su clasificación.

\begin{tabular}{lc}
\hline \hline \multicolumn{3}{c}{ Tabla 1. } \\
Tabla de constante dieléctrica de solventes a \\
$20^{\circ} \mathrm{C}[3][4]$ \\
\hline \hline solvente & Constante dieléctrica \\
\hline \hline & \\
Acetona & 21 \\
Acetonitrilo & 37 \\
& \\
Etanol & Polares próticos apróticos \\
Agua & 24 \\
\hline \hline
\end{tabular}

Se preparó una solución acuosa del complejo RePtr. Esta solución se dividió en tres fracciones a las que se le ajustó la acidez a tres valores de pH, 3; 6 y 10 utilizando acido perclórico e hidróxido de sodio según correspondiera. Se registraron los espectros de absorción de las soluciones. En la figura 2 se muestran los espectros obtenidos. En la figura 3 se muestran los espectros obtenidos utilizando ACN como solvente, en el mismo grafico se muestra el espectro de una solución del complejo RePtr en ACN a la que se agregó $\mathrm{HClO}_{4}$ hasta una concentración $10^{-4} \mathrm{M}$. La descripción y análisis de estos espectros se realizó en el capítulo III y aquí solo se presentan para facilitar la posterior discusión. 


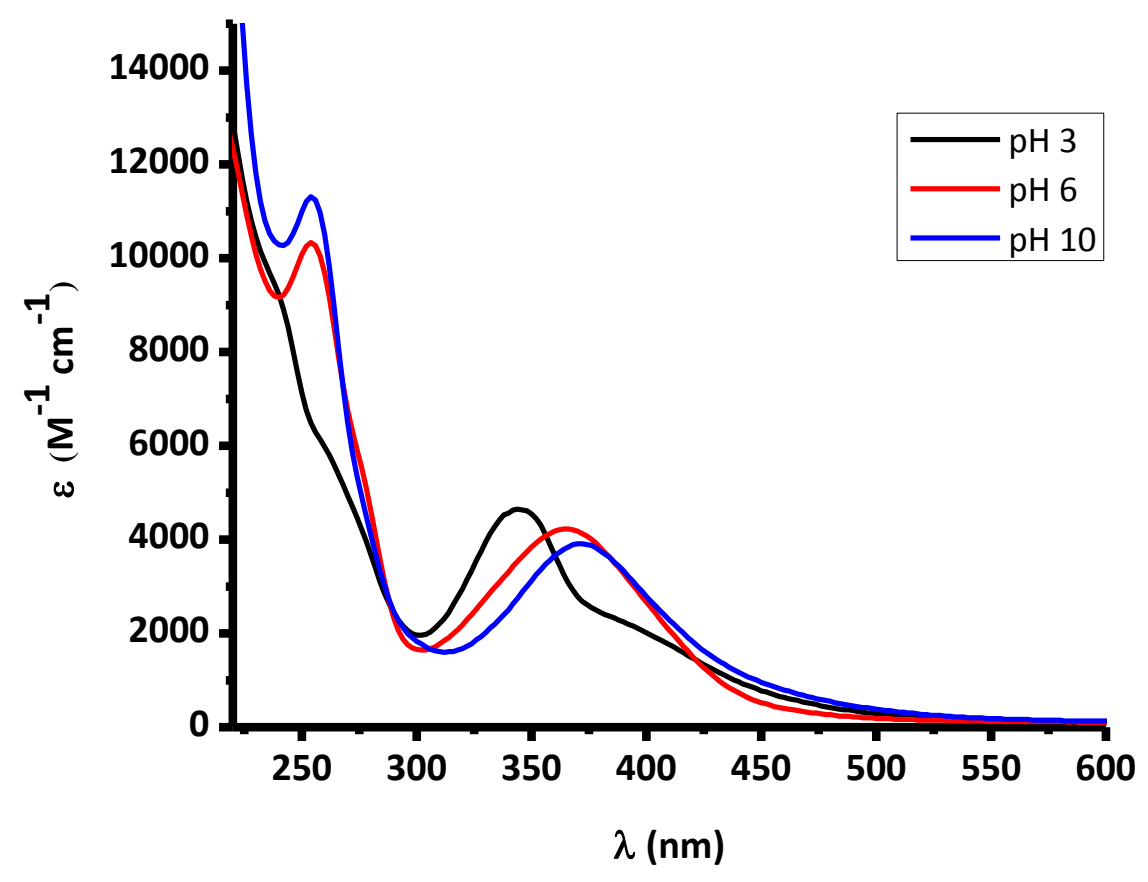

Figura 2.

Espectros de absorción UV-Vis de soluciones acuosas del complejo RePtr a tres condiciones de $\mathrm{pH}$ que se indican en la Figura.

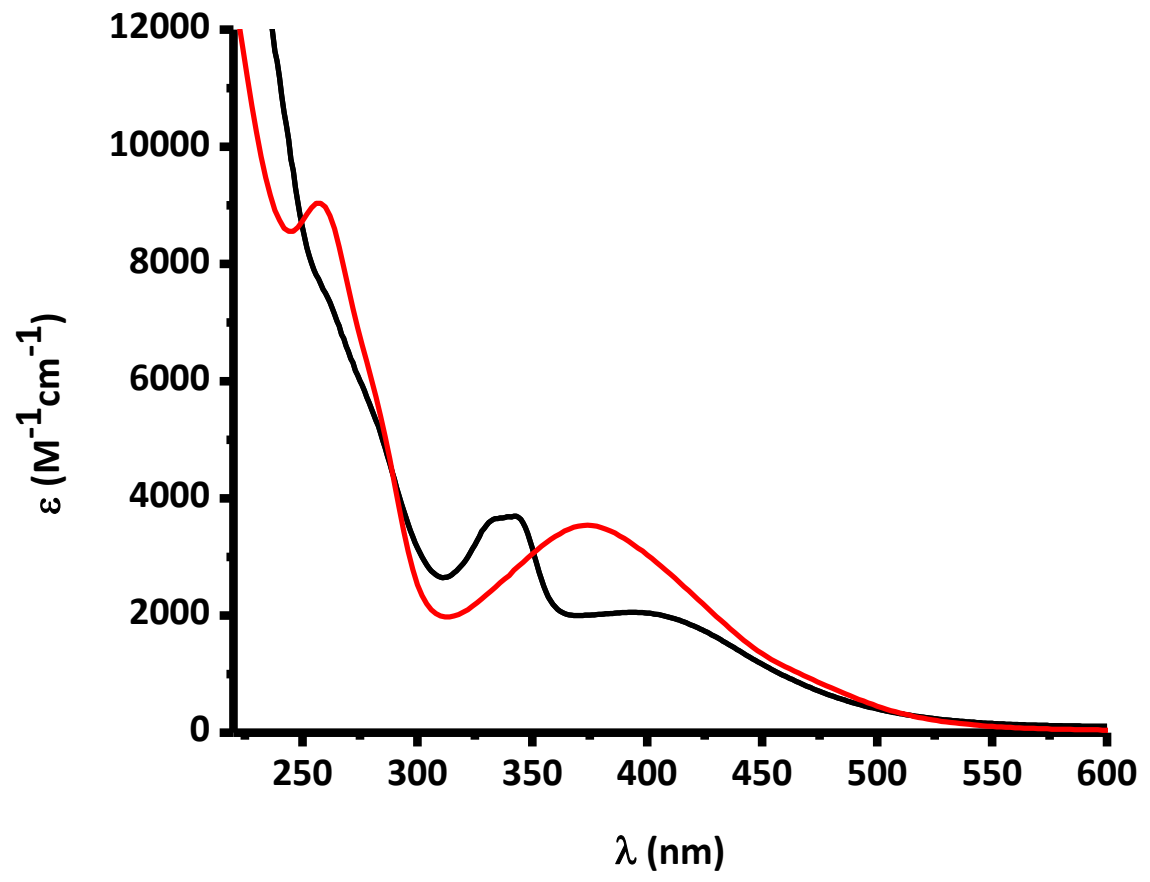

Figura 3

Espectros de absorción UV-Vis de soluciones del complejo RePtr - en $\mathrm{ACN}+\mathrm{HClO}_{4}$. -en ACN 
El espectro de absorción del complejo RePtr medido en EtOH (figura 4) presenta una banda ancha centrada en $376 \mathrm{~nm}$ y una superposición de bandas entre 220 y $300 \mathrm{~nm}$ entre las que se diferencia una con máximo en $256 \mathrm{~nm}$.

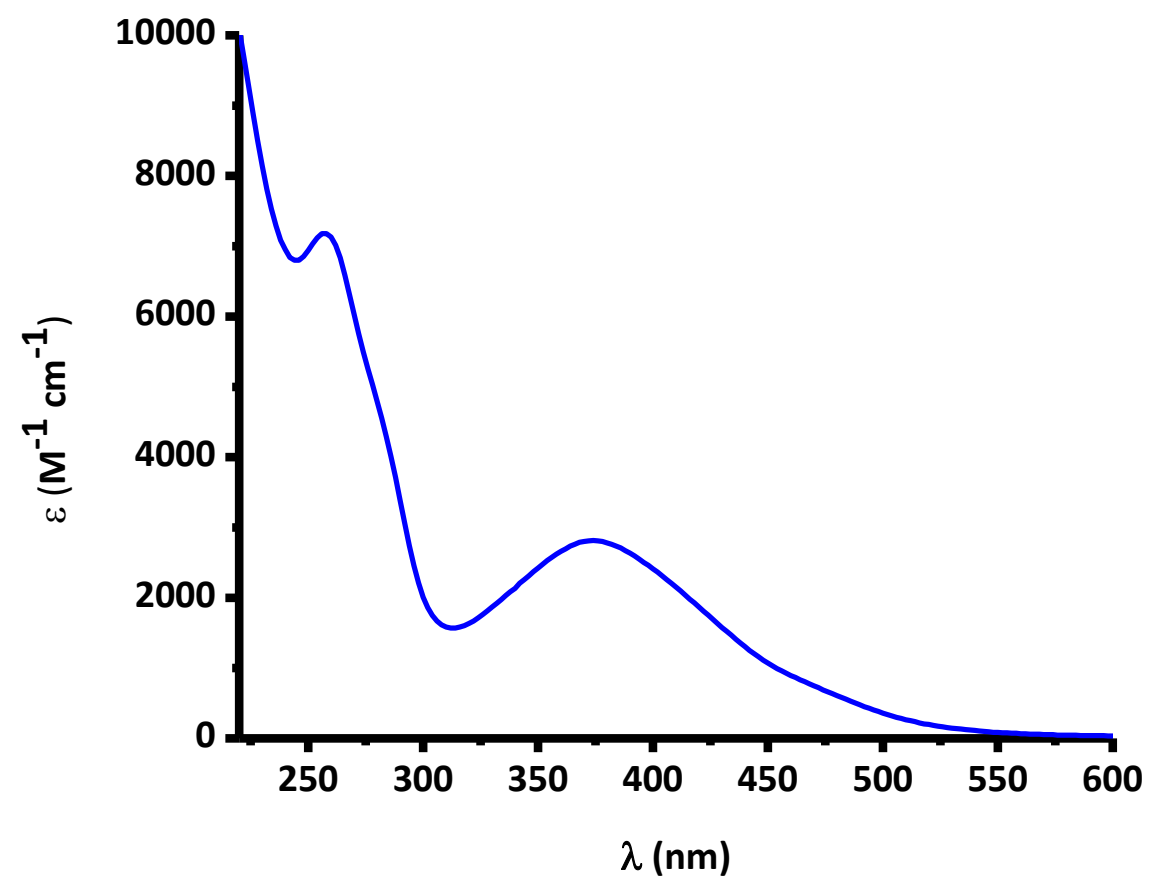

Figura 4

Espectros de absorción UV-Vis de una solución del complejo RePtr en EtOH

El espectro de absorción del complejo RePtr en acetona (figura 5) muestra dos bandas, dentro de la ventana que permite el espectro de absorción del solvente. Una banda ancha a baja energía centrada en $401 \mathrm{~nm}$ y otra más angosta, parcialmente superpuesta con la primera, centrada en $346 \mathrm{~nm}$. La forma de este espectro presenta un aspecto similar a la forma del espectro del complejo en agua a $\mathrm{pH}$ acido $\left(\lambda_{\max }=344\right.$ y $400 \mathrm{~nm})$. 


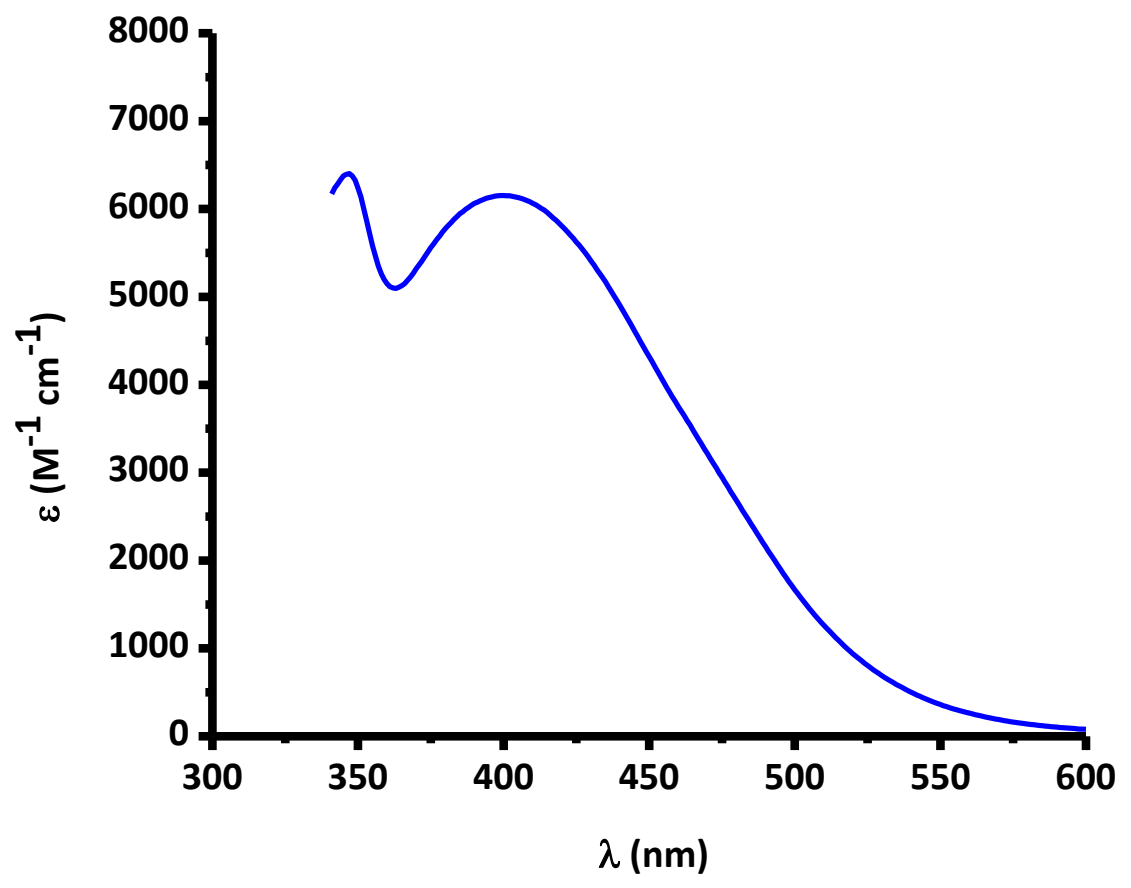

Figura 5

Espectros de absorción UV-Vis de una solución del complejo RePtr en acetona.

Analizando las bandas de absorción de más alta energía registradas en distintos solventes, puede apreciarse que no sufren modificación en la posición del máximo $(\approx 255 \mathrm{~nm})$. El complejo presenta equilibrios acido base en agua y en ACN que han sido estudiados, sin embargo no se tiene información de este equilibrio en otros solventes. Las distintas especies acido-base presentan marcadas diferencias en la posición de la banda de menor energía. De este modo no es posible establecer el efecto del medio sobre la posición de esta banda.

\subsection{Emisión luminiscente del complejo RePtr}

\subsubsection{Espectros de emisión luminiscente en estado estacionario}

Se registraron espectros de emisión luminiscente en estado estacionario de soluciones diluidas de complejo RePtr. Las medidas fueron realizadas tanto en soluciones deaireadas con $\mathrm{N}_{2}$ como sin deairear. Los fundamentos de la técnica, la metodología y el instrumental se describen en el capítulo I. 


\section{Capitulo IV}

\subsubsection{Luminiscencia en medio acuoso}

Se registraron los espectros de emisión de soluciones del complejo RePtr en medio acuoso a pH 3, 6 y 10. Los valores de $\mathrm{pH}$ de las soluciones se eligieron de modo de tener una especie predominante en una proporción mayor al 95\% con respecto a las otras, de acuerdo a la distribución de especies presentada en el capítulo III. El espectro de emisión del ligando pterina se midió en medio acuoso a pH 5,5 para utilizarlo como referencia. La acidez se ajustó agregando $\mathrm{NaOH}$ o $\mathrm{HClO}_{4}$.

Los espectros de emisión obtenidos en solución acuosa no mostraron cambios en la intensidad ni corrimientos del máximo cuando la solución fue deaireada con $\mathrm{N}_{2}$, comparados con el espectro sin deairear. En la figura 6 a se muestran los espectros obtenidos en las tres condiciones de acidez, mientras que en la figura $\mathbf{6}$ b se muestra el espectro correspondiente al ligando libre. La luz de excitación fue de longitud de onda $\lambda_{\mathrm{exc}}=350 \mathrm{~nm}$.

El espectro de emisión de la solución acuosa del complejo RePtr a pH 3 muestra una única banda con su máximo centrado en $442 \mathrm{~nm}$. El espectro obtenido a $\mathrm{pH} 6$ posee una banda con mayor intensidad centrada a la misma longitud de onda. El espectro de la solución del complejo registrado a pH 10, muestra una banda centrada en $453 \mathrm{~nm}$ con mayor intensidad que la banda correspondiente el espectro medido en medio acido.

El espectro de emisión obtenido para la solución del ligando a pH 5,5 muestra una única banda centrada en $442 \mathrm{~nm}$. Este resultado es coincidente con el espectro publicado [5]. 

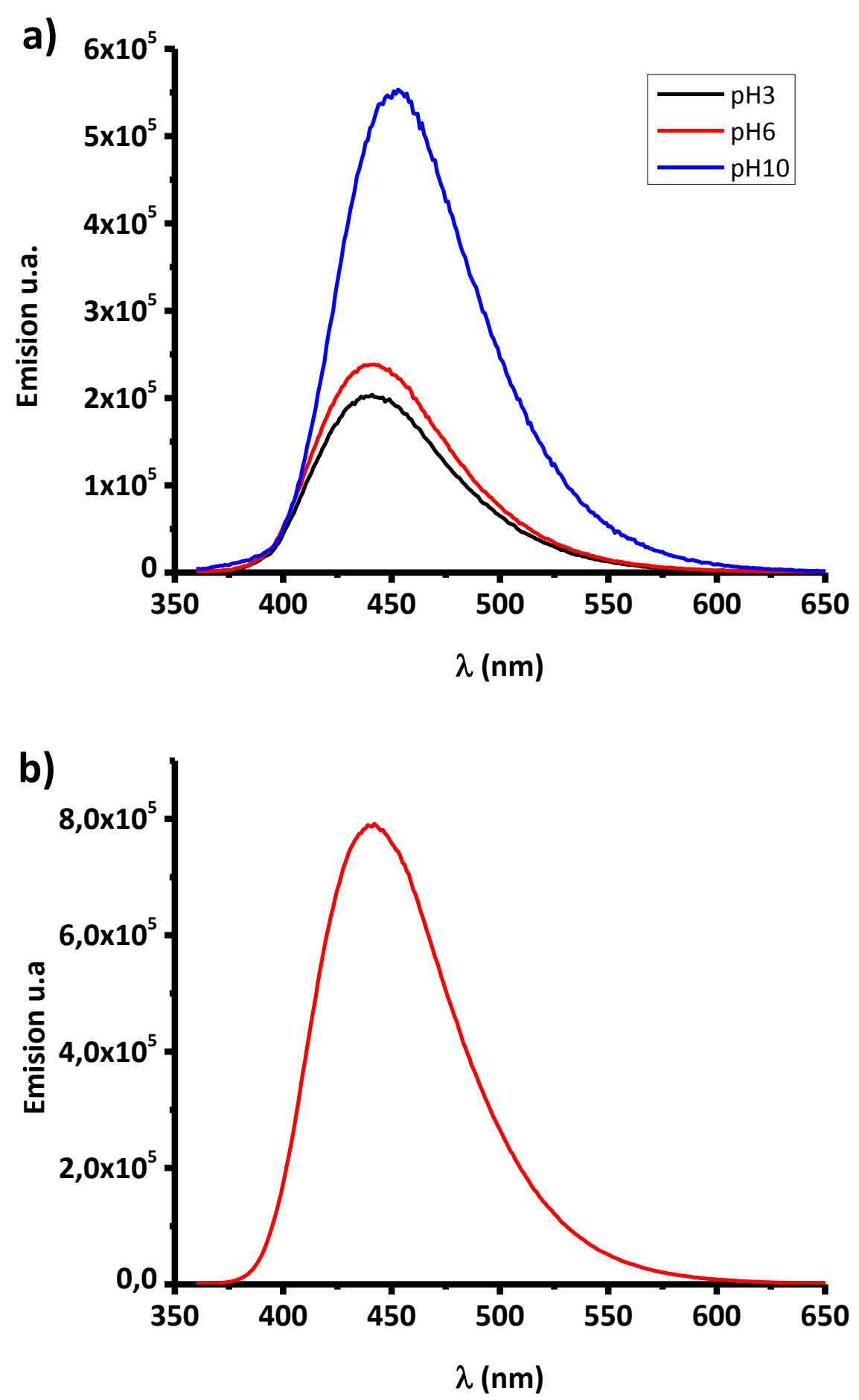

\section{Figura 6}

Espectros de emisión luminiscente de soluciones acuosas del complejo RePtr excitando con luz de $350 \mathrm{~nm}$.

a) solución acuosa a pH 3, 6 y 10, sin deairear.

b) una solución acuosa a pH 5,5 del ligando pterina en atmosfera saturada en $\mathrm{N}_{2}$. 


\subsubsection{Luminiscencia en ACN}

Las medidas de emisión luminiscentes de una solución en ACN del complejo RePtr se realizaron en soluciones deaireadas por burbujeo de $\mathrm{N}_{2}$ y en soluciones sin deairear. Las longitudes de onda elegidas para la excitación fueron $\lambda_{\mathrm{exc}}=350$ y $400 \mathrm{~nm}$. En la figura 7 se presentan los espectros obtenidos cuando se excitó al complejo con luz de $350 \mathrm{~nm}$.

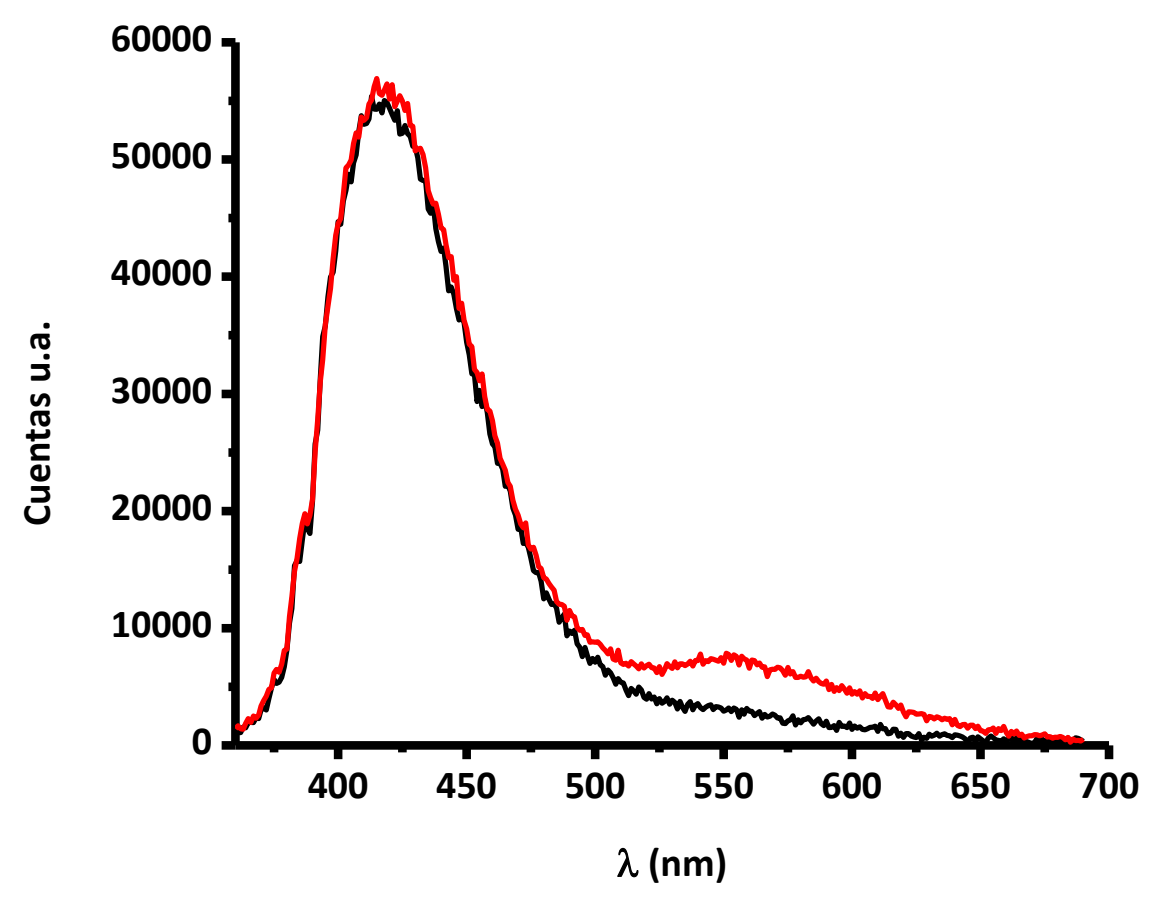

Figura 7

Espectros de emisión luminiscente de soluciones en ACN del complejo $\operatorname{RePtr}(\lambda=350$ $\mathrm{nm})$. - Solución en atmosfera saturada en $\mathrm{N}_{2}$ - Solución sin deairear.

El espectro de emisión del complejo RePtr en solución de ACN sin deairear, presenta una banda ancha bien definida centrada en los $416 \mathrm{~nm}$ con una larga cola que se extiende hasta los $650 \mathrm{~nm}$. Cuando se elimina la presencia de oxígeno de la solución por burbujeo con $\mathrm{N}_{2}$, la banda centrada en $416 \mathrm{~nm}$ permanece prácticamente inalterada, sin embargo, aparece otra banda ancha a menor energía, centrada en 555 $\mathrm{nm}$, con una intensidad seis veces menor que la banda centrada de mayor energía. La presencia de la banda centrada en $555 \mathrm{~nm}$ que se registra al retirar el oxígeno disuelto en la solución es un indicativo claro de la desactivación por oxígeno molecular. 
Adicionalmente se registraron los espectros de emisión en presencia y ausencia de oxígeno excitando la muestra con luz de $\lambda_{\text {exc }}=400 \mathrm{~nm}$. Los espectros correspondientes se muestran en la figura 8.

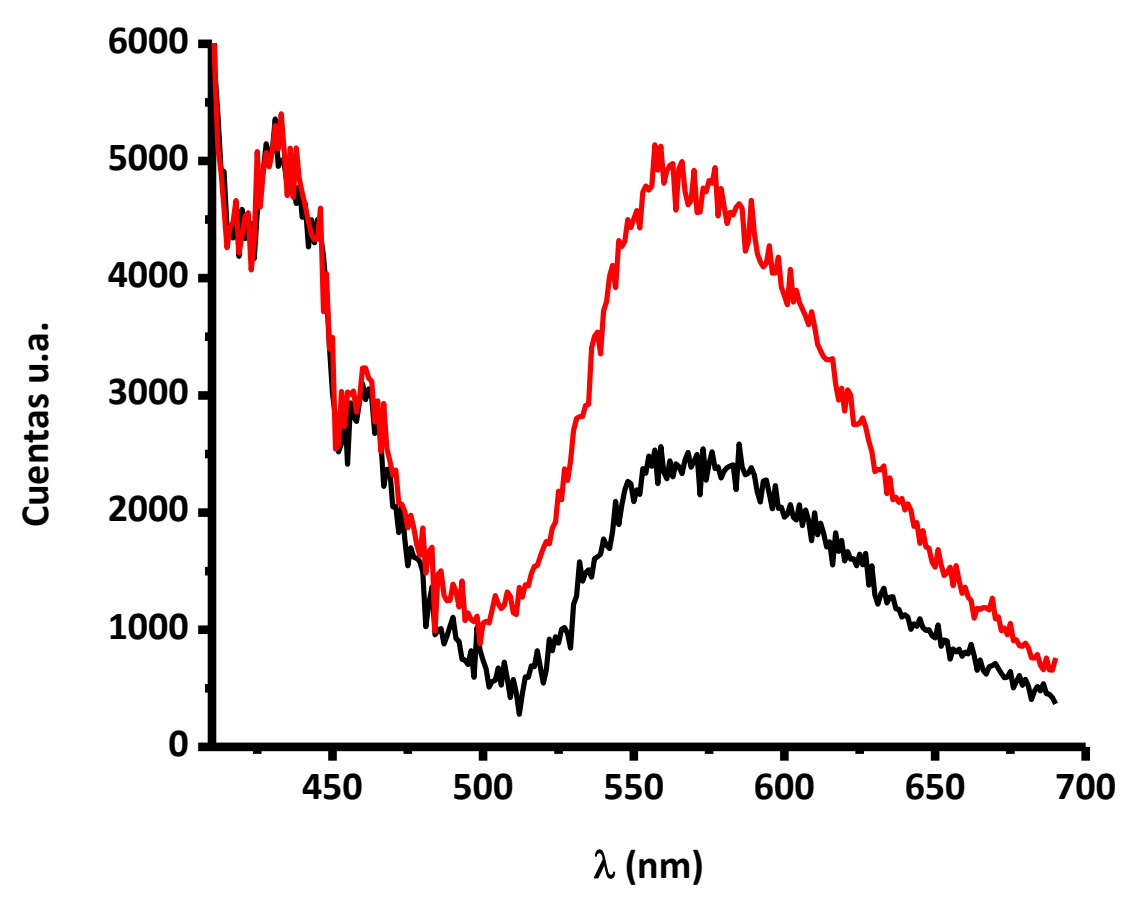

Figura 8

Espectros de emisión luminiscente de soluciones en ACN del complejo $\operatorname{RePtr}\left(\lambda_{\text {ex }}=400\right.$ $\mathrm{nm})$. - Solución en atmosfera saturada en $\mathrm{N}_{2}-$ Solución sin deairear.

El espectro obtenido cuando se irradia la muestra con luz de $400 \mathrm{~nm}$ y en solución saturada en aire muestra el mismo máximo que el observado cuando se excita a 350 $\mathrm{nm}(555 \mathrm{~nm})$. Además se observa la última porción de la banda centrada en $416 \mathrm{~nm}$ aunque ahora con intensidad similar a la banda de menor energía. Cuando la solución es deaireada con $\mathrm{N}_{2}$ se percibe un aumento en la banda centrada en $555 \mathrm{~nm}$.

\subsubsection{Emisión a $77 \mathrm{~K}$}

Se realizaron medidas de emisión del complejo RePtr utilizando como solvente $s$ una mezcla Metanol/Etanol 4:1. Se registró el espectro de esta solución, luego se enfrió a 
77K y se midió su espectro nuevamente. En la figura 9 se presentan los espectros obtenidos excitando con luz de $350 \mathrm{~nm}$. La emisión a $298 \mathrm{~K}$ presenta un máximo a 435 nm. Al enfriar a 77K se observa una banda en la misma posición con menor intensidad. Además aparece una banda ancha e intensa centrada en $566 \mathrm{~nm}$.

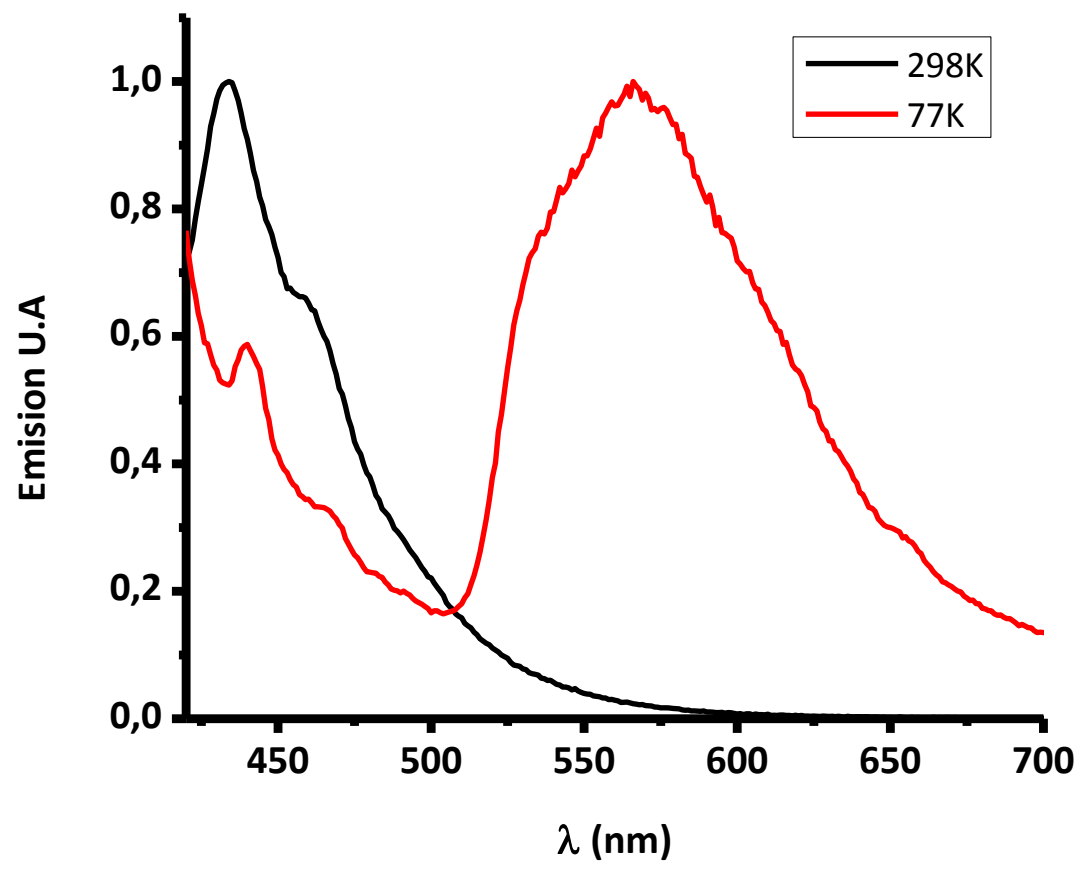

Figura 9

Espectros de emisión en estado estacionario del complejo RePtr en una mezcla $\mathrm{MeOH} / \mathrm{EtOH}$ irradiando a $350 \mathrm{~nm}$.

\subsubsection{Calculo de los rendimientos cuánticos de emisión}

Los cálculos de los rendimientos cuánticos de emisión se realizaron utilizando las áreas obtenidas bajo la curva de emisión en función de la longitud de onda de las muestras y de la referencia, tal como se explicó en el capítulo I. La referencia utilizada fue pterina en solución acuosa a pH 5,5 en atmosfera saturada de $N_{2}$, cuyo valor de $\phi_{r}$ se tomó como 0,33 [6]. Los valores obtenidos se detallan en la tabla 2. 
Tabla 2.

Rendimientos cuánticos de emisión para el complejo RePtr. $\left(\lambda_{\text {exc }}=350 \mathrm{~nm}\right)$

\begin{tabular}{cc}
\hline \hline Solvente & $\phi_{\text {em }}$ \\
Agua pH 3 & $6,38 \times 10^{-2}$ \\
Agua pH 6 & $9,11 \times 10^{-2}$ \\
Agua pH 10 & 0,25 \\
ACN* & $1,91 \times 10^{-2}$ \\
\hline \hline & *solución saturada en $\mathrm{N}_{2}$. \\
\hline \hline
\end{tabular}

\subsubsection{Emisión resuelta en el tiempo}

Se registraron trazas del decaimiento radiativo del estado excitado emisor del complejo RePtr, en solución acuosa a los pH 3, 6 y 10 y en ACN. En la excitación de las muestras se utilizó un nano LED de 341 nm, la emisión se midió a 450 nm y 550 nm.

Las trazas obtenidas midiendo la emisión a $450 \mathrm{~nm}$ se analizaron mediante un ajuste de decaimiento mono-exponencial. Con la constante de decaimiento obtenida se calculó el tiempo de vida del estado excitado. En las figuras 10 y 11 se muestran algunas de las trazas obtenidas. En la tabla $\mathbf{3}$ se muestran los resultados de los ajustes de los decaimientos.

Las trazas de decaimiento obtenidos para los del complejo RePtr en agua y en ACN en medidos a 450 nm, no mostraron diferencias entre sí.

Las medidas de emisión resuelta en el tiempo excitando con luz de $341 \mathrm{~nm}$ se realizaron en tres condiciones. Estas condiciones fueron, atmosfera libre de $\mathrm{O}_{2}$ por burbujeo con $\mathrm{N}_{2}$; solución saturada en $\mathrm{O}_{2}$ y solución en equilibrio con aire. Las trazas obtenidas fueron analizadas obteniéndose un buen ajuste con dos exponenciales, Los tiempos de vida en las distintas condiciones se detallan en la tabla 4. 


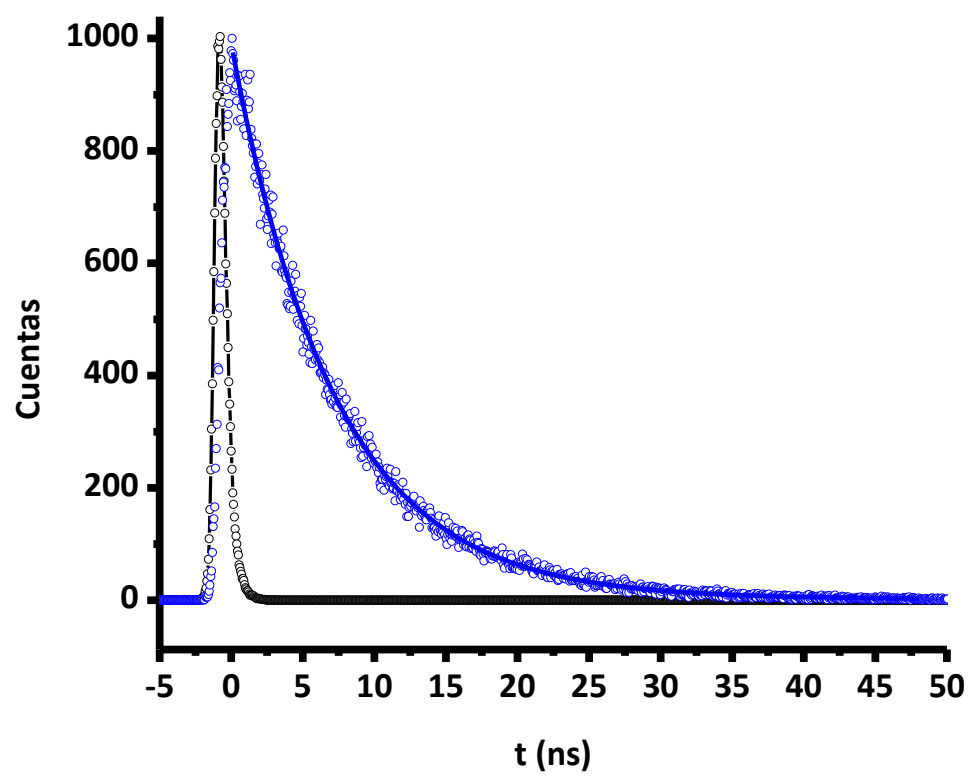

\section{Figura 10}

- Traza correspondiente al decaimiento radiativo del estado excitado del complejo RePtr en solución acuosa a pH $6\left(\lambda_{\text {exc }}=341 \mathrm{~nm}, \lambda_{\text {emi }}=450 \mathrm{~nm}\right)$. $\circ$ Pico correspondiente al pulso del LED. En líneas solidas se muestran los ajustes.

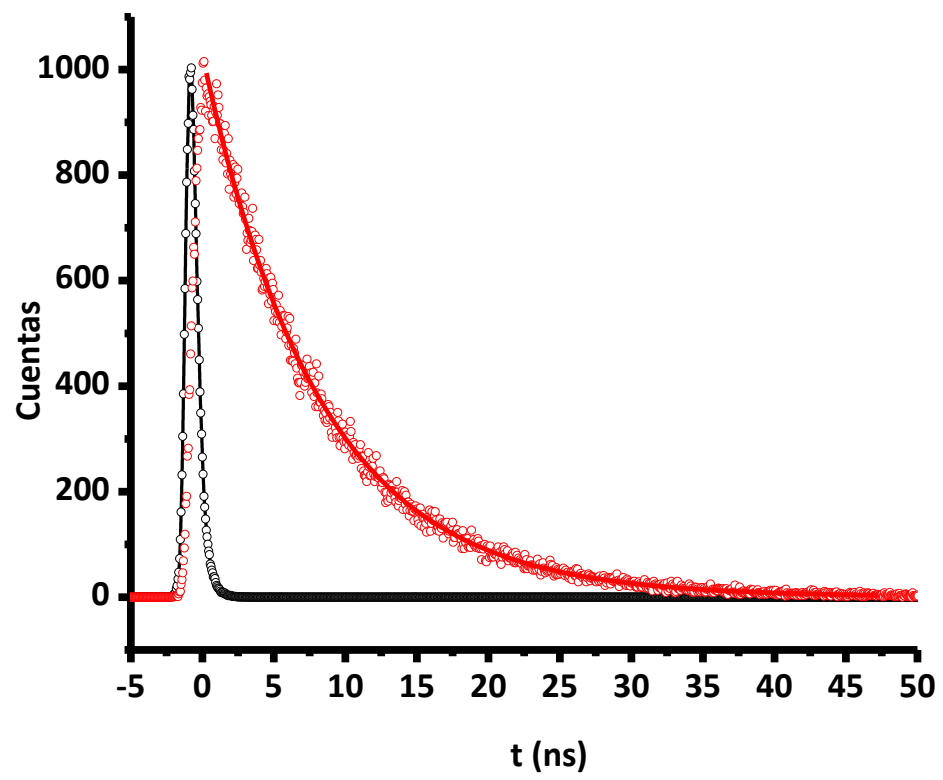

\section{Figura 11}

- Traza correspondiente al decaimiento radiativo del estado excitado del complejo RePtr en ACN $\left(\lambda_{\text {ex }}=341 \mathrm{~nm}, \lambda_{\text {emi }}=450 \mathrm{~nm}\right)$. o Pico correspondiente al pulso del LED. En líneas solidas se muestran los ajustes. 
Tabla 3.

Tiempos de vida media del decaimiento radiativo para el complejo RePtr en atmosfera de $\mathrm{N}_{2}\left(\lambda_{\text {exc }}=341 \mathrm{~nm}, \lambda_{\text {emi }}=\right.$ $450 \mathrm{~nm})$.

\begin{tabular}{cc}
\hline \hline Solvente & $\tau_{\mathrm{em}}(\mathrm{ns}) \pm 0,2$ \\
Agua pH 3 & 7,2 \\
Agua pH 6 & 8,2 \\
Agua pH 10 & 6,8 \\
ACN & 8,0 \\
\hline \hline
\end{tabular}

Tabla 4.

Tiempos de vida media del decaimiento radiativo para el complejo RePtr en ACN ( $\left.\lambda_{\text {exc }}=341 \mathrm{~nm}, \lambda_{\text {emi }}=550 \mathrm{~nm}\right)$.

\begin{tabular}{ccc}
\hline \hline Condición & $\tau_{\mathrm{em}}{ }^{1}(\mathrm{~ns}) \pm 10 \%$ & $\tau_{\mathrm{em}}{ }^{2}(\mathrm{~ns}) \pm 10 \%$ \\
$\mathrm{~N}_{2}$ & 8,0 & 290 \\
Aire & 6,3 & 150 \\
$\mathrm{O}_{2}$ & 4,5 & 52 \\
\hline \hline
\end{tabular}

El tiempo de vida largo $\left(\tau_{\mathrm{em}}{ }^{2}\right)$ correspondiente a la traza obtenida midiendo la emisión a $550 \mathrm{~nm}$, muestra una notable disminución a medida que aumenta la concentración de oxígeno disuelto en la solución. Este comportamiento evidencia la desactivación de este estado excitado por el oxígeno. Los cambios en el primer tiempo de vida $\tau_{\mathrm{em}}{ }^{1}$ no resultan significativos, ya que presentan una gran diferencia de magnitud con el segundo tiempo del ajuste.

\subsubsection{Constante bimolecular de desactivación por Oxígeno}

A partir del análisis de los cambios en los tiempos de vida del estado excitado emisor, que emite a $555 \mathrm{~nm}$, del compuesto estudiado, en presencia de distintas concentraciones de desactivador, pudo calcularse la constante de velocidad del proceso de desactivación biomolecular por Oxígeno en ACN. Para ello se utilizaron las pendientes de los gráficos lineales de Stern-Volmer.

$$
\frac{\tau_{0}}{\tau_{x}}=1+k_{q} \tau_{0}\left[O_{2}\right]
$$


Donde $\tau_{0}$ y $\tau_{x}$ son los tiempos de vida del estado excitado del complejo en ausencia $y$ presencia de oxígeno, respectivamente, $\left[\mathrm{O}_{2}\right]$ es la concentración de Oxígeno y $k_{\mathrm{q}}$ es la constante bimolecular de desactivación. La concentración de oxígeno se estimó según, $\left[\mathrm{O}_{2}\right]=0.21\left(\mathrm{P}_{\mathrm{A}}-\mathrm{P}_{\mathrm{v}}\right)\left[\mathrm{O}_{2}\right]_{\mathrm{P}=1}$, donde $\mathrm{P}_{\mathrm{A}} \mathrm{y} \mathrm{P}_{\mathrm{v}}$ son la presión atmosférica y la presión de vapor del solvente, respectivamente, y $\left[\mathrm{O}_{2}\right]_{\mathrm{P}=1}$ es la concentración de Oxígeno en el solvente a $1 \mathrm{~atm}$ de presión parcial de oxígeno, con un valor de $8,1 \times 10^{-3} \mathrm{M}$ [7]. Éste último valor se tomó como la concentración de oxígeno disuelto cuando se burbujeo la solución con $\mathrm{O}_{2}$.

En la figura 12 se muestra el ajuste lineal obtenido del gráfico de S-V. El valor calculado para la constante de desactivación fue, $\mathbf{k}_{\mathrm{q}}=1,9 \times 10^{9} \mathrm{M}^{-1} \mathrm{seg}^{-1}$.

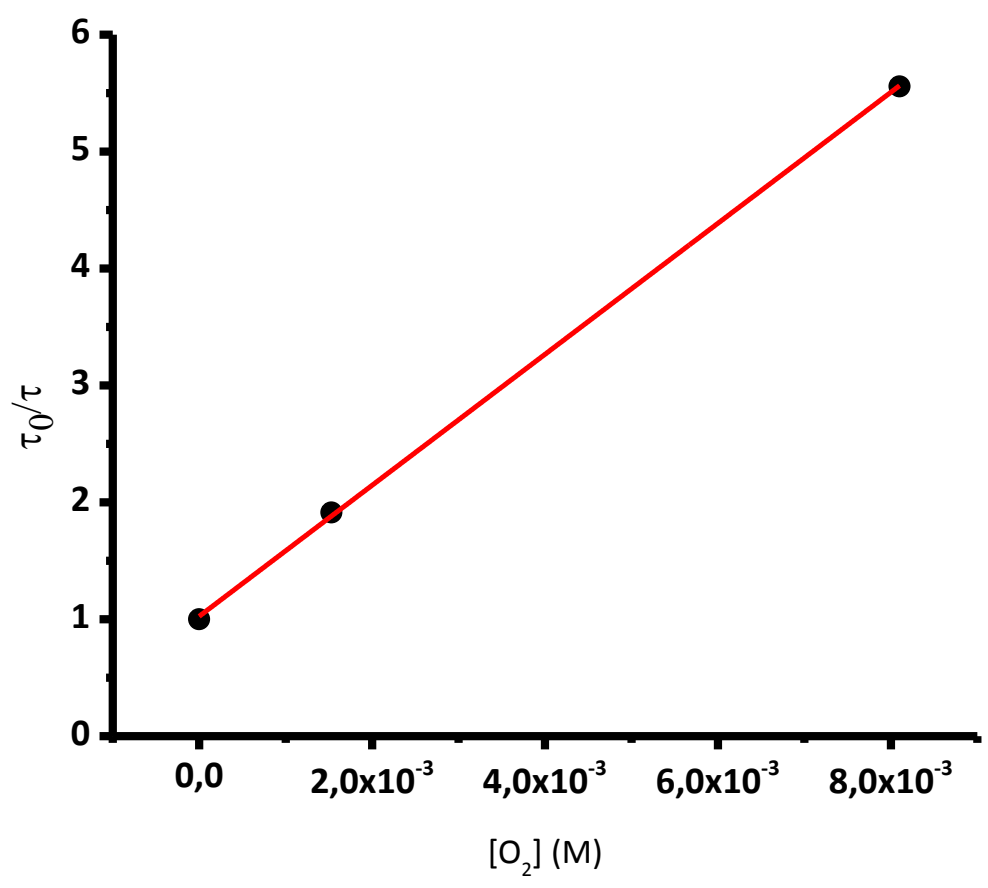

\section{Figura 12}

Gráfico de Stern-Volmer para la desactivación de la emisión centrada a $555 \mathrm{~nm}$ del complejo RePtr por $\mathrm{O}_{2}$ en $\mathrm{ACN}$. 


\subsection{Rendimiento cuántico de generación de Oxígeno singlete.}

Se realizaron medidas resueltas en el tiempo de la emisión infrarroja propia de la especie excitada de oxígeno ${ }^{1} \mathrm{O}_{2}\left({ }^{1} \Delta_{\mathrm{g}}\right)$, registrada a $1270 \mathrm{~nm}$. El tiempo de vida $\left(\tau_{\Delta}\right)$ de esta especie depende fuertemente del solvente, mientras que se desactiva rápidamente en agua $\left(\tau_{\Delta}{ }^{\text {Agua }}=2 \mu \mathrm{s}\right)$, el tiempo de vida en agua deuterada $\left(D_{2} \mathrm{O}\right)$ y en $\mathrm{ACN}$ es lo suficientemente largo como para ser detectado en las condiciones experimentales empleadas $\left(\tau_{\Delta}{ }^{\mathrm{D} 2 \mathrm{O}}=20 \mu \mathrm{s}, \tau_{\Delta}{ }^{\mathrm{ACN}}=60 \mu \mathrm{s}\right)$ [8][9].

Se realizaron medidas de soluciones del complejo RePtr en $A C N$ y en $D_{2} \mathrm{O}$ de varias concentraciones sin deairear. Se ajustó la acidez de las soluciones en $D_{2} \mathrm{O}$ con soluciones preparadas en $\mathrm{D}_{2} \mathrm{O}$ de $\mathrm{NaOH}$ o $\mathrm{HClO}_{4}$ según corresponda, hasta los valores equivalentes a los pD 3, 6 y 10 (despreciando el error que introduce la diferencia entre $\mathrm{pH}$ y $\mathrm{pD}$ y el pequeño agregado de ${ }^{1} \mathrm{H}$ ). Las determinaciones se llevaron a cabo excitando la solución con luz láser de $355 \mathrm{~nm}$. Como referencia se utilizó fenalenona $\left(\phi_{\Delta}=0,98\right)[10]$. Tal como se mencionó en el Capítulo I, el rendimiento cuántico de producción de oxígeno singlete $\phi_{\Delta}$ se calculó mediante el empleo del método comparativo.

Las medidas se realizaron con cinco soluciones de distinta concentración, tanto para la muestra como para la referencia. Las soluciones del complejo RePtr preparadas en $\mathrm{D}_{2} \mathrm{O}$ a los pD 3, 6 y 10 presentaron rendimientos cuánticos de producción de ${ }^{1} \mathrm{O}_{2}$ menores a $10^{-3}$ (límite de detección del método). Mientras que en ACN el valor calculado de $\phi_{\Delta}$ para el complejo fue de $6 \times 10^{-2}$.

\subsection{Medidas de espectroscopia optoacústica LIOAS.}

Las medidas fotoacústicas LIOAS, fueron realizadas usando una configuración ya descripta en el capítulo I. Las medidas fueron realizadas promediando las señales acústicas generadas por 16 disparos del láser, para mejorar la relación señal-ruido. Los espectros UV-Vis de la solución se chequearon antes y después de cada conjunto de disparos, sin encontrar diferencias que indiquen degradación Luego de cada serie de disparos se renovó la solución de la celda, de este modo nos aseguramos de no tener 
posibles fotoproductos que no se hayan detectado por UV-Vis. Como referencia calorimétrica se usó 2-Hidroxibenzofenona (2-HBF) [11] y el colorante New coccine [12]. Para los experimentos se hicieron coincidir los valores de las concentraciones de las muestras y la referencia, dentro del $2 \%$ de error, usando valores entre 0,1 y 0,2 unidades de absorbancia a la longitud de onda del láser. Los experimentos se llevaron a cabo en atmosfera controlada, burbujeando $\mathrm{O}_{2} \circ \mathrm{N}_{2}$ por 15 minutos. En principio, todas las especies excitadas con tiempos de vida $\tau \leq 1 / 5 \tau_{\mathrm{R}}$ (200 ns) liberan su contenido de calor como calor rápido. Mientras que las especies excitadas que viven más de $5 \tau_{R}$, actúan como reservorio de calor, dentro del tiempo de resolución del experimento. En la figura 13 se muestra una típica señal optoacústica.

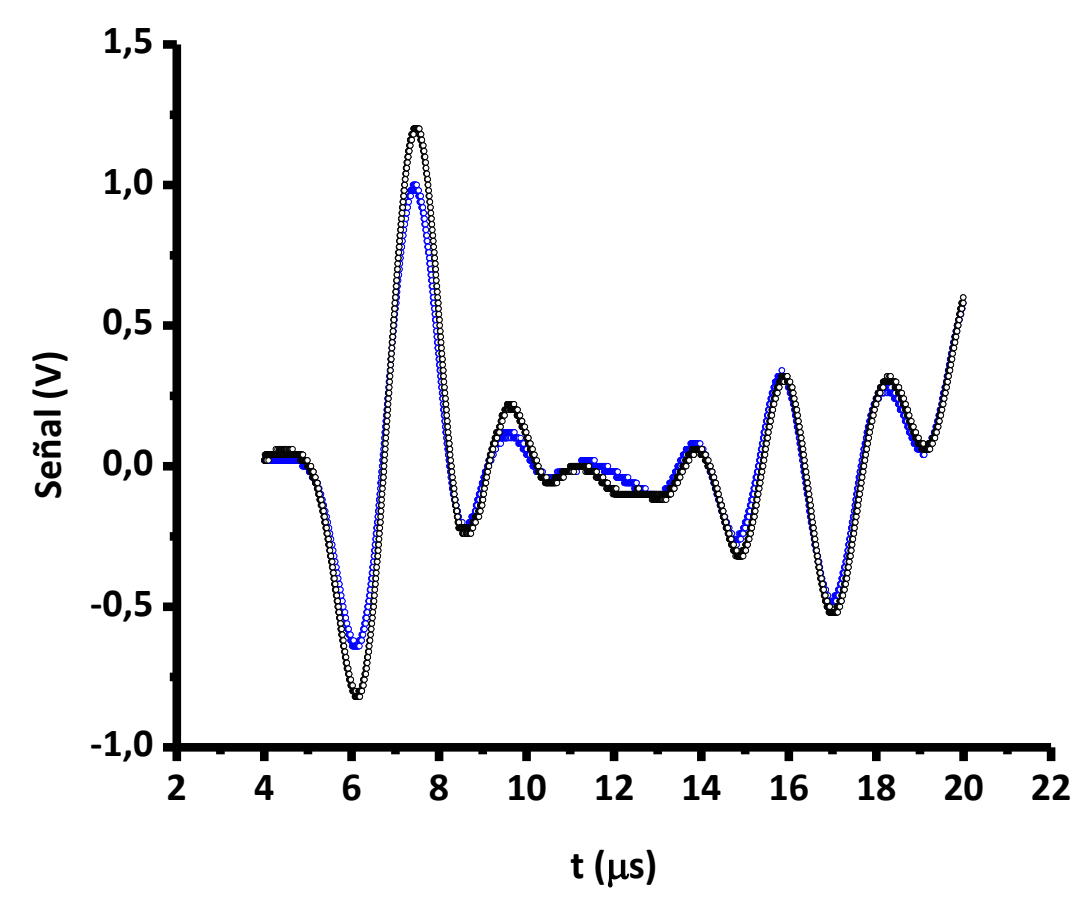

\section{Figura 13}

- Señal optoacústica de una muestra de RePtr en $\operatorname{ACN}\left(\mathrm{O}_{2}\right)$. o Señal optoacústica de la referencia en ACN.

En los experimentos LIOAS se obtuvo una relación lineal entre $\mathrm{H}$ y $\mathrm{F}$ para las muestras y la referencia a varias Abs, en el rango de fluencia entre 1 y $20 \mathrm{~J} / \mathrm{m}^{2}$ (figura 14). De la pendiente de esas líneas se obtuvo la energía normalizada de la señal optoacústica, 
$H / F$, que fue graficada en función de $\left(1-10^{-A}\right)$. Se realizó un ajuste lineal sobre la gráfica anterior. De la relación entre la pendiente de estas rectas para la muestra y para la referencia se obtuvo el valor de $\alpha$ para la muestra. Se obtuvieron varios valores de $\alpha$ que fueron promediados. Este procedimiento fue realizado bajo condiciones de atmosfera de $\mathrm{N}_{2}$ y $\mathrm{O}_{2}$. Los resultados obtenidos para el complejo RePtr se muestran en la tabla 5, no se encontraron diferencias significativas entre los valores obtenidos en atmosfera de $\mathrm{N}_{2}$ y $\mathrm{O}_{2}$ en ningún solvente.

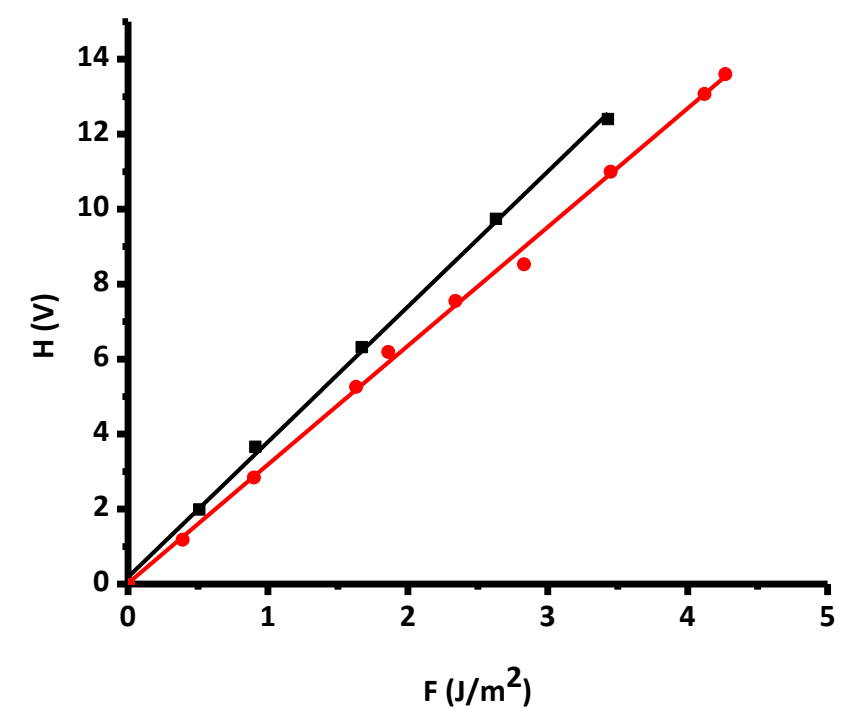

\section{Figura 14}

Gráfico de H vs F para la muestra de $\operatorname{RePtr}(-)$ y la referencia (-) en ACN en atmosfera saturada con $\mathrm{O}_{2}$.

\section{Tabla 5}

Coeficiente $\alpha$ para el complejo RePtr en agua y ACN en aire $\left(\lambda_{\mathrm{ex}}=355 \mathrm{~nm}\right)$.

\section{Solvente}

$\alpha$

Agua $\mathrm{pH} 3$

$1,01 \pm 0,02$

Agua $\mathrm{pH} 6$

$0,98 \pm 0,03$

Agua $\mathrm{pH} 10$

$1,02 \pm 0,01$

$\mathrm{ACN}$

$0,98 \pm 0,02$ 


\section{Fotofísica de los complejos ReBpyTf, RePhenTf y ReBpyPy.}

Los estudios fisicoquímicos ensayados sobre estos tres complejos tricarbonílicos, $\operatorname{Re}^{\prime}(\mathrm{CO})_{3}($ bpy $)\left(\mathrm{CF}_{3} \mathrm{SO}_{3}\right) \quad$ (ReBpyTf), $\operatorname{Re}^{\prime}(\mathrm{CO})_{3}\left(\right.$ phen) $\left(\mathrm{CF}_{3} \mathrm{SO}_{3}\right)$ (RePhenTf) y $\left[\operatorname{Re}^{\prime}(\mathrm{CO})_{3}\left(\right.\right.$ bpy) $($ py) $] \mathrm{CF}_{3} \mathrm{SO}_{3}$ (ReBpyPy), se realizaron utilizando como solvente $\mathrm{ACN}$, en presencia y en ausencia de oxígeno. A fin de poder realizar un análisis completo de la formación y desaparición de los estados excitados, se presentan aquí los espectros de absorción en el rango UV-Vis, los espectros de emisión en el estado estacionario, los decaimientos radiativos de los estados excitados, la fracción de energía absorbida liberada como calor rápido y el rendimiento cuántico de formación de oxígeno singlete. Los experimentos fueron realizados en similares condiciones que los correspondientes para el complejo RePtr por lo que se obviarán los detalles. Las técnicas empleadas se describen en el capítulo I.

\subsection{Espectroscopía de absorción UV-Visible}

Los espectros de absorción UV-visible de estos tres complejos se obtuvieron en soluciones sin deairear y a temperatura ambiente. En la figura 15 se muestran los espectros obtenidos.

Los espectros de absorción de los complejos RebpyTf y ReBpyPy poseen intensas y estructuradas bandas de absorción en la región del UV por debajo de los $320 \mathrm{~nm}$. Estas son asignadas principalmente a transiciones electrónicas del tipo IL. Además, presentan una banda ancha centrada en $\approx 350 \mathrm{~nm}$. Estas bandas fueron asignadas a transiciones del tipo MLCT. No se observan bandas de absorción de luz por encima de los $450 \mathrm{~nm}$. 


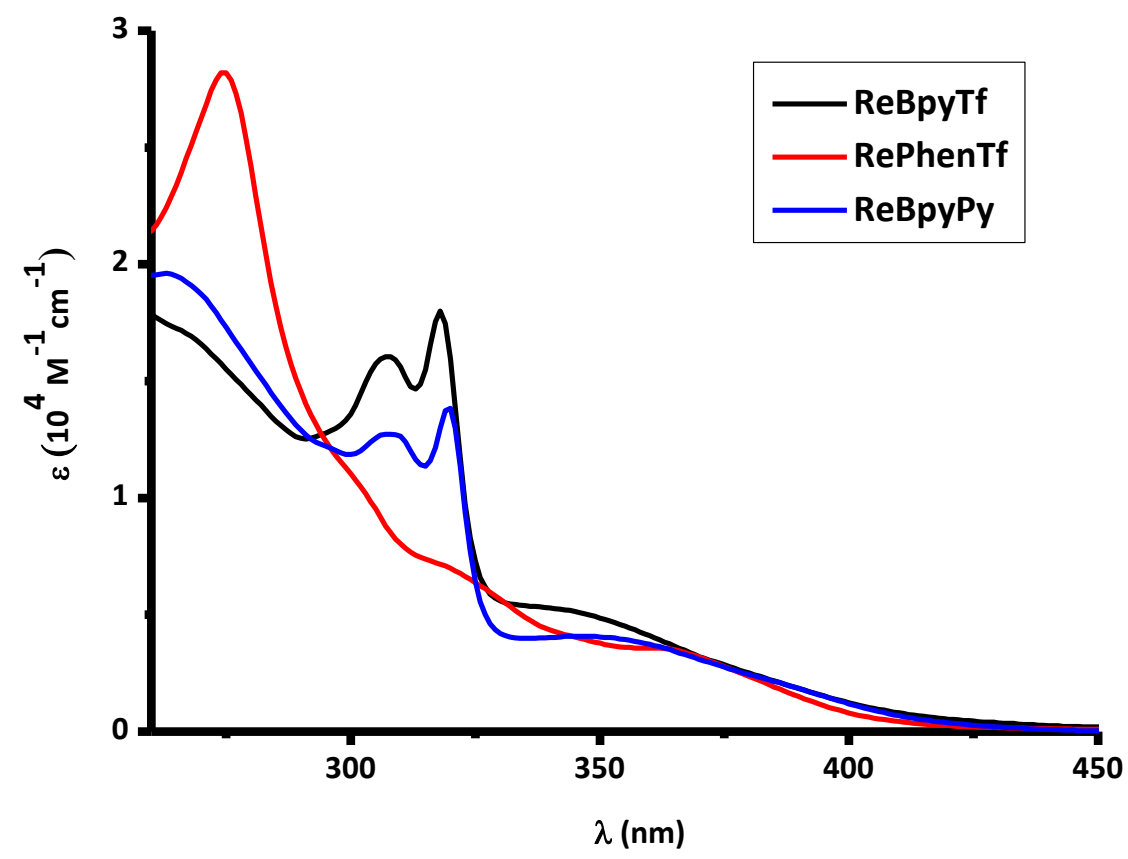

Figura 15

Espectros de absorción UV-Vis de soluciones de ACN de los complejos ReBpyTf, RePhenTf y ReBpyPy.

El espectro del complejo RePhenTf presenta una intensa banda $274 \mathrm{~nm}$ y otra menos intensa centrada en $320 \mathrm{~nm}$, coincidentes con las bandas del ligando libre. Además se observa una banda en $340 \mathrm{~nm}$ asignada a un estado excitado del tipo MLCT. El espectro de este complejo no presenta bandas de absorción por encima de los $450 \mathrm{~nm}$ [1]

\subsection{Emisión luminiscente en estado estacionario}

Se registraron espectros de emisión luminiscente en estado estacionario de soluciones diluidas. La concentración de las soluciones se ajustó de modo que sus absorciones coincidieran a la longitud de onda de excitación. Las medidas fueron realizadas en soluciones de $A C N$ deaireadas con $\mathrm{N}_{2}$ y sin deairear. En la figura 16 se muestran los espectros obtenidos para los complejos ReBpyTf, RePhenTf y ReBpyPy. 
Los espectros de emisión de los tres complejos muestran una única banda de emisión cuando se los excita con luz de $350 \mathrm{~nm}$. Los máximos de estas emisiones se encuentran en 538, 539 y 557 nm para los complejos ReBpyTf, RePhenTf y ReBpyPy respectivamente. Los rendimientos cuánticos de emisión luminiscente se obtuvieron de bibliografía [2], [13], [14][15].

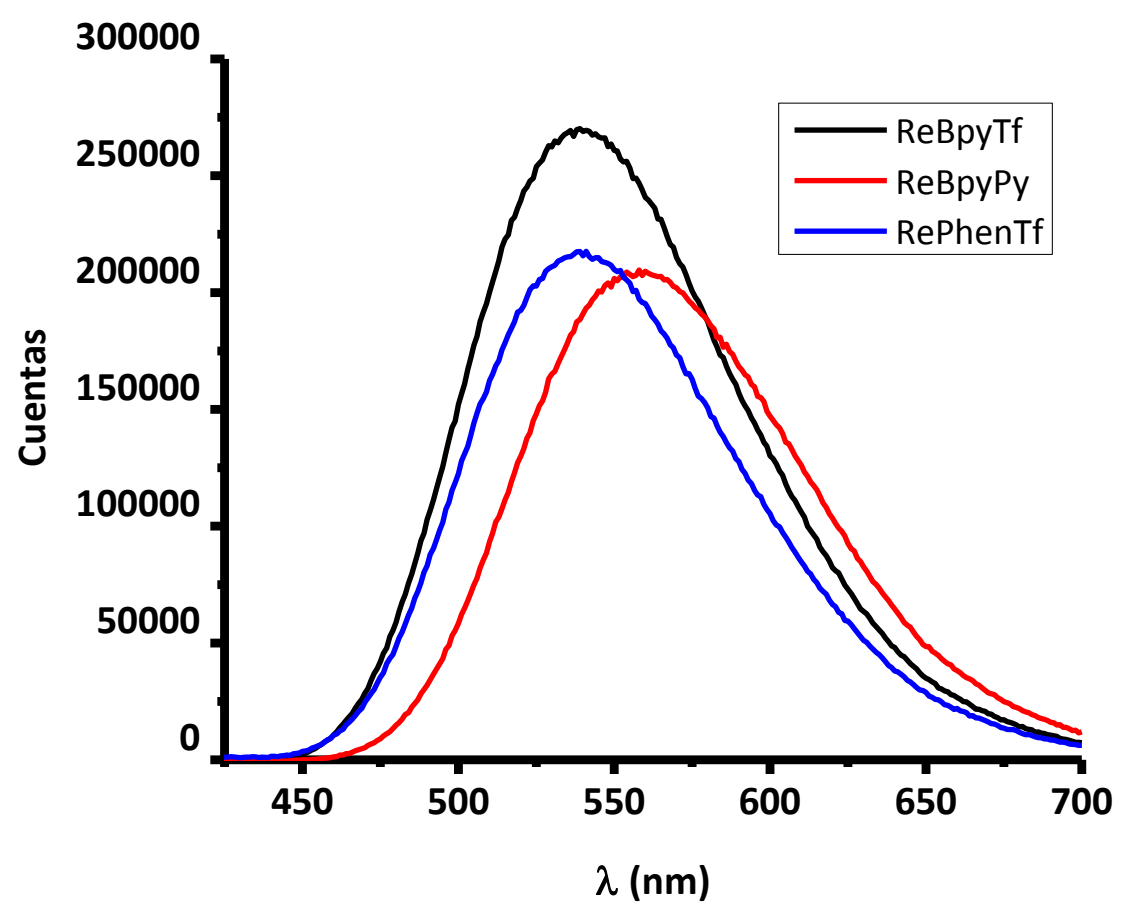

\section{Figura 16}

Espectros de emisión en estado estacionario de soluciones en ACN deaireadas con $\mathrm{N}_{2}$ de los complejos ReBpyTf, RePhenTf y ReBpyPy. $\left(\lambda_{\mathrm{exc}}=350 \mathrm{~nm}\right.$.)

Los tiempos de vida del estado excitado fueron determinados a partir de las medidas de emisión resuelta en el tiempo utilizando como fuente de excitación luz láser de longitud de onda de $355 \mathrm{~nm}$. Los valores obtenidos para los parámetros de emisión estacionaria y resuelta en el tiempo se resumen en la tabla 6. Las trazas obtenidas pudieron ajustarse con decaimientos mono-exponenciales. 


\section{Tabla 6}

Parámetros de emisión luminiscente y decaimiento radiativo del estado excitado de los complejos $X \operatorname{Re}(C O)_{3} L$, medidos en $A C N, \lambda_{\text {exc }}=355 \mathrm{~nm}$ [2], [13], [14][15].

\begin{tabular}{ccc}
\hline \hline Compuesto & $\lambda_{\text {em }}(\mathrm{nm})$ & $\tau_{\mathrm{em}} \mathrm{N}_{2}(\mathrm{~ns})( \pm 10 \%)$ \\
ReBpyTf & 538 & 519 \\
RePhenTf & 539 & 1690 \\
ReBpyPy & 557 & 245 \\
\hline \hline
\end{tabular}

\subsection{Experimentos LIOAS.}

Se realizaron medidas optoacústicas de los complejos ReBpyTf, RePhenTf y ReBpyPy. Los registros de las ondas obtenidas mostraron una dependencia lineal en el comportamiento de la amplitud de la primer onda en función de la fluencia del láser de excitación, $\mathrm{H}$ Vs. $\mathrm{F}$, cuando fueron medidos en atmosferas de $\mathrm{N}_{2}$ y $\mathrm{O}_{2}$. Se observó una buena reproducibilidad de las medidas a diferentes Abs, con una energía del pulso $E_{0}<30 \mathrm{~J} / \mathrm{m}^{2}$. Se observó que las pendientes dependen de la atmosfera específica $\left(\mathrm{O}_{2} \mathrm{O}\right.$ $\mathrm{N}_{2}$ ) y fueron diferentes a la pendiente de la referencia.

A partir de estas gráficas, considerando que $\alpha_{R}=1$ para la referencia $2-\mathrm{HBP}$, con los valores de la razón $\mathrm{H} / \mathrm{F}$ obtenidos para la muestra y la referencia se obtuvieron los valores de $\alpha$ para la muestra, que se presentan en la tabla 7.

\subsection{Rendimiento cuántico de generación de oxígeno singlete.}

Se determinaron los rendimientos cuánticos de producción de oxígeno singlete ${ }^{1} \mathrm{O}_{2}\left({ }^{1} \Delta_{\mathrm{g}}\right)$ para los tres complejos ReBpyTf, RePhenTf y ReBpyPy procediendo de igual forma que para el complejo RePtr. Los valores obtenidos se presentan en la tabla 7. 
Tabla 7

Valores de $\alpha, \Phi_{\Delta}$ y $k_{q}$ para los complejos ReBpyTf, RePhenTf y ReBpyPy medidos en ACN en atmosfera de $\mathrm{N}_{2}, \mathrm{O}_{2}$ y aire.

\begin{tabular}{|c|c|c|c|}
\hline Compuesto & $\alpha\left(\mathrm{N}_{2}\right)( \pm 10 \%)$ & $\alpha\left(\mathrm{O}_{2}\right)( \pm 10 \%)$ & $\Phi_{\Delta}$ (air) ( $\left.\pm 10 \%\right)$ \\
\hline ReBpyTf & 0.60 & 0.81 & 0.63 \\
\hline RePhenTf & 0.33 & 0.80 & 0.89 \\
\hline ReBpyPy & 0.83 & 0.81 & 0.51 \\
\hline
\end{tabular}

\subsection{Balance de energía}

Los valores de los datos de fluorescencia, de los rendimientos cuánticos de producción de oxígeno singlete y de la fracción de energía liberada como calor rápido combinados, ajustan correctamente en el balance de energía de la ecuación 5 para los cuatro complejos estudiados en este capítulo dentro del error experimental.

$$
E_{\mathrm{a}}=\phi_{\mathrm{f}} E_{\mathrm{f}}+\alpha E_{\mathrm{a}}+\phi_{\mathrm{st}} E_{\mathrm{st}}
$$

Donde, $\phi_{f}$ es el rendimiento cuántico de fluorescencia, $E_{f}$ es la energía de luminiscencia, $E_{\mathrm{a}}$ es la energía molar del pulso del láser $\left(h c / \lambda_{\mathrm{exc}}\right)$ [J], mientras que $E_{\mathrm{st}}$ es la energía molar contenida en las especies formadas, con rendimiento cuántico $\phi_{\text {st, }}$ que acumulan energía por tiempos más largos que $\tau_{\mathrm{R}}$ y decaen con un tiempo de vida $\tau$. Si la especie que acumula energía es el estado excitado singlete del oxígeno, ${ }^{1} \mathrm{O}_{2}\left({ }^{1} \Delta_{\mathrm{g}}\right)$, entonces, $\phi_{\mathrm{st}}=\phi_{\Delta}$. En acetonitrilo el tiempo de vida de esta especie es $\tau_{\Delta} \sim 60 \mu \mathrm{s}$, mientras que en $\mathrm{D}_{2} \mathrm{O} \tau_{\Delta} \sim 52 \mu$ s por lo que el ${ }^{1} \mathrm{O}_{2}$ actúa como reserva de energía dentro del tiempo de resolución del experimento LIOAS. En la tabla 8 se muestran los parámetros fotofísicos usados para los balances de energía del complejo RePtr. 


\section{Tabla 8}

Parámetros utilizados en el balance de energía para el complejo RePtr en distintos solventes en soluciones sin deairear $\left(\lambda_{\mathrm{exc}}=355 \mathrm{~nm}\right)$.

\begin{tabular}{ccccc}
\hline \hline Solvente & $\phi_{\mathrm{f}}( \pm 10 \%)$ & $\lambda_{\text {emi }}$ & $\alpha( \pm 10 \%)$ & $\Phi_{\Delta}( \pm 10 \%)$ \\
Agua pH 3 & 0,06 & 442 & 1 & $\leq 10^{-3}$ \\
Agua pH 6 & 0,09 & 442 & 0,98 & $\leq 10^{-3}$ \\
Agua pH 10 & 0,25 & 453 & 0,86 & $\leq 10^{-3}$ \\
ACN & 0,02 & $416-555$ & 0,98 & 0,06 \\
\hline \hline
\end{tabular}

\subsection{Evaluación de las vías de generación de ${ }^{1} \mathrm{O}_{2}$}

Con el fin de encontrar una expresión para el rendimiento cuántico de producción de ${ }^{1} \mathrm{O}_{2}\left({ }^{1} \Delta_{\mathrm{g}}\right),\left(\phi_{\Delta}\right)$, como función de los parámetros del estado excitado del sensibilizador, deben ser considerados varios caminos fotofísicos y fotoquímicos. Luego de la excitación óptica de los complejos $\mathrm{XRe}(\mathrm{CO})_{3} \mathrm{~L}$ con energías fotónicas $\leq 340 \mathrm{~kJ} / \mathrm{mol}$ (350 $\mathrm{nm}$.), cuando la absorción del ${ }^{1} \mathrm{IL}$ es poco significativa tal como ocurre en los complejos $\operatorname{Re}^{\prime}(\mathrm{CO})_{3}($ bpy $)\left(\mathrm{CF}_{3} \mathrm{SO}_{3}\right), \operatorname{Re}^{\prime}(\mathrm{CO})_{3}($ phen $\left.)\left(\mathrm{CF}_{3} \mathrm{SO}_{3}\right)\right)$ y $\left[\operatorname{Re}^{\prime}(\mathrm{CO})_{3}(\right.$ bpy $)($ py $\left.)\right] \mathrm{CF}_{3} \mathrm{SO}_{3}$, se puebla el primer estado singlete excitado ${ }^{1} \mathrm{MLCT}$. Este estado produce ${ }^{3} \mathrm{MLCT}$ por CIS en unos pocos cientos de femto segundos. Finalmente, el estado excitado ${ }^{3} \mathrm{MLCT}$ decae por vías radiativas y no radiativas, como se indica en las ecuaciones 1-3.

$$
\begin{gathered}
{\left[\mathrm{XRe}(\mathrm{CO})_{3} \mathrm{~L}\right] \stackrel{h v}{\longrightarrow}{ }^{1} M L C T \stackrel{k_{c i s}}{\longrightarrow}{ }^{3} M L C T} \\
{ }^{3} M L C T \stackrel{k_{r}}{\longrightarrow}\left[\mathrm{XRe}(\mathrm{CO})_{3} \mathrm{~L}\right]+h v \\
{ }^{3} M L C T \stackrel{k_{n r}}{\longrightarrow}\left[\mathrm{XRe}(\mathrm{CO})_{3} \mathrm{~L}\right]
\end{gathered}
$$

Sin embargo, este no es el caso del complejo $\operatorname{Re}^{\prime}(\mathrm{CO})_{3}($ pterina $)\left(\mathrm{H}_{2} \mathrm{O}\right)$, ya que el ligando pterina posee absorciones IL significativas a energías $\leq 340 \mathrm{~kJ} / \mathrm{mol}$ y por lo tanto, luego de la excitación fotónica, se generan los estados, ${ }^{1} \mathrm{MLCT}$ e ${ }^{1} \mathrm{IL}$, los que por CIS generan los estados ${ }^{3} \mathrm{MLCT}$ e ${ }^{3} \mathrm{IL}$ que decaen por vías radiativas y no radiativas (Ecuaciones 4-9) 


$$
\begin{gathered}
{[\operatorname{RePtr}] \stackrel{h v}{\longrightarrow}{ }^{1} M L C T \stackrel{k_{c i s}^{\prime}}{\longrightarrow}{ }^{3} M L C T} \\
{ }^{3} M L C T \stackrel{k_{r}^{\prime}}{\longrightarrow}[\operatorname{RePtr}] \stackrel{h v}{\longrightarrow}{ }^{1} I L \stackrel{k_{c i s}^{\prime \prime}}{\longrightarrow}{ }^{3} I L \\
{ }^{3} M L C T \stackrel{k_{n r}^{\prime}}{\longrightarrow}[\operatorname{RePtr}] \\
{ }^{3} I L \stackrel{k_{r}^{\prime \prime}}{\longrightarrow}[\operatorname{RePtr}]+h v^{\prime \prime} \\
{ }^{3} I L \stackrel{k_{n r}^{\prime \prime}}{\longrightarrow}[\operatorname{RePtr}]
\end{gathered}
$$

Todos estos complejos $\mathrm{XRe}(\mathrm{CO})_{3} \mathrm{~L}$ son buenos luminóforos, con valores de $\phi_{\mathrm{emi}}$ en el rango entre 0,02 y 0,5 en atmosfera de $\mathrm{N}_{2}$ en acetonitrilo. Sin embargo, bajo atmosfera de $\mathrm{O}_{2}$, esta luminiscencia es fuertemente desactivada (tablas 6 y 8). En presencia de Oxígeno y en ACN los complejos estudiados pueden ser usados como sensibilizadores produciendo ${ }^{1} \mathrm{O}_{2}$ por transferencia de energía desde el ${ }^{3} \mathrm{MLCT}$, o ${ }^{3} \mathrm{IL}$ al Oxígeno molecular. (Ecuación 10)

$$
{ }^{3} S+O_{2}\left({ }^{3} \Sigma_{g}^{-}\right) \stackrel{k_{\Delta}}{\longrightarrow}\left[\mathrm{XRe}(\mathrm{CO})_{3} \mathrm{~L}\right]+{ }^{1} O_{2}
$$

Donde, $k_{\Delta}$ representa la constante de velocidad del proceso de transferencia de energía desde ${ }^{3} \mathrm{~S}\left({ }^{3} \mathrm{MLCT},{ }^{3} \mathrm{IL}\right)$ al oxígeno generando ${ }^{1} \mathrm{O}_{2}$. El mecanismo de desactivación por el Oxígeno del estado triplete excitado del sensibilizador ${ }^{3} \mathrm{~S}^{*}$ está dado por las ecuaciones 11-13 [16], [17]. 


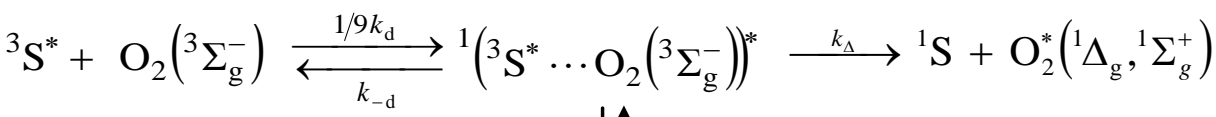

$$
\begin{aligned}
& \begin{array}{ll}
1 & \hat{1} \\
1 & 1 \\
1 & 1 \\
\text { v } & 1
\end{array} \\
& { }^{3} \mathrm{~S}^{*}+\mathrm{O}_{2}\left({ }^{3} \Sigma_{\mathrm{g}}^{-}\right) \stackrel{3 / 9 k_{\mathrm{d}}}{\rightleftarrows}{ }_{k_{-\mathrm{d}}}{ }^{3}\left({ }^{3} \mathrm{~S}^{*} \cdots \mathrm{O}_{2}\left({ }^{3} \Sigma_{\mathrm{g}}^{-}\right)\right)^{*} \stackrel{k_{\mathrm{Td}}}{\longrightarrow}{ }^{1} \mathrm{~S}+\mathrm{O}_{2}\left({ }^{3} \Sigma_{\mathrm{g}}^{-}\right) \\
& \begin{array}{l}
1 \\
1 \\
1 \\
1 \\
1 \\
\forall
\end{array} \\
& { }^{3} \mathrm{~S}^{*}+\mathrm{O}_{2}\left({ }^{3} \Sigma_{\mathrm{g}}^{-}\right) \underset{k_{-\mathrm{d}}}{\stackrel{5 / 9 k_{\mathrm{d}}}{\rightleftarrows}}{ }^{5}\left({ }^{3} \mathrm{~S}^{*} \ldots \mathrm{O}_{2}\left({ }^{3} \Sigma_{\mathrm{g}}^{-}\right)\right)^{*}
\end{aligned}
$$

En este mecanismo ${ }^{3} \mathrm{~S}^{*}$ representa el triplete excitado del sensibilizador, $k_{\mathrm{d}} \mathrm{y} k_{-\mathrm{d}}$ representan las constantes de velocidad difusionales para el encuentro y separación de los complejos de encuentro ${ }^{1,3,5}\left({ }^{3} \mathrm{~S}^{*} \ldots{ }^{3} \mathrm{O}_{2}\right)$ y $k_{\mathrm{Td}}$ representa la constante de velocidad del decaimiento del triplete catalizado por oxígeno molecular. Los superíndices indican los valores de multiplicidad. Los complejos de encuentro ${ }^{1,3}\left({ }^{3} \mathrm{~S}^{*} \ldots{ }^{3} \mathrm{O}_{2}\right)$ pueden, eventualmente, evolucionar hacia una transferencia de carga entre los componentes del complejo de encuentro, i.e. ${ }^{1,3}\left({ }^{2} S^{\delta+} \ldots{ }^{2} \mathrm{O}_{2}{ }^{\delta-}\right)$, que no está representada en el esquema de las ecuaciones 11-13, tal como fue descrito previamente por Wilkinson et. al. [17]. La fracción $1 / 9,3 / 90 \%$ en las constantes, representa el factor estadístico de spin, el cual refleja la probabilidad estadística de formación del estado de spin (singlete, triplete o quintuplete) cuando un complejo de encuentro se formó por la colisión de dos moléculas en estados triplete [16]. La ecuación 11 incluye tanto la producción directa de ${ }^{1} \mathrm{O}_{2}\left({ }^{1} \Delta_{\mathrm{g}}\right)$ desde la desactivación por oxígeno, así como el ${ }^{1} \mathrm{O}_{2}$ $\left({ }^{1} \Delta_{\mathrm{g}}\right)$ formado a partir del ${ }^{1} \mathrm{O}_{2}\left({ }^{1} \Sigma_{g}^{+}\right)$producido inicialmente. Las flechas discontinuas representan el CIS, el cual es reforzado por el efecto de átomo pesado que ejerce el $\operatorname{Re}(I)$ entre los canales singlete, triplete y quintuplete. El rendimiento cuántico de producción de oxígeno singlete $\left(\phi_{\Delta}\right)$ por desactivación del estado triplete por oxígeno es dado por las ecuaciones 14-19

$$
\phi_{\Delta}=\phi_{T} P_{O_{2}}^{T} f_{O_{2}}^{T}
$$




$$
\begin{gathered}
P_{O_{2}}^{T}=\frac{k_{q}\left[\mathrm{O}_{2}\right]}{k_{r}+k_{n r}+k_{q}\left[\mathrm{O}_{2}\right]}=\tau k_{q}\left[\mathrm{O}_{2}\right]=1-\frac{\tau}{\tau_{0}}=1-\frac{I}{I_{0}} \\
k_{\mathrm{D}}=k_{\Delta}+k_{\mathrm{Td}} \\
f_{O_{2}}^{T}=\frac{k_{\Delta}}{k_{\mathrm{D}}} \\
\tau=\frac{1}{k_{r}+k_{n r}+k_{q}\left[\mathrm{O}_{2}\right]} \\
\tau_{0}=\frac{1}{k_{r}+k_{n r}}
\end{gathered}
$$

Donde $\phi_{\top}$ es el rendimiento cuántico de formación de triplete, $k_{\mathrm{q}}$ es la constante de velocidad global de desactivación del estado triplete por oxígeno; $P_{\mathrm{O}_{2}}^{\mathrm{T}}$ es la proporción del estado triplete desactivado por oxígeno; $f_{\mathrm{O}_{2}}^{\mathrm{T}}$ es la fracción del estado triplete desactivado por $\mathrm{O}_{2}$ que conduce a ${ }^{1} \mathrm{O}_{2}\left({ }^{1} \Delta_{\mathrm{g}}\right) \cdot \tau_{0}, \tau, I_{0}$ e I son los tiempos de vida $\mathrm{e}$ intensidad de luminiscencia de los tripletes en ausencia y presencia de oxígeno respectivamente.

El mecanismo de las ecuaciones 10-12 fue originalmente desarrollado para la generación de oxígeno singlete por el estado triplete de sensibilizadores orgánicos. Por consiguiente el $\mathrm{CIS}$ entre los complejos ${ }^{1,3,5}\left({ }^{3} \mathrm{~S}^{*} \ldots{ }^{3} \mathrm{O}_{2}\right)$ con diferente multiplicidad de spin no fue tenido en cuenta [17]. De este modo, si no se consideran las flechas punteadas en el esquema anterior, $f_{\mathrm{O}_{2}}^{\mathrm{T}}$ debe ser 1 y $k_{\mathrm{q}} \leq 1 / 9 k_{\mathrm{d}}$, si solo el canal singlete está involucrado, mientras que $f_{\mathrm{O}_{2}}^{\mathrm{T}}=0.25$ y $k_{\mathrm{q}} \leq{ }^{4} / 9 k_{\mathrm{d}} \mathrm{si}$, tanto los canales singlete como triplete están igualmente involucrados.

Los complejos ReBpyTf, RePhenTf y ReBpyPy tienen $\phi_{\Delta}$ entre 0,5 y 1 . Estos generan ${ }^{1} \mathrm{O}_{2}\left({ }^{1} \Delta_{\mathrm{g}}\right)$ exclusivamente por la desactivación por oxígeno de sus estados ${ }^{3} \mathrm{TCML}$ luminiscentes. El $\phi_{\Delta}$ medido para el complejo RePtr en ACN fue de 0,06 y la producción de ${ }^{1} \mathrm{O}_{2}\left({ }^{1} \Delta_{\mathrm{g}}\right)$ se asoció a la desactivación del estado ${ }^{3} \mathrm{MLCT}$. Dado que se ha informado 
que $\phi_{\top}$ es unitario para todos estos complejos debido al alto grado de acoplamiento spin-orbita [18], la ecuación 14 se reduce a la ecuación 20.

$$
\phi_{\Delta}=P_{O_{2}}^{T} f_{O_{2}}^{T}
$$

Los valores de $P_{\mathrm{O}_{2}}^{\mathrm{T}}$ para los cuatro complejos se calcularon con la ecuación 15. Para estos cálculos, se utilizaron el tiempo de vida de luminiscencia o la intensidad de luminiscencia en $\mathrm{N}_{2}, \mathrm{O}_{2}$ y aire. Los correspondientes valores obtenidos se resumen en la tabla 9.

Se determinaron las constantes de velocidad bimolecular para la desactivación de la emisión de estos complejos por el oxígeno $\left(k_{\mathrm{q}}\right)$ usando las pendientes de los gráficos lineales de Stern-Volmer $\left(\tau_{0} / \tau=1+k_{\mathrm{q}} \tau_{0}\left[\mathrm{O}_{2}\right]\right)$, calculados con los valores de los tiempos de vida de la emisión en ausencia y en presencia de oxígeno ( $\tau_{0}$ en $\mathrm{N}_{2}$ y $\tau$ en aire y $\mathrm{O}_{2}$, respectivamente). Los valores de $k_{\mathrm{q}}$ obtenidos se encuentran dentro del rango 1 y $3 \mathrm{x}$ $10^{9} \mathrm{M}^{-1} \mathrm{~s}^{-1}$ y están de acuerdo con los valores reportados para complejos de $\operatorname{Re}(\mathrm{I})$ similares con $f_{\mathrm{O}_{2}}^{\mathrm{T}}$ cercanos a la unidad [18]. Dado que el valor de $k_{\mathrm{d}}$ en ACN está alrededor de $3 \times 10^{10} \mathrm{M}^{-1} \mathrm{~s}^{-1}$ [18], los valores de $k_{\mathrm{q}}$ obtenidos para estos complejos fueron $\leq 1 / 9 k_{\mathrm{d}}$. Estos resultados están en buen acuerdo con los valores unitarios obtenidos para $f_{\mathrm{O}_{2}}^{\mathrm{T}} \mathrm{y}$ con la predominancia del canal singlete (Ecuación 11) en el mecanismo de generación de oxígeno singlete cuando se usan estos complejos de $\operatorname{Re}(\mathrm{I})$ como fotosensibilizadores. Con el fin de obtener una expresión para $k_{\mathrm{D}}$ con los valores experimentales de $k_{\mathrm{q}}$, se consideró una simplificación del mecanismo de las ecuaciones 11-13 (Ecuación 21).

$$
{ }^{3} \mathrm{~S}^{*}+{ }^{3} \mathrm{O}_{2} \underset{k_{-\mathrm{d}}}{\stackrel{k_{\mathrm{d}}}{\rightleftarrows}}{ }^{1,3,5}\left({ }^{3} \mathrm{~S}^{*} \ldots{ }^{3} \mathrm{O}_{2}\right) \longrightarrow \longrightarrow \begin{aligned}
& { }^{1} \mathrm{~S}+{ }^{3} \mathrm{O}_{2} \\
& { }^{1} \mathrm{~S}+{ }^{1} \mathrm{O}_{2}
\end{aligned}
$$

En el primer paso de la desactivación, el sensibilizador excitado ${ }^{3} \mathrm{~S}^{*}$ y el oxígeno ${ }^{3} \mathrm{O}_{2}$ ( $\left.{ }^{3} \Sigma_{g}^{-}\right)$difunden juntos en la forma excitada del complejo de encuentro ${ }^{1,3,5}\left({ }^{3} \mathrm{~S}^{*} \ldots{ }^{3} \mathrm{O}_{2}\right)$ con multiplicidad de spin $\mathrm{m}=1,3$ y 5 y con una constante de velocidad difusional $k_{\mathrm{d}}$ 
(notar que $k_{\mathrm{d}}=\sum k_{\mathrm{d}, \mathrm{i}}$ de la ecuación 11-13). Este complejo se disocia con una constante de velocidad $k_{-d}$ o reacciona hacia adelante en dos direcciones:

1- ${ }^{1}\left({ }^{3} \mathrm{~S}^{*} \ldots{ }^{3} \mathrm{O}_{2}\right)$ evoluciona hacia el estado singlete del sensibilizador en estado basal y ${ }^{1} \mathrm{O}_{2}\left({ }^{1} \Sigma_{g}^{+}\right) \circ{ }^{1} \mathrm{O}_{2}\left({ }^{1} \Delta_{\mathrm{g}}\right)$

2- ${ }^{3}\left({ }^{3} \mathrm{~S}^{*} \ldots{ }^{3} \mathrm{O}_{2}\right)$ evoluciona hacia el estado del singlete sensibilizador en estado basal y ${ }^{3} \mathrm{O}_{2}\left({ }^{3} \Sigma_{g}^{-}\right)$.

El quintuplete del complejo, ${ }^{5}\left({ }^{3} \mathrm{~S}^{*} \ldots{ }^{3} \mathrm{O}_{2}\right)$, no tiene vía de producción directa de producto [19]. La constante global de velocidad $\left(k_{\mathrm{D}}=k_{\Delta}+k_{\mathrm{Td}}\right)$ es calculada con la ecuación 22:

$$
k_{\mathrm{D}}=\frac{\mathrm{k}_{-d} \mathrm{k}_{q}}{\mathrm{k}_{d}-\mathrm{k}_{q}}
$$

La constante de velocidad disociativa $k_{-d}$, se calculó de acuerdo con $k_{-d} / k_{d}=1 \mathrm{M}$, donde $\mathrm{M}$ es la unidad mol por litro [20], usando el valor de $k_{\mathrm{d}}=3,1 \times 10^{10} \mathrm{M}^{-1} \mathrm{~s}^{-1}$ para la constante de velocidad difusional de procesos biomoleculares de $\mathrm{O}_{2}$ en acetonitrilo [18]. Los valores calculados de $k_{\mathrm{D}}$ desde los valores de $k_{\mathrm{q}}$ para los complejos se presentaron en la tabla 9.

Tabla 9

Datos calculados de producción de oxígeno singlete para los cuatro complejos estudiados en ACN ( $\lambda_{\text {exc }}=355 \mathrm{~nm}$ )

\begin{tabular}{lcccccc}
\hline \hline Complejo & $P_{O_{2}}^{T}=1-\frac{\tau}{\tau_{0}}$ & $P_{O_{2}}^{T}=1-\frac{I}{I_{0}}$ & $P_{O_{2}}^{T}$ & $f_{O_{2}}^{T}$ & $k_{\mathrm{q}}\left(10^{9} \mathrm{M}^{-1} \mathrm{~s}^{-1}\right)$ & $K_{\mathrm{D}}\left(10^{9} \mathrm{~s}^{-1}\right)$ \\
ReBpyTf & 0,68 & 0,63 & 0,66 & 0,95 & 2,0 & 2,1 \\
RePhenTf & 0,84 & 0,84 & 0,84 & 1,02 & 1,3 & 1,4 \\
ReBpyPy & 0,49 & 0,50 & 0,50 & 1,02 & 1,9 & 2,0 \\
RePtr & 0,83 & - & 0,83 & 1,02 & 1,9 & 2,0 \\
\hline \hline
\end{tabular}




\section{Estudios de reacciones térmicas y fotoquímicas del complejo fac-Re' $(\mathrm{CO})_{3}$ (pterina) $\left(\mathrm{H}_{2} \mathrm{O}\right)$}

Se realizaron una serie de ensayos tendientes a determinar la reactividad fotoquímica del complejo $\operatorname{Re}^{\prime}(\mathrm{CO})_{3}($ pterina $)\left(\mathrm{H}_{2} \mathrm{O}\right)$. Asimismo, se estudiaron ciertas reacciones térmicas del estado basal con algunos agentes oxidantes y reductores. Las técnicas utilizadas fueron la de láser flash fotólisis (LFF) y radiólisis de pulso (PR).

La descripción de estas técnicas, así como su fundamento teórico e interpretación de sus resultados, se encuentran detallados en el capítulo I.

\subsection{Espectroscopia LFF}

Se prepararon soluciones del complejo RePtr en acetonitrilo, disolviendo el sólido y ajustando la concentración por absorbancia con la ayuda del coeficiente de extinción molar ya conocido. Las muestras fueron deaireadas con $\mathrm{N}_{2}$ antes de cada medida, cuando fue necesario se utilizó un sistema de flujo para refrescar la solución luego de una serie de medidas. La fotoestabilidad del complejo fue monitoreada por el seguimiento de los espectros UV-Vis del estado basal antes y después de cada conjunto de disparos Se encontró que el espectro del estado basal del complejo permanece inalterado durante la serie de medidas, lo que permite asumir que no se inducen cambios significativos en el complejo. El camino óptico de irradiación fue de 1 $\mathrm{cm}$. El $\Delta \mathrm{A}$ resuelto en el tiempo fue medido utilizando un promedio de 24 disparos para cada longitud de onda.

\subsubsection{Transientes de absorción.}

Se realizaron medidas en diferentes solventes (e.g. Agua, metanol, etanol, 2-propanol, DMSO y ACN). Se barrió el espectro entre 350 y $800 \mathrm{~nm}$. Se probaron distintas potencias en el disparo del flash para optimizar la intensidad de la señal. Aun así, solo se observaron transientes de absorción en ACN. 


\subsubsection{Transiente en ACN}

Se excitó una muestra del complejo en ACN de concentración 1,9 x 10-4 M (Abs=0,6) con luz láser de $355 \mathrm{~nm}$. Se registraron las trazas del decaimiento temporal de la absorción de especie transitoria. Estas trazas permitieron muy buenos ajustes para un decaimiento exponencial simple (figura 17).

Las trazas obtenidas a distintos $\lambda_{\text {abs }}$ entre 420 y $700 \mathrm{~nm}$ presentaron el mismo tiempo de vida de $1,1 \mu$ s. Entre 400 y $410 \mathrm{~nm}$ las trazas decaen con un tiempo de vida de $\approx 300$ ns.

A partir del análisis de los decaimientos, fueron obtenidos los espectros de la especie transiente del complejo RePtr a distintos tiempos luego del pulso, que se muestran en la figura 18. El espectro de absorción de esta especie, presenta una forma estructurada de tres bandas centradas en 400,550 y $480 \mathrm{~nm}$.

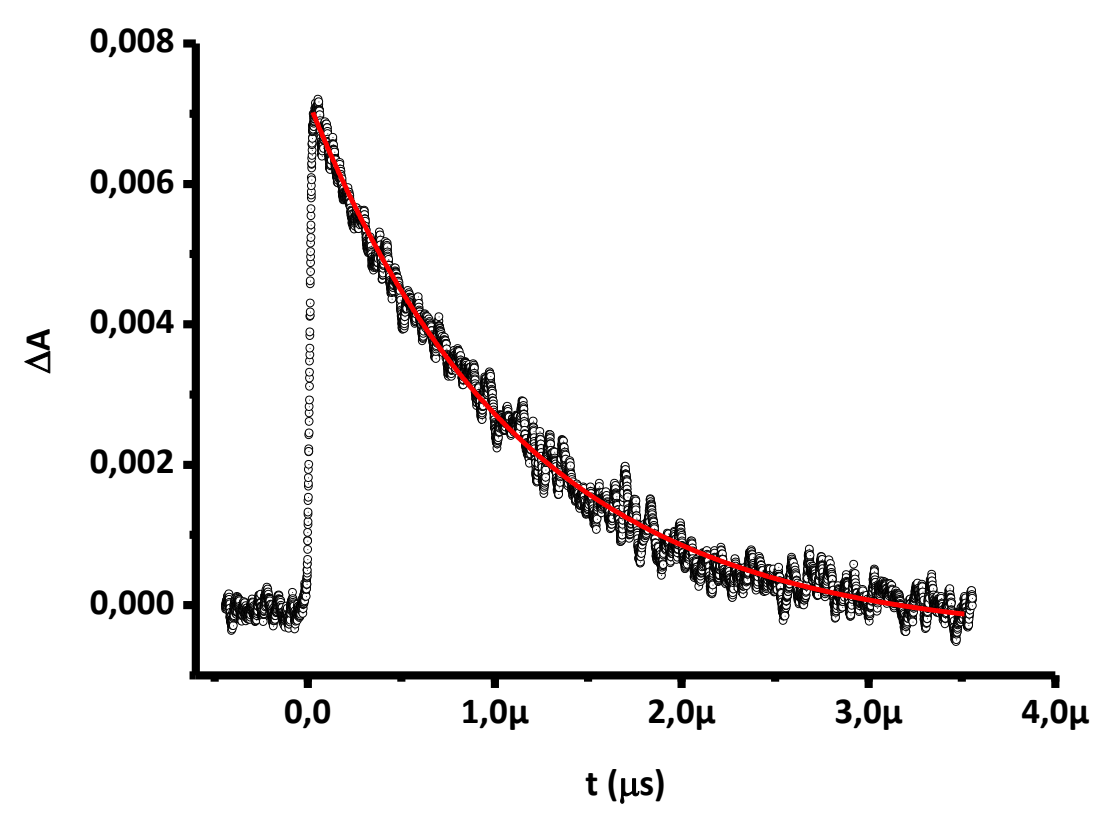

\section{Figura 17}

Traza obtenida del decaimiento de la absorción de la especie transiente, obtenida irradiando una solución en ACN del complejo RePtr con luz de $355 \mathrm{~nm}$ y midiendo a $540 \mathrm{~nm}$. 


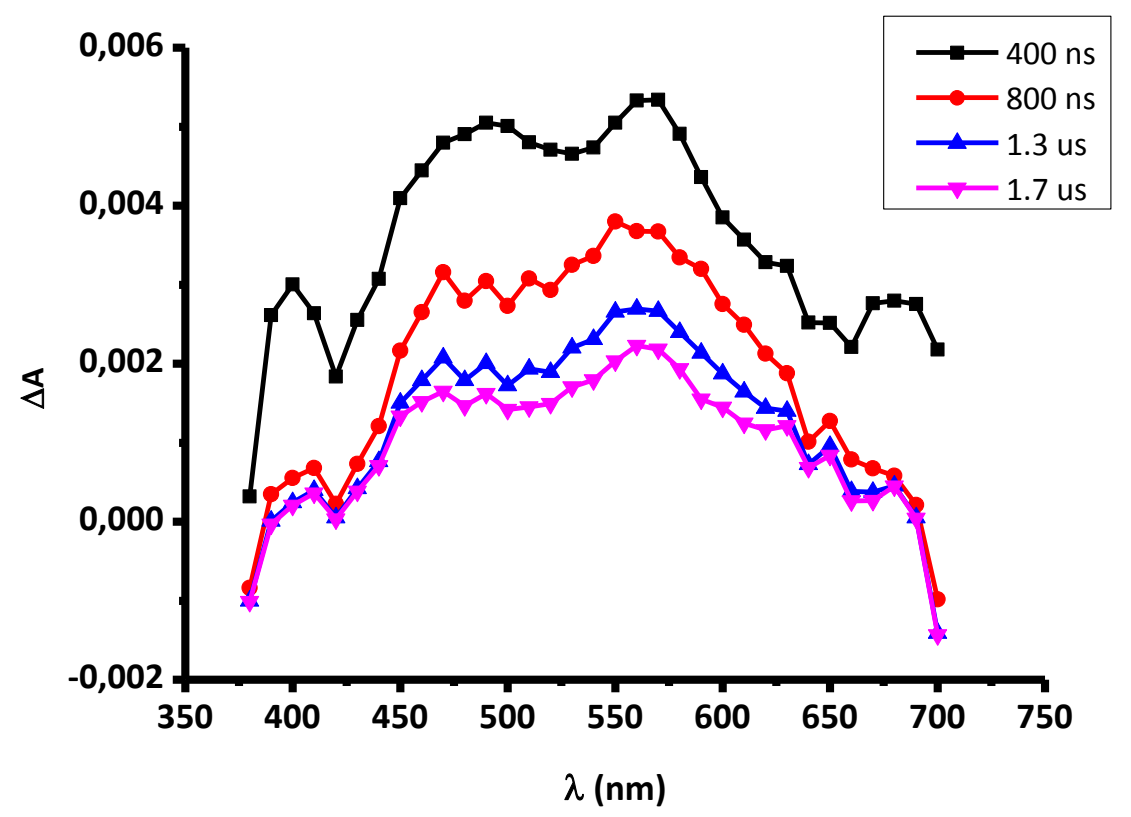

\section{Figura 18}

Espectros de absorción de la especie transitoria obtenidos a los tiempos 400, 800, 1300 y 1700 ns luego de irradiada la muestra del complejo RePtr en ACN con luz de longitud de onda de $355 \mathrm{~nm}$.

Por otra parte, se realizaron una serie de experimentos agregando agua, ácidos y bases a una solución del complejo en acetonitrilo. Cuando se agregaron tanto agua como distintos ácidos aun en baja concentración, dejó de observarse la traza del transiente. Se prepararon soluciones del complejo en $\mathrm{ACN}$ con distintas concentraciones de $\mathrm{HClO}_{4}$. Las concentraciones de ácido utilizadas fueron de $10^{-6}, 10^{-5}, 2 \times 10^{-5}, 10^{-4}$ y $10^{-3} \mathrm{M}$. Las trazas obtenidas de las soluciones de $10^{-6}$ a $2 \times 10^{-5} \mathrm{M}$ no mostraron cambios en los tiempos de vida de la especie transiente. Las soluciones $10^{-4}$ y $10^{-3} \mathrm{M}$ no permitieron observar trazas.

En otra serie de experimentos se utilizó TEA, la cual es una base con buena solubilidad en ACN. Se midió una solución $10^{-5} \mathrm{M}$ del complejo en $\mathrm{ACN}$ con TEA $10^{-4} \mathrm{M}$. Con estas concentraciones suponiendo una constante difusional para el encuentro, puede despreciarse una posible reacción entre el transiente y la TEA. La figura 19 muestra una de las trazas obtenidas excitando a $355 \mathrm{~nm}$. El espectro de la especie transitoria obtenido para estas condiciones se muestra en la figura 20. 


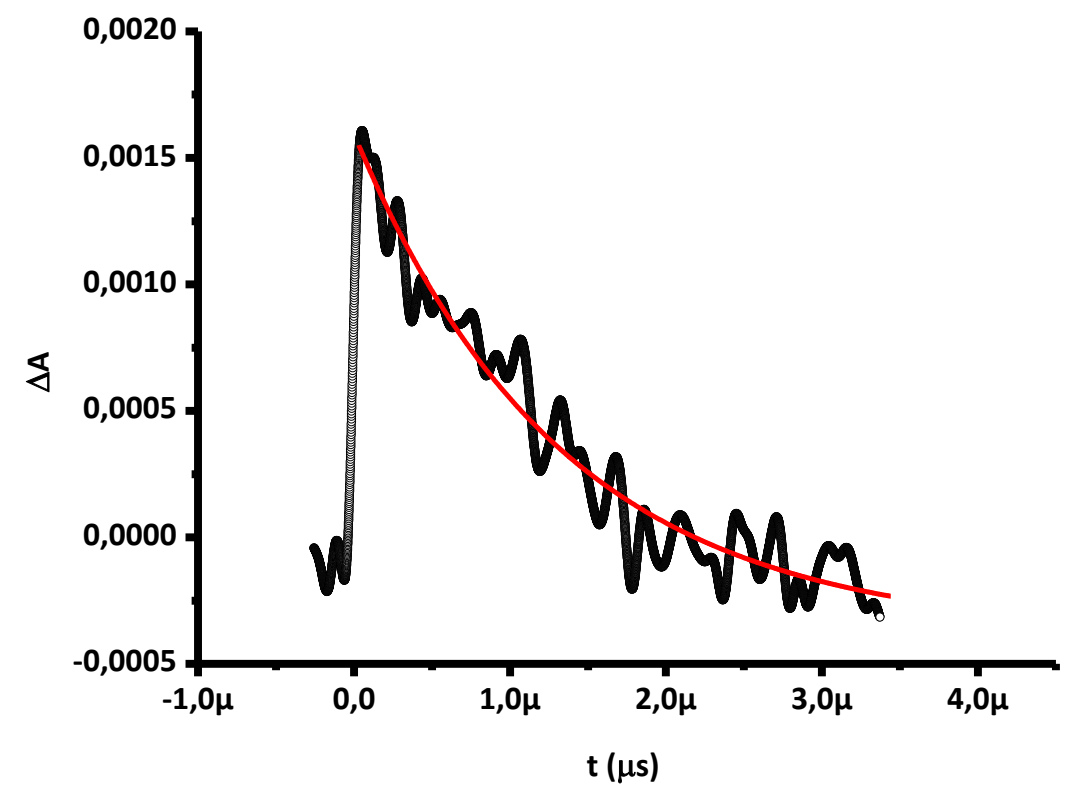

\section{Figura 19}

Traza obtenida del decaimiento de la especie transitoria medida a $540 \mathrm{~nm}$, obtenida irradiando una solución en ACN del complejo RePtr $10^{-5} \mathrm{M}$ con TEA $10^{-4} \mathrm{M}\left(\lambda_{\mathrm{exc}}=355\right.$ nm.)

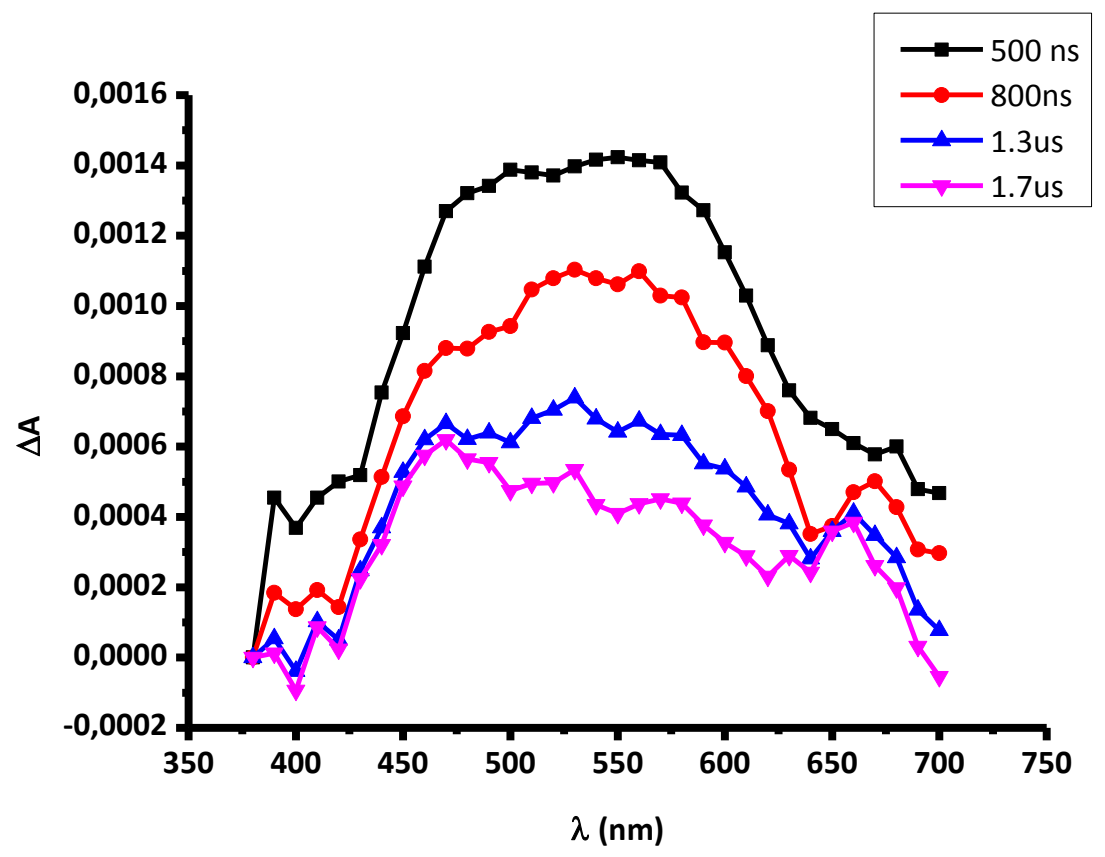

Figura 20

Espectros de absorción de la especie transitoria obtenidos a los tiempos 500, 800, 1300 y 1700 ns luego de irradiada la muestra del complejo RePtr $10^{-5} \mathrm{M}$ en ACN, con TEA $10^{-4} \mathrm{M},\left(\lambda_{\text {exc }}=355 \mathrm{~nm}\right)$ 


\subsubsection{Estudio con TEA}

Utilizando TEA en altas concentraciones (mayor a $10^{-2} \mathrm{M}$ ) es posible estudiar la reactividad redox del estado excitado del complejo.

Se realizaron medidas de una solución del complejo RePtr en ACN con TEA 0,1 M. Se utilizó luz de $355 \mathrm{~nm}$ para la excitación y se midieron las trazas de decaimiento entre 380 y $700 \mathrm{~nm}$. Las trazas medidas fueron analizadas mediante un ajuste a un decaimiento mono-exponencial. Se obtuvo el mismo tiempo de vida para todas las trazas. El tiempo de vida calculado de la especie transiente fue de $3 \mu \mathrm{s}$. La traza utilizada fue medida a $460 \mathrm{~nm}$ (figura 21). El espectro obtenido para esta especie transiente (figura 22), muestra un único máximo cercano a los $460 \mathrm{~nm}$.

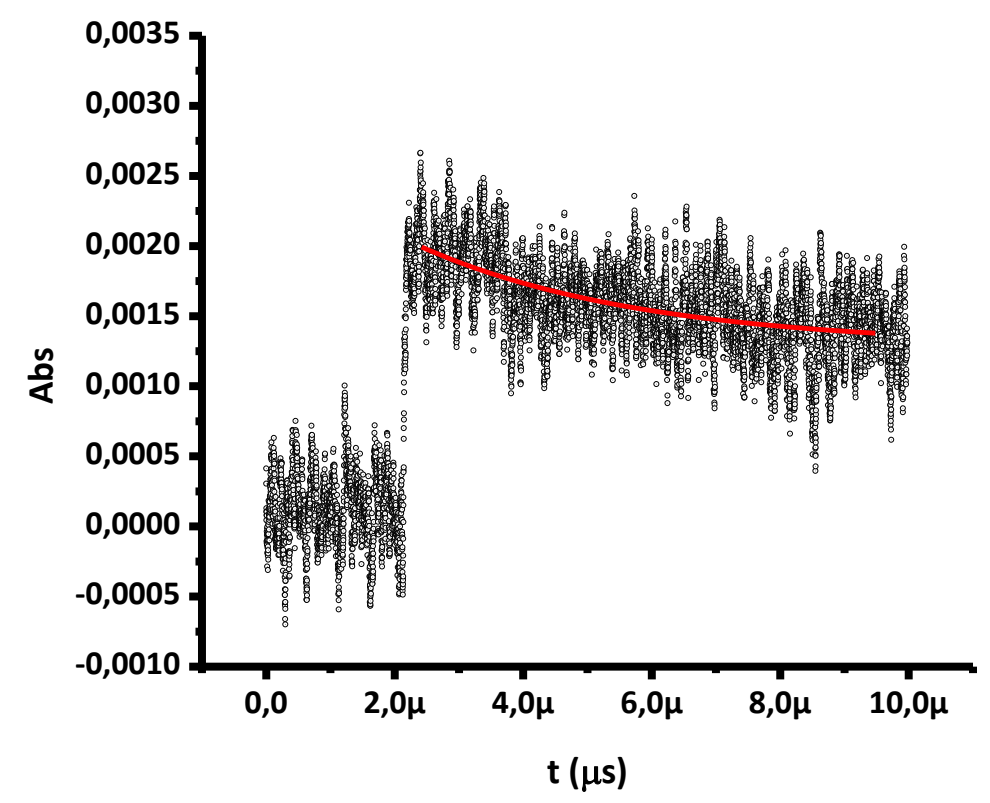

Figura 21

Traza obtenida del decaimiento de la especie transitoria medida a $460 \mathrm{~nm}$, obtenida irradiando una solución en ACN del complejo RePtr con TEA 0,1 M $\left(\lambda_{\text {exc }}=355 \mathrm{~nm}\right)$ 


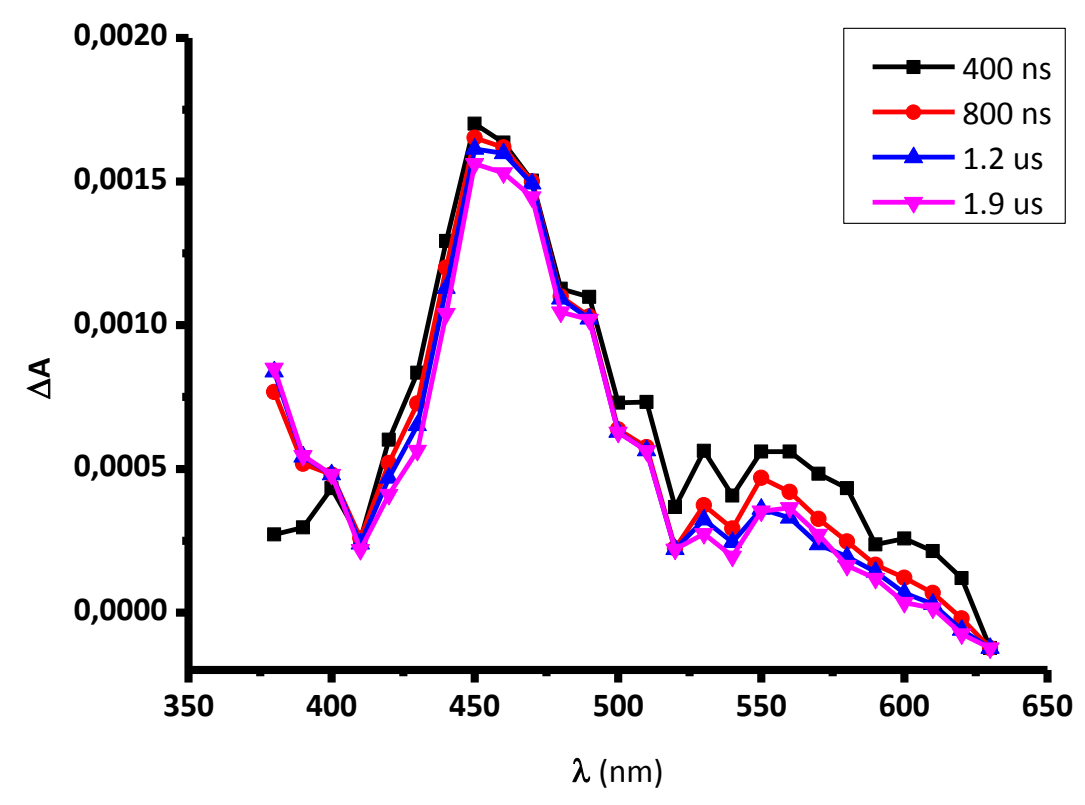

Figura 22

Espectros de absorción de la especie transitoria del complejo RePtr en ACN con TEA $0,1 \mathrm{M}$ obtenidos a los tiempos 400, 800, 1200 y $1900 \mathrm{~ns}\left(\lambda_{\mathrm{exc}}=355 \mathrm{~nm}\right)$

\subsection{Radiólisis de pulso}

Las especies reductoras generadas en forma directa o indirecta fueron el $\mathrm{e}_{\mathrm{sv}}{ }^{-}$, el radical $\mathrm{CO}_{2}^{\bullet-}$ y el radical del 2-propanol $\left(\mathrm{CH}_{3}\right)_{2} \mathrm{COH}^{\bullet}$ Como especie oxidante se utilizó el radical de la Azida $\mathrm{N}_{3}{ }^{\circ}$.

\subsubsection{Reacciones con especies reductoras}

Se preparó una solución acuosa del complejo RePtr de concentración $1.78 \times 10^{-5} \mathrm{M}$, la acidez de la solución se ajustó a pH 6 con un buffer fosfato. Luego se agregó formiato de sodio $\left(\mathrm{NaHCO}_{2}\right)$ hasta concentración 0,01 M. La solución se separó en dos fracciones, a una de ellas se la burbujeo con $\mathrm{N}_{2} \mathrm{O}$ y a la otra con $\mathrm{N}_{2}$.

Luego del pulso, se generan cantidades iguales del $\mathrm{e}_{\mathrm{sv}}{ }^{-} \mathrm{y}$ de $\mathrm{OH}^{\bullet}$. En esta condición de acidez, la concentración de $\mathrm{H}^{+}$es despreciable por lo tanto no se tiene en cuenta la 
influencia del átomo de $\mathrm{H}$. Estos radicales primarios, en atmosfera de $\mathrm{N}_{2} \mathrm{O}$, reaccionan con el formiato según las siguientes reacciones.

$$
\begin{aligned}
e_{s v}^{-}+\mathrm{N}_{2} \mathrm{O} & \rightarrow \mathrm{N}_{2}+\mathrm{O}^{\bullet-} \\
\mathrm{O}^{\bullet-}+\mathrm{H}_{2} \mathrm{O} & \rightarrow \mathrm{OH}^{\bullet}+\mathrm{OH}^{-} \\
\mathrm{OH}^{\bullet}+\mathrm{HCO}_{2}^{-} & \rightarrow \mathrm{CO}_{2}^{\bullet-}+\mathrm{H}_{2} \mathrm{O}
\end{aligned}
$$

Las especies transientes generadas por reacción de estos radicales con el complejo RePtr se siguieron por absorción resuelta en el tiempo. Los espectros resultantes obtenidos del análisis de las trazas de decaimiento del transiente se presentan en la figuras 23 a y $b$.

a) 0

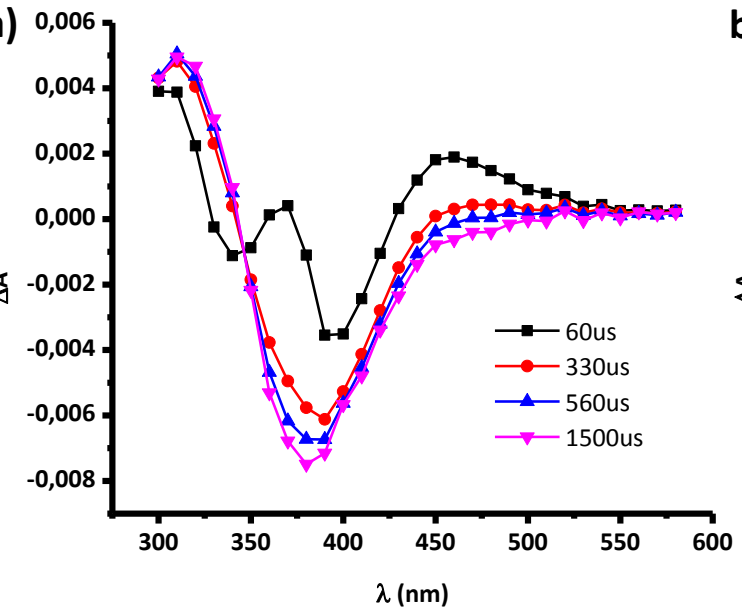

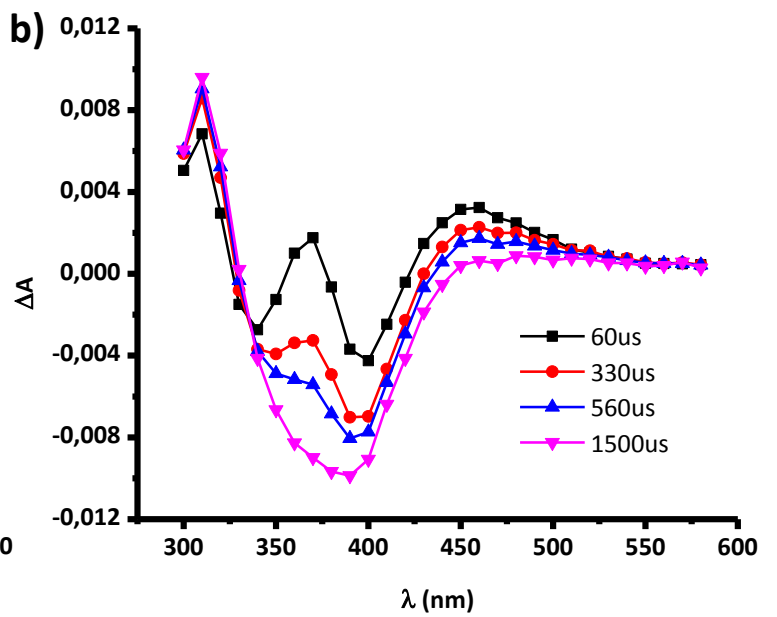

\section{Figura 23}

Espectros de absorción del transiente generado en una solución acuosa del complejo RePtr en presencia de formiato. a) en solución saturada con $\mathrm{N}_{2} \mathrm{O}$, b) solución saturada con $\mathrm{N}_{2}$

Se realizaron medidas agregando 2-propanol hasta concentración 0,1 M a la solución acuosa del complejo RePtr burbujeada con $\mathrm{N}_{2} \mathrm{O}$. Las reacciones de formación de radicales, son las siguientes:

$$
\begin{gathered}
e_{s v}^{-}+\mathrm{N}_{2} \mathrm{O} \rightarrow \mathrm{N}_{2}+\mathrm{O}^{\bullet-} \\
\mathrm{O}^{\bullet-}+\mathrm{H}_{2} \mathrm{O} \rightarrow \mathrm{OH}^{\bullet}+\mathrm{OH}^{-}
\end{gathered}
$$




$$
\mathrm{OH}^{\bullet}+\left(\mathrm{CH}_{3}\right)_{2} \mathrm{COH} \rightarrow\left(\mathrm{CH}_{3}\right)_{2} \mathrm{COH}^{\bullet}
$$

Los espectros resultantes obtenidos del análisis de las trazas de decaimiento del transiente se presentan en la figura 24.

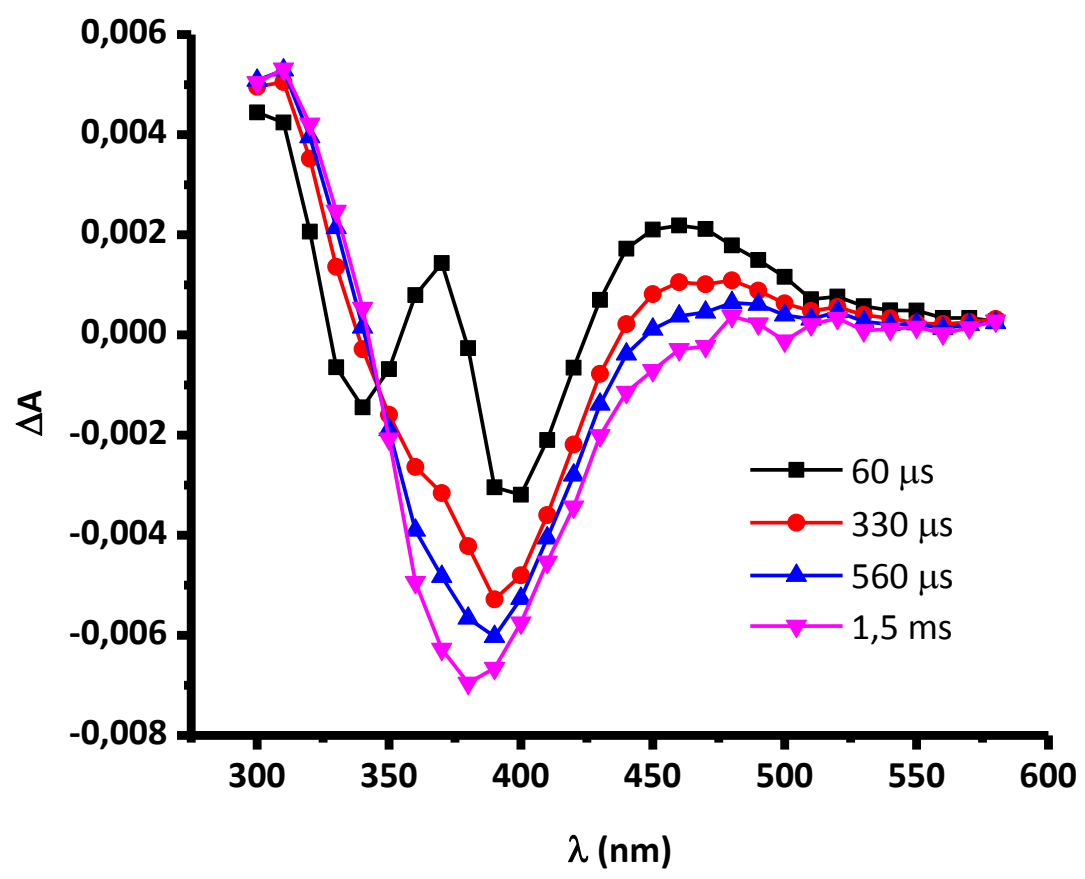

Figura 24.

Espectros de absorción del transiente generado en una solución acuosa del complejo RePtr en presencia de 2-propanol 0,1 M, en solución saturada con $\mathrm{N}_{2} \mathrm{O}$.

\subsubsection{Reacciones con el radical Azida.}

Se preparó una solución acuosa del complejo RePtr $4 \times 10^{-5} \mathrm{M}$ en buffer fosfato a pH 6 . A esta solución se agregó Azida de sodio $\left(\mathrm{NaN}_{3}\right)$ hasta concentración $0,01 \mathrm{M}$, la solución se burbujeo con $\mathrm{N}_{2} \mathrm{O}$. Las reacciones de formación de radicales secundarios son las siguientes:

$$
\begin{gathered}
e_{S v}^{-}+N_{2} O \rightarrow N_{2}+\mathrm{O}^{\bullet-} \\
\mathrm{O}^{\bullet-}+\mathrm{H}_{2} \mathrm{O} \rightarrow \mathrm{OH}^{\bullet}+\mathrm{OH}^{-} \\
O H^{\bullet}+\mathrm{N}_{3}^{-} \rightarrow \mathrm{N}_{3}^{\bullet}+\mathrm{OH}^{-}
\end{gathered}
$$


La especie radical generada es un radical de gran poder oxidante (1,7 V Vs ENH) [21]. Se registraron los cambios de absorción en el tiempo luego del pulso a distintas longitudes de onda. Se graficaron los espectros a distintos tiempos luego del pulso. Los espectros obtenidos se presentan en la figura 25.

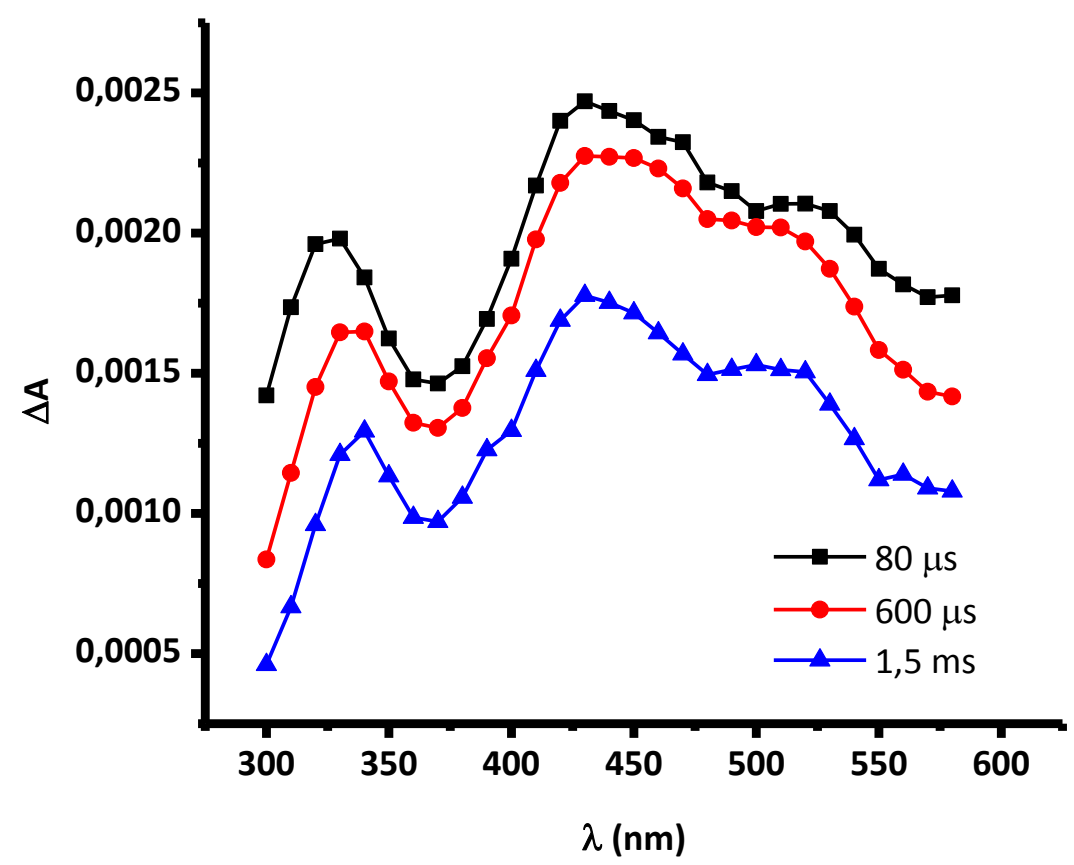

Figura 25.

Espectros de absorción del transiente generado en una solución acuosa del complejo RePtr en presencia de Azida de Sodio en solución saturada con $\mathrm{N}_{2}$.

\section{Conclusiones del capítulo IV}

Los rasgos característicos del espectro de absorción del complejo RePtr, nos permiten comenzar a responder algunos de los interrogantes planteados. En particular aquellos centrados sobre la naturaleza de los estados que son poblados inmediatamente después de la absorción de luz.

El espectro del complejo RePtr en los distintos solventes presenta, en general, dos bandas de absorción. Una banda ubicada en la región UV, centrada cerca de los 250 $\mathrm{nm}$ y otra banda ancha en la región visible, ubicada entre los 350 y $450 \mathrm{~nm}$. Esta banda 
de baja energía no estaba presente en el ligando libre, por lo que se la asocia al poblamiento de un estado excitado del tipo MLCT. La asignación de esta banda está también en concordancia con asignaciones realizadas en compuestos relacionados [13], [22]. La banda ubicada en la región UV es coincidente en posición con la banda de mayor energía de la forma alcalina del ligando libre. Esta banda no presenta corrimientos al variar la polaridad del solvente. Es por estas características, que se asoció esta banda a la transición que puebla el estado IL. El ligando libre presenta otra banda centrada en los $340 \mathrm{~nm}$. De este modo es posible que los estados IL y MLCT se pueblen simultáneamente. La contribución de los orbitales de los CO coordinados por el Renio a las transiciones que originan las bandas de absorción, se determinó utilizando cálculos computacionales de TD-FT realizados sobre este complejo [23]. Según estos cálculos, banda de menor energía está asociada a una transición de transferencia de carga $d \pi\left(\operatorname{Re}^{\prime}\right)-\pi C O \rightarrow \pi^{*}$ (ptr), que genera el estado excitado MLLCT $\operatorname{Re}(\mathrm{CO})_{3} \rightarrow$ Ptr. La banda de mayor energía, $\lambda_{\max }=254 \mathrm{~nm}$, fue asignada principalmente a transiciones $\pi \rightarrow \pi^{*}$ centradas en la pterina, poblando un estado excitado de naturaleza IL.

De este modo sería más apropiado referirnos a estos estados como MLLCT en lugar de MLCT. Este estado MLLCT puede entenderse como la combinación de los estados MLCT y LLCT, de modo que en muchos casos nos seguiremos refiriendo al estado MLCT para diferenciarlo del estado IL. En la figura 26 se presenta un diagrama que describe cualitativamente los orbitales del complejo RePtr y las transiciones que se observan luego de la absorción de luz.

Las medidas de emisión luminiscente nos permiten conocer los atributos fundamentales de los estados excitados de menor energía. Entre estos, los más relevantes son, la naturaleza y tiempo de vida del estado emisor. La emisión estacionaria para este complejo en medio acuoso, se muestra como una banda ancha sin estructura, con un máximo alrededor de $\lambda \approx 450 \mathrm{~nm}$. El tiempo de vida de este estado excitado es cercano a los $8 \mathrm{~ns}$, y la intensidad de luminiscencia no se ve afectada por los cambio en la concentración de oxígeno disuelto. Estas características son similares a las observadas para la fluorescencia del ligando libre [5]. En la pterina, se asignó esta banda de fluorescencia a la desexcitación del estado excitado singlete a su estado basal $S_{1} \rightarrow S_{0}$. De este modo, la banda de emisión del complejo centrada a 
$450 \mathrm{~nm}$ se asigna a la desexcitación radiativa del estado singlete intraligando. ${ }^{1} \mathrm{IL}$. EI rendimiento cuántico de emisión del complejo en agua, es similar para las condiciones de $\mathrm{pH} 3$ y 6 . El valor de este rendimiento registra un aumento en el $\phi_{\mathrm{emi}}$ al ajustar el $\mathrm{pH}$ a 10. Una manera de racionalizar este resultado de aumento de rendimiento cuántico de emisión a pH alcalino es tener en cuenta lo siguiente. El estado basal del complejo por encima de $\mathrm{pH} 8$ se presenta mayoritariamente con el agua coordinada al Re desprotonada. En la forma cristalina del complejo, esta agua se encuentra formando puentes de hidrogeno con las aguas de cristalización. De este modo, es posible que al deprotonarse se vea desfavorecida la relajación no radiativa y favorecida la vía radiativa. Esta interpretación es coherente con la disminución del $\alpha$ en esta condición.

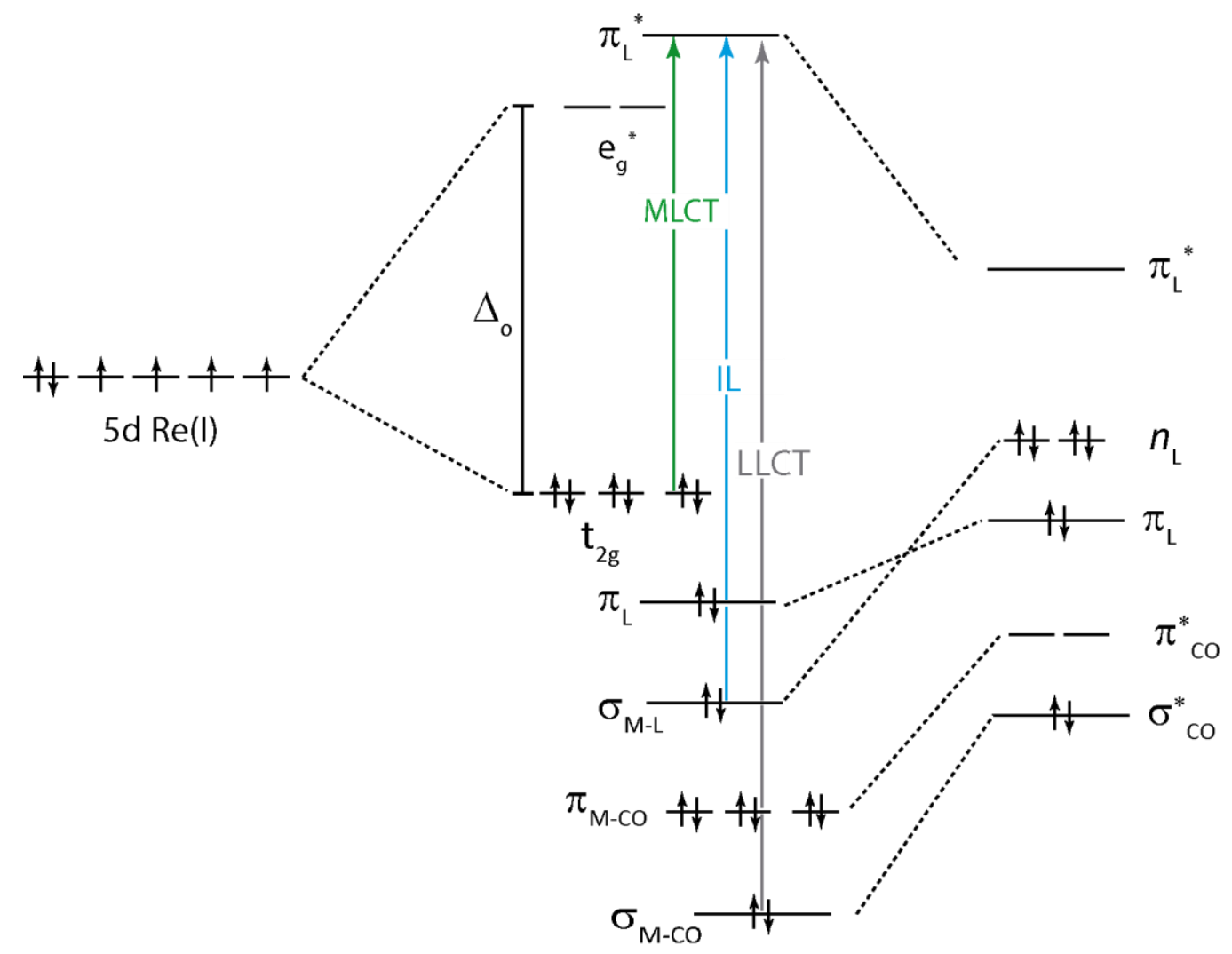

Orbitales del metal

\section{Figura 26}

Diagrama cualitativo de los orbitales del complejo RePtr, con flechas se indican las transiciones observadas luego de la absorción de un fotón.

Al realizar medidas de emisión luminiscente en $\mathrm{ACN}$, se observan dos bandas de emisión. Una banda centrada en $416 \mathrm{~nm}$ con un tiempo de vida de 8 ns y un 
rendimiento cuántico de $2 \times 10^{-2}$. Y otra banda centrada en $555 \mathrm{~nm}$ con una intensidad de luminiscencia en el máximo un orden de magnitud menor que la primera. La banda centrada en $416 \mathrm{~nm}$, por evidente similitud con la banda de emisión que se observa en medio acuoso, se reconoce como producto de la desexcitación del estado ${ }^{1} \mathrm{IL}$.

Cuando la solución del complejo RePtr se burbujeo con $\mathrm{N}_{2}$, se registró un aumento en la intensidad de la banda de $555 \mathrm{~nm}$. El tiempo de vida del estado excitado responsable de esta emisión es de $\approx 300 \mathrm{~ns}$ en $\mathrm{N}_{2}$, disminuyendo a un valor $\approx 50 \mathrm{~ns}$ cuando la solución se satura en Oxígeno. La magnitud del tiempo de vida y la capacidad de interaccionar con el triplete del Oxígeno, indican que el estado emisor es de naturaleza triplete. Esta emisión también se registra cuando la solución se irradia con luz de $400 \mathrm{~nm}$. A esa longitud de onda, la absorción de radiación conduce a generación del estado excitado ${ }^{1} \mathrm{MLCT}$, el cual por CIS puebla el ${ }^{3} \mathrm{MLCT}$.

El espectro de emisión obtenido a $77 \mathrm{~K}$ muestra un máximo a $566 \mathrm{~nm}$. Este experimento aporta evidencia sobre la identidad ${ }^{3} \mathrm{MLCT}$ que se encuentra desplazado por el efecto rigidocrómico. Con esta evidencia, sabemos que el estado ${ }^{3} \mathrm{MLCT}$ es el estado emisor.

El exceso de energía del estado excitado que no es liberado mediante la emisión de luz, lo hace por vías no radiativas. Estos caminos de desexcitación pueden conducir a la liberación de energía térmica al medio o bien puede ceder esta energía a otras moléculas. La transferencia de energía del estado excitado triplete del complejo al triplete del oxígeno para generar oxígeno singlete, representa una de los procesos de fotosensibilización más interesantes. Esto es así, tanto por la utilidad que puede darse al ${ }^{1} \mathrm{O}_{2}$, como por la información que puede obtenerse sobre los caminos no radiativos. Se eligieron tres complejos de Renio, ReBipyTf, RePhenTf y ReBpyPy para ser estudiados en paralelo con el RePtr. Se evaluaron las vías de desexcitación luminiscente y no luminiscente. Para esto fue necesario completar la información fotofísica de estos complejos que aún no había sido evaluada. Todos estos complejos en solución de $A C N$ presentan emisión luminiscente. Esta emisión es originada en la desexcitación de estado ${ }^{3} \mathrm{MLCT}$. La longitud de onda del máximo de emisión en todos los casos se encuentra entre los 540 y $560 \mathrm{~nm}$. El tiempo de vida de los estados excitados es del orden de los cientos de nanosegundos. Estas coincidencias reflejan las similitudes entre los estados emisores. Estas similitudes se deben a que el proceso de 
transferencia de carga, en todos los casos, ocurre desde el tricarbonilo de Renio hacia un ligando orgánico aceptor de electrones con una extensa nube $\pi$.

La desactivación del estado excitado emisor por vías no emisivas fue cuantificada mediante la técnica de optoacústica. Los valores de $\alpha$ calculados para todos los complejos estudiados, fueron altos, superiores a 0,8. En particular para el complejo RePtr se encontró que la fracción de energía liberada como calor, en ACN, tanto es cercana a la unidad. Se evaluaron las vías de generación de ${ }^{1} \mathrm{O}_{2}$ para todos los complejos. Esto se hizo, midiendo en forma directa el rendimiento de generación de ${ }^{1} \mathrm{O}_{2}$ y calculando los rendimientos de cada uno de los caminos que conducen a la generación de oxígeno singlete.

El $\phi_{\Delta}$ medido para el complejo RePtr en $\mathrm{ACN}$ fue de 0,06 . No de detectó generación ${ }^{1} \mathrm{O}_{2}$ en agua. Los otros tres complejos presentaron valores altos de $\phi_{\Delta}$, que se encuentran entre 0,6 y 0,8 . El $\phi_{\Delta}$ aumenta a medida que aumenta el tiempo de vida del estado ${ }^{3}$ MLCT. Para todos los complejos el balance de energía planteado reflejo valores cercanos a la unidad. Este resultado, por un lado nos confirma los valores medidos y por otro indica la ausencia de fotoproductos que pudieran actuar como reservorios de energía con $\tau>5 \mu s$.

Se estudiaron las características fotofísicas del transiente de absorción del complejo RePtr generado por LFF en ACN. Se encontró un espectro con tres bandas en 400, 480 y $550 \mathrm{~nm}$. En este espectro se distinguieron dos transientes, uno asociado a la banda con máximos en 480 y $550 \mathrm{~nm}$, que decae con un tiempo de vida de 1,1 $\mu \mathrm{s}$. El otro transiente asociado a la banda centrada en $400 \mathrm{~nm}$ que decae con un tiempo de vida de $\approx 300$ ns. Este último transiente, presenta el mismo tiempo de vida que el estado ${ }^{3} \mathrm{MLCT}$. Con base en esta similitud proponemos que se trata del mismo estado excitado.

El espectro del transiente de vida más larga, se encuentra en buena concordancia con el espectro publicado para el triplete de uno de los tautomeros del ligando pterina. Este transiente publicado decae con un tiempo de vida de 2,3 $\mu$ s [24]. Con base en estas similitudes espectrales, el transiente observado por LFF en ACN, con tiempo de vida de vida $1,1 \mu \mathrm{s}$, se asignó al estado ${ }^{3}$ IL del complejo.

La modificación de la acidez del medio por adición de TEA, en baja concentración, no produjo, en general, ninguna alteración observable en el número de bandas y rasgos 
de absorción del espectro del transiente. Sin embargo sí se notó una disminución en la intensidad de la banda centrada en $400 \mathrm{~nm}$.

Para explicar la ausencia de trazas cuando se trabajó en agua o cuando se agregaron sustancias próticas al ACN se analizó la influencia de la acidez del medio sobre el tiempo de vida del ${ }^{3}$ IL. No se encontraron variaciones significativas. Sin embargo cuando la acidez del medio fue tal, que la forma predominante en estado basal fue la forma acida del complejo, no pudo obtenerse ninguna traza. Esto permitió descartar una posible desactivación dinámica del estado excitado por parte del $\mathrm{H}^{+}$. La ausencia de trazas, puede explicarse considerando que el triplete de la especie acida del complejo en $\mathrm{ACN}\left[\mathrm{RePtrH}^{+}\right]$posee una rápida relajación al estado basal.

Todas las propiedades fotofísicas hasta aquí encontradas se resumen en un diagrama de términos presentado en la figura 27.

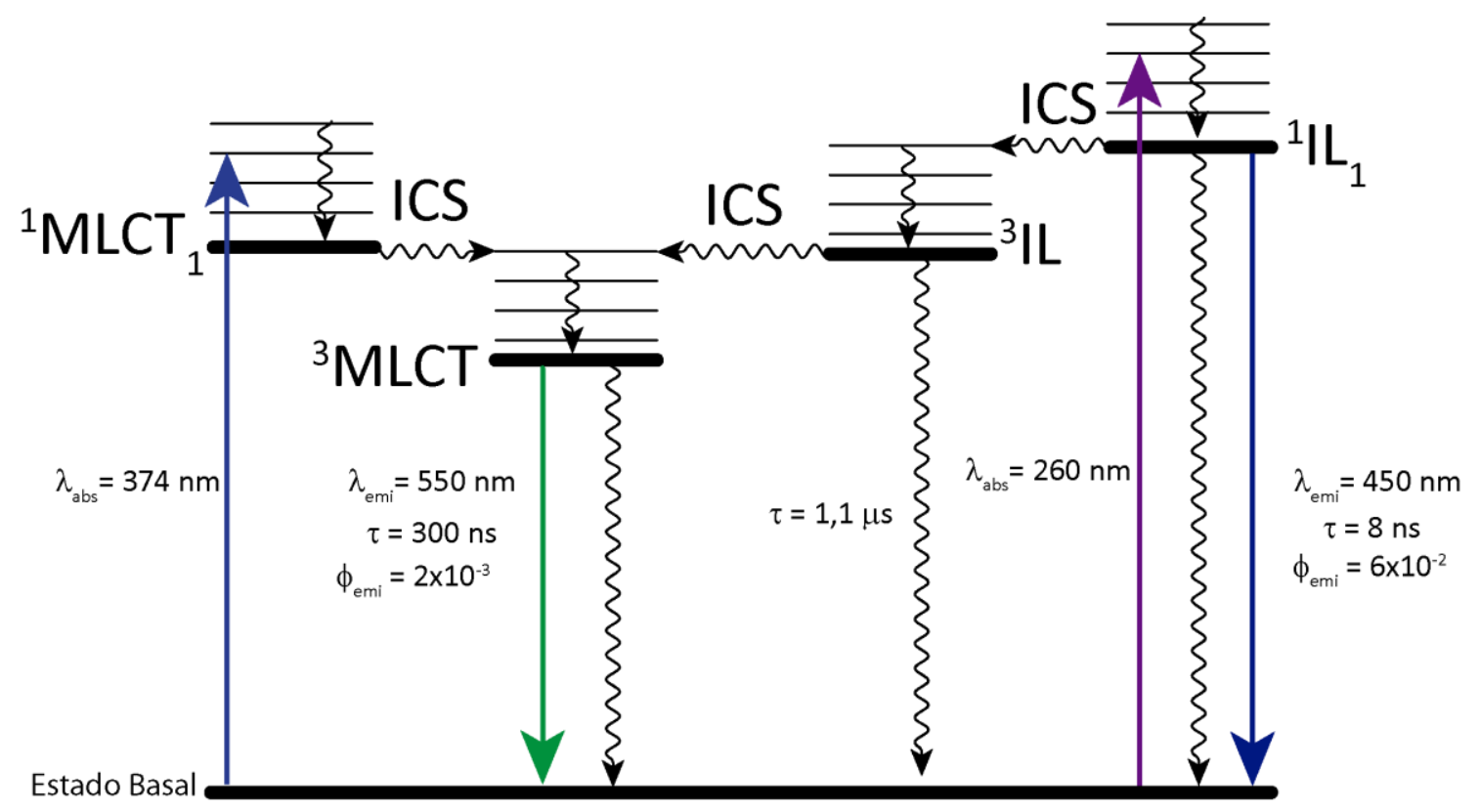

Figura 27.

Diagrama de términos del complejo RePtr, en flechas enteras ascendentes se muestran las absorciones de luz, en flechas enteras descendentes se muestran las emisiones luminiscentes. Con flechas curvas se indican las transiciones no radiativas.

Con el objetivo de determinar las características redox del estado excitado del complejo, se agregó TEA a una solución en ACN del complejo. Se usó una concentración lo suficientemente alta como para desactivar todos los estados 
excitados generados del complejo. En estas condiciones, la TEA reacciona cediendo un átomo de $\mathrm{H}$ [25], [26]. El espectro del transiente obtenido resulto compatible con el espectro publicado para la especie reducida del ligando [24][27]. El tiempo de vida calculado para este transiente fue de 3,0 $\mu \mathrm{s}$.

Se realizaron experimentos de PR utilizando formiato para generar el radical $\mathrm{CO}_{2}{ }^{\bullet-}$. Se estudió el espectro del transiente obtenido por reacción de este radical y con el $\mathrm{e}_{\mathrm{sv}}{ }^{-}$. Se logró observar los espectros de las especies transientes generada por reacción con estos radicales. La forma de los espectros generados en las dos condiciones presenta $n$ formas similares. Ambos espectros medidos a $60 \mu$ s presentan máximos en 370 y 470 $\mathrm{nm}$. Los espectros medidos a 1,7 ms, presentan un gran declive entre 350 y $450 \mathrm{~nm}$ con un pequeño máximo a 450nm. Los espectros del transiente obtenidos de la solución del complejo en atmosfera de $\mathrm{N}_{2}$, responden al transiente generado por reacción con el radical $\mathrm{CO}_{2}{ }^{\bullet-}$ y el $\mathrm{e}_{\mathrm{sv}}{ }^{-}$. Aunque, debido a su mayor potencial, el $\mathrm{e}_{\mathrm{sv}}{ }^{-}$es quien domina la reacción. De este modo, este espectro pertenece al radical reducido del complejo RePtr. Por similitud se puede afirmar que el transiente obtenido por reacción con $\mathrm{CO}_{2}{ }^{\circ}$, es también el del transiente reducido del complejo.

Se utilizó 2-propanol para generar el radical $\left(\mathrm{CO}_{3}\right)_{2} \mathrm{COH}^{\bullet}$. Se obtuvieron los espectros del transiente generado. Estos espectros presentaron la misma forma que el espectro del transiente reducido observado en la reacción con el radical $\mathrm{CO}_{2}{ }^{\circ-}$.

Estos transientes observados corresponden a una especie reducida del complejo RePtr y se encuentra en buen acuerdo con el obtenido por LFF utilizando TEA como reductor. Estos espectros también presentan el mismo aspecto que el espectro publicado para la especie semi-reducida del ligando [24][28]. De este modo se concluye que los transientes observados por LFF con TEA y por PR en condiciones reductoras corresponden a un transiente reducido del complejo RePtr y que esa reducción ocurre en el ligando pterina coordinado.

$$
\begin{gathered}
\operatorname{RePtr}^{*}+\mathrm{TEA} \rightarrow \operatorname{RePtrH} H^{\bullet}+\mathrm{TEA}_{\text {ox }} \\
\operatorname{RePtr}+\mathrm{HCO}_{2}^{\bullet-} \rightarrow \operatorname{RePtr} H^{\bullet}+\mathrm{CO}_{2} \\
\operatorname{RePtr}+\left(\mathrm{CO}_{3}\right)_{2} \mathrm{COH}^{\bullet-} \rightarrow \operatorname{RePtr} H^{\bullet}+\left(\mathrm{CO}_{3}\right)_{2} \mathrm{CO}
\end{gathered}
$$


Utilizando la misma técnica con el agregado de $\mathrm{NaN}_{3}$ se estudió el espectro del transiente oxidado del complejo RePtr. Este espectro presenta la forma característica del transiente de $\operatorname{Re}(I I)$ [21]. Por lo cual, concluimos que por oxidación se obtiene una especie transiente oxidada del complejo con el Re en estado de oxidación +2 .

$$
R e^{I} P t r+\mathrm{N}_{3}^{\bullet} \rightarrow \operatorname{Re}^{I I} \operatorname{Ptr}^{+\bullet}+\mathrm{N}_{3}^{-}
$$

\section{Referencias bibliográficas}

[1] E. Wolcan and G. Ferraudi, "Photochemical and Photophysical Properties of FacRe(I) Tricarbonyl Complexes: A Comparison of Monomer and Polymer Species with -Rel(CO)3Phen Chromophores," J. Phys. Chem. A, vol. 104, no. 41, pp. 3-8, 2000.

[2] E. Wolcan and M. R. Feliz, "Temperature and medium effects on the photophysical properties of $\operatorname{Re}(\mathrm{CO}) 3\left(2,2^{\prime}\right.$-bipyridine) pendant chromophores coordinated to a poly(4-vinylpyridine) backbone," Photochem. Photobiol. Sci., vol. 2, no. 4, p. 412, 2003.

[3] G. A. Vidulich, D. F. Evans, and R. L. Kay, "The Dielectric Constant of Water and Heavy Water between 0 and 40 ", J. Phys. Chem., vol. 71, no. 5, pp. 656-662, 1966.

[4] I. M. Smallwood, Handbook of organic solvent properties. New York, 1997.

[5] C. Lorente and A. H. Thomas, "Photophysics and photochemistry of pterins in aqueous solution.," Acc. Chem. Res., vol. 39, no. 6, pp. 395-402, Jun. 2006.

[6] A. A. H. Thomas, C. Lorente, A. L. Capparelli, M. R. Pokhrel, A. M. Braun, and E. Oliveros, "Fluorescence of pterin, 6-formylpterin, 6-carboxypterin and folic acid in aqueous solution: pH effects," Photochem. Photobiol. Sci., vol. 1, no. 6, pp. 421-426, Jun. 2002.

[7] J. M. Achord and C. L. Hussey, "Determination of Dissolved Oxygen in Nonaqueous Electrochemical Solvents Determination of 1 , 2-Diols by Indirect Atomic Absorption with Digested Lead Periodate," pp. 601-602, 1980.

[8] P. B. Merkel and D. R. Kearns, "Radiationless decay of singlet molecular oxygen in solution. Experimental and theoretical study of electronic-to-vibrational energy transfer," J. Am. Chem. Soc., vol. 94, no. 21, pp. 7244-7253, Oct. 1972. 
[9] F. Wilkinson and J. G. Brummer, "Rate constants for the decay and reactions of the lowest electronically excited singlet state of molecular oxygen in solution," J. Phys. Chem. Ref. Data, vol. 10, no. 4, p. 809, 1981.

[10] R. Schmidt, C. Tanielian, R. Dunsbach, and C. Wolff, "Phenalenone, a universal reference compound for the determination of quantum yields of singlet oxygen 102 sensitization," J. Photochem. Photobiol. A Chem., vol. 79, pp. 11-17, 1994.

[11] P. Van and M. Van Der Auweraer, "References for laser-induced using UV excitation," J. Photochem. Photobiol. A Chem., vol. 63, pp. 265-277, 1992.

[12] S. Abbruzzetti, C. Viappiani, D. H. Murgida, R. Erra-Balsells, and G. M. Bilmes, "Non-toxic, water-soluble photocalorimetric reference compounds for UV and visible excitation," Chem. Phys. Lett., vol. 304, no. April, pp. 167-172, 1999.

[13] L. Wallace and D. Rillema, "Photophysical properties of rhenium (I) tricarbonyl complexes containing alkyl-and aryl-substituted phenanthrolines as ligands," Inorg. Chem., vol. 32, no. 18, pp. 3836-3843, 1993.

[14] T. R. I. Chem, L. Sacksteder, A. P. Zipp, E. A. Brown, J. Streich, J. N. Demas, and B. A. Degraff, "Luminescence Studies of Pyridine a-Diimine Rhenium ( I ) Tricarbonyl Complexest," vol. 2, pp. 4335-4340, 1990.

[15] U. N. Fagioli, F. S. García Einschlag, C. J. Cobos, G. T. Ruiz, M. R. Féliz, and E. Wolcan, "On the mechanism of $\operatorname{Re}(\mathrm{I})$-carboxylate bond cleavage by perchloric acid: a kinetic and spectroscopic study.," J. Phys. Chem. A, vol. 115, no. 40, pp. 10979-87, Oct. 2011.

[16] O. Gijzeman, F. Kaufman, and G. Porter, "Oxygen quenching of aromatic triplet states in solution. Part 1," J. Chem. SOC., Faraday Trans, vol. 69, p. 708-720, 1973.

[17] F. Wilkinson and A. a. Abdel-Shafi, "Mechanism of Quenching of Triplet States by Molecular Oxygen: Biphenyl Derivatives in Different Solvents," J. Phys. Chem. A, vol. 103, no. 28, pp. 5425-5435, Jul. 1999.

[18] A. a Abdel-Shafi, J. L. Bourdelande, and S. S. Ali, "Photosensitized generation of singlet oxygen from rhenium(I) and iridium(III) complexes.," Dalton Trans., no. 24, pp. 2510-6, Jun. 2007.

[19] Q. Li, C. Batchelor-McAuley, N. S. Lawrence, R. S. Hartshorne, and R. G. Compton, "Anomalous solubility of oxygen in acetonitrile/water mixture containing tetra-n-butylammonium perchlorate supporting electrolyte; the solubility and diffusion coefficient of oxygen in anhydrous acetonitrile and aqueous mixtures," J. Electroanal. Chem., vol. 688, pp. 328-335, Jan. 2013. 
[20] R. Schmidt, "The effect of solvent polarity on the balance between charge transfer and non-charge transfer pathways in the sensitization of singlet oxygen by pipi triplet states.," J. Phys. Chem. A, vol. 110, no. 18, pp. 5990-7, May 2006.

[21] G. T. Ruiz, M. P. Juliarena, E. Wolcan, and G. Ferraudi, "Kinetic and spectroscopic observations on the azidyl, , radical oxidation of fac(Lspectator)Rel(CO)3(Lacceptor) to fac-(Lspectator)Rell(CO)3(Lacceptor), Lspectator=4,4'-bpy; Lacceptor=dipyridyl[3,2-a:2'3'-c]phenazine or Lspectator=Cl-; Lacceptor=bathocup," Inorganica Chim. Acta, vol. 360, no. 12, pp. 3681-3687, Sep. 2007.

[22] Y. Gao, S. Sun, and K. Han, "Electronic structures and spectroscopic properties of rhenium (I) tricarbonyl photosensitizer: [Re(4,4'-(COOEt)2-2,2'bpy)(CO)3py]PF6.," Spectrochim. Acta. A. Mol. Biomol. Spectrosc., vol. 71, no. 5, pp. 2016-22, Jan. 2009.

[23] E. Wolcan, "On the origins of the absorption spectroscopy of pterin and $\operatorname{Re}(\mathrm{CO}) 3$ (pterin)(H2O) aqueous solutions. A combined theoretical and experimental study.", Spectrochim. Acta. A. Mol. Biomol. Spectrosc., vol. 129, pp. 173-83, Aug. 2014.

[24] C. Chahidi and M. Aubailly, "Photophysical and photosensitizing properties of 2amino-4 pteridinone: a natural pigment," Photochem. Photobiol., vol. 33, pp. 641-649, 1981.

[25] T. Okutsu, M. Ooyama, H. Hiratsuka, J. Tsuchiya, and K. Obi, "A Laser Flash Photolysis Study on the Reaction Mechanisms of Benzil with Various Amines," J. Phys. Chem. A, vol. 104, pp. 288-292, 2000.

[26] G. Kciuk, T. Szreder, J. R. De Fuente, C. Aliaga, and A. Ca, "Photoreduction of Azaoxoisoaporphines by Amines: Laser Flash and Steady-State Photolysis and Pulse Radiolysis Studies †," pp. 1417-1426, 2013.

[27] P. Moorthy and E. Hayon, "One-electron redox reactions of water-soluble vitamins. II. Pterin and folic acid," J. Org. Chem., vol. 41, no. 9, pp. 1607-1613, 1976.

[28] M. Farahani, P. S. Surdhar, S. Allen, and D. A. Armstrong, "Reactions of CO2.Radicals with Pterin and Pterin-6-carboxylate Ions," j. Chem. Soc. Perkin Trans., pp. 1687-1693, 1991. 


\title{
Capítulo V
}

Estudios sobre la interacción de

\author{
los complejos del tipo

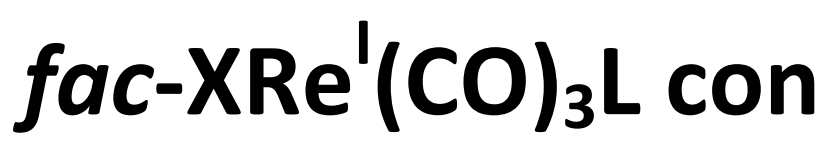 \\ biopolímeros.
}




\section{Introducción}

La naturaleza y la dinámica de la unión de complejos metálicos a biopolímeros representan un área de investigación activa. Los estudios dirigidos hacia el diseño de reactivos sitio-específicos aportan rutas hacia el diseño racional de fármacos, así como un medio para desarrollar sondas químicas sensibles a la estructura del polímero.

Los complejos metálicos han sido reconocidos como agentes importantes de la química de los ácidos nucleicos. La comprensión de cómo interactúan estos complejos metálicos con el ADN se ha convertido en un área de investigación activa en la interfaz entre la química, la biología molecular y la medicina.

Es posible encontrar un gran número de trabajos científicos en los que se reportan estudios sobre la interacción entre complejos de metales de transición y ADN [1]-[13]. Los tipos de interacción que surgen entre los complejos organometálicos y los ácidos nucleicos atrae la atención de los científicos desde hace varias décadas, resultando de esto numerosas publicaciones en el tema [1]-[29]. Se han estudiado intensamente los modos de interacción por diversas técnicas. Además, de los efectos que los complejos inducen sobre variadas biomoléculas, tales como ADN eucariota, plásmidos bacterianos y polinucleótidos sintéticos.

Por otro lado, con un enfoque biomédico, nos encontramos con un extenso y profundo campo de estudio. Abocado a la generación de conocimiento sobre la asociación entre los complejos organometálicos y las proteínas de transporte que circulan en el plasma de los mamíferos [30]-[33].

Siguiendo esta línea, se realizaron estudios de la interacción de tres complejos tricarbonílicos de $\operatorname{Re}(\mathrm{l})$ con diversos ácidos nucleicos y con seroalbúminas. La interacción con ADN se estudió siguiendo los cambios en la absorción y la emisión luminiscente de los complejos, al variar la concentración de ADN. Estos estudios son presentados en este capítulo. Estos estudios son discutidos en este capítulo, donde se presentarán también el efecto que estos complejos inducen sobre algunos plásmidos bacterianos utilizando dos técnicas de relieve para estas investigaciones: la electroforesis y la microscopía de fuerza atómica (AFM). En la segunda mitad del capítulo, se detallan los resultados de los estudios de asociación del complejo RePtr 
con seroalbúminas humana y bovina (HSA y BSA) utilizando técnicas de emisión estacionaria, dicroísmo circular y cálculos de transferencia de energía de resonancia de Förster (FRET). También, se presentan los resultados que se obtuvieron de los valores de los parámetros termodinámicos del proceso de asociación.

Los tres complejos ensayados, son tricarbonilos de Re(I) del tipo RePtr, ReBpyTf y $(d p p z) \operatorname{Re}^{\prime}(\mathrm{CO})_{3}\left(4,4^{\prime}\right.$ bipiridina $) \mathrm{JO}_{3} \mathrm{SCF}_{3}$ (Redppz) (dppz =dipiridil[3,2-a:2'3'-c]fenazina). Estos fueron sintetizados y caracterizados fisicoquímicamente en nuestro grupo. La elección de estos complejos responde a varias cuestiones. Los estudios del complejo RePtr son parte de la trama central de esta tesis, en capítulos anteriores se presentó su síntesis y caracterización. El complejo Redppz es un complejo sobre el cual se dispone información sobre su comportamiento frente a polinucleótidos sintéticos. Sin embargo no se había reportado ningún trabajo sobre la interacción con otros tipos de ADN. Además este complejo es un conocido intercalador. Estas documentadas características del complejo Redppz, son de gran utilidad para interpretar los resultados de interacción de este complejo. Además, es posible comparar los resultados experimentales de la interacción de este complejo, con los datos obtenidos de los ensayos usando los otros complejos. $Y$ de esta forma, obtener nuevas apreciaciones de los resultados experimentales. El complejo ReBpyTf posee un ligando 2,2'bipiridina. Se han estudiado varios complejos metálicos con este ligando y se sabe que no intercala y que no presenta cambios en sus propiedades fotofísicas al interaccionar con ADN [34]. Es por esto, que posee utilidad estratégica como punto de referencia de los resultados. Por otra parte, dado que son conocidas y están bien descriptas las características de interacción del ligando libre de cada uno de estos con los ácidos nucleicos, es posible utilizar este conocimiento para extraer importantes conclusiones sobre los resultados de los experimentos de interacción. La estructura y propiedades de los complejos RePtr y ReBpyTF ya fueron expuestas en capítulos anteriores, la estructura del complejo Redppz se detalla en la figura 1. 


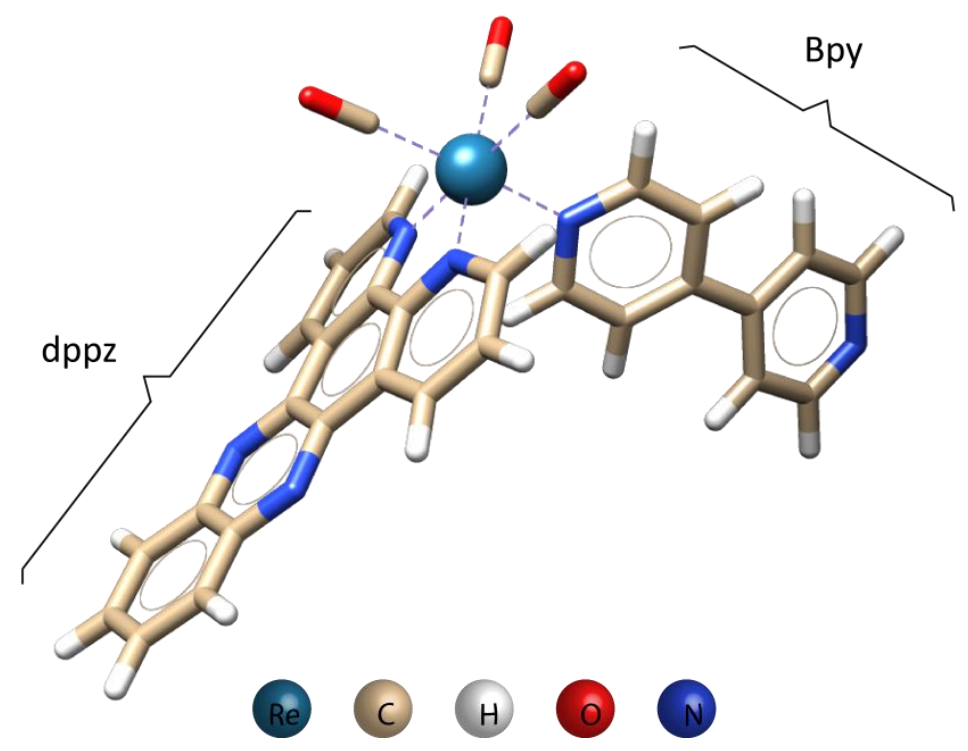

Figura 1

Estructura del complejo Redppz. 


\section{Índice}

\section{Capítulo V}

\section{Estudios sobre la interacción de los complejos del tipo fac-XRe'(CO ${ }_{3} L$ con biopolímeros.}

Introducción 193

Índice 197

Capítulo V

1. Estudios de la interacción con ácidos nucleicos. 199

1.1. Cambios en la absorción y emisión inducidos por la interacción con ADN... 199

1.1.1. Interacción del complejo RePtr con ADN. 199

1.1.2. Interacción del complejo Redppz con ADN 204

1.1.3. Interacción del complejo ReBpyTf con ADN..... 207

1.2. Cambios estructurales inducidos en plásmidos seguidos por electroforesis. 208

1.2.1. Cambios inducidos en el plásmido por la interacción con el estado basal del complejo. 209

1.2.2. Fotosensibilización de DNA plasmídico ............................................. 213

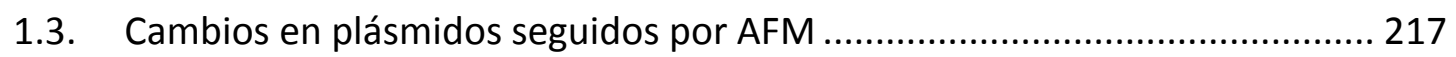

1.3.1. Imágenes de AFM del plásmido Gra7-YFp...................................... 218

1.3.2. Imágenes de AFM del plásmido Gra7-YFp + RePtr.............................. 219

1.3.3. Imágenes de AFM del plásmido Gra7-YFp fotosensibilizado con RePtr 221

1.4. Conclusiones de la interacción complejo-ADN. 222

2. Estudios de interacción entre $f a c-\operatorname{Re}^{\prime}(\mathrm{CO})_{3}$ (pterina) $\left(\mathrm{H}_{2} \mathrm{O}\right)$ y sero-albuminas ...... 225

2.1. Asociación seguida por desactivación de la emisión. 226

2.1.1. Dominio de asociación. 229 
2.1.2. Determinación de fluoróforos involucrados

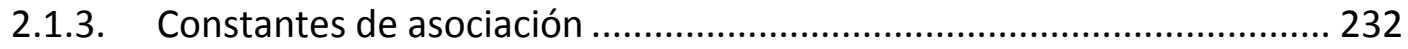

2.2. Parámetros termodinámicos de asociación ............................................... 234

2.3. Calculo de la distancia donor-aceptor por FRET ........................................ 235

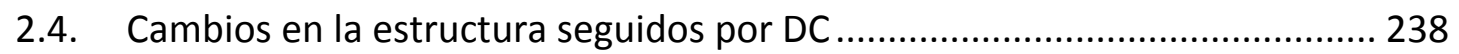

2.5. Conclusiones de la asociación con sero-albuminas...................................... 239

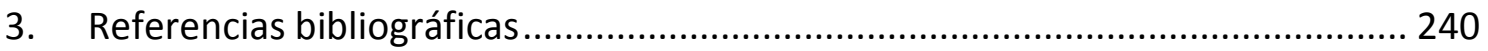




\section{Estudios de la interacción con ácidos nucleicos.}

\subsection{Cambios en la absorción y emisión inducidos por la interacción con ADN.}

El estado excitado emisor de un fluoróforo, puede sufrir cambios en su emisión luminiscente al interaccionar con otra molécula en estado basal. Estos cambios, están relacionados con el tiempo de vida, la intensidad y la energía de la emisión. La determinación y análisis de estos cambios aporta valiosa información sobre el modo de interacción entre las moléculas. Estas interacciones pueden ser de distinta naturaleza, tales como enlaces covalentes, puentes de hidrogeno, uniones electrostáticas o mediadas por interacciones hidrofóbicas. El estudio de los cambios que ocurren en la absorción de un cromóforo, producto de la interacción con otra molécula, aporta información muy útil sobre la naturaleza de este proceso.

En esta sección se presentan los resultados de los ensayos de interacción entre los tres complejos emisores utilizados en este capítulo (RePtr, Redppz y ReBpyTf), y tres distintos tipos de ácidos nucleicos. Se ensayaron, plásmidos bacterianos $\left(A D N_{p l}\right)$; $A D N$ de timo de ternero $\left(A D N_{c t}\right)$ y dos polinucleótidos sintéticos (poly[dAdT $]_{2}$ y poly $\left.[\mathrm{dCdG}]_{2}\right)$.

Se analizan los cambios en la emisión de los complejos, representándolos en una gráfica $I / I_{0} V s[A D N]$, donde I e $I_{0}$ representan la intensidad de emisión en el máximo para el complejo con ADN y para el complejo solo, respectivamente.

Este tipo de representación permite una visualización directa del efecto que el aumento de la concentración de ADN tiene sobre la emisión del complejo. La concentración de la solución madre de ADN se ajustó por absorción. El coeficiente de absortividad usado fue $\varepsilon^{260}=6600 \mathrm{~cm}^{-1} \mathrm{Mpb}^{-1}$. La concentración esta expresada como mol de pares de bases por litro de solución (Mpb).

\subsubsection{Interacción del complejo RePtr con ADN.}


Se preparó una solución del complejo RePtr en buffer TRIS base $10 \mathrm{mM}$, ajustado el pH a 7,4. Sobre $2 \mathrm{ml}$ de esta solución se adicionaron alícuotas de $10 \mu \mathrm{l}$ de la solución de madre de ADN. Luego de cada adición, la mezcla se incubo 10 minutos a temperatura ambiente. Se realizó la medida de intensidad de luminiscencia en estado estacionario de la muestra y se registró el espectro de absorción. Los valores, se corrigieron con la emisión del solvente y por el factor de dilución. Las soluciones se midieron sin deairear.

\subsubsection{Ensayos con $\mathrm{ADN}_{\mathrm{ct}}$}

Se utilizó una solución de $\mathrm{ADN}_{\mathrm{ct}}$ de concentración $1 \times 10^{-2} \mathrm{Mpb}$. La concentración del complejo RePtr en la solución fue $9 \times 10^{-5} \mathrm{M}$. Los espectros de emisión fluorescente de cada una de las soluciones del complejo con el $A D N_{c t}$ se presentan en la figura 2 a. El análisis de los cambios en la emisión se presenta en la figura $\mathbf{2}$ b.

\subsubsection{Ensayos con $A D N_{p l}$}

Como solución de trabajo se utilizó, una solución del plásmido Gra7-YFp 1×10-3 Mpb. La concentración del complejo RePtr en la solución fue $2 \times 10^{-4} \mathrm{M}$. Los espectros de emisión fluorescente de cada una de las soluciones del complejo con el $\operatorname{ADN}_{\mathrm{pl}}$, se presentan en la figura $\mathbf{3}$ a. El análisis de los cambios en la emisión se presenta en la figura $3 \mathbf{b}$.

\subsubsection{Ensayos con Poly[dCdG $]_{2}$.}

Se utilizó una solución del polinucleótido sintético poly[dCdG $]_{2}$ de concentración $1,3 \times 10^{-3} \mathrm{Mpb}$. La concentración del complejo en la mezcla fue $1 \times 10^{-4} \mathrm{M}$. Se midieron los espectros de emisión fluorescente de cada una de las mezclas (Figura 4a) El análisis de los cambios en la emisión se presenta en la Figura $\mathbf{4}$ b.

\subsubsection{Ensayos con Poly[dAdT $]_{2}$}

Se utilizó, una solución del polinucleótido sintético poly[dAdT $]_{2}$ de concentración $6,2 \times 10^{-3} \mathrm{Mpb}$. El complejo se usó en una concentración $2,7 \times 10^{-4} \mathrm{M}$. Se midieron los espectros de emisión fluorescente de cada una de las mezclas (figura $\mathbf{5}$ a). El análisis de los cambios en la emisión se presenta en la figura $\mathbf{5}$ b. 

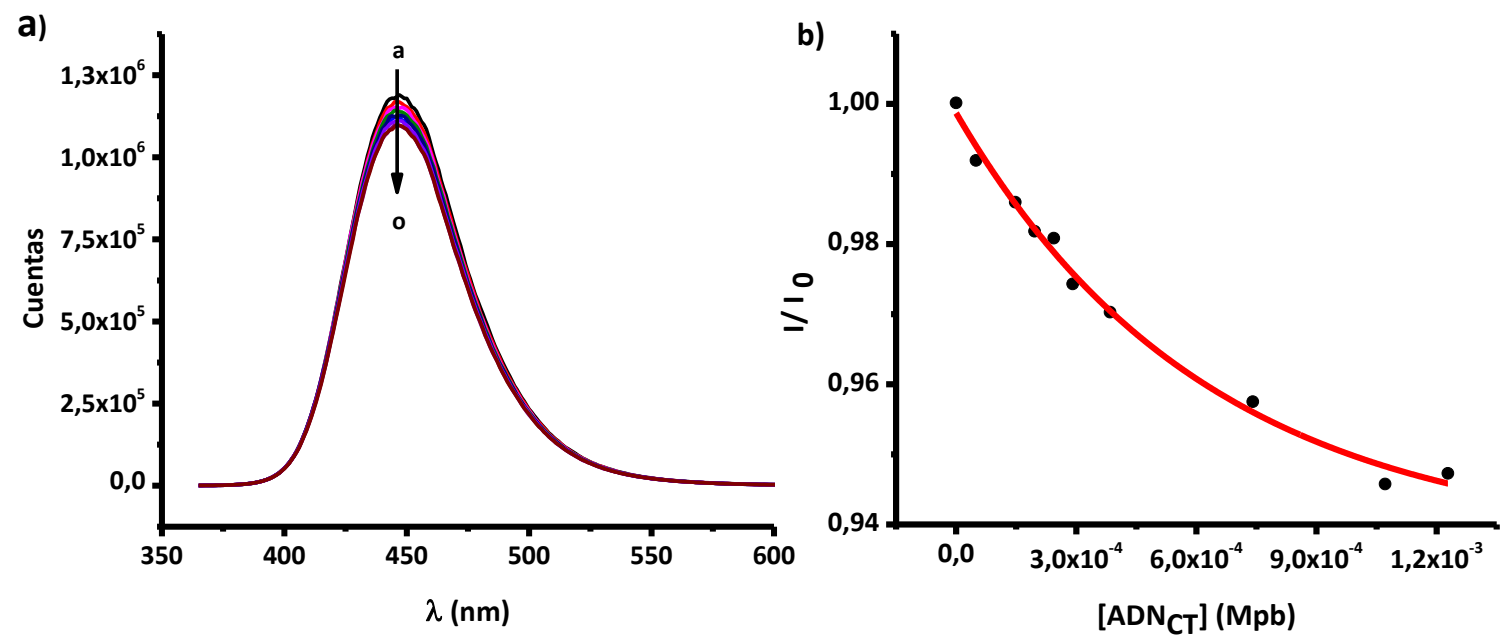

\section{Figura 2}

a) Cambios en la intensidad de emisión de una solución de RePtr $9 \times 10^{-5} \mathrm{M}$ en función del aumento de la concentración de $\operatorname{ADN}_{\mathrm{ct}}\left(\mathrm{a}=0,0=1,3 \times 10^{-3} \mathrm{Mpb}\right)$.

b) Gráfico de $1 / I_{0}$ vs [ADN] para la desactivación de la emisión del complejo RePtr por interacción con ADNct. $\lambda_{\text {exc }}=350 \mathrm{~nm}, \mathrm{pH}=7,4$.
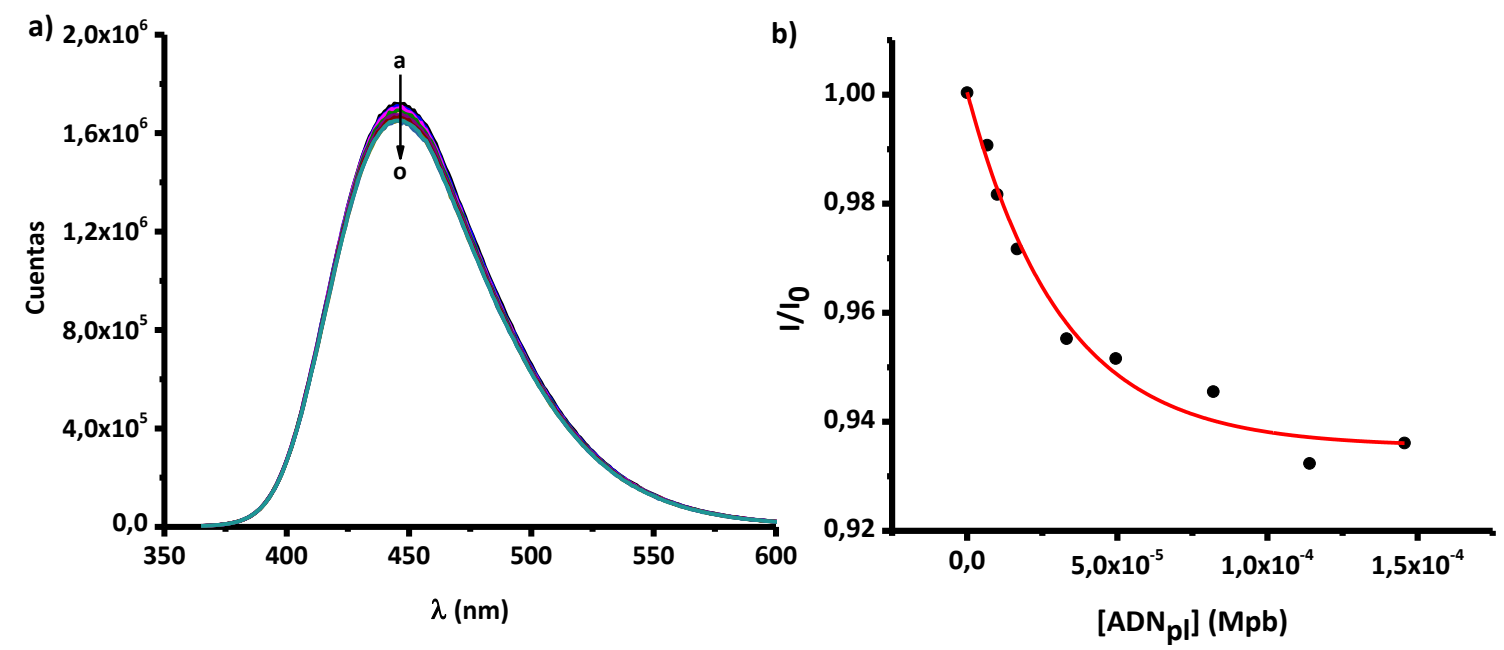

\section{Figura 3}

a) Cambios en la intensidad de emisión de una solución de RePtr $1 \times 10^{-4} \mathrm{M}$ en función del aumento de la concentración de $\operatorname{ADN}_{\mathrm{pl}}\left(\mathrm{a}=0,0=1,5 \times 10^{-4} \mathrm{Mpb}\right) . \lambda_{\text {exc }}=350 \mathrm{~nm}, \mathrm{pH}=$ 7,4 .

b) Gráfico de $\mathrm{I} / \mathrm{I}_{0}$ vs $\left[\mathrm{ADN}_{\mathrm{pl}}\right]$ para la desactivación de la emisión del complejo RePtr por interacción con $A D N_{p l}$. 

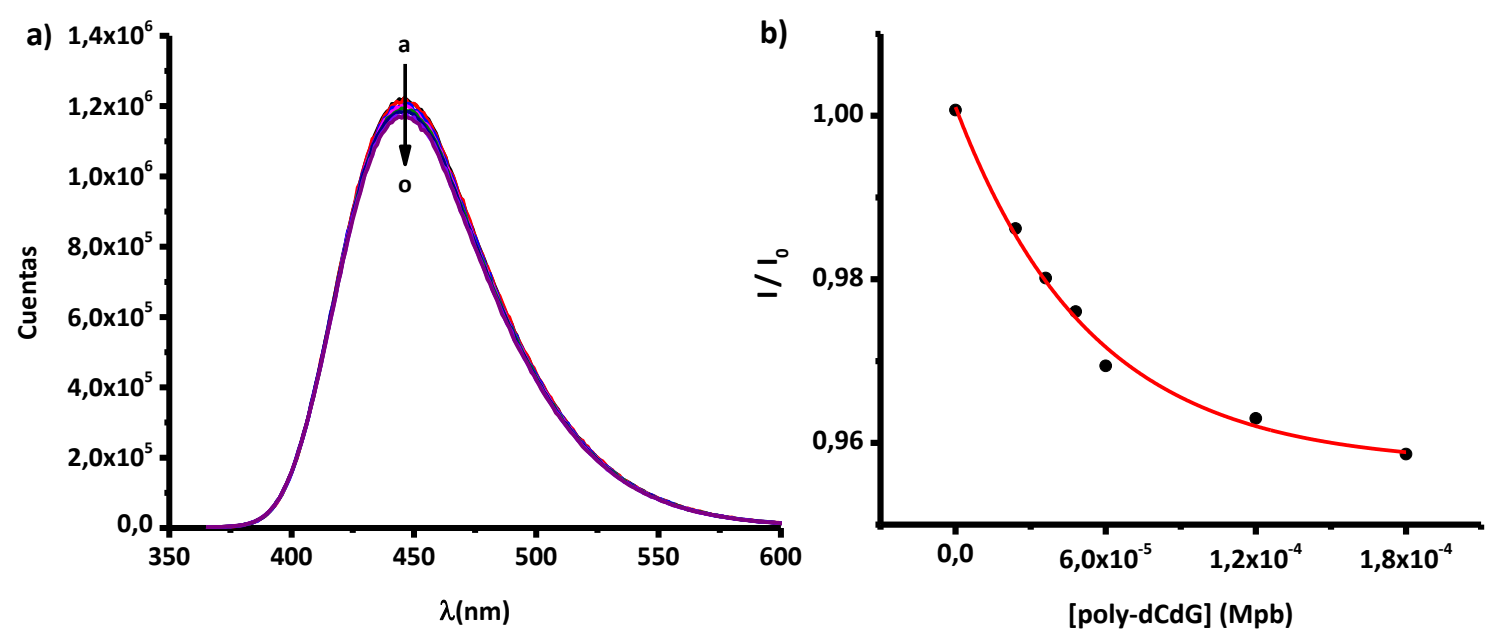

\section{Figura 4}

a) Cambios en la intensidad de emisión de una solución de $\operatorname{RePtr} 1 \times 10^{-4} \mathrm{M}$ en función del aumento de la concentración de Poly $[\mathrm{dCdG}]_{2}\left(\mathrm{a}=0, \mathrm{o}=2 \times 10^{-4} \mathrm{Mpb}\right) . \lambda_{\mathrm{exc}}=350 \mathrm{~nm}, \mathrm{pH}$ $=7,4$.

b) Gráfico de $\mathrm{l} / \mathrm{I}_{0}$ vs poly-[dCdG$]_{2}$ para la desactivación de la emisión del complejo RePtr por interacción con Poly[dCdG $]_{2}$.
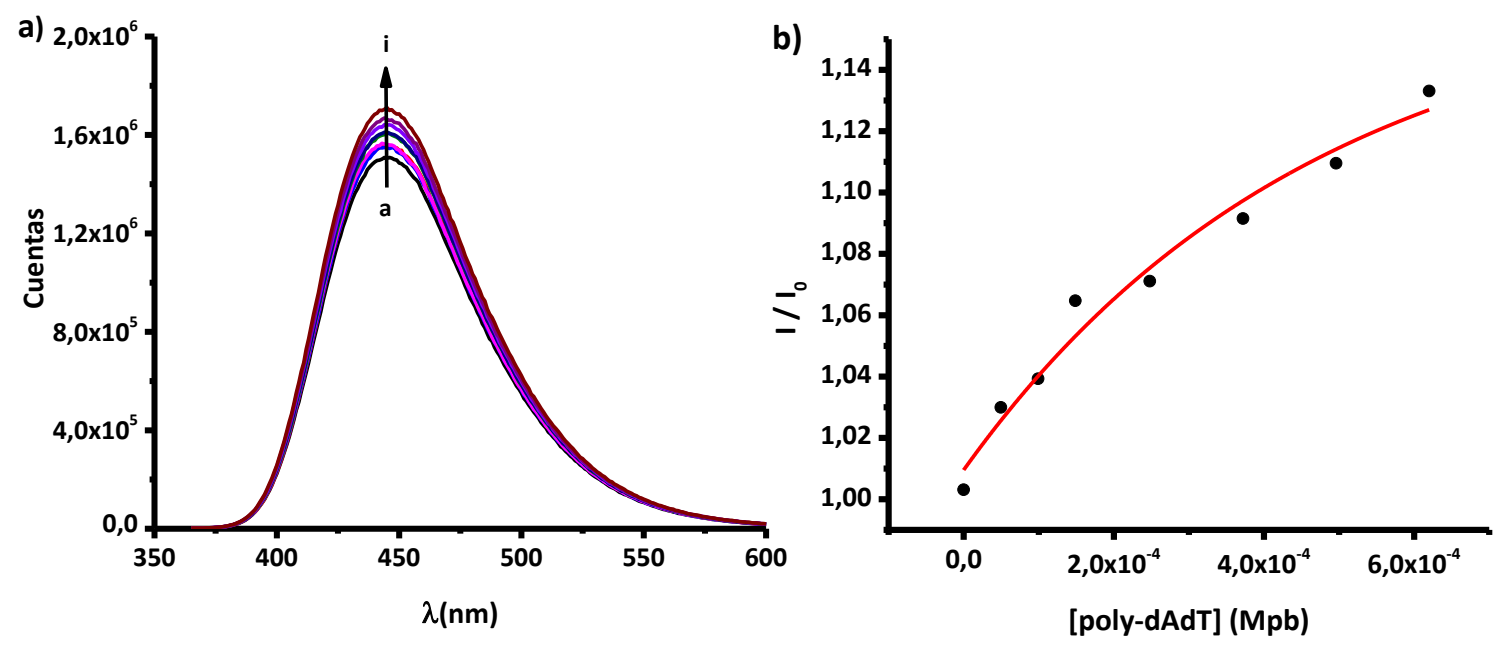

\section{Figura 5}

a) Cambios en la intensidad de emisión de una solución de RePtr $3 \times 10^{-4} \mathrm{M}$ en función del aumento de la concentración de poly[dAdT $]_{2}\left(a=0, i=6 \times 10^{-4} \mathrm{Mpb}\right) . \lambda_{\text {exc }}=350 \mathrm{~nm}, \mathrm{pH}$ $=7,4$.

b) Gráfico de $\mathrm{l} / \mathrm{I}_{0}$ vs $[\mathrm{dAdT}]$ para los cambios en la emisión del complejo RePtr por interacción con poly[dAdT $]_{2}$. 


\subsubsection{Cambios en la absorción.}

Se registraron los espectros de absorción UV-Vis del complejo y de las soluciones con distinta concentración de cada uno de los tipos de ADN. Las medidas se realizaron midiendo a longitudes de onda mayores de $350 \mathrm{~nm}$. De esta forma descartamos los cambios espectrales fruto del aumento de la concentración de ADN. En ninguno de los espectros se encontraron cambios con respecto del espectro del complejo.

\subsubsection{Resultados de la interacción del complejo RePtr con ADN.}

Los espectros de emisión del complejo RePtr registrados a distinta concentración de $A D N_{C T}, A D N$ plasmídico y polinucleótido poly $[d C d G]_{2}$, muestran una disminución en la intensidad de emisión al aumentar la concentración del ADN. En la curva $I / I_{0}$ vs $[A D N] p l$, se observa una meseta a altas concentraciones de ADN. Sin embargo no resulta tan claro este comportamiento en el resto de los gráficos.

El análisis del ensayo interacción del complejo RePtr con el polímero poly[dAdT $]_{2}$ revela un aumento de la intensidad de la emisión al aumentar la concentración del polinucleótido. Se realizó la representación de los datos en una gráfica de SternVolmer $I_{0} / I$ vs $[A D N]$, en ningún caso se observó un comportamiento lineal para todo el rango de $[A D N]$ usado.

Se ha estudiado la interacción entre el ligando pterina y los distintos nucleótidos [35]. Los autores de este trabajo presentan la interacción como una combinación de dos procesos. Estos dos procesos de desactivación, uno dinámico y otro estático se informan con constantes de S-V del orden de $10^{1} \mathrm{M}^{-1}$. El análisis de este comportamiento se realiza utilizando un modelo que combina los dos tipos de desactivación, obteniendo una relación cuadrática entre la relación $I_{0} / I$ vs [ADN]. También se indica la presencia de diferencias en estas constantes para la desactivación por los distintos nucleótidos. Por otro lado, también se ha estudiado la interacción de complejos relacionados con ADN [7][8]. Sin embargo no existen estudios sobre la interacción del ligando pterina libre o coordinado con ADN.

La desactivación de la emisión del complejo por los distintos tipos de ADN por un mecanismo dinámico o estático fue descartada para explicar los datos obtenidos. Esto resultó así, debido a la no linealidad de la representación de S-V. La desactivación, podría entonces responder, a la combinación de un proceso estático y uno dinámico. 
Sin embargo, las representaciones de los datos experimentales, no ajustan con una distribución cuadrática que propone el modelo para la combinación de los dos procesos de desactivación.

Para interpretar los datos de los ensayos de interacción con ADN, se propone un mecanismo en el cual se forma un aducto entre el complejo y el ADN Este aducto debe poseer un rendimiento cuántico de emisión distinto que el del complejo libre, mayor para la interacción con poly[dAdT $]_{2}$ y menor en el caso de la interacción entre el complejo RePtre y el $\mathrm{ADN}_{\mathrm{CT}}, \mathrm{ADN}_{\mathrm{pl}}$ y poly $[\mathrm{dCdG}]_{2}$,

El modelo de Scatchard modificado, indicado en el capítulo I parece el indicado para analizar los datos obtenidos. Sin embargo los pequeños valores en el cambio de la emisión, impiden obtener resultados confiables de este tipo de análisis.

Por otra parte, se presume que no existe intercalación entre las bases debido a la ausencia de cambios en el espectro de absorción típicos de este comportamiento [8][36].

\subsubsection{Interacción del complejo Redppz con ADN}

Se preparó una solución del complejo Redppz, disolviendo el sólido en metanol $(\mathrm{MeOH})$ y agregando luego buffer TRIS base $10 \mathrm{mM}$ hasta una relación 1:10 $\mathrm{MeOH} /$ Tris. La concentración final fue de $3,5 \times 10^{-5} \mathrm{M}$. A continuación, sobre $2,5 \mathrm{ml}$ de esta solución, se adicionaron alícuotas de $10 \mu \mathrm{l}$ de la solución madre de ADN. Luego de 10 minutos de incubación se registraron los espectros de emisión y de absorción de las soluciones. Los espectros se corrigieron por el blanco y por un factor de dilución. Los cambios en los espectros de emisión se analizan con un gráfico $A / A_{0}$ vs $[A D N]$, donde $A$ y $A_{0}$ son las áreas bajo la curva de emisión para las mezclas ADN-complejo y para el complejo solo, respectivamente.

\subsubsection{Ensayos con $\mathrm{ADN}_{\mathrm{ct}}$}

La solución de trabajo del $A_{D N}$ ct utilizada fue de concentración $3 \times 10^{-3} \mathrm{Mpb}$. Los espectros de emisión se presentan en la figura 6 a. En la figura 6 b se presenta un gráfico $A / A_{0}$ vs $\left[A D N_{c t}\right]$. 


\subsubsection{Ensayos con $A D N_{p l}$.}

Se utilizó el plásmido Gra7-YFP, la solución madre utilizada fue de concentración $1 \times 10^{-3}$ Mpb. Los espectros de emisión obtenidos se muestran en la figura 7 a. En la figura $\mathbf{7}$ b se presenta un gráfico $A_{0} / A$ vs $\left[A D N_{p l}\right]$.
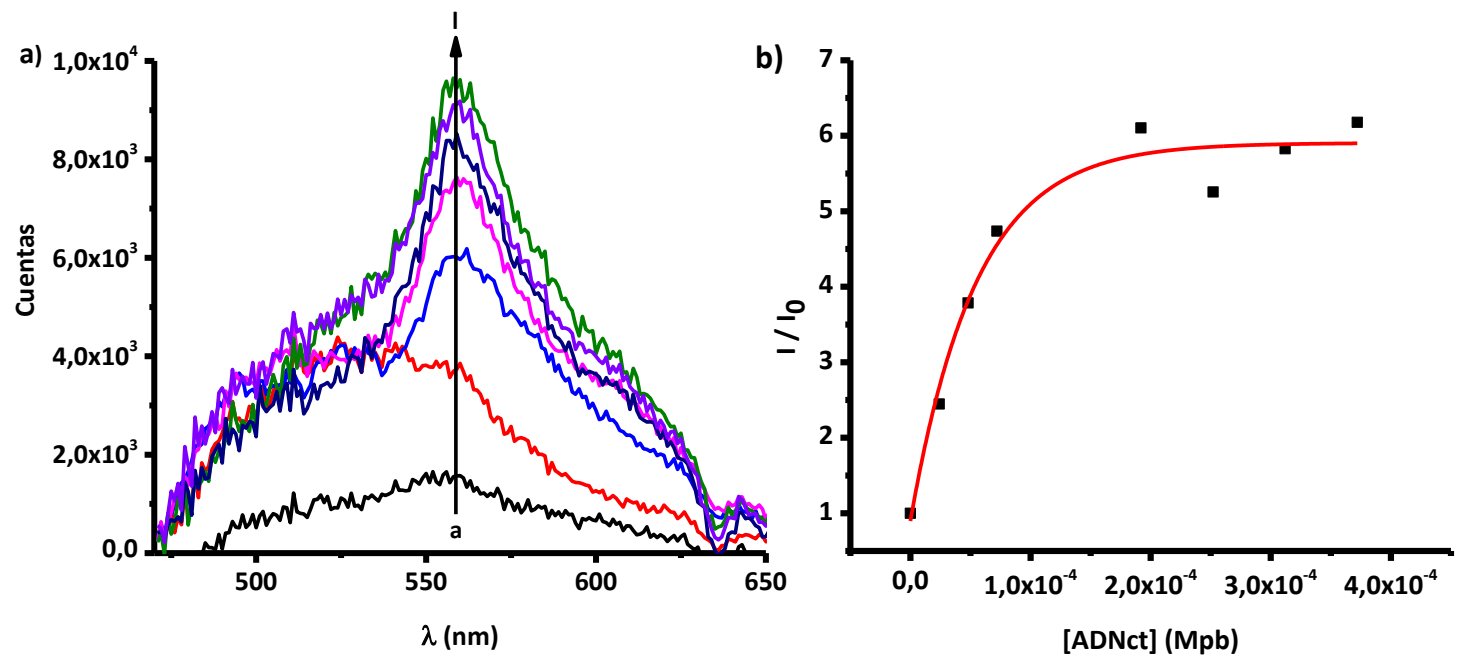

\section{Figura 6}

a) Cambios en la intensidad de emisión de una solución de Redppz en función del aumento de la concentración de $\operatorname{ADN}_{\mathrm{ct}}\left(\mathrm{a}=0, \mathrm{l}=4 \times 10^{-4} \mathrm{Mpb}\right) . \lambda_{\mathrm{exc}}=350 \mathrm{~nm}, \mathrm{pH}=7,4$. b) Gráfico de $A / A_{0}$ vs $\left[A D N_{c t}\right]$ para los cambios en la emisión del complejo Redppz por interacción con $\mathrm{ADN}_{\mathrm{ct}}$.
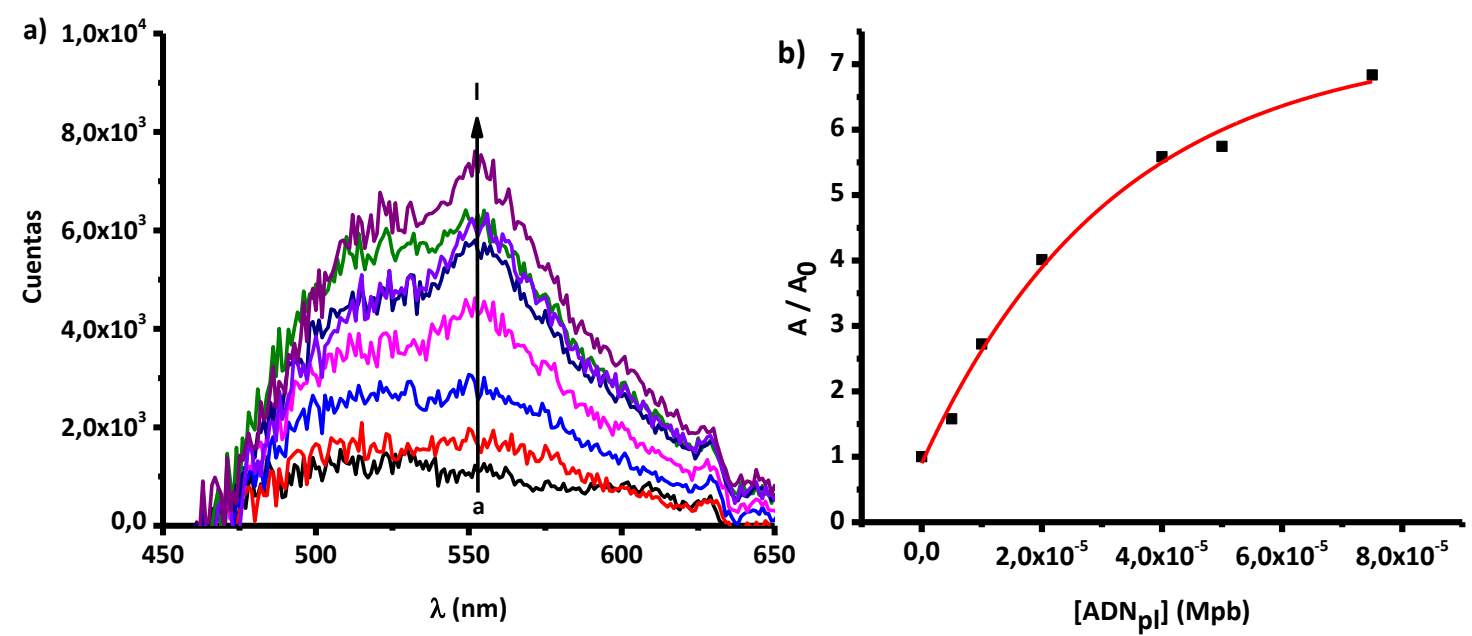

\section{Figura 7}

a) Cambios en la intensidad de emisión de una solución de Redppz en función del aumento de la concentración de $\operatorname{ADN}_{\mathrm{pl}}\left(\mathrm{a}=0, \mathrm{l}=8 \times 10^{-5} \mathrm{Mpb}\right) . \lambda_{\mathrm{exc}}=350 \mathrm{~nm}, \mathrm{pH}=7,4$. b) Gráfico de $A / A_{0}$ vs $\left[A D N_{p l}\right]$ para los cambios en la emisión del complejo Redppz por interacción con $A D N_{p l}$ 
En la figura 8 se muestran los espectros de absorción del complejo puro y la mezcla con la máxima concentración de ADN usada.
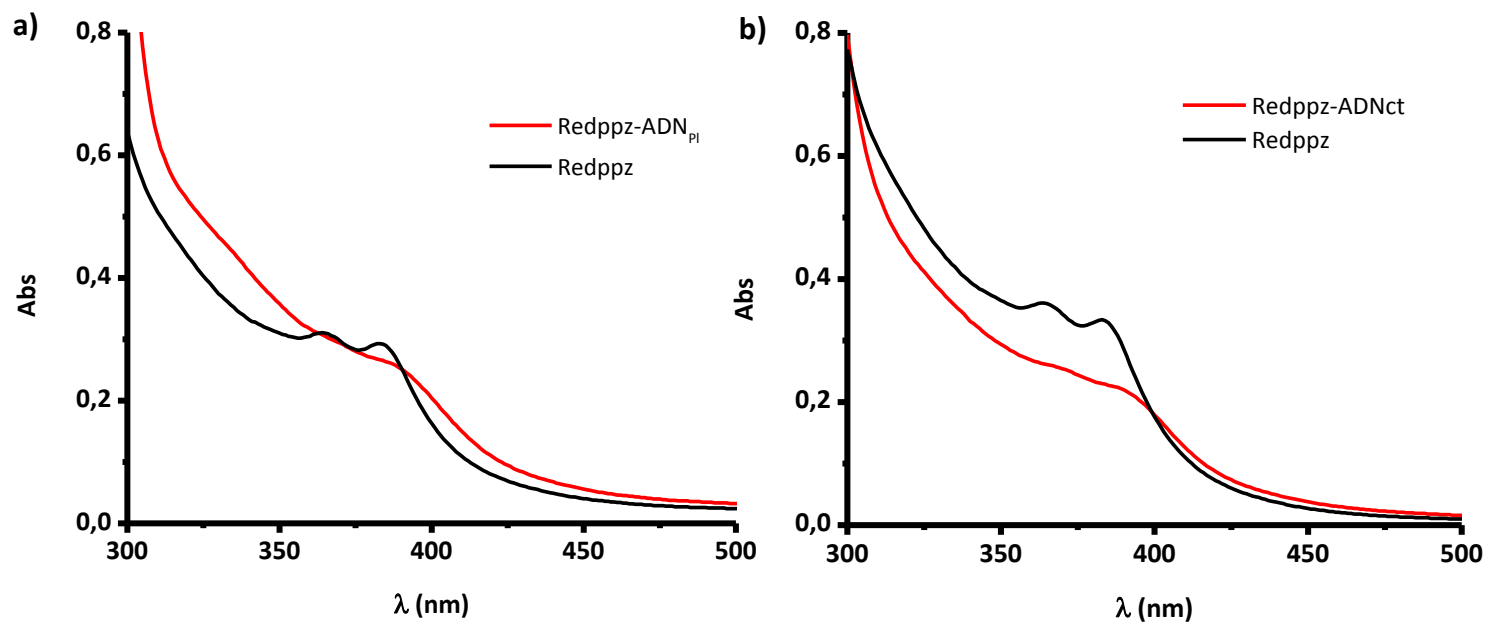

Figura 8

Espectros de absorción del complejo Redppz en metanol-agua (1:10) y de una mezcla de: a) $A D N_{p l}-$ Redppz , donde $\left[A D N_{p l}\right]=1 \times 10^{-3} \mathrm{Mpb}$. b) $A D N_{c t}-\operatorname{Redppz}$ con $\left[A D N_{c t}\right]=4 \times 10^{-4}$ Mpb.

\subsubsection{Interacción con polinucleótidos.}

La interacción del complejo Redppz con los polinucleótidos sintéticos poly[dAdT $]_{2}$ y poly $[d C d G]_{2}$ ya había sido estudiada dentro del grupo[37]. Este trabajo, informa sobre la intercalación del complejo entre las bases y se calculan las constantes de asociación, que están en el orden de $10^{5}$.

\subsubsection{Resultados de la interacción del complejo Redppz con ADN.}

Como se indica en los trabajos consultados, tanto el ligando dppz como muchos de los complejos que lo incluyen como ligando intercalan entre las bases del ADN [5], [6], [9], [10], [37]-[39]. La emisión del complejo Redppz en medio orgánico se presenta como una banda estructurada con alto rendimiento cuántico. Esta emisión es fuertemente desactivada en medio acuoso [37]. Cuando este complejo intercala entre las bases del $A D N$, al encontrarse en un entorno más hidrofóbico aumenta su emisión. Con los datos obtenidos para la interacción entre en complejo Redppz y el ADN plasmídico y de 
eucariota, se complementan los estudios de interacción con poli-nucleótidos realizados en el grupo [37].

Los espectros de emisión obtenidos en los ensayos de interacción del complejo Redppz con ADN muestran un aumento en la intensidad de emisión al aumentar la concentración de $A D N$. El análisis de los cambios mediante la gráfica $A / A_{0}$ vs $\left[A D N_{p}\right]$ presenta un comportamiento no lineal. $A$ altas relaciones $A D N / R e$ se observa una meseta. Comparando las relaciones $A / A_{0}$ para ambos tipos de $A D N$ a la misma relación $\mathrm{Re} /[\mathrm{ADN}]=1$, se tiene un valor de 3,25 con $A D N_{\text {CT }}$ y 5 con $A D N_{P 1}$. Si suponemos que la interacción con los dos tipos de ADN ocurren por el mismo proceso de intercalación. Éste resultado indica una mayor afinidad del ligando por el $A D N_{p}$, ya que a misma relación $\mathrm{Re} /[\mathrm{ADN}]$ hay más complejo unido al $A D N_{\mathrm{Pl}}$. Al comparar los espectros de absorción del complejo puro con el de la mezcla ADN-complejo, se observan corrimientos batocrómico e hipocrómico. Estos resultados son compatibles con la intercalación y se corresponden con los estudios citados.

\subsubsection{Interacción del complejo ReBpyTf con ADN}

Se preparó una solución del complejo ReBpyTf disolviendo el sólido en metanol y luego agregando 9 partes de buffer TRIS base $10 \mathrm{mM}$. Se obtuvo concentración final de $4,6 \times 10^{-4} \mathrm{M}$. Sobre $2 \mathrm{ml}$ de esta solución se adicionaron alícuotas de $10 \mu \mathrm{l}$ de una solución de ADN. Luego de 10 minutos de incubación se registraron los espectros de emisión. Los espectros se corrigieron por el blanco y por un factor de dilución. Se registraron, también, los espectros de absorción UV-Visible de cada una de las mezclas.

\subsubsection{Ensayos con $A D N_{c t}$}

Como solución de trabajo se utilizó, una solución de $\operatorname{ADN}_{\mathrm{ct}} 3 \times 10^{-3} \mathrm{Mpb}$, alícuotas de esta solución se agregaron sobre una solución $4,6 \times 10^{-4} \mathrm{M}$ del complejo ReBpyTf.

\subsubsection{Ensayos con $A D N_{p l}$}

Como solución de trabajo se utilizó, una solución del plásmido Gra7-YFp $1 \times 10^{-3} \mathrm{Mpb}$. La concentración de la solución del complejo fue de $4,6 \times 10^{-4} \mathrm{M}$. 


\subsubsection{Ensayos con Poly $[\mathrm{dCdG}]_{2}$.}

Se utilizó una solución del polinucleótido sintético poly $[\mathrm{dCdG}]_{2}$ de concentración $1,3 \times 10^{-3} \mathrm{Mpb}$. La concentración del complejo en la mezcla fue de $4,6 \times 10^{-4} \mathrm{M}$

\subsubsection{Ensayos con Poly $[\mathrm{dAdT}]_{2}$}

Se utilizó, una solución del polinucleótido sintético poly[dAdT $]_{2}$ de concentración

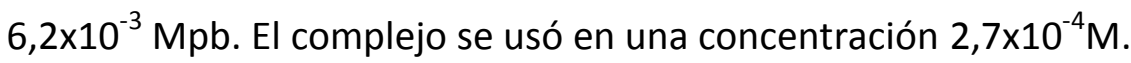

\subsubsection{Resultados de la interacción del complejo ReBpyTf con ADN}

No se observaron cambios significativos en la emisión del complejo ReBpyTf en ninguno de los ensayos de interacción. Tampoco se observaron cambios en los espectros de absorción.

Este comportamiento está de acuerdo con lo esperado, en función de lo reportado para otros complejos metálicos con el ligando 2,2'-bpy [34].

\subsection{Cambios estructurales inducidos en plásmidos seguidos por electroforesis.}

Las modificaciones que puedan inducirse sobre la tensión helicoidal de la doble hebra circular de una molécula de plásmido, inciden directamente sobre el grado de superenrollamiento del mismo. El grado de relajación o de superenrollamiento del plásmido se ve reflejado en el cambio de las propiedades hidrodinámicas de la macromolécula. En esta sección se presentan estudios sobre los cambios en la movilidad electroforética de algunos plásmidos como resultado de la interacción con los tres complejos de $\operatorname{Re}($ I) presentados al comienzo del capítulo (figura 9). 


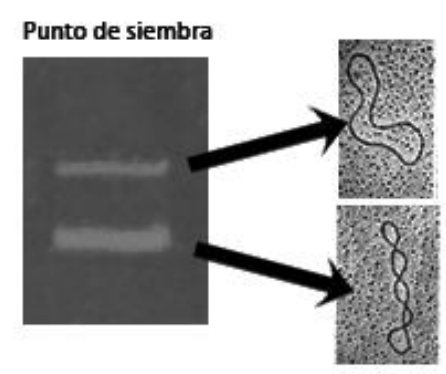

\section{Figura 9.}

Formas relajada (superior) y superenrollada (inferior) de un plásmido, en una corrida electroforética de un plásmido. Se muestran dos micrografías a modo de ejemplo de plásmidos, relajado y superenrollado.

\subsubsection{Cambios inducidos en el plásmido por la interacción con el estado basal del complejo.}

Se siguieron los cambios en la movilidad electroforética de tres plásmidos distintos luego de la incubación con cada uno de los tres complejos. Para esto, se prepararon soluciones de los tres complejos RePtr, Redppz y ReBpyTf en buffer TAE (TRIS, Acetato, EDTA), pH 7,4. Los complejos Redppz y ReBpyTf se disolvieron inicialmente en metanol y luego se llevaron a volumen con buffer. La concentración de las soluciones se ajustó por absorción, siendo los coeficientes de extinción molar usados, $\varepsilon^{355}=4200 \mathrm{M}^{-1} \mathrm{~cm}^{-1}$, $8600 \mathrm{M}^{-1} \mathrm{~cm}^{-1}, 1066 \mathrm{M}^{-1} \mathrm{~cm}^{-1}$ y las concentraciones respectivas $2,5 \times 10^{-4} \mathrm{M}, 8,1 \times 10^{-5} \mathrm{M}$ y $4,3 \times 10^{-4} \mathrm{M}$ para los complejos RePtr, Redppz y ReBpyTf respectivamente. De estas soluciones se prepararon diluciones, $10 \mu \mathrm{l}$ de cada una de estas diluciones se mezcló con $0,5 \mu$ del plásmido (y se incubó 1 hora a $37^{\circ} \mathrm{C}$ en oscuridad, luego se agregaron 2 $\mu l$ de solución de carga (Azul de Bromofenol+ Glicerol) a cada una de las mezclas. De cada una de las diluciones de cada mezcla complejo-plásmido, se sembraron $10 \mu \mathrm{l}$ por calle en un gel $1 \%$ de agarosa y se realizó una corrida electroforética con buffer TAE a $60 \mathrm{~V}$ durante 1 hora, seguido por 30 min de tinción con Bromuro de Etidio (1 mg / ml). Una vez teñidos todos los geles se fotografiaron en un transiluminador UV utilizando una cámara digital con un filtro naranja. Las imágenes fueron escaneadas con un densitómetro y las bandas se integraron utilizando el software TotalLab de Nonlinear Dinamics Itd. 


\subsubsection{Cambios inducidos por RePtr.}

Las diluciones de trabajo fueron 1:1, 1:5, 1:10, 1:100 y 1:1000 de la solución madre del complejo $\operatorname{RePtr}\left(2,5 \times 10^{-4} \mathrm{M}\right)$, de cada una, se mezclaron $10 \mu \mathrm{l}$ con $0,5 \mu \mathrm{l}$ de la solución del plásmido de concentración $150 \mathrm{ng} / \mu \mathrm{l}\left(2,27 \times 10^{-4} \mathrm{MPb}\right)$ obteniéndose relaciones 0,05; 0,25; 0,5; 5 y 50 (moles de pares de bases de ADN / moles del complejo). Se ensayaron tres plásmidos distintos, con diferente tamaño y secuencia, los plásmidos Gra7-YFp, pRSET A, y PTy. Las características de estos plásmidos se detallan en el capítulo I. Las imágenes de los geles obtenidos luego de la corrida se muestran en la figura 10. En la tabla 1 se muestran los resultados del análisis de intensidad de las bandas.

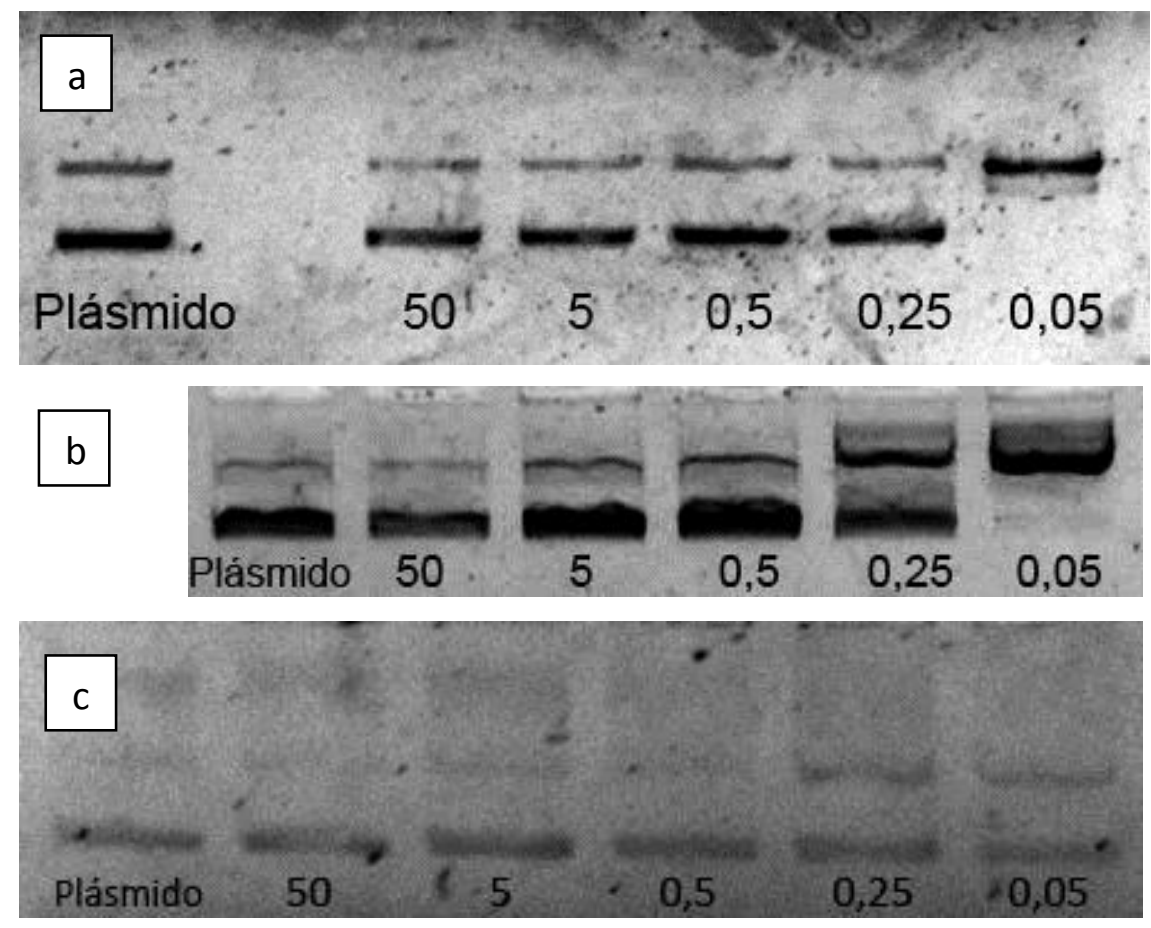

\section{Figura 10}

Geles revelados de la corrida electroforética del plásmido solo, e incubado con el complejo RePtr. Se indican relaciones ADN/Complejo (Mpb/M) de la mezcla sembrada. a) plásmido Gra7-YFp. b) plásmido PTy c) plásmido pRSET A. En todas las corridas, el punto de siembra se encuentra en la parte superior, a la banda inferior se denomina como $2^{\circ}$ Banda. 


\section{Tabla 1}

Resultado del análisis de intensidad de las bandas del gel de electroforesis para la mezcla del complejo RePtr con los plásmidos PTy, pRSET A y Gra7-YFp (porcentual).

\begin{tabular}{c|cccccc|cccccc|cccccc}
\hline \multicolumn{10}{c}{ Gra7-YFp } & \multicolumn{11}{c}{ PTy } & \multicolumn{1}{c}{ pRSET A } \\
\hline \hline Bda/tot & PI. & 50 & 5 & 0,5 & 0,25 & 0,05 & PI. & 50 & 5 & 0,5 & 0,25 & 0,05 & PI. & 50 & 5 & 0,5 & 0,25 & 0,05 \\
\hline $1^{\circ}$ Bda & 12 & 23 & 19 & 27 & 17 & 100 & 12 & 7 & 14 & 14 & 37 & 100 & 15 & 11 & 14 & 22 & 37 & 33 \\
$2^{\circ}$ Bda & 88 & 77 & 81 & 73 & 83 & 0 & 88 & 93 & 86 & 86 & 63 & 0 & 85 & 89 & 86 & 78 & 63 & 67 \\
\hline \hline
\end{tabular}

Los resultados encontrados para los tres plásmidos resultaron comparables entre sí, permitiendo aceptar que se experimenta el mismo efecto en ellos. El análisis de la intensidad de las bandas, generadas en la corrida electroforética de la mezcla de las diluciones del complejo RePtr con los plásmidos Gra7-YFpy PTy y pRSET A, muestra que en la primer calle, con la mayor la relación ADN/Re, existen dos bandas con diferente movilidad entre sí. Estas bandas presentan igual movilidad e igual relación de intensidades que las correspondientes a las del plásmido sin complejo. Este resultado nos permite asumir que se trata de las dos formas (relajada y superenrollada) del plásmido. En las siguientes calles, a medida que disminuye la relación ADN/Re se observa una disminución de la banda del plásmido superenrollado y un aumento de la banda del plásmido relajado. En la última calle de los geles correspondientes a las mezclas del complejo RePtr con los plásmidos Gra7-YFp y PTy se llega a observar la desaparición total de la banda correspondiente a la forma superenrollada (relación $\mathrm{ADN} / \mathrm{Re}=0,05)$

\subsubsection{Cambios inducidos por Redppz.}

Las diluciones de trabajo fueron 1:1, 1:10 y 1:100 de la solución madre del complejo Redppz en Buffer/Metanol 90:10 (8,1 x10 $\left.10^{-5} \mathrm{M}\right)$, de cada una, se mezclaron $10 \mu \mathrm{l}$ con 0,5 $\mu \mathrm{l}$ de la solución del plásmido de concentración $150 \mathrm{ng} / \mu \mathrm{l}\left(2,27 \times 10^{-4} \mathrm{MPb}\right)$ obteniéndose relaciones 0,$14 ; 1,4$ y 14 (moles de pares de bases de ADN /moles del complejo) respectivamente. En la figura 11 se muestra la imagen del gel obtenido luego de la corrida electroforética. En la tabla 2 se muestran los resultados del análisis de intensidad de las bandas. 


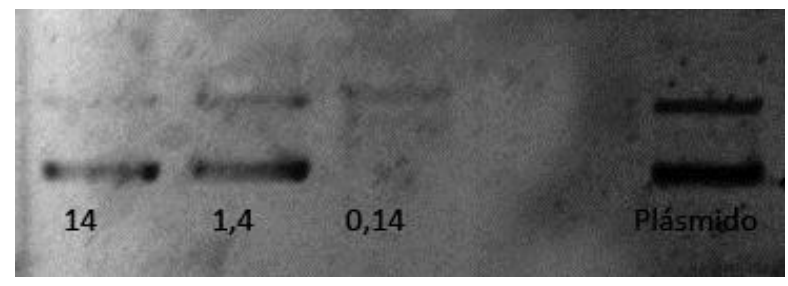

\section{Figura 11}

Gel revelado de la corrida electroforética del Gra7-YFp solo e incubado con el complejo Redppz. Se indican relaciones ADN/Complejo (Mpb/M) de la mezcla sembrada. En todas las corridas, el punto de siembra se encuentra en la parte superior, a la banda inferior se denomina como $2^{\circ}$ Banda.

El análisis del gel en el cual se analiza la interacción del complejo Redppz con el plásmido Gra7-YFp, muestra el mismo patrón de bandas que el descripto para la interacción con RePtr. En el gel se observa la desaparición total de la banda de mayor movilidad al alcanzar la relación $\mathrm{ADN} / \mathrm{Re}=0,14$.

\section{Tabla 2}

Resultado del análisis de intensidad de las bandas del gel de electroforesis para la mezcla del complejo Redppz con el plásmido Gra7-YFp.

\begin{tabular}{lllll}
\hline \hline \hline ADN/Complejo & PI. & 14 & 1,4 & 0,14 \\
$1^{\circ}$ Banda/Total & 26 & 14 & 23 & 100 \\
$2^{\circ}$ Banda/Total & 74 & 86 & 77 & 0 \\
\hline \hline
\end{tabular}

\subsubsection{Cambios inducidos por ReBpyTf}

Se trabajó con diluciones $1: 1,1: 10,1: 20,1: 100$ y 1:1000 de la solución madre del complejo ReBpyTf en Buffer/Metanol 90:10 (4,3 ×10 $\left.0^{-4} \mathrm{M}\right)$, de cada una, se mezclaron $10 \mu \mathrm{l}$ con $0,5 \mu \mathrm{l}$ de la solución del plásmido de concentración $150 \mathrm{ng} / \mu \mathrm{l}\left(1,14 \times 10^{-4} \mathrm{MPb}\right)$ obteniéndose relaciones 0,$025 ; 0,25 ; 0,12 ; 2,5$ y 25 (moles de pares de bases de ADN /moles del complejo) respectivamente. En la figura 12 se muestra la imagen del gel obtenido luego de la corrida electroforética. En la tabla 3 se muestran los resultados del análisis de intensidad de las bandas. 


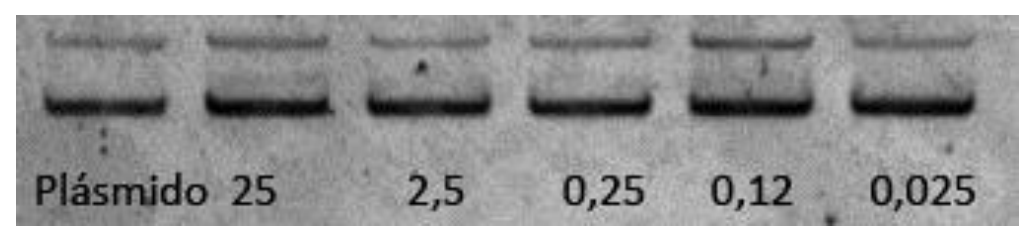

\section{Figura 12}

Gel revelado de la corrida electroforética del plásmido Gra7-YFp solo, e incubado con el complejo ReBpyTf, se indican relaciones ADN/Complejo (Mpb/M) de la mezcla sembrada. La calle inferior corresponde a la banda de mayor movilidad y se denomina como $2^{\circ}$ banda.

\section{Tabla 3}

Resultado del análisis de intensidad de las bandas del gel de electroforesis para la mezcla del complejo ReBpyTf con el plásmido Gra7-YFp.

\begin{tabular}{lcccccc}
\hline \hline ADN/Complejo & $\mathrm{PI}$. & 50 & 5 & 0,5 & 0,25 & 0,05 \\
$1^{\circ}$ Banda/Total & 18 & 20 & 11 & 20 & 24 & 16 \\
$2^{\circ}$ Banda/Total & 82 & 80 & 89 & 80 & 76 & 84 \\
\hline \hline
\end{tabular}

En el gel de la corrida electroforética del complejo ReBpyTf con el plásmido Gra7-YFp, no se observan cambios significativos en la movilidad de las bandas, para ninguna mezcla, tomando como referencia la banda del plásmido.

\subsubsection{Fotosensibilización de DNA plasmídico}

Luego de la interacción de cada uno de los tres complejos con el plásmido, se irradiaron las muestras, para luego analizar los fotoproductos por electroforesis. Para esto, se prepararon mezclas de soluciones de cada uno de los tres complejos (RePtr, Redppz y ReBpyTf) con una solución del plásmido Gra7-YFp. También se utilizó una solución del plásmido sin complejo. Se utilizaron las mezclas con las relaciones ADN/Re que mostraron mayor efecto sobre la movilidad del plásmido. Las mezclas se incubaron durante 45 minutos a $37^{\circ} \mathrm{C}$, luego, se cargaron $150 \mu$ le la mezcla incubada en una cubeta de cuarzo abierta a la atmosfera y con agitación, se irradiaron durante 120 minutos con una lámpara UV $\left(\lambda_{\max }=350 \mathrm{~nm}\right)$. De estas mezclas bajo irradiación, se tomaron muestras de $10 \mu \mathrm{l}$ a distintos tiempos. Las alícuotas se mezclaron con $2 \mu \mathrm{l}$ de la solución de carga (Azul de Bromofenol + Glicerol). Todas las muestras se analizaron por electroforesis en gel de agarosa, seguido de tinción con Bromuro de Etidio y 
análisis de las bandas procediendo de igual forma que la indicada en la sección anterior. Se realizaron controles irradiando al complejo. No se observaron cambios en su espectro de absorción, lo que nos permite inferir su foto-estabilidad. También se realizó un control irradiando al plásmido. No se vieron cambios en su movilidad electroforética (figura 13). El esquema del dispositivo de irradiación se describió en el capítulo I.

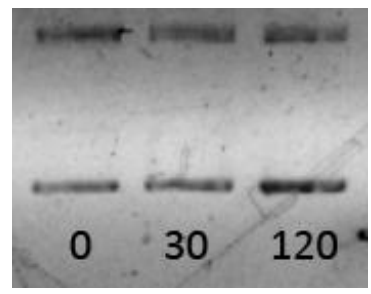

\section{Figura 13}

Gel revelado de la corrida electroforética del plásmido Gra7-YFp sin irradiar e irradiado 30 y 120 minutos.

\subsubsection{Cambios foto-inducidos por RePtr.}

Se preparó una solución del complejo RePtr en buffer de pH 7,4 con absorbancia 1,5 a $350 \mathrm{~nm}\left(2,5 \times 10^{-4} \mathrm{M}\right)$, se mezclaron $140 \mu \mathrm{l}$ de esta con $10 \mu \mathrm{l}$ del plásmido Gra7-YFp 150ng/ $\mu$ l. La mezcla se incubó y se irradio, la fotografía del gel revelado se muestra en la figura 14. En la tabla 4 se muestran los resultados del análisis de la densidad óptica del gel.

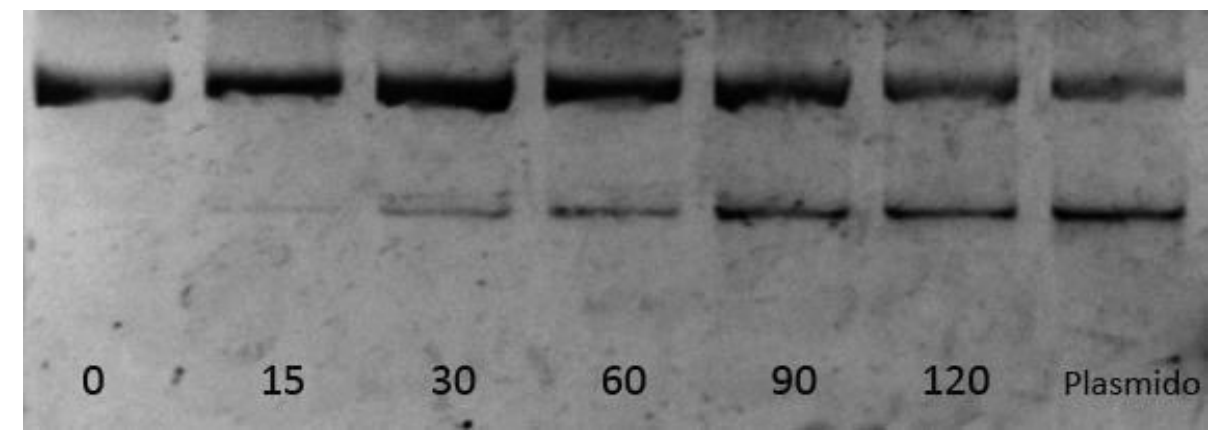

\section{Figura 14}

Gel revelado de la corrida electroforética del plásmido Gra7-YFp y de la mezcla del plásmido Gra7-YFp con el complejo RePtr incubado e irradiado. El punto se siembra se encuentra en la parte superior. En la parte inferior se indican los tiempos de irradiación en minutos. 


\section{Tabla 4}

Resultado del análisis de intensidad de las bandas del gel de electroforesis para las muestras incubadas e irradiadas del complejo RePtr con el plásmido Gra7-YFp.

\begin{tabular}{lccccccc}
\hline \hline Tiempo de irradiación (min.) & 0 & 15 & 30 & 60 & 90 & 120 & $\mathrm{pl}$ \\
$1^{\circ}$ Banda/Total & 100 & 93 & 88 & 75 & 67 & 56 & 45 \\
$2^{\circ}$ Banda/Total & 0 & 7 & 12 & 25 & 33 & 44 & 55 \\
\hline \hline
\end{tabular}

El gel de la corrida electroforética del ensayos de fotosensibilización del ADN plasmídico utilizando al complejo RePtr como sensibilizador, presentó cambios en la movilidad de las bandas. En la calle correspondiente a la mezcla sin irradiar existe una única banda, similar a la observada en el experimento térmico con esta relación ADN/Re. En el resto de las calles se encontró un patrón de dos bandas con distinta movilidad. Donde, la banda de mayor movilidad, aumentó en intensidad e expensas de la banda de menor movilidad a medida que nos movemos hacia las calles conteniendo muestras con mayor tiempo de irradiación. La banda del plásmido irradiado 120 min no presento cambios en su movilidad con respecto al plásmido sin irradiar.

\subsubsection{Cambios fotoinducidos por Redppz}

Se preparó una solución del complejo Redppz disolviendo el complejo en metanol para luego llevar a volumen final con buffer TAE pH 7,4 llegando a una mezcla Buffer/Metanol 90:10 con absorción 0,7 a $350 \mathrm{~nm}\left(8,1 \times 10^{-5} \mathrm{M}\right)$. Se mezclaron $140 \mu \mathrm{l}$ de esta solución con $10 \mu \mathrm{l}$ del plásmido Gra7-YFp $150 \mathrm{ng} / \mu \mathrm{l}$. La mezcla se incubó 45 minutos y se irradió como se indicó anteriormente en esta sección. En la figura 15 se muestra una fotografía del gel revelado. En la tabla 5 se muestran los resultados de este análisis de la densidad de las bandas. 


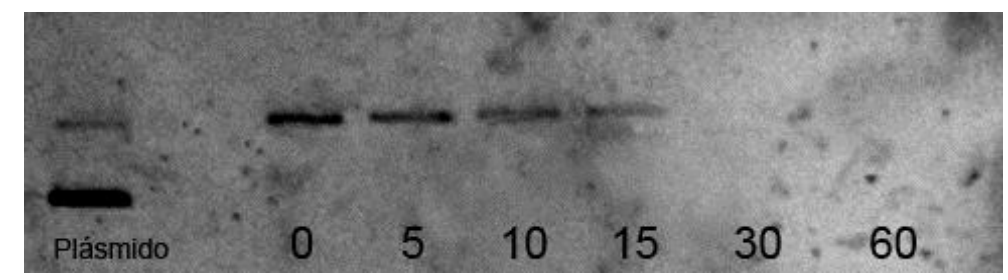

\section{Figura 15}

Gel revelado de la corrida electroforética del plásmido solo y de la mezcla del plásmido Gra7-YFp incubado e irradiado con el complejo Redppz. El punto se siembra se encuentra en la parte superior. En la parte inferior se indican los tiempos de irradiación en minutos.

\section{Tabla 5}

Resultado del análisis de intensidad de las bandas del gel de electroforesis para las muestras incubadas e irradiadas del complejo Redppz con el plásmido Gra7-YFp.

\begin{tabular}{llllllll}
\hline \hline Tiempo de irradiación (min.) & Plásmido & 0 & 5 & 10 & 15 & 30 & 60 \\
$1^{\circ}$ Banda & 10279 & 28674 & 19410 & 18490 & 14262 & 0 & 0 \\
$2^{\circ}$ Banda & 42418 & 0 & 0 & 0 & 0 & 0 & 0 \\
Relación $I_{t x} / I_{\text {to }}$ & & 1,0 & 0,7 & 0,6 & 0,5 & 0 & 0 \\
\hline \hline
\end{tabular}

En el gel revelado de la corrida electroforética de la mezcla del complejo Redppz con el plásmido Gra7-YFp irradiada, se observó una única banda. Esta banda presento una movilidad coincidente con la de la banda correspondiente a la forma relajada del plásmido. Esta banda disminuyó en intensidad hasta tornarse indetectable a partir de la calle que contiene la muestra correspondiente a 30 minutos de irradiación.

\subsubsection{Cambios en foto-inducidos por ReBpyTf}

Se preparó una solución del complejo ReBpyTf en metanol que luego se llevó a volumen final con buffer TAE pH 7,4. Con una relación Buffer/Metanol 90:10. La absorción de las solución a $350 \mathrm{~nm}$ se ajustó a $1\left(4,3 \times 10^{-4} \mathrm{M}\right)$. Se mezclaron $140 \mu \mathrm{l}$ de esta solución con $10 \mu \mathrm{l}$ del plásmido Gra7-YFp $150 \mathrm{ng} / \mu \mathrm{l}$. La mezcla se incubó 45 minutos y se irradió. En la figura 16 se muestra una fotografía del gel revelado. En la tabla 6 se muestran los resultados del análisis de la densidad óptica de las bandas. 


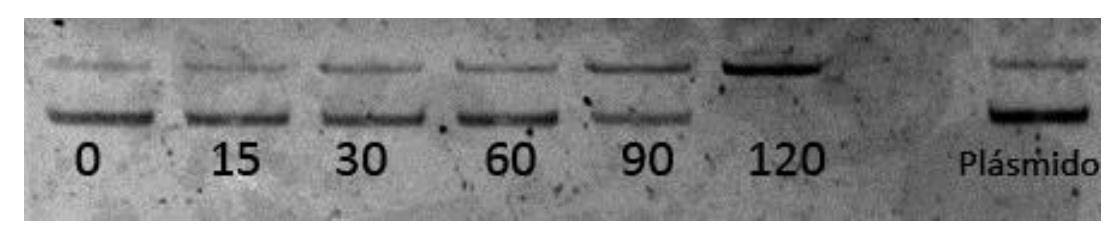

\section{Figura 16}

Gel revelado de la corrida electroforética del plásmido solo y de la mezcla del plásmido Gra7-YFp incubado e irradiado con el complejo ReBpyTf. El punto se siembra se encuentra en la parte superior. En la parte inferior se indican los tiempos de irradiación en minutos.

\section{Tabla 6}

Resultado del análisis de intensidad de las bandas del gel de electroforesis para las muestras incubadas e irradiadas del complejo ReBpyTf con el plásmido Gra7-YFp y el plásmido solo.

\begin{tabular}{llllllll}
\hline \hline Tiempo de irradiación (min.) & 0 & 15 & 30 & 60 & 90 & 120 & $\mathrm{Pl}$. \\
$1^{\circ}$ Banda/Total & 19 & 23 & 29 & 20 & 37 & 100 & 24 \\
$2^{\circ}$ Banda/Total & 81 & 77 & 71 & 80 & 63 & 0 & 76 \\
\hline \hline
\end{tabular}

Los ensayos de fotosensibilización utilizando al complejo ReBpyTf como sensibilizador, seguidos por electroforesis, mostraron un patrón de dos bandas. Estas bandas resultaron de igual movilidad que las bandas del plásmido puro. Al aumentar el tiempo de irradiación se verificó un aumento de la intensidad de la banda de menor movilidad y una disminución en la intensidad de la banda con mayor movilidad. Se observó, que la calle que contienen la muestra sometida a un tiempo de irradiación de 120 minutos, presenta una única banda coincidente con la forma relajada del plásmido.

\subsection{Cambios en plásmidos seguidos por AFM}

La microscopia de AFM permite distinguir topologías en el orden de los nanómetros. Esta técnica ha sido empleada con éxito para distinguir el grado de superenrollamiento de plásmidos [40]. En este trabajo se utilizó esta técnica para caracterizar el efecto que el estado basal y excitado del complejo RePtr induce sobre la conformación de un plásmido bacteriano. La técnica empleada es una técnica de contacto conocida como "tapping". 
El procedimiento de preparación de la muestra y observación ya fue descripto en el capítulo I. Las muestras observadas fueron tres. La primer muestra se preparó mezclando $2 \mu \mathrm{l}$ de la solución madre del plásmido Gra7-YFp con $1 \mu \mathrm{l}$ de $\mathrm{CaCl}_{2}$ 0,1M y 10 $\mu \mathrm{l}$ de agua. La segunda muestra se preparó con $12 \mu \mathrm{l}$ de una mezcla del complejo y el plásmido en relación $\mathrm{DNA} / \mathrm{Re}=$ 0;05 (la misma que provocó cambios en los ensayos de electroforesis) con $1 \mu \mathrm{l}$ de $\mathrm{CaCl}_{2} 0,1 \mathrm{M}$ y $10 \mu \mathrm{l}$ de agua. La mezcla del plásmido y el complejo ya había sido incubada 30 minutos. La cantidad de ADN fue la misma que en la primera muestra. Por último se observó una tercera muestra, de igual preparación que la muestra anterior. En este caso mezcla del plásmido con el complejo luego de ser incubada 1 hora, fue irradiada 2 hs. La irradiación se realizó en las mismas condiciones y con el mismo dispositivo con el que se irradiaron las muestras seguidas por electroforesis.

Las imágenes obtenidas se optimizaron digitalmente. Se obtuvieron medidas de longitud y altura de los plásmidos observados, realizando medidas sobre las imágenes.

\subsubsection{Imágenes de AFM del plásmido Gra7-YFp}

En la figura 17 se muestra la imagen optimizada obtenida de la muestra del plásmido puro.

La figura 17 a muestra uno de los muchos campos observados de $20 \times 20 \mu \mathrm{m}$. En este campo se observa una veintena de estructuras compactas alargadas. La observación a mayor escala de una de estas estructuras que se presenta en la zona encerrada (figura 17 b) revela una estructura con forma de "coma" de unos $200 \mathrm{~nm}$ de largo. El análisis de la altura de esta estructura (figura 17 c) indicó una altura de entre 2 y $7 \mathrm{~nm}$. Todas estas características observadas se corresponden con las propias de la forma superenrollada de un plásmido, de acuerdo a los reportado en un trabajo publicado sobre caracterización de plásmidos por AFM [40]. 
a)

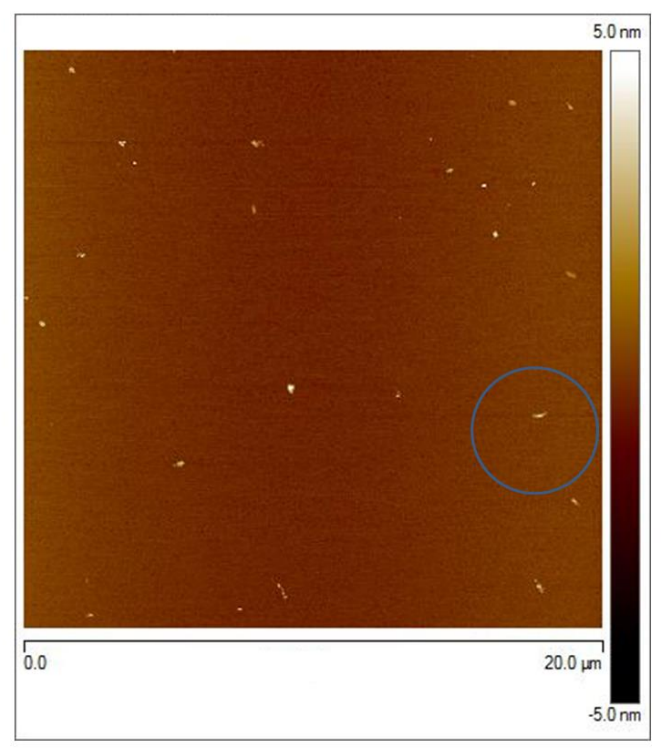

b)

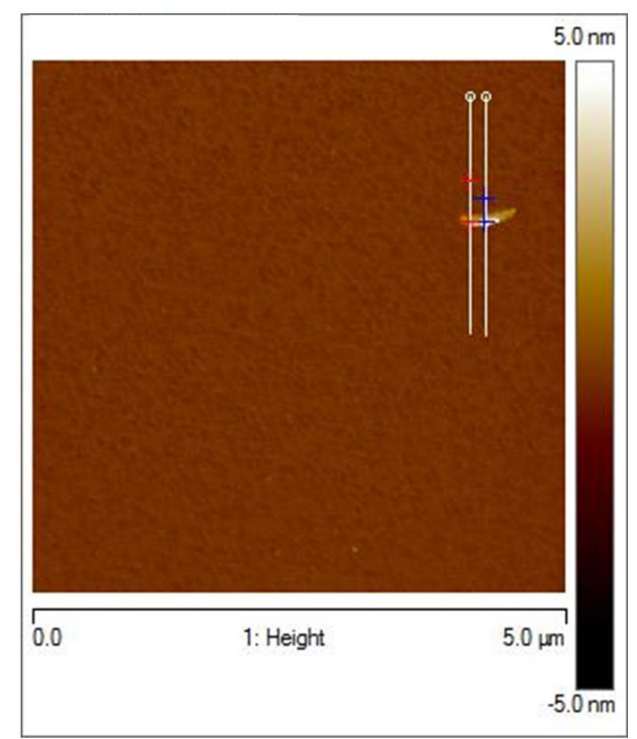

c) 7

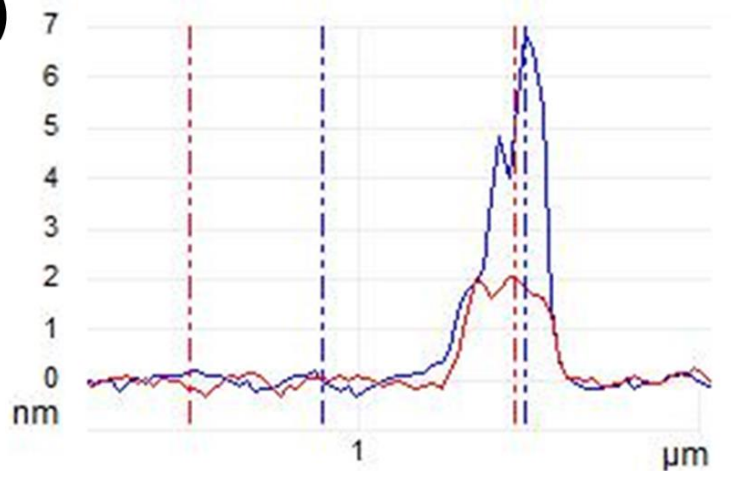

\section{Figura 17}

Imágenes de AFM del plásmido Gra7-YFp

a) Campo de $20 \times 20 \mu \mathrm{m}$. b) ampliación de la zona marcada con un circulo c) grafico de la altura para el plásmido de la figura $b$.

\subsubsection{Imágenes de AFM del plásmido Gra7-YFp + RePtr}

La figura 18 muestra las imágenes obtenidas para la mezcla del plásmido y el complejo RePtr incubada $1 \mathrm{~h}$.

La figura 18 a muestra uno de los muchos campos observados de $20 \times 20 \mu \mathrm{m}$. En esta imagen pueden distinguirse dos tipos de estructuras, unas compactas similares a las observadas en el plásmido solo y otras estructuras menos compactas. Estas estructuras menos compactas se muestran encerradas en círculos. La observación a mayor escala de una de estas zonas encerradas (figura $\mathbf{1 8}$ b) revela una estructura en forma de hilo 
cerrado de unos $500 \mathrm{~nm}$ de radio. El análisis de la altura de esta estructura (figura $18 \mathrm{c}$ ) indicó que tiene una altura de entre 2 y $6 \mathrm{~nm}$.

La estructura desplegada que se observa en la imagen de mayor escala es consistente con las imágenes de AFM publicadas de plásmidos relajados [11], [40].

a)

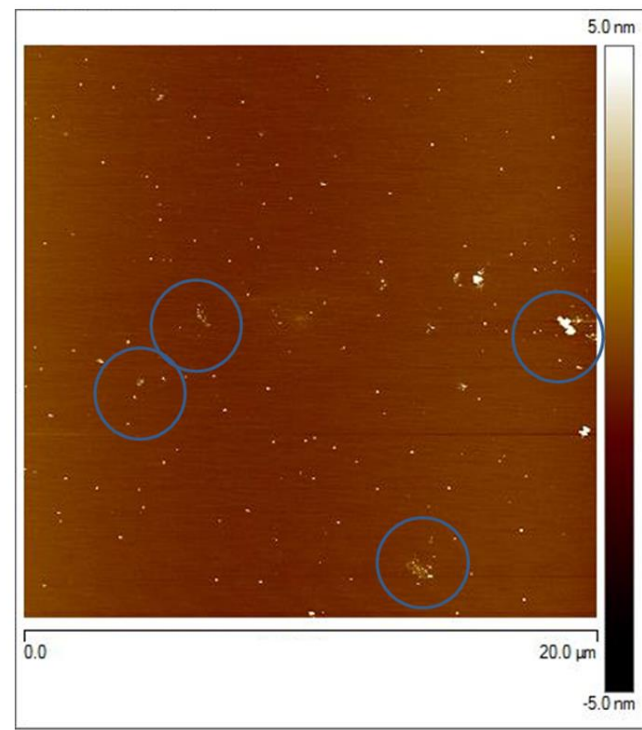

b)

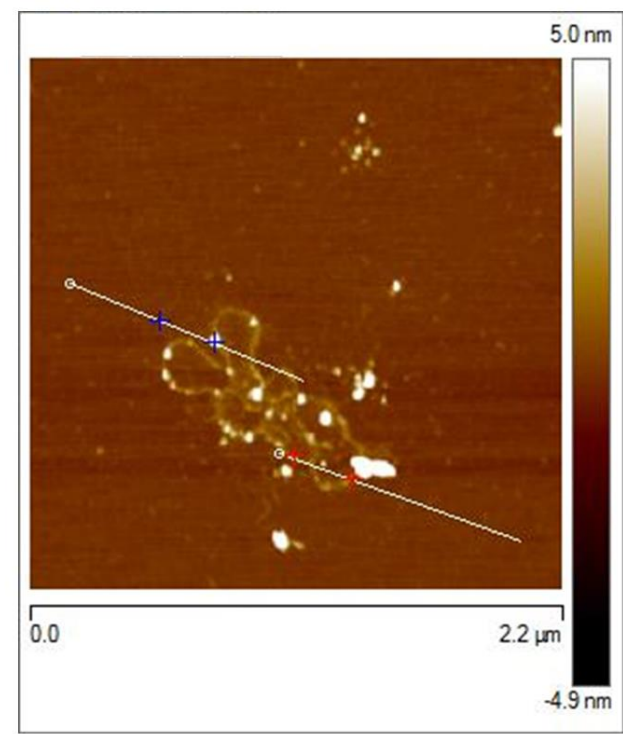

c)

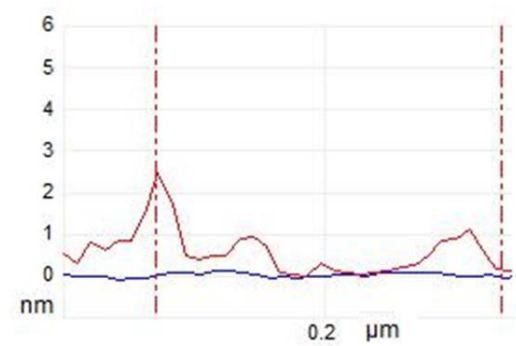

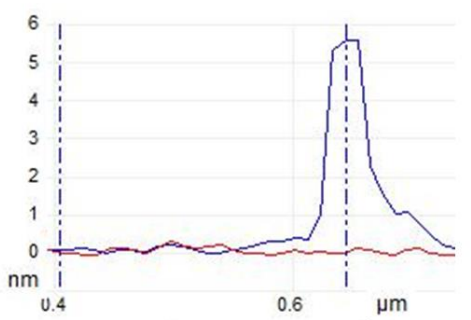

\section{Figura 18}

Imágenes de AFM de la mezcla incubada plásmido-complejo

a) Campo de 20 × $20 \mu \mathrm{m}$. b) ampliación de la zona más baja, marcada con un circulo c) grafico de la altura para el plásmido de la figura $b$.

La figura 19 muestra las imágenes obtenidas para la mezcla del plásmido y el complejo, la cual fue incubada e irradiada. 


\subsubsection{Imágenes de AFM del plásmido Gra7-YFp fotosensibilizado con RePtr}

a)

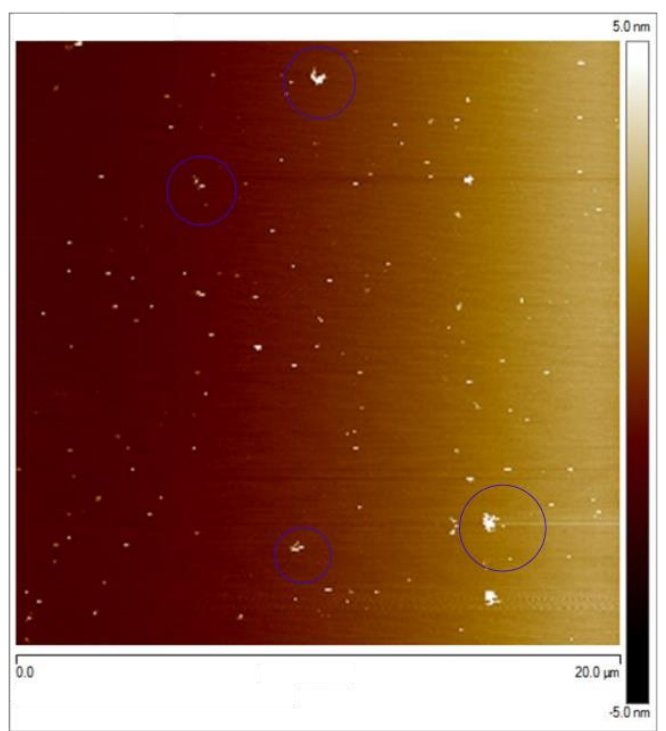

b)

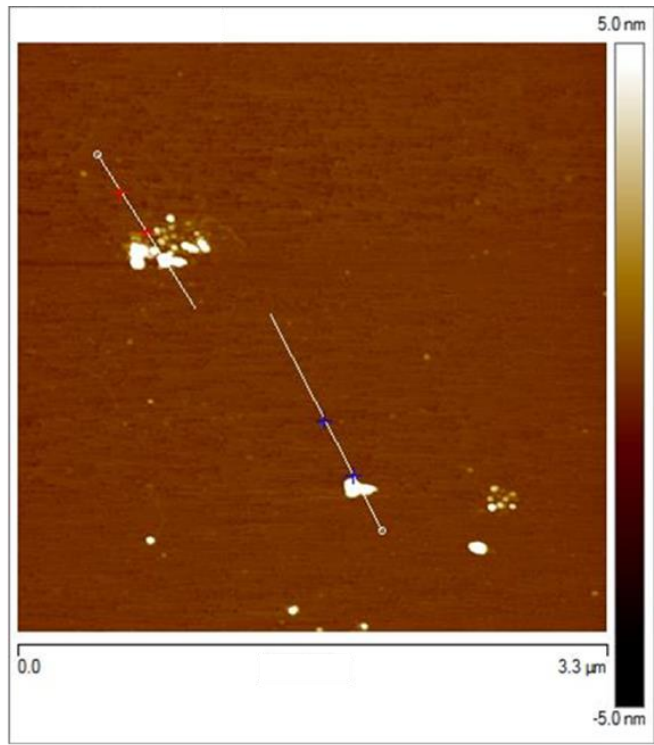

c)

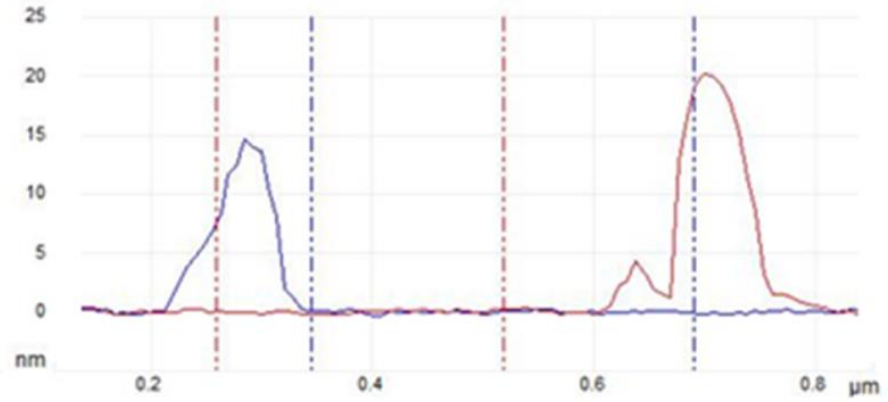

Figura 19.

Imágenes de AFM de la mezcla irradiada plásmido-complejo

a) Campo de $20 \times 20 \mu \mathrm{m}$. b) ampliación de la zona marcada con un circulo c) grafico de la altura para el plásmido de la figura $b$.

La figura 19 a muestra uno de los muchos campos observados de $20 \times 20 \mu$, en este se ven dos tipos de estructuras. Se observan estructuras compactas similares a las observadas en el plásmido solo y otras estructuras, encerradas en círculos, más desplegadas y con puntos compactos en su interior. La observación a mayor escala de una de estas la zona encerrada (figura 19 b) revela una estructura semi-compacta con hilos muy finos y grandes cúmulos con un radio total de unos $500 \mathrm{~nm}$. El análisis de la altura de esta estructura (figura 19 c) indicó que esta varía entre 15 y $20 \mathrm{~nm}$ para las zonas compactas y de $1 \mathrm{~nm}$ para las zonas desplegadas. Todas estas características 
observadas son compatibles con una mezcla entre la forma superenrollada y una forma semi-desplegada del plásmido diferente a la forma relajada.

\subsection{Conclusiones de la interacción complejo-ADN}

En este capítulo se presentaron los resultados de una serie de ensayos en los que se estudió la interacción de tres complejos de $\operatorname{Re}(\mathrm{I})$ con distintos tipos de $A D N$ siguiendo los cambios en la emisión y la absorción de los complejos.

Se encontró que tanto el complejo RePtr como el complejo Redppz interaccionan de un modo efectivo con todos los tipos de ADN. Mientras que los estudios con el complejo ReBpyTf no permitieron observar ningún tipo de interacción.

Los resultados de los ensayos de interacción con el complejo RePtr con los distintos tipos de ácidos nucleicos, se interpretaron proponiendo un mecanismo en el cual se forma un aducto entre el complejo y ADN. Los resultados se resumen en la figura 20.

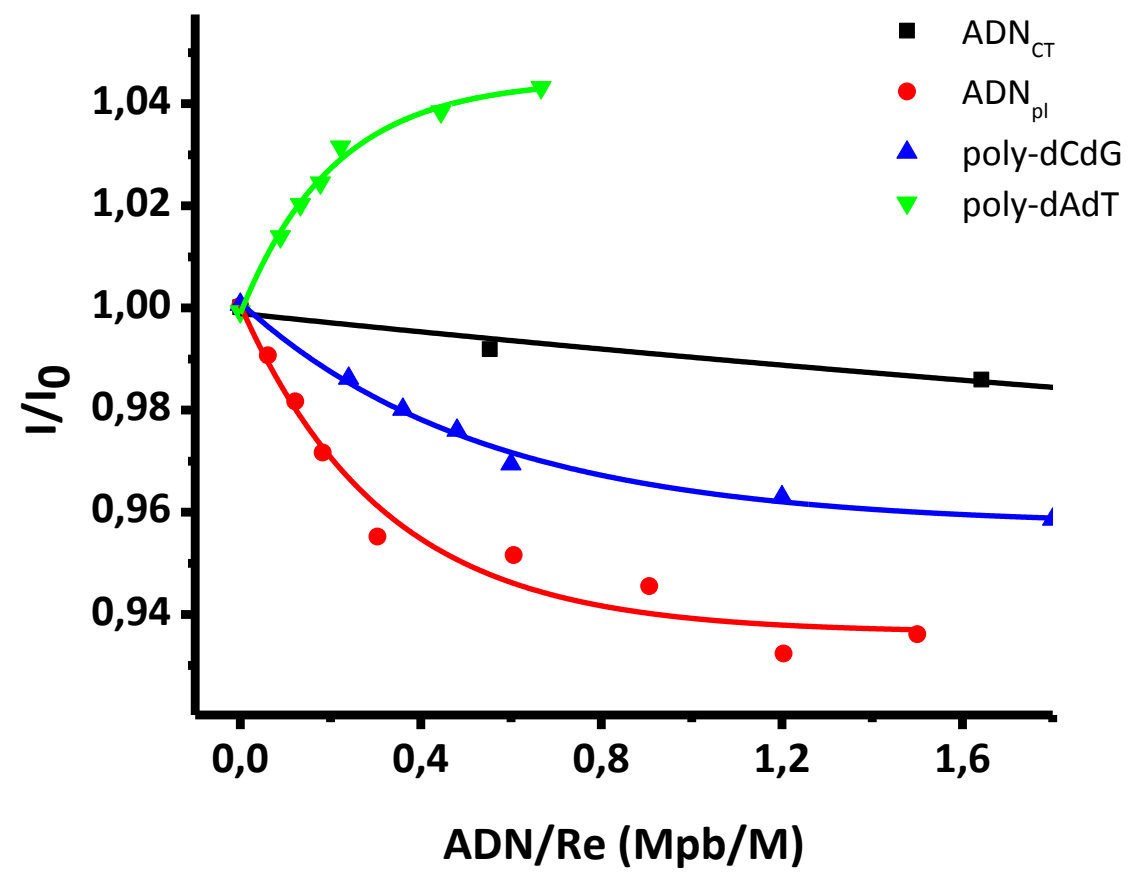

Figura 20

Análisis de los cambios en la emisión de los ensayos de interacción del complejo RePtr con poly $[\mathrm{dAdT}]_{2}, A D N_{C T}$, poly $[\mathrm{dCdG}]_{2}$ y $A D N_{\mathrm{pl}}$. Los cambios en la intensidad se representan en función de la relación molar ADN/complejo. 
En el grafico anterior puede apreciarse que el ADN plasmídico produce una mayor disminución de la fluorescencia del complejo RePtr. Esta comparación se hace para los otros tipos de ADN con la misma relación molar ADN/complejo

También se observa que se alcanza una meseta en una relación aproximada de 0,8. Este comportamiento apoya la hipótesis de formación de un aducto.

Los ensayos de interacción con el complejo Redppz, indican claramente que el complejo intercala en los dos tipos de ADN ensayado.

Los cambios observados en las bandas de los geles de electroforesis en los ensayos de interacción del complejo $f a c-\operatorname{Re}^{\prime}(\mathrm{CO})_{3}($ pterina $)\left(\mathrm{H}_{2} \mathrm{O}\right)$ con los distintos plásmidos, demuestran que existe una efectiva interacción entre el estado basal del complejo RePtr y el $A D N_{p l}$. El resultado de esta interacción, a relaciones $A D N /$ Re menores a 0,05, parece ser el de disminuir la tensión estructural del plásmido, relajándolo. Este efecto es compatible con el modelo de asociación propuesto anteriormente.

Además, las imágenes de microscopia AFM muestran que luego de la incubación del plásmido con el complejo RePtr se obtiene una población significativa de estructuras identificadas como plásmidos desplegados. Por otro lado, el estado excitado del complejo, que se genera luego de la absorción de luz, conduce a compactar nuevamente la estructura del plásmido. Se ha reportado un comportamiento similar, para otros complejos relacionados y se lo asocia al entrecruzamiento entre guaninas de cadenas de ADN adyacentes [11]. Ha sido estudiada la reacción del estado excitado del ligando libre con $A D N_{C T}$, los autores de este trabajo reportan la formación fotoinducida de 7,8-dihidro-8-oxo-2'-deoxiguanosina. Sin embargo, otros autores estudiaron el efecto de fotosensibilización de plásmidos por el ligando libre pterina y reportaron un corte foto-inducido de la doble hebra[41]. De este modo es posible que el efecto producido por el estado excitado del complejo RePtr sea el de oxidar a la guanina generando dímeros que entrecrucen las cadenas de ADN. Este entrecruzamiento es el que daría lugar a la formación de las estructuras compactas observadas por microscopia AFM de la mezcla irradiada del complejo y el plásmido (figura 19 b).

Los cambios conformacionales en el ADN plasmídico producto de la interacción con el complejo [fac-(dppz) Re $(C O)_{3}\left(4,4^{\prime}\right.$ bipiridina $\left.)\right]\left(P F_{6}\right)$ se encuentran dentro de los 
resultados esperados para este tipo de complejos, ya que es bien conocida la capacidad del ligando dppz de intercalar entre las bases del ADN [1], [37]

Sobre este modo de acción por intercalación entre las bases, se sabe que, provoca una disminución de la tensión de la doble hebra y con ésto una disminución en el grado de superenrollamiento [42].

Cuando la muestra fue irradiada con luz UV de 350 nm en forma continua se observó la desaparición de la única banda que corre como la banda de la forma relajada del plásmido, usado como referencia. Cuando el tiempo de irradiación fue mayor a 30 minutos, la banda dejo de detectarse. Este resultado, es compatible con el fotoclivaje de la molécula del plásmido, inducido por el estado excitado del complejo. De este modo, los fragmentos producto del fotoclivaje, tienen tan corta longitud que no son detectados en esta condición de corrida.

Cuando se analizó el experimento de interacción del complejo fac$\operatorname{Re}^{\prime}(\mathrm{CO})_{3}\left(2,2^{\prime}\right.$ bipiridina $\left.)\right]\left(\mathrm{O}_{3} \mathrm{SCF}_{3}\right)$ con el plásmido no se observaron cambios en la conformación del mismo, sin embargo cuando la muestra fue irradiada 120 minutos, se dejó de observar la banda correspondiente al plásmido superenrollado. Este resultado indica la relajación fotoinducida del plásmido. Con la evidencia reunida, no podemos verificar que exista una interacción entre este complejo y el plásmido. Sin embargo la efectiva interacción del estado excitado del complejo que genera el despegamiento del plásmido, permite suponer una interacción previa. La relajación observada, puede deberse al corte de una de las hebras de la cadena de ADN, inducido por el estado excitado del complejo. Este corte conduce a la desaparición de la tensión estructural del plásmido y con esto el superenrollamiento. En la figura $\mathbf{2 1}$ se resumen en forma esquemática las conclusiones de los ensayos de interacción. 


\section{Capítulo V}

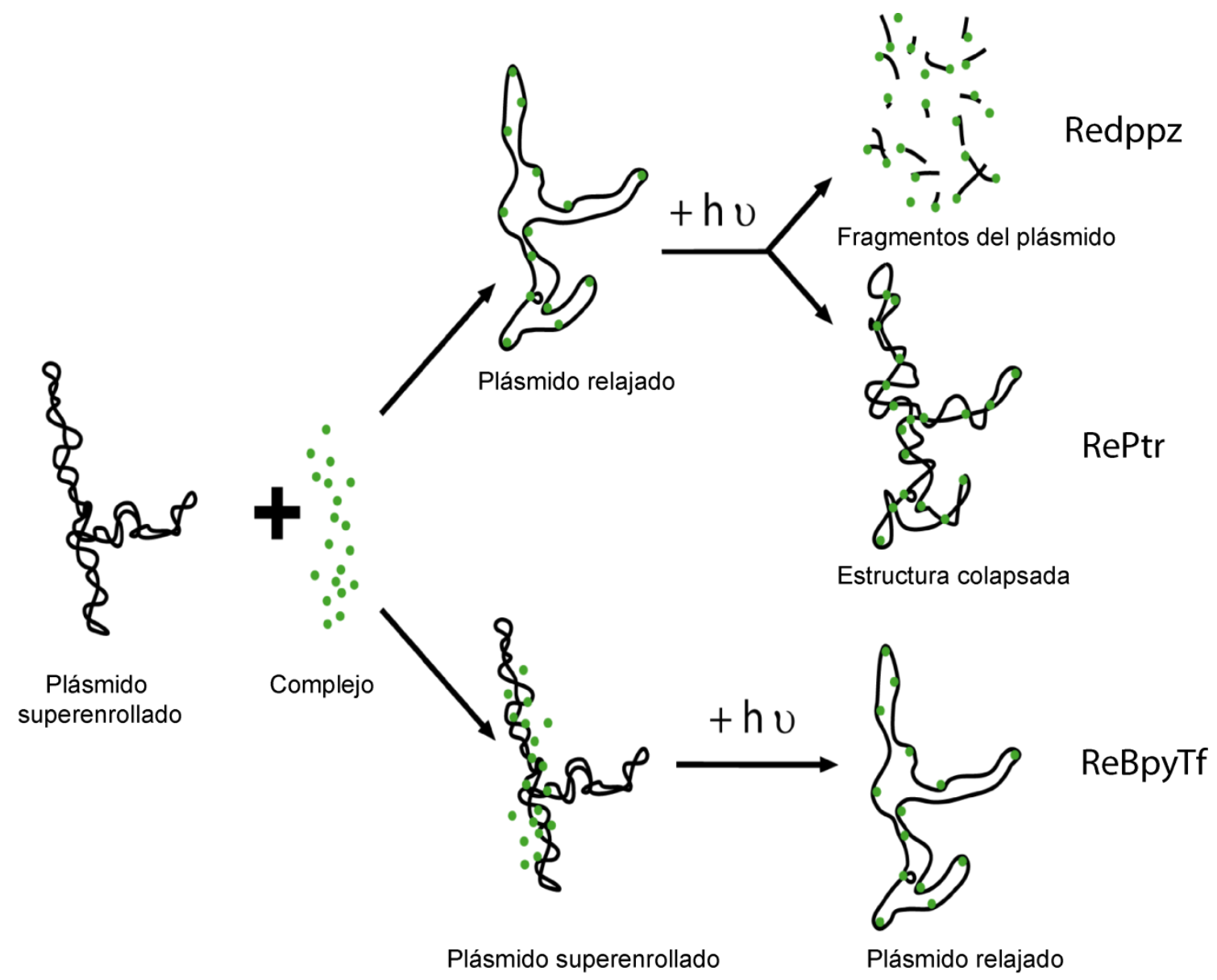

\section{Figura 21}

Representación esquemática de los cambios que ocurren en el plásmido cuando interacciona con cada uno de los tres complejos y el efecto de la fotosensibilización

\section{Estudios de interacción entre $f a c-\operatorname{Re}^{\prime}(\mathrm{CO})_{3}($ pterina $)\left(\mathrm{H}_{2} \mathrm{O}\right)$ y sero-albuminas}

La espectroscopia de fluorescencia es un método ampliamente usado para el estudio de la interacción entre ligandos y bio-macromoléculas, dado que brinda valiosa información acerca de los cambios que sufre el microambiente que rodea a los fluoróforos presentes en la macromolécula cuando interaccionan con un ligando.

La fluorescencia en la albúmina se origina a partir de dos tipos de fluoróforos: el triptófano (Trp) y la tirosina (Tyr), principalmente.

La seroalbúmina bovina (BSA) contiene dos residuos de Trp localizados en diferentes subdominios: el Trp-214, expuesto a un ambiente hidrofóbico en el subdominio IIA y el 
Trp-135, localizado en el subdominio IB en un entorno hidrofílico. Por el contrario la seroalbúmina humana (HSA), solo posee un Trp ubicado en el subdominio IIA (Trp 214). Cuando se excita una muestra de albumina con luz de $\lambda_{\text {exc. }}=295 \mathrm{~nm}$, la fluorescencia de la albúmina proviene solo del Trp, mientras que si la luz de excitación es de $\lambda_{\text {exc. }}=280 \mathrm{~nm}$ ambos residuos absorben la luz, pero se observa solo un máximo de emisión que corresponde al Trp. Esto ocurre así ya que estos sistemas están acoplados y existe una transferencia de energía desde la Tyr al Trp.

Buscando establecer el subdominio donde se asocian los complejos de $\operatorname{Re}(\mathrm{l})$ a la albúmina, en primera instancia se realizó un análisis comparativo de la desactivación de la fluorescencia de la BSA y HSA por los complejos metálicos. Luego, con el propósito de determinar si ambos fluoróforos están involucrados en el proceso de asociación, se comparó la fluorescencia de la albúmina excitada a 280 y $295 \mathrm{~nm}$. Utilizando la magnitud de los cambios espectrales en función de la concentración de complejo se calcularon las constantes de asociación con ambas proteínas. Los cálculos de las constantes a distintas temperaturas, permitieron obtener los parámetros termodinámicos de asociación.

Las seroalbúminas son proteínas cuya función biológica de transporte de sustancias en suero, depende se la integridad de su estructura. Para evaluar el grado en que, la asociación afecta a la conformación terciaria de la proteína se realizaron medidas de dicroísmo circular. Finalmente se realizaron cálculos de distancia entre la proteína y el complejo en la asociación, mediante el cálculo de la eficiencia de transferencia de energía resonante utilizando el modelo de FRET.

\subsection{Asociación seguida por desactivación de la emisión.}

En las figuras $\mathbf{2 4}$ y $\mathbf{2 5}$ se observa el efecto del complejo RePtr sobre la intensidad de fluorescencia de HSA excitando a $\lambda=295$ y $280 \mathrm{~nm}$. En las figuras 26 y 27 se muestra el efecto del complejo RePtr sobre la intensidad de fluorescencia de BSA excitando a $\lambda=$ 295 y $280 \mathrm{~nm}$. 


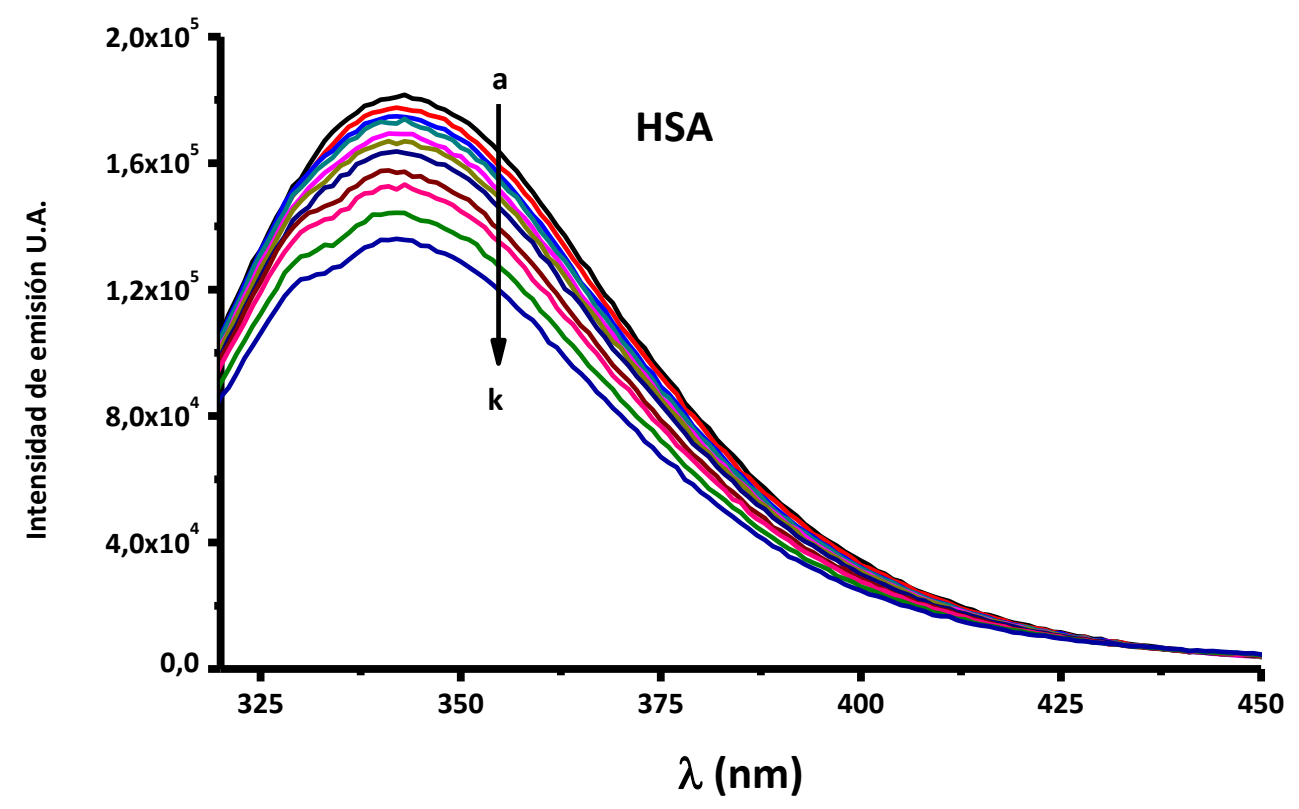

\section{Figura 24}

Espectros de emisión de fluorescencia de HSA $\left(1,5 \times 10^{-6} \mathrm{M}\right)$ luego del agregado del complejo RePtr, en buffer fosfatos $\mathrm{pH}=7,4 ; \mathrm{T}=298 \mathrm{~K}, \lambda_{\text {exc }}=280 \mathrm{~nm},\left(\mathrm{a}=0, \mathrm{k}=6 \times 10^{-6} \mathrm{M}\right)$

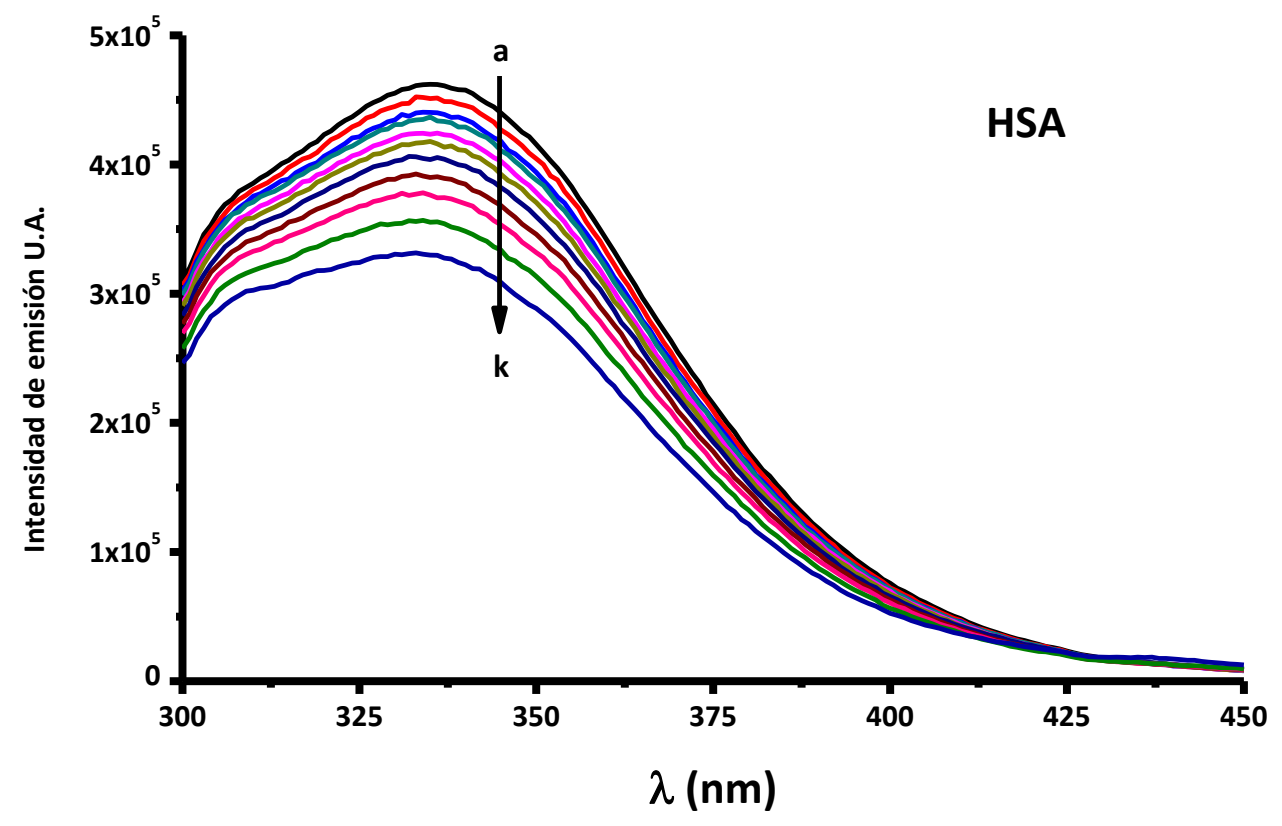

\section{Figura 25}

Espectros de emisión de fluorescencia de HSA $\left(1,5 \times 10^{-6} \mathrm{M}\right)$ luego del agregado del complejo RePtr, en buffer fosfatos $\mathrm{pH}=7,4 ; \mathrm{T}=298 \mathrm{~K}, \lambda_{\text {exc }}=295 \mathrm{~nm},\left(\mathrm{a}=0, \mathrm{k}=6 \times 10^{-6} \mathrm{M}\right)$ 


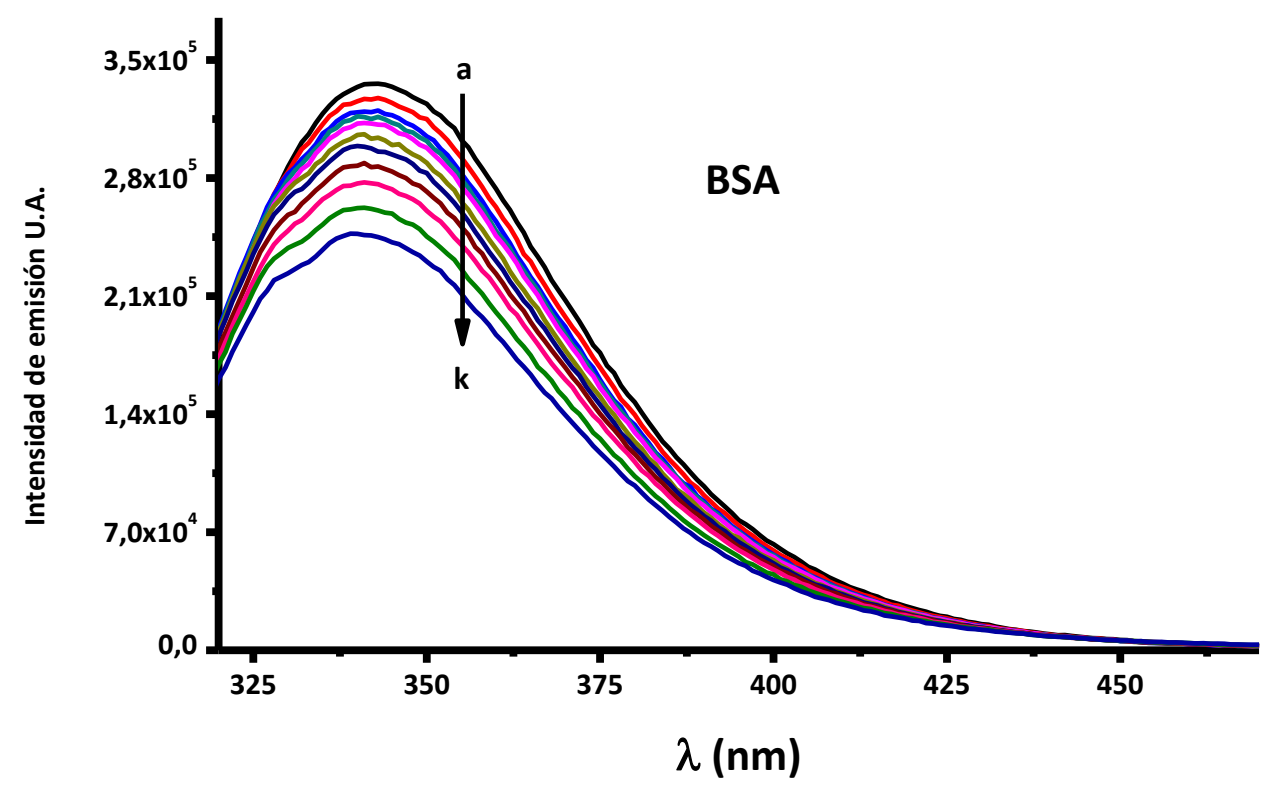

\section{Figura 26}

Espectros de emisión de fluorescencia de la BSA $\left(1,5 \times 10^{-6} \mathrm{M}\right)$ luego del agregado del complejo RePtr, en buffer fosfatos $\mathrm{pH}=7,4 ; \mathrm{T}=298 \mathrm{~K}, \lambda_{\text {exc. }}=280 \mathrm{~nm},\left(\mathrm{a}=0, \mathrm{k}=6 \times 10^{-6} \mathrm{M}\right)$

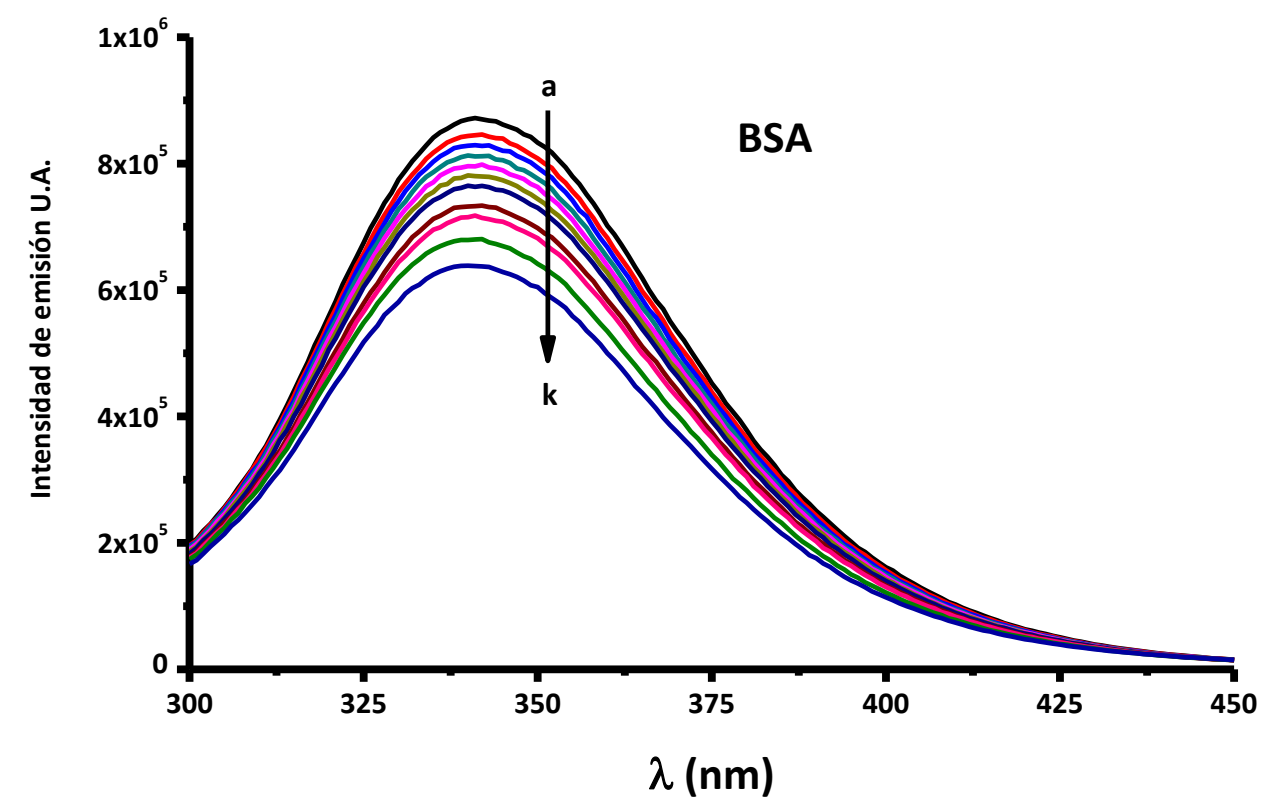

Figura 27

Espectros de emisión de fluorescencia de BSA $\left(1,5 \times 10^{-6} \mathrm{M}\right)$ luego del agregado del complejo RePtr, en buffer fosfatos $\mathrm{pH}=7,4 ; \mathrm{T}=298 \mathrm{~K}, \lambda_{\text {exc. }}=295 \mathrm{~nm},\left(\mathrm{a}=0, \mathrm{k}=6 \times 10^{-6} \mathrm{M}\right)$ 
Al comparar los cambios en la intensidad de la emisión de la BSA y la HSA al excitar con una $\lambda_{\mathrm{ex}}=280$ y $295 \mathrm{~nm}$, puede notarse, una disminución en la intensidad de emisión al aumentar la concentración del complejo. También, puede verse que las bandas de emisión observadas no sufren modificaciones en su forma ni en la posición del máximo.

\subsubsection{Dominio de asociación}

Para establecer el subdominio donde se asocia el complejo de $\operatorname{Re}(I)$ a la albúmina, se analizaron comparativamente la desactivación de la fluorescencia de BSA y HSA. $\left(I / I_{0}\right)$. Cuando un ligando inhibe la fluorescencia de HSA, revela que dicho proceso está ocurriendo en el subdominio IIA, donde se encuentra el Trp-214.

Cuando se midió la desactivación de la emisión por el complejo RePtr, no se observaron diferencias significativas entre la extensión de la desactivación de la emisión de BSA y HSA tanto a $\lambda_{\text {exc. }}=280 \mathrm{~nm}$ (figura 28), como a $\lambda_{\text {exc. }}=295 \mathrm{~nm}$ (figura 29).

El fenómeno observado indica que probablemente el Trp-135, sólo presente en BSA, no se encuentra involucrado en el proceso de asociación. Estos resultados sugieren que, el subdominio IIA, es el principal sitio de unión del complejo RePtr a ambas proteínas 


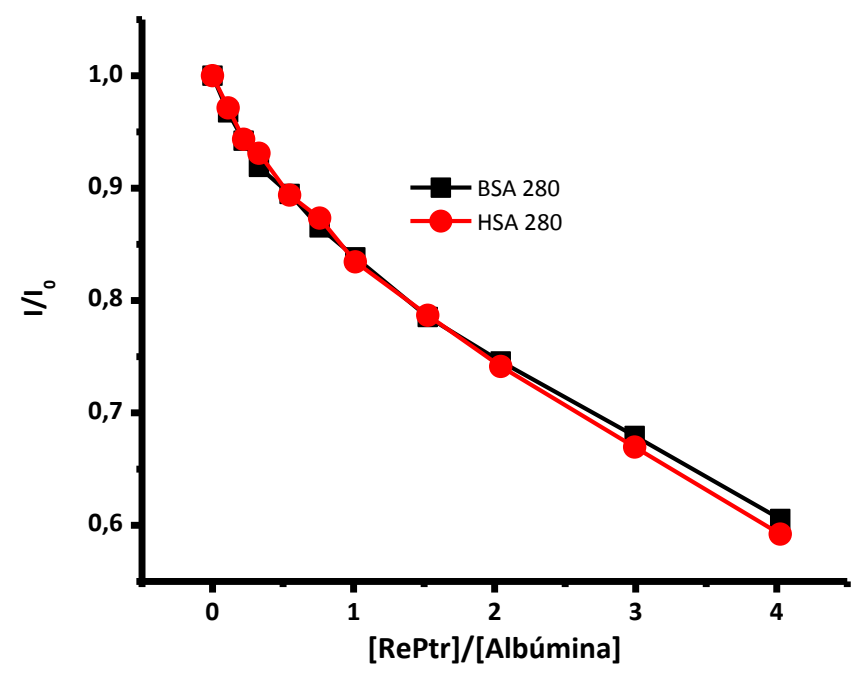

\section{Figura 28}

Gráfico de intensidad de fluorescencia relativa en el máximo de albúmina sérica $\left(\mathrm{I} / \mathrm{I}_{0}\right)$ vs [RePtr]/[albúmina]. $\lambda_{\text {exc. }}=280 \mathrm{~nm}$ : BSA-[RePtr], ( $\square$ ) y HSA-[RePtr], (O);buffer fosfatos $\mathrm{pH}=7,4 . \mathrm{T}=298 \mathrm{~K}$

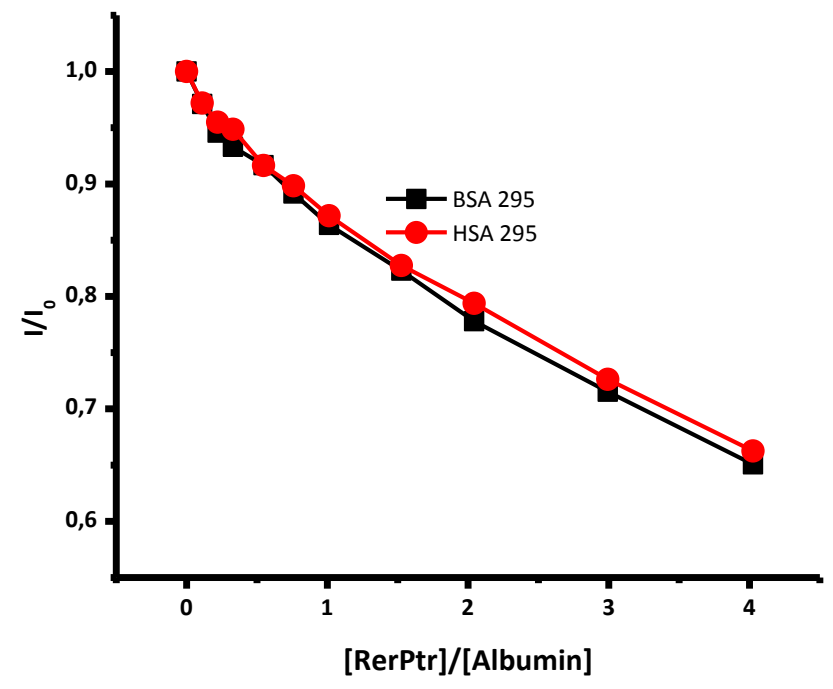

Figura 29

Gráfico de intensidad de fluorescencia relativa de albúmina sérica $\left(I / I_{0}\right)$ vs [RePtr]/[albúmina] $\lambda_{\text {exc. }}=295 \mathrm{~nm}$ : BSA-[RePtr], y HSA-[RePtr]; BSA-[RePtr], (ם) y HSA[RePtr], (O) buffer fosfatos $\mathrm{pH}=7,4 . \mathrm{T}=298 \mathrm{~K}$ 


\subsubsection{Determinación de fluoróforos involucrados}

Para determinar si ambos fluoróforos (Trp y Tyr) están involucrados en el proceso de asociación, se comparó la desactivación de fluorescencia de BSA y HSA excitadas a $\lambda=$ 280 y 295 nm (figura 30 y 31).

Al comparar la desactivación de la emisión de la HSA cuando se excita a 280 y 289 nm, se observa, que para una relación molar $\left(r_{\mathrm{i}}\right)[\mathrm{Re}] /\left[\right.$ proteína] $r_{\mathrm{i}}=4$, cuando se excita a $\lambda_{\text {exc. }}=280 \mathrm{~nm}$, la emisión es del $59 \%$ de la inicial. Mientras que cuando se excita con luz de $\lambda_{\text {exc. }}=295 \mathrm{~nm}$ es de $66 \%$.

La comparación de la desactivación de la emisión de la BSA a las dos longitudes de onda de excitación reveló, que la extensión de desactivación es similar a la observada para HSA. Se observa una disminución al $\approx 60 \%$ de la emisión cuando se excita con luz de $\lambda_{\text {exc }}=280 \mathrm{~nm}$ y al $\approx 65 \%$ con $\lambda_{\text {exc }}=295 \mathrm{~nm}$.

Esta diferencia entre el efecto observado a $\lambda=280$ y $295 \mathrm{~nm}$ para ambos sistemas evidencia que los residuos de Tyr también toman parte en la interacción molecular proteína-complejo metálico.

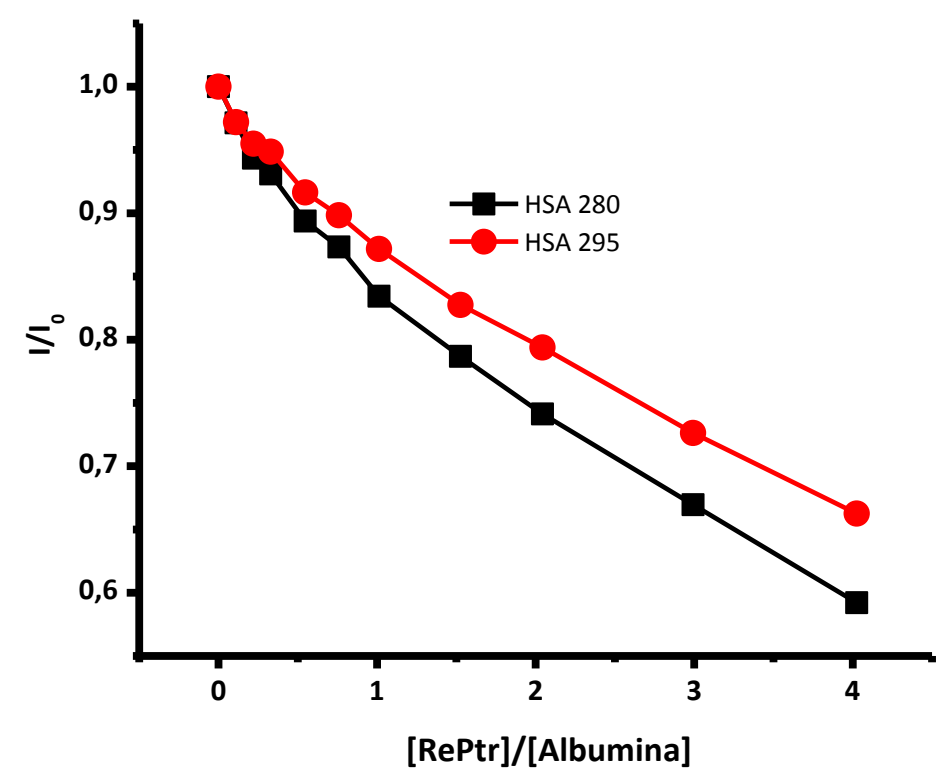

Figura 30

Gráfico de intensidad de fluorescencia relativa de HSA (I/I0) vs [RePtr]/[HSA]; $\lambda_{\text {exc. }}=280$ $\mathrm{nm}$ y $\lambda_{\text {exc. }}=295 \mathrm{~nm}$, buffer fosfatos $\mathrm{pH}=7,4 ; \mathrm{T}=298 \mathrm{~K}$. 


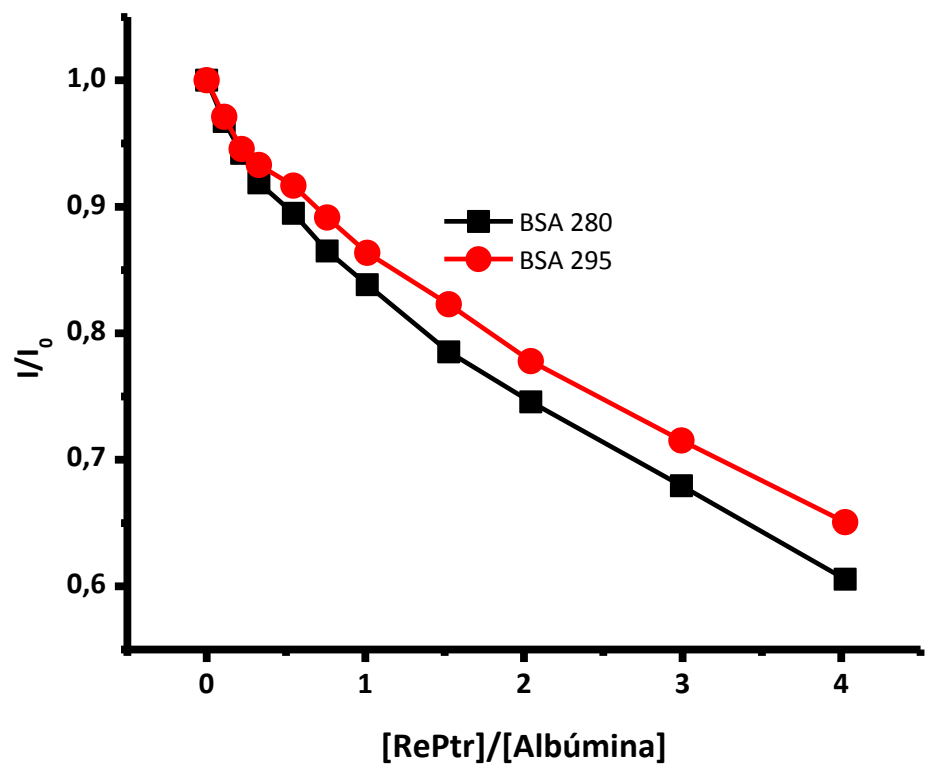

Figura 31

Gráfico de intensidad de fluorescencia relativa de BSA (I/I0) vs [RePtr]/[BSA]; $\lambda_{\text {exc. }}=280$ $\mathrm{nm}$ y $\lambda_{\text {exc. }}=295 \mathrm{~nm}$, buffer fosfatos $\mathrm{pH}=7,4 ; \mathrm{T}=298 \mathrm{~K}$.

\subsubsection{Constantes de asociación}

Motivados por revelar cuan afín es este complejo metálico por el sitio de unión de las albúminas, se determinaron las constantes de asociación para los dos sistemas en estudio a partir de los datos de fluorescencia. Las constantes $K_{b}$ se calcularon usando el modelo desarrollado por Bhattacharyya, presentado en el capítulo I. Los gráficos 1/(I$I_{0}$ ) vs $1 /[Q]$ para los sistemas BSA-RePtr y HSA-RePtr se presentan en la figura 32. 


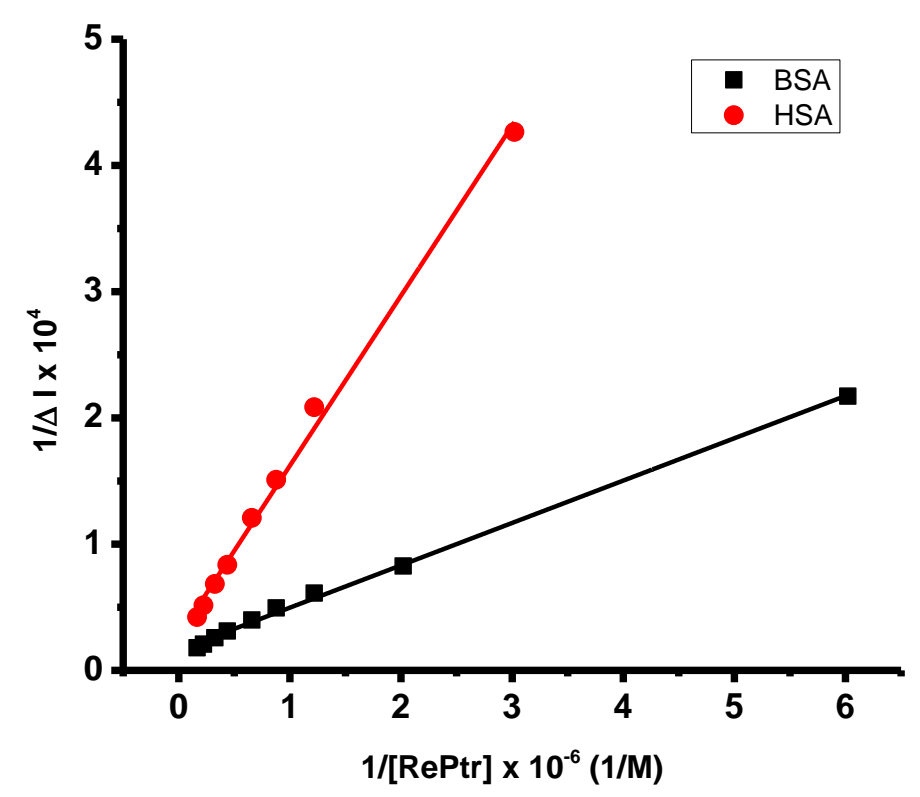

\section{Figura 32}

Gráfico de $1 / \Delta /$ vs $1 /[$ RePtr] para los sistemas BSA-[RePtr]y HSA-[RePtr]. T = $298 \mathrm{~K}$, buffer fosfatos $\mathrm{pH}=7,4 ; \lambda_{\text {exc. }}=280 \mathrm{~nm}$.

El comportamiento lineal de los datos experimentales responde a un modelo de interacción uno a uno entre ambas partes, proteína y complejo metálico de acuerdo al modelo empleado.

Las constantes de asociación complejo-proteína para los sistemas planteados fueron determinadas a partir de los cambios de la intensidad de fluorescencia de la proteína en presencia de complejo metálico. En primer lugar, se obtuvieron los espectros de emisión de las soluciones de BSA y HSA $\left(1,5 \times 10^{-6} \mathrm{M}\right)$ y, posteriormente, se registraron los espectros de la misma solución de proteína en presencia de diferentes concentraciones de complejo $\left(0-7,5 \times 10^{-6} \mathrm{M}\right)$.

Con los valores obtenidos de la regresión lineal de $1 / \Delta F$ vs $1 /[$ RePtr], se determinaron las constantes $K_{b}$ a tres temperaturas diferentes. Las constantes de asociación obtenidas se listan en la tabla 7. 


\begin{tabular}{llcc}
\hline \hline \multirow{2}{*}{$T(\mathrm{~K})$} & Albúmina & \multicolumn{2}{c}{ [RePtr] } \\
\cline { 3 - 4 } & & $K_{b} \times 10^{-5}\left(\mathrm{M}^{-1}\right)$ & $r^{2}$ \\
\hline \multirow{2}{*}{298,0} & BSA & $7,0 \pm 0,3$ & 0,9995 \\
& HSA & $2,2 \pm 0,3$ & 0,9979 \\
303,7 & BSA & $6,0 \pm 0,1$ & 0,9998 \\
& HSA & $1,9 \pm 0,1$ & 0,9996 \\
309,5 & BSA & $5,1 \pm 0,2$ & 0,9996 \\
& HSA & $1,6 \pm 0,1$ & 0,9999 \\
\hline \hline \multirow{2}{*}{ Constantes de asociación para los sistemas Albúmina- } \\
[RePtr] en estudio, en buffer fosfatos pH = 7,4. \\
\hline \hline
\end{tabular}

Los valores de las constantes obtenidos son un reflejo de la alta afinidad que presentan el complejo RePtr y las proteínas. El valor de $K_{b}$ disminuye con el aumento de la temperatura para los sistemas HSA-[RePtr] y BSA-[RePtr]. Las constantes $K_{b}$ a diferentes temperaturas fueron usadas para determinar los parámetros termodinámicos.

\subsection{Parámetros termodinámicos de asociación}

Los parámetros termodinámicos fueron analizados con el fin de caracterizar las fuerzas de interacción involucradas en el proceso de asociación entre albúmina y RePtr.

Las fuerzas moleculares que contribuyen a las interacciones entre una proteína y pequeñas moléculas incluyen principalmente: fuerzas de interacción hidrofóbicas, interacciones de Van der Waals, puentes de hidrógeno, fuerzas electrostáticas, entre otras.

Los parámetros termodinámicos, cambio de entalpía $(\Delta H)$, entropía $(\Delta S)$ y energía libre $(\Delta G)$, son esenciales para caracterizar el modo de unión. Los parámetros termodinámicos $(\Delta H$ y $\Delta S)$ se estimaron a partir de la pendiente y la ordenada al origen a partir de la representación de Van'tHoff. (Ec.2) (figura 33). 

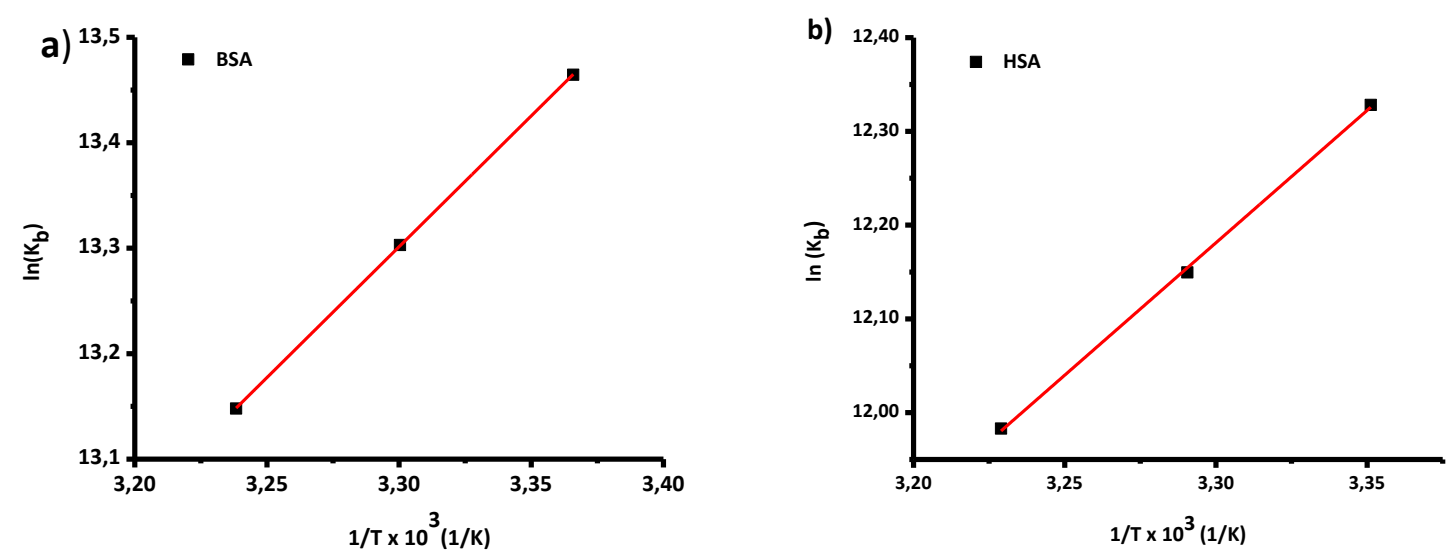

Figura 33

Representación de Van'tHoff. a) Sistema BSA-[RePtr]. b) Sistema HSA-[RePtr].

Los valores de $\Delta G$ se calcularon a partir de los valores de $\Delta H$ y $\Delta S$ mediante la ecuación de Gibbs. Los valores obtenidos se listan en la tabla 8.

\begin{tabular}{lllll}
\hline \hline $\begin{array}{l}T \\
(\mathrm{~K})\end{array}$ & Albúmina & $\begin{array}{l}\Delta G \\
\left(\mathrm{KJ} \mathrm{mol}^{-1}\right)\end{array}$ & $\begin{array}{l}\Delta H \\
\left(\mathrm{~kJ} \mathrm{~mol}^{-1}\right)\end{array}$ & $\begin{array}{l}\Delta S \\
\left(\mathrm{~J} \mathrm{~mol}^{-1} \mathrm{~K}^{-1}\right)\end{array}$ \\
\hline 298,6 & BSA & $-33,1 \pm 0,2$ & $-20,6 \pm 0,2$ & $42 \pm 0,6$ \\
297,8 & $\mathrm{HSA}$ & $-30,6 \pm 0,2$ & $-23,5 \pm 0,2$ & $23,8 \pm 0,6$ \\
304,5 & BSA & $-33,4 \pm 0,2$ & $-20,6 \pm 0,2$ & $42 \pm 0,6$ \\
303,0 & $\mathrm{HSA}$ & $-30,7 \pm 0,2$ & $-23,5 \pm 0,2$ & $23,8 \pm 0,6$ \\
309,5 & BSA & $-33,6 \pm 0,2$ & $-20,6 \pm 0,2$ & $42 \pm 0,6$ \\
309,6 & $\mathrm{HSA}$ & $-30,8 \pm 0,2$ & $-23,5 \pm 0,2$ & $23,8 \pm 0,6$ \\
\hline \hline
\end{tabular}

Tabla 8

Parámetros termodinámicos para el proceso de asociación Albúmina-[RePtr].

\subsection{Calculo de la distancia donor-aceptor por FRET}

El cálculo de la eficiencia de la transferencia de energía, se utilizó para evaluar la distancia entre el complejo y el fluoróforo en la proteína. La teoría de la transferencia de energía de resonancia de Förster establece que, la transferencia de energía ocurrirá dependiendo de la orientación relativa entre los dipolos del donante y aceptor y del grado de solapamiento entre el espectro de emisión fluorescente del donante con el 
espectro de absorción del aceptor. Además debe cumplirse que la distancia entre el donor (proteína) y el aceptor (RePtr) sea inferior a $100 \mathrm{~nm}$. La desactivación de la fluorescencia de las albúminas, producto de la interacción con el complejo RePtr, es un indicativo de que se produjo la transferencia de energía entre las dos especies. La superposición del espectro absorción UV-Vis del complejo con el espectro de emisión fluorescente de BSA y HSA se muestra en las figuras 34 a y b.

Las eficiencias de transferencia de energía, $\phi_{\mathrm{T}}$, se obtuvieron según la teoría de la transferencia de energía de Förster, detallada en el capítulo I.

J se calculó mediante la integración del espectro de la superposición en el rango de longitud de onda de 300-500 $\mathrm{nm}$. Para el sistema utilizado: $\mathrm{k}^{2}=2 / 3, \eta=1,33$ y $\Phi_{\mathrm{f}}=$ 0,13 [43]. Los resultados obtenidos para el sistema de BSA-RePtr fueron $\phi_{\mathrm{T}}=0,16, \mathrm{~J}=$ $5,82 \times 10^{-15} \mathrm{~cm}^{3} \mathrm{M}^{-1}, \mathrm{R}_{0}=2,29 \mathrm{~nm}, \mathrm{y} \mathrm{r}=3,02 \mathrm{~nm}$ y para el sistema HSA-RePtr se obtuvo, $\phi_{\mathrm{T}}=0,16, \mathrm{~J}=5,83 \times 10^{-15} \mathrm{~cm}^{3} \mathrm{M}^{-1}, \mathrm{R}_{0}=2,27 \mathrm{~nm}, \mathrm{y} \mathrm{r}=3,01 \mathrm{~nm}$. Las distancias donoraceptor resultaron menores a $10 \mathrm{~nm}$, lo que indica que la transferencia de energía de BSA a RePtr y HSA a RePtr se produce con alta probabilidad. 
a)

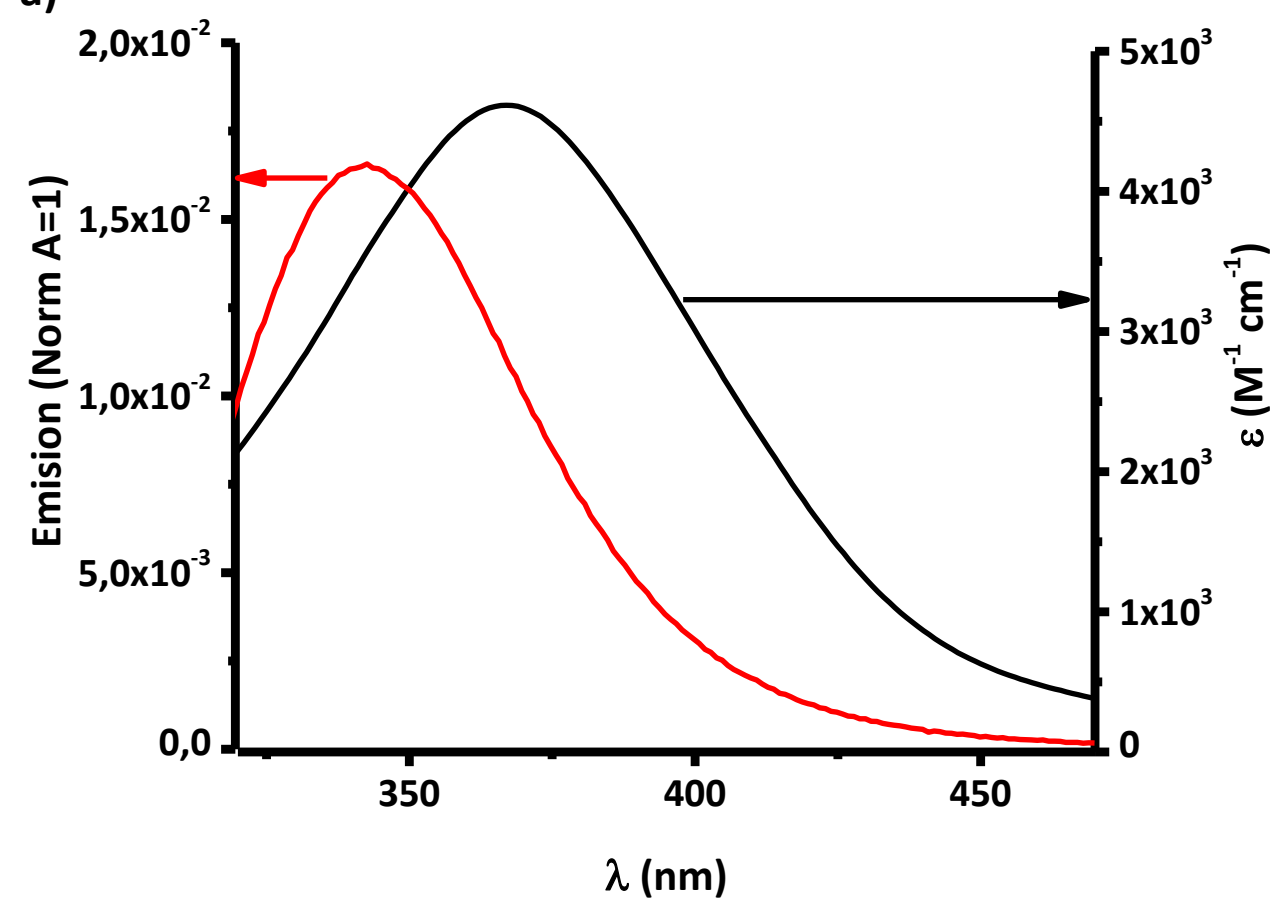

b)

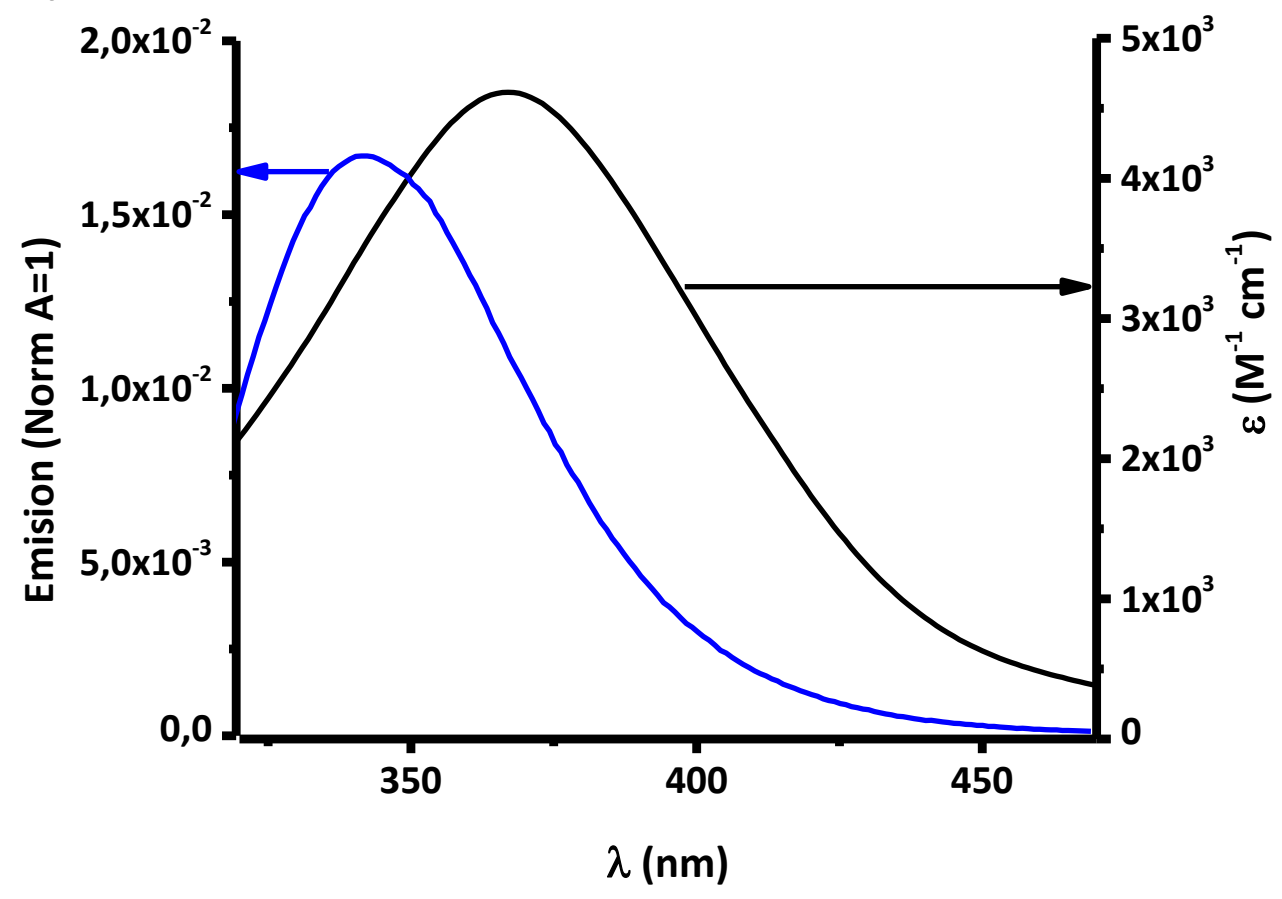

Figura 34

Solapamientos espectrales entre el espectro de absorción normalizado del complejo RePtr y el espectro de emisión normalizado de la a) HSA b) BSA. $\lambda_{\text {exc }}=280 \mathrm{~nm}$. 


\subsection{Cambios en la estructura seguidos por DC}

El entorno de los residuos ópticamente activos en las albuminas en forma nativa, determina el ángulo de desviación que sufre la luz polarizada. Los cambios conformacionales que puede ocasionar la interacción con el complejo se verán reflejados en la modificación de estos entornos y, consecuentemente en el ángulo de desviación. Se realizaron medidas de dicroísmo circular (DC) en el rango del UV lejano (180 a $250 \mathrm{~nm}$ ). Los espectros de DC de BSA y HSA en presencia y ausencia del complejo RePtr se muestran en las figuras 35 a y $\mathbf{b}$.

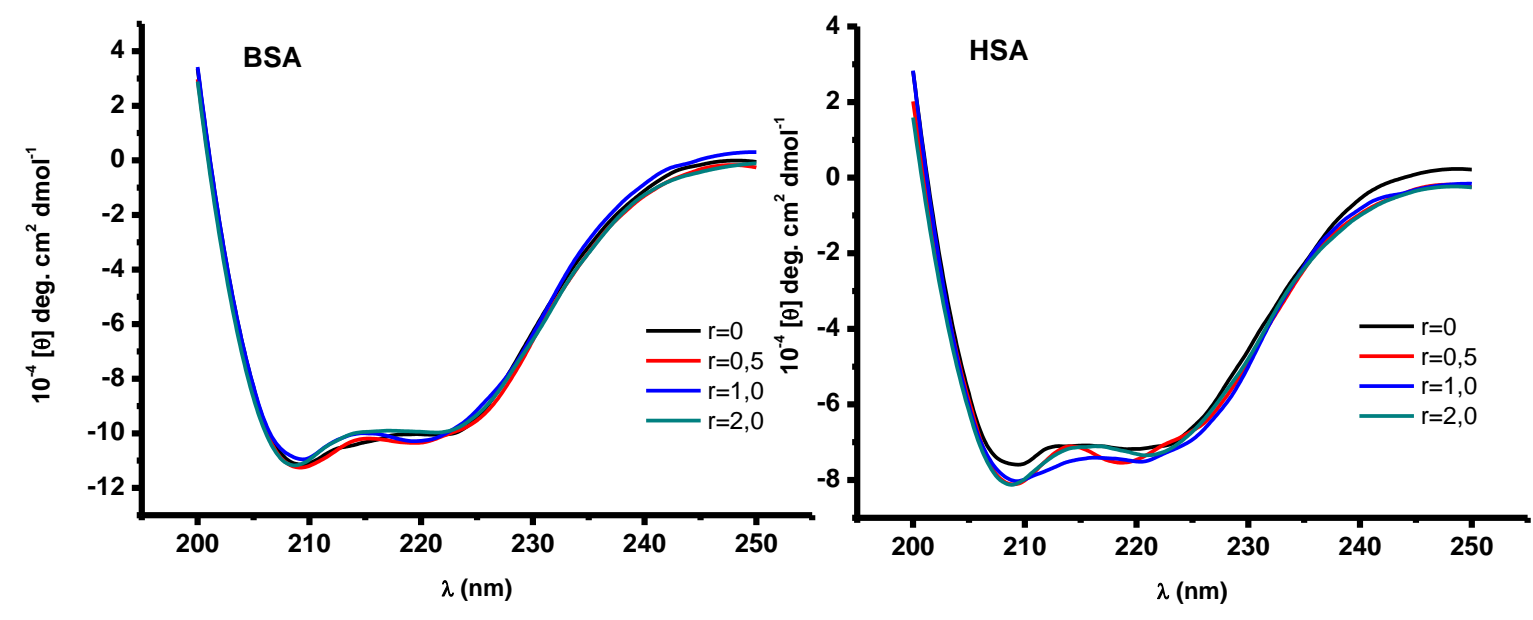

Figura 35

Espectro de dicroísmo circular de BSA-RePtr (a) y HSA-RePtr (b). Las concentraciones usadas fueron de $5 \times 10^{-6} \mathrm{M}$ para ambas proteínas y de $0 ; 2,5 \times 10^{-6} ; 5 \times 10^{-6}$ y $1 \times 10^{-5} \mathrm{M}$ para el complejo obteniéndose las relaciones $r=0 ; 0,5 ; 1$; y 2 respectivamente.

Los espectros de DC de la BSA y HSA, exhiben dos bandas negativas en la región UV a 208 y $222 \mathrm{~nm}$, siendo esto un rasgo típico de la estructura $\alpha$-hélice de estas proteínas [44]. La explicación probable es que los picos negativos entre 208-209 nm y 222-223 $\mathrm{nm}$ son ambos contribución de la transición $\mathrm{n} \rightarrow \pi^{*}$ del enlace peptídico $\alpha$-helicoidal [45]. Los espectros CD de las sero-albúminas de suero en presencia y ausencia del complejo, son similares en forma, lo que indica que la estructura de BSA y HSA es se mantiene predominantemente $\alpha$-helicoidal. De los resultados anteriores, es evidente que el complejo no provoca un cambio conformacional en las sero-albúmina. 


\subsection{Conclusiones de la asociación con sero-albuminas}

La asociación del complejo RePtr con las sero-albuminas muestra claramente que la interacción es entre el complejo y los dos fluoróforos de la proteína, Tyr y Trp. El sitio de asociación a ambas proteínas es el subdominio IIA, el cual es un bolsillo hidrofóbico. La desactivación cumple con el modelo de Bhattacharyya para una asociación complejo-fluoróforo 1:1, por lo cual fue posible calcular las constantes del proceso de asociación. Los valores calculados para estas constantes $\left(2-7 \times 10^{5} \mathrm{M}^{-1}\right.$ para la HSA y BSA respectivamente) mostraron buena concordancia con los valores publicados para otros complejos [30], [46], [47].

Anteriormente fue estudiada la interacción entre el ligando libre y la BSA. Los autores reportaron una constante de asociación del orden de $10^{3}$ [48], este valor es mucho más pequeño que el valor encontrado para el complejo. Esta diferencia permite presumir diferencias importantes en el modo de interacción del ligando y el complejo con la proteína.

Los parámetros termodinámicos calculados mostraron un $\Delta \mathrm{H}$ negativo y un $\Delta \mathrm{S}$ positivo. Estos resultados pueden ser analizados teniendo en cuenta el trabajo publicado por Ross [49]. Este trabajo postula la existencia de interacciones electrostáticas cuando el $\Delta \mathrm{H}$ negativo y un $\Delta \mathrm{S}$ positivo. Sin embargo, el hecho de que la interacción ocurra en un bolsillo hidrofóbico y que el signo del $\Delta \mathrm{S}$ sea positivo, nos indica la probable existencia de interacciones del tipo hidrofóbicas.

La unión del complejo a estas proteínas puede conducir a cambios conformacionales que induzcan la pérdida de las propiedades biológicas de la macromolécula. Sin embargo, el estudio de DC indica que la asociación del complejo a las albuminas no induce cambios significativos en la estructura de las proteínas.

Los atributos particulares del complejo, tales como, su solubilidad y estabilidad en agua y su capacidad de unirse y provocar cambios foto-sensibilizados en el ADN, sugieren, que el complejo puede ser un candidato atractivo para su potencial aplicación en terapia fotodinámica. Debido a esto, los resultados de las interacciones del complejo con las proteínas del plasma, en particular con albúmina de suero, resultan de gran relevancia, ya que esta molécula constituye la principal proteína en el plasma. 


\section{Referencias bibliográficas}

[1] E. Gicquel, J.-P. Souchard, F. Magnusson, J. Chemaly, P. Calsou, and P. Vicendo, "Role of intercalation and redox potential in DNA photosensitization by ruthenium(II) polypyridyl complexes: assessment using DNA repair protein tests.," Photochem. Photobiol. Sci., vol. 12, no. 8, pp. 1517-26, Aug. 2013.

[2] J. Mlcouskova, J. Stepankova, and V. Brabec, "Antitumor carboplatin is more toxic in tumor cells when photoactivated: enhanced DNA binding.," J. Biol. Inorg. Chem., vol. 17, no. 6, pp. 891-8, Aug. 2012.

[3] F. Berg, J. Wilken, C. a Helm, and S. Block, "AFM-Based Quantification of Conformational Changes in DNA Caused by Reactive Oxygen Species.," J. Phys. Chem. B, vol. 119, no. 1, pp. 25-32, Jan. 2015.

[4] G. Colmenarejo, M. C. Gutirrez-alonso, F. Montero, and G. Orellana, "DNA photocleavage by novel intercalating 6-(2-pyridinium)phenanthridinium viologens," vol. 374, pp. 426-428, 1995.

[5] K. D. Barker, B. R. Benoit, J. a Bordelon, R. J. Davis, A. S. Delmas, O. V Mytykh, J. T. Petty, J. F. Wheeler, and N. a. . Kane-Maguire, "Intercalative binding and photoredox behavior of [Cr(phen)2(dppz)]3+ with B-DNA," Inorganica Chim. Acta, vol. 322, no. 1-2, pp. 74-78, Oct. 2001.

[6] A. Friedman and J. Chambron, "A molecular light switch for DNA: Ru (bpy) 2 (dppz) 2+," J. Am. Chem. Soc., vol. 112, pp. 4960-4962, 1990.

[7] F. Zobi, B. Spingler, and R. Alberto, "Guanine and plasmid DNA binding of monoand trinuclear fac-[Re(CO)3]+ complexes with amino acid ligands.,"

Chembiochem, vol. 6, no. 8, pp. 1397-405, Aug. 2005.

[8] S. R. Dalton, S. Glazier, B. Leung, S. Win, C. Megatulski, and S. J. N. Burgmayer, "DNA binding by Ru(II)-bis(bipyridine)-pteridinyl complexes.," J. Biol. Inorg. Chem., vol. 13, no. 7, pp. 1133-48, Sep. 2008.

[9] T. Phillips, I. Haq, A. J. H. M. Meijer, H. Adams, I. Soutar, L. Swanson, M. J. Sykes, and J. a Thomas, "DNA binding of an organic dppz-based intercalator.," Biochemistry, vol. 43, no. 43, pp. 13657-65, Nov. 2004.

[10] A. K. Patra, T. Bhowmick, S. Ramakumar, M. Nethaji, and A. R. Chakravarty, "DNA cleavage in red light promoted by copper(II) complexes of alpha-amino acids and photoactive phenanthroline bases.," Dalton Trans., no. 48, pp. 696676, Dec. 2008.

[11] W. Vanderlinden, M. Blunt, C. C. David, C. Moucheron, A. Kirsch-De Mesmaeker, S. De Feyter, A. Kirsch-de, and S. De Feyter, "Mesoscale DNA structural changes 
on binding and photo-reaction with Ru[(TAP)2(PHEHAT)]2+," J. Am. Chem. Soc., vol. 134, no. 24, pp. 10214-21, Jun. 2012.

[12] S. Anbu, S. Kamalraj, B. Varghese, J. Muthumary, and M. Kandaswamy, "A series of oxyimine-based macrocyclic dinuclear zinc(II) complexes enhances phosphate ester hydrolysis, DNA binding, DNA hydrolysis, and lactate dehydrogenase inhibition and induces apoptosis.," Inorg. Chem., vol. 51, no. 10, pp. 5580-92, May 2012.

[13] F. Li, W. Chen, C. Tang, and S. Zhang, "Recent development of interaction of transition metal complexes with DNA based on biosensor and its applications.," Talanta, vol. 77, no. 1, pp. 1-8, Oct. 2008.

[14] N. Deepika, Y. P. Kumar, C. Shobha Devi, P. V. Reddy, A. Srishailam, and S. Satyanarayana, "Synthesis, characterization, and DNA binding, photocleavage, cytotoxicity, cellular uptake, apoptosis, and on-off light switching studies of $\mathrm{Ru}$ (II) mixed-ligand complexes containing 7-fluorodipyrido[3,2-a:2',3'c]phenazine.," J. Biol. Inorg. Chem. JBIC a, vol. 18, no. 7, pp. 751-66, Oct. 2013.

[15] S. Swavey and K. J. Brewer, "Visible light induced photocleavage of DNA by a mixed-metal supramolecular complex: [[(bpy)(2)Ru(dpp)](2)RhCl2]5+.," Inorg. Chem., vol. 41, no. 24, pp. 6196-8, Dec. 2002.

[16] D. a Lutterman, A. Chouai, Y. Liu, Y. Sun, C. D. Stewart, K. R. Dunbar, and C. Turro, "Intercalation is not required for DNA light-switch behavior.," J. Am. Chem. Soc., vol. 130, no. 4, pp. 1163-70, Jan. 2008.

[17] C. Turro, D. Hall, and W. Chen, "Solution photoreactivity of phenanthrenequinone diimine complexes of rhodium and correlations with DNA photocleavage and photooxidation," J. Phys. Chem. A, vol. 102, pp. 5708-5715, 1998.

[18] A. J. McConnell, M. H. Lim, E. D. Olmon, H. Song, E. E. Dervan, and J. K. Barton, "Luminescent Properties of Ruthenium(II) Complexes with Sterically Expansive Ligands Bound to DNA Defects.," Inorg. Chem., vol. 51, no. 22, pp. 12511-20, Nov. 2012.

[19] P. Lincoln and B. Norde, "Enantioselective DNA Threading Dynamics by Phenazine-Linked [Ru(phen)2dppz]2+ Dimers," J. Am. Chem. SOC, vol. 123, pp. 3630-3637, 2001.

[20] S. J. Burya, A. M. Palmer, J. C. Gallucci, and C. Turro, "Photoinduced ligand exchange and covalent DNA binding by two new dirhodium bis-amidato complexes.," Inorg. Chem., vol. 51, no. 21, pp. 11882-90, Nov. 2012.

[21] B. R. Williams, S. R. Dalton, M. Skiba, S. E. Kim, A. Shatz, P. J. Carroll, and S. J. N. Burgmayer, "Pteridine cleavage facilitates DNA photocleavage by Ru(II) 
polypyridyl compounds.," Inorg. Chem., vol. 51, no. 23, pp. 12669-81, Dec. 2012.

[22] L. J. Boerner and J. M. Zaleski, "Metal complex-DNA interactions: from transcription inhibition to photoactivated cleavage.," Curr. Opin. Chem. Biol., vol. 9, no. 2, pp. 135-44, Apr. 2005.

[23] R. Hartshorn and J. Barton, "Novel dipyridophenazine complexes of ruthenium (II): exploring luminescent reporters of DNA," J. Am. Chem. Soc., no. 1, pp. 59195925, 1992.

[24] T. Miao, S. Li, J. Chen, F. Ma, and K. Zheng, "Theoretical studies on DNAphotocleavage efficiencies and mechanisms of Ru (II) polypyridyl complexes," JBIC J. Biol. Chem., vol. 17, pp. 1177-1185, 2012.

[25] I. Ortmans, B. Elias, J. M. Kelly, C. Moucheron, and A. Kirsch-DeMesmaeker, "[Ru(TAP)2(dppz)]2+: a DNA intercalating complex, which luminesces strongly in water and undergoes photo-induced proton-coupled electron transfer with guanosine-5'-monophosphate.," Dalton Trans., vol. 2, no. 4, pp. 668-76, Feb. 2004.

[26] A. M. J. Fichtinger-schepman, P. H. M. Lohmant, and J. Reedk, "Detection and quantification of adducts formed upon interaction of diamminedichlorophtinum (II) with DNA, by anion-exchafge chromatography after enzymatic degadation," Nucleic Acids Res., vol. 10, no. 17, pp. 5345-5356, 1982.

[27] Y. Liu, R. Hammitt, D. a Lutterman, R. P. Thummel, and C. Turro, "Marked differences in light-switch behavior of Ru(II) complexes possessing a tridentate DNA intercalating ligand.," Inorg. Chem., vol. 46, no. 15, pp. 6011-21, Jul. 2007.

[28] S. L. H. Higgins, T. a White, B. S. J. Winkel, and K. J. Brewer, "Redox, spectroscopic, and photophysical properties of Ru-Pt mixed-metal complexes incorporating 4,7-diphenyl-1,10-phenanthroline as efficient DNA binding and photocleaving agents.," Inorg. Chem., vol. 50, no. 2, pp. 463-70, Jan. 2011.

[29] A. Kirsch-DeMesmaeker, "Photoreactions of metal complexes whith dna, especially those involving primary photo-electron transfer.pdf." .

[30] J. Toneatto and G. a Argüello, "New advances in the study on the interaction of [Cr(phen)2(dppz)]3+ complex with biological models; association to transporting proteins.," J. Inorg. Biochem., vol. 105, no. 5, pp. 645-51, May 2011.

[31] K. K.-W. Lo, W.-K. Hui, C.-K. Chung, K. H.-K. Tsang, D. C.-M. Ng, N. Zhu, and K.-K. Cheung, "Biological labelling reagents and probes derived from luminescent transition metal polypyridine complexes," Coord. Chem. Rev., vol. 249, no. 1314, pp. 1434-1450, Jul. 2005. 
[32] K. K.-W. Lo, K. Y. Zhang, and S. P.-Y. Li, "Recent Exploitation of Luminescent Rhenium(I) Tricarbonyl Polypyridine Complexes as Biomolecular and Cellular Probes," Eur. J. Inorg. Chem., vol. 2011, no. 24, pp. 3551-3568, Aug. 2011.

[33] R. K. Gupta, G. Sharma, R. Pandey, A. Kumar, B. Koch, P.-Z. Li, Q. Xu, and D. S. Pandey, "DNA/protein binding, molecular docking, and in vitro anticancer activity of some thioether-dipyrrinato complexes.," Inorg. Chem., vol. 52, no. 24, pp. 13984-96, Dec. 2013.

[34] C. V Kumar, J. K. Barton, and N. J. Turro, "Photophysics of ruthenium complexes bound to double helical DNA," J. Am. Chem. Soc., vol. 107, no. 15, pp. 55185523, 1985.

[35] G. Petroselli, M. L. Dántola, F. M. Cabrerizo, C. Lorente, A. M. Braun, E. Oliveros, and A. H. Thomas, "Quenching of the fluorescence of aromatic pterins by deoxynucleotides," J. Phys. Chem. A, vol. 113, pp. 1794-1799, 2009.

[36] N. Shahabadi, S. Mohammadi, and R. Alizadeh, "DNA interaction studies of a new platinum(II) complex containing different aromatic dinitrogen ligands," Bioinorg. Chem. Appl., vol. 2011, 2011.

[37] G. T. Ruiz, M. P. Juliarena, R. O. Lezna, E. Wolcan, M. R. Feliz, and G. Ferraudi, "Intercalation of fac-[(4,4'-bpy)Rel(CO)3(dppz)]+, dppz = dipyridyl[3,2-a:2'3'c]phenazine, in polynucleotides. On the UV-vis photophysics of the $\operatorname{Re}(\mathrm{I})$ intercalator and the redox reactions with pulse radiolysis-generated radicals.," Dalton Trans., vol. 3, no. 20, pp. 2020-9, May 2007.

[38] V. W. Yam, K. K. Lo, K. Cheung, and R. Y. Kong, "Deoxyribonucleic acid binding and photocleavage studies of rhenium(I) dipyridophenazine complexes," J. Chem. Soc. Dalt. Trans., pp. 2067-2072, 1997.

[39] E. D. Olmon, P. a Sontz, A. M. Blanco-Rodríguez, M. Towrie, I. P. Clark, A. Vlček, and J. K. Barton, "Charge photoinjection in intercalated and covalently bound $[\operatorname{Re}(\mathrm{CO}) 3(\mathrm{dppz})(\mathrm{py})]+-\mathrm{DNA}$ constructs monitored by time-resolved visible and infrared spectroscopy.," J. Am. Chem. Soc., vol. 133, no. 34, pp. 13718-30, Aug. 2011.

[40] K. Rippe, N. Mücke, and J. Langowski, "Superhelix dimensions of a 1868 base pair plasmid determined by scanning force microscopy in air and in aqueous solution.," Nucleic Acids Res., vol. 25, no. 9, pp. 1736-1744, May 1997.

[41] C. Lorente, A. H. Thomas, L. Villata, D. Hozbor, A. Lagares, and A. L. Capparelli, "Photoinduced cleavage of plasmid DNA in the presence of pterin," Pteridines, vol. 11, pp. 100-105, 2000.

[42] M. V Keck and S. J. Lippard, "Unwinding of Supercoiled DNA by PlatinumEthidium and Related Complexes," J. Am. Chem. SOC, no. 22, pp. 3386-3390, 1992. 
[43] M. Suzukida, H. P. Le, F. Shahid, R. A. Mcpherson, E. R. Birnbaum, and D. W. Darnall, "Resonance Energy Transfer between Cysteine-34 and Tryptophan-214 in Human Serum Albumin. Distance Measurements as a Function of $\mathrm{pH}$," Biochemistry, vol. 22, pp. 2415-2420, 1983.

[44] J. Liu, J. Tian, W. He, J. Xie, Z. Hu, and X. Chen, "Spectrofluorimetric study of the binding of daphnetin to bovine serum albumin," J. Pharm. Biomed. Anal., vol. 35, pp. 671-677, 2004.

[45] P. Yang and F. Gao, The principle of bioinorganic chemistry. Beijing: Science, 2002.

[46] B. P. Espósito and R. Najjar, "Interactions of antitumoral platinum-group metallodrugs with albumin," Coord. Chem. Rev., vol. 232, pp. 137-149, 2002.

[47] J. Toneatto, P. F. Garcia, and G. A. Argüello, "Advances on the interaction of polypyridyl $\mathrm{Cr}$ (III) complexes with transporting proteins and its potential relevance in photodynamic therapy.," J. Inorg. Biochem., vol. 105, no. 10, pp. 1299-305, Oct. 2011.

[48] A. H. Thomas, C. Lorente, K. Roitman, M. M. Morales, and M. L. Dántola, "Biology Photosensitization of bovine serum albumin by pterin : A mechanistic study," J. Photochem. Photobiol. B Biol., vol. 120, pp. 52-58, 2013.

[49] P. D. Ross and S. Subramanian, "Thermodynamics of protein association reactions: forces contributing to stability.," Biochemistry, vol. 20, pp. 30963102, 1981. 


\section{Tercera parte}

Conclusiones 



\section{Capítulo VI}

Resumen de las conclusiones 


\section{Índice}

\section{Capítulo VI \\ Resumen de las conclusiones}

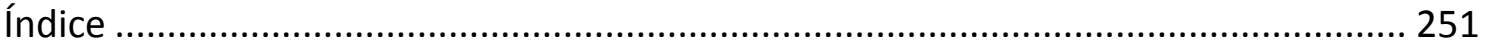

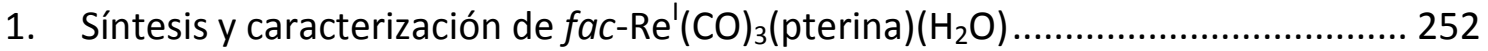

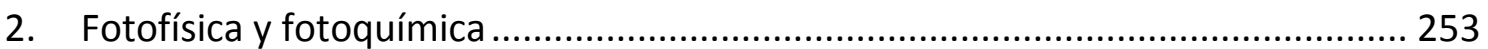

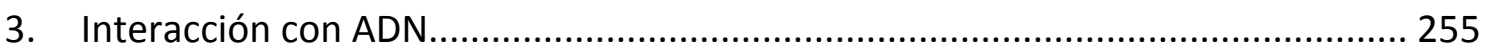

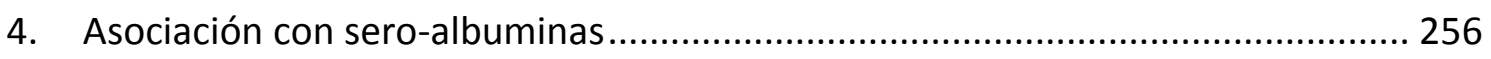

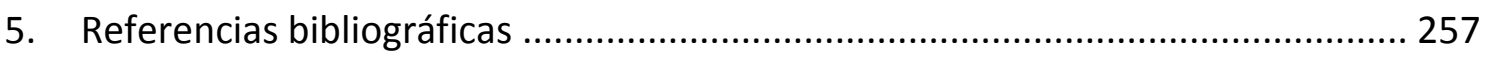




\section{Síntesis y caracterización de $f a c-\operatorname{Re}^{\prime}(\mathrm{CO})_{3}($ pterina $)\left(\mathrm{H}_{2} \mathrm{O}\right)$}

Existen en la bibliografía numerosos ejemplos de complejos metálicos conteniendo al ligando pterina [1]-[13], sin embargo hasta el momento de la escritura de este trabajo no se registran trabajos sobre complejos de Renio(I) con el ligando Pterina. La pterina es una molécula de origen natural, sus derivados se encuentran involucrados en varios procesos metabólicos en tales como la síntesis de aminoácidos y nucleótidos. La fotofísica y fotoquímica de esta molécula fue muy estudiada por su relación con un defecto metabólico en la piel Ilamado vitíligo[14]. La pterina se encuentra coordinada al Molibdeno en la enzima nitrato reductasa de Neurospora [15].

La relevancia biológica de la pterina junto con el vasto conocimiento sobre su fotofísica la convirtieron en un ligando con gran potencial. Es así que se llevó adelante la síntesis del nuevo complejo de coordinación fac- $\operatorname{Re}^{\prime}(\mathrm{CO})_{3}($ pterina $)\left(\mathrm{H}_{2} \mathrm{O}\right)$. Se utilizaron, exitosamente dos vías de síntesis (ambas con rendimientos $>70 \%$ ). Primero se utilizó el método tradicional, reportado para otros complejos tricarbonilicos de $\operatorname{Re}(\mathrm{I})$ con ligandos similares[16]-[19]. Adicionalmente, se utilizó un método de síntesis en el cual previo a la síntesis propia del complejo, se prepara el precursor fac- $\mathrm{Re}^{\prime}(\mathrm{CO})_{3}\left(\mathrm{H}_{2} \mathrm{O}\right)_{3}{ }^{+}$. El más efectivo intercambio de ligandos permite evitar el exceso de ligando, evitando de este modo varios pasos de recristalización. Además, la utilización de este precursor soluble en agua permitió eliminar el etanol y llevar adelante la síntesis y purificación completamente en medio acuoso. La elevada solubilidad en agua que presenta este complejo le aporta una cualidad de gran interés en posibles aplicaciones que requieran un entorno fisiológico [20].

La completa caracterización del complejo permitió confirmar su estructura. Se probó que la pterina es coordinada por el $\operatorname{Re}(\mathrm{I})$ en las posiciones $\mathrm{O} 4$ y N5, que la misma se encuentra desprotonada en el N3. Además se comprobó que los 3 carbonilos se encuentran coordinados en posición facial y que la sexta posición de coordinación es ocupada por un agua (en solución acosa).

Al preparar soluciones de este complejo en distintos solventes, se observa un cambio en la coloración de la solución. Este proceso fue identificado como una lenta 
disociación de un dímero del complejo que se forma durante el paso re rotavaporación. De este modo a fin de evitar la presencia del dímero se trabajó en soluciones preparadas con 24 hs de antelación. Este tiempo es el que corresponde a la total disociación del dímero en la condición de solvente que hace más lento el proceso. Al preparar soluciones del complejo RePtr en agua con distintas condiciones de acidez se observó una variación en la coloración. Conociendo la existencia de equilibrios acido-base en el ligando libre, se encaró un estudio espectroscópico de los equilibrios acido-base presentes en una solución del complejo. Se identificaron tres especies presentes en los dos equilibrios acido base de este complejo. Estas presentan notables cambios espectrales, en particular entre las especies predominantes en el primer equilibrio. Estos cambios en la posición e intensidad de los máximos de absorción pueden ser aplicados en el desarrollo de nuevos bio-sensores de $\mathrm{pH}$ [21].

El estudio espectroscópico de las especies del complejo presentes en distintas condiciones de $\mathrm{pH}$, resultó de gran importancia para los objetivos de esta tesis. Ya que aportó evidencia directa sobre la naturaleza de las especies en sus estados basales. Esta información se utilizó en el estudio de otras propiedades fotofísicas y fotoquímicas, así como también, en estudios sobre el comportamiento de asociación con otras moléculas.

Los datos obtenidos de la síntesis y caracterización del complejo, junto a los estudios de protonación dieron origen a una publicación en el año 2012 en el European Journal of inorganic Chemistry [22].

\section{Fotofísica y fotoquímica}

Se realizaron numerosos ensayos enmarcados en el estudio sistemático de las propiedades fotofísicas y fotoquímicas de un grupo de complejos tricarbonilicos de $\operatorname{Re}(\mathrm{I})$. Los complejos estudiados fueron el nuevo complejo sintetizado fac$\operatorname{Re}^{\prime}(\mathrm{CO})_{3}$ (Pterina) $\left(\mathrm{H}_{2} \mathrm{O}\right)$ (RePtr) y otros tres complejos obtenidos dentro del grupo para otros trabajos fac- $\operatorname{Re}^{\prime}(\mathrm{CO})_{3}\left(\text { bpy) } \mathrm{CF}_{3} \mathrm{SO}_{3} \text { (ReBpyTf), fac-Re'(CO) }\right)_{3}$ (phen) $\mathrm{CF}_{3} \mathrm{SO}_{3}$ (RePhen) y $[\text { fac-Re'(CO) })_{3}($ bpy)(py) $] \mathrm{CF}_{3} \mathrm{SO}_{3}$ (ReBpyPy). 
Se realizó un estudio espectroscópico del complejo RePtr en distintos solventes. Las bandas observadas en los espectros fueron asignadas a distintas transiciones. La banda de menor energía se asignó a una transición de transferencia de carga $d \pi\left(\operatorname{Re}^{\prime}\right)-\pi C O \rightarrow$ $\pi^{*}$ (ptr), que genera el estado excitado TCMLL $\operatorname{Re}(\mathrm{CO})_{3} \rightarrow$ Ptr. Mientras que la banda de mayor energía $(\approx 255 \mathrm{~nm})$, fue asignada principalmente a transiciones $\pi \rightarrow \pi^{*}$ centradas en la pterina, poblando un estado excitado de naturaleza IL. Aun así, en la práctica estos estados se encuentran conectados por ICS y se pueblan simultáneamente al utilizar luz de $350 \mathrm{~nm}$.

La emisión estacionaria para este complejo en medio acuoso tiene las características típicas de la correspondiente a la desexcitación del estado excitado singlete del ligando pterina a su estado basal [23].El tiempo de vida de este estado excitado ronda los 8 ns. Esta luminiscencia no se ve afectada por la presencia de Oxígeno disuelto. El rendimiento cuántico de emisión calculado en agua exhibió un importante cambio al variar la acidez del medio, aumentando significativamente el rendimiento de la forma aniónica.

En ACN se observan dos bandas de emisión, la de mayor energía fruto de la desexcitación del estado ${ }^{1} \mathrm{IL}$, con un tiempo de vida similar al medido en agua y otra de menor energía con un tiempo de vida de 300 ns y con menor $\phi_{\text {emi. }}$ Esta última se origina en la desactivación del ${ }^{3} \mathrm{MLCT}$. Este estado triplete, es además capaz de generar ${ }^{1} \mathrm{O}_{2}$ en $\mathrm{ACN}$ con un rendimiento cuántico de $6 \times 10^{-2}$. La desactivación no radiativa, sin embargo, es la vía de desexcitación principal, ya que más del $98 \%$ de la energía absorbida es liberada en forma vibracional al solvente. Existe además otro triplete no emisor que corresponde al ${ }^{3} \mathrm{IL}$, con un tiempo de vida de cercano a $1 \mu$. El transiente de esta especie fue observado por LFF.

Se observaron diferencias en el comportamiento del complejo RePtr, en medio acuoso y en ACN. La presencia de la banda de emisión centrada en $555 \mathrm{~nm}$ y la capacidad de generar oxigeno singlete en $\mathrm{ACN}$, responden claramente a la naturaleza triplete de este estado emisor. Este estado, como se comprobó midiendo el espectro a 77K, es eficientemente desactivado por el agua.

Se midió mayor rendimiento cuántico de emisión en solución acuosa a pH alcalino, comparado con el medido a $\mathrm{pH}$ neutro y acido. Esta diferencia puede explicarse teniendo en cuenta la diferente coordinación de las especies involucradas. Tanto a pH 
acido como neutro en $\operatorname{Re}(\mathrm{l})$ coordina en la sexta posición a una molécula de agua. El puente de hidrogeno que forma esta molécula con las moléculas de agua del solvente representan una efectiva vía de relajación no radiativo [24]. A pH alcalino esta posición de coordinación se encuentra ocupada por un oxidrilo. De este modo, el aumento en el rendimiento cuántico de emisión de la especie presente en medio alcalino, puede responder a que no cuenta con esta vía de desexcitación no radiativa.

Se realizaron estudios sobre las vías de generación de oxigeno singlete llevados a cabo con los cuatro complejos. Los resultados de los mismos permitieron determinar que es el estado ${ }^{3} \mathrm{MLCT}$ el responsable de la generación fotoinducida de ${ }^{1} \mathrm{O}_{2}$. Además que es el canal singlete el principal involucrado en la generación de ${ }^{1} \mathrm{O}_{2}$. Los resultados de los ensayos con estos complejos, junto a otros cuatro complejos dieron origen a un trabajo publicado en el año 2013 en The Journal of Physical Chemistry A [25].

\section{Interacción con ADN}

SE realizaron estudios de interacción entre cuatro complejos de $\operatorname{Re}(\mathrm{I})$ y $A D N$ de distinta naturaleza. Los complejos utilizados fueron RePtr y otros dos complejos obtenidos de trabajos anteriores realizados dentro del grupo Redppz y ReBpyTf.

Los estudios de interacción, realizados con el complejo Redppz, demostraron claramente la capacidad de este complejo de intercalar entre las bases del ADN. Esta capacidad, además le permitió participar en la escisión fotoinducida de la doble hebra cuando se irradio la mezcla del complejo con un plásmido bacteriano.

Los ensayos con ReBpyTf, no fueron capaces de evidenciar la interacción de este complejo con el ADN. Sin embargo, se demostró la capacidad de este complejo de producir un corte en una de las hebras del ADN plasmídico mediante un proceso fotosensibilizado.

Los ensayos con el complejo RePtr, demostraron la capacidad de este complejo de ser de interaccionar con todas los tipos de ácidos nucleicos. Se encontraron evidencias para proponer un modo de interacción estático con formación de un aducto. Esta interacción se puso en evidencia en los ensayos de interacción y fotolisis con plásmidos. La relajación de la forma superenrollada del plásmido luego de la 
interacción con el estado basal del complejo, puede explicarse en función de los cambios en la tensión helicoidal que genera la unión del complejo al ADN. Además, el estado excitado del complejo, que se genera luego de la absorción de luz, conduce a compactar nuevamente la estructura del plásmido. Este efecto, producido por el estado excitado del complejo, se lo asocia al entrecruzamiento entre guaninas de cadenas de ADN adyacentes. Estos cambios inducidos en el plásmido por el complejo RePtr, fueron observados mediante microscopia AFM. El la figura 1 se muestran micrografías que ilustran los procesos que ocurren en un plásmido luego de la interacción con el complejo y luego de la irradiación.

a)

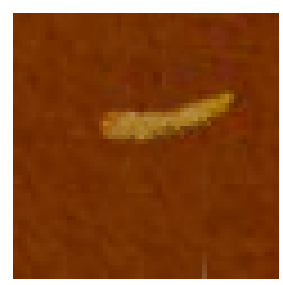

b)

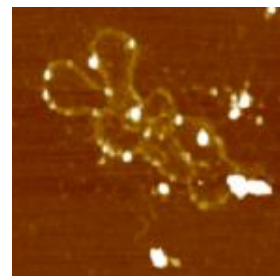

c)

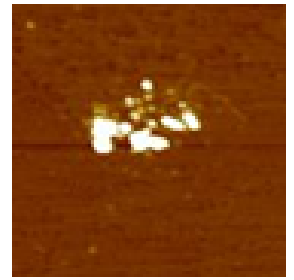

\section{Figura 1}

Micrografías de AFM de $1 \times 1 \mu \mathrm{m}$ de a) el plásmido solo b) el plásmido incubado con RePtr y c) el plasmido incubado con RePtr e irradiado a $350 \mathrm{~nm}$.

\section{Asociación con sero-albuminas}

Las albuminas séricas representan un modelo extensamente estudiado de transporte de moléculas en sangre. Buscando evaluar la capacidad del complejo RePtr de ser transportado por este tipo de proteínas, se realizaron estudios de asociación del complejo RePtr con seroalbúminas humana y bovina.

La asociación del complejo con las sero-albuminas, muestran claramente que la interacción se da con los dos fluoróforos de la proteína, Tyr y Trp. El sitio de asociación a ambas proteínas es subdominio IIA, el cual es un bolsillo hidrofóbico. La desactivación pudo ser interpretada según el modelo de Bhattacharyya. Con este modelo, fue posible calcular las constantes del proceso de asociación. Los valores calculados estas constantes $\left(2-7 \times 10^{5} \mathrm{M}^{-1}\right.$ para la HSA y BSA respectivamente) 
mostraron buena concordancia con los valores publicados para otros complejos. Los parámetros termodinámicos calculados, asociados al hecho de que la interacción ocurre en un bolsillo hidrofóbico, nos dan indicio de que en la interacción existen fuerzas del tipo hidrofóbicas y electrostáticas. Realizando medidas de dicroísmo circular, se encontró evidencia que indica que la asociación del complejo con las albuminas no induce cambios significativos en la estructura de las proteínas. La distancia entre el complejo y el fluoróforo fue estimada mediante el cálculo de la eficiencia de transferencia de energía de resonancia y resulto ser de $\approx 3 \mathrm{~nm}$, lo cual indica una alta probabilidad de transferencia de energía.

\section{Referencias bibliográficas}

[1] J. Perkinson, S. Brodie, K. Yoon, K. Mosny, P. J. Carroll, T. V. Morgan, and S. J. Nieter, "Preparations and Properties of Transition-Metal Pterin Complexes . Models for the," Inorg. Chem., vol. 30, no. 4, pp. 719-727, 1991.

[2] S. Burgmayer, E. Stiefel, C. It, W. Oh, and B. Ni, "Transition-Metal Pteridine Complexes. Preparation and Characterization," Am. Chem. Soc., vol. 27, no. 22, pp. 4059-4065, 1988.

[3] T. Kojima, T. Sakamoto, Y. Matsuda, K. Ohkubo, and S. Fukuzumi, “A ruthenium pterin complex showing proton-coupled electron transfer: synthesis and characterization.," Angew. Chem. Int. Ed. Engl., vol. 42, no. 40, pp. 4951-4, Oct. 2003.

[4] A. Odani, O. Yamauchi, H. Masuda, K. Inukai, and O. Yamamuchi, "PteridineContaining Ternary and Quaternary Complexes as Models for MetalloenzymePterin Cofactor-Substrate Association. Structure of Ternary Copper(11)-2,2'Bipyridine-Lumazine Complex and Successful Equilibrium Study of a Quaternary Copper( 11) System," J. Am. Chem. SOC, vol. 114, no. 114, pp. 6294-6300, 1992.

[5] M. Mitsumi, J. Toyoda, and K. Nakasuji, "Metal-pteridine complexes having three-dimensional hydrogen-bonded networks," Inorg. Chem., vol. 34, pp. 3367-3370, 1995. 
[6] C. Acta and U. Shdtgart, "Complexes of folic acid, lumiflavin and riboflavin with Facilitated formation of flavosemiquinone complexes and substantial decrease of pKa( NH )," Inorganica Chim. Acta, vol. 195, pp. 123-126, 1992.

[7] S. Miyazaki, T. Kojima, T. Sakamoto, T. Matsumoto, K. Ohkubo, and S. Fukuzumi, "Proton-coupled electron transfer in ruthenium(II)-pterin complexes: formation of ruthenium-coordinated pterin radicals and their electronic structures.," Inorg. Chem., vol. 47, no. 1, pp. 333-43, Jan. 2008.

[8] A. Abelleira, R. Galang, and M. Clarke, "Synthesis and electrochemistry of pterins coordinated to tetraammineruthenium (II)," Inorg. Chem., vol. 29, no. 4, pp. 633-639, 1990.

[9] Y. Funahashi, Y. Hara, H. Masuda, and O. Yamauchi, "Structures and Spectral Properties of Iron ( II ), Cobalt ( II ), and Copper ( II ) Complexes Involving 2- ( Dimethylamino ) -4 ( 3 H ) -pteridinone," Inorg. Chem., vol. 4, no. li, pp. 38693875, 1997.

[10] P. Basu and S. J. N. Burgmayer, "Pterin chemistry and its relationship to the molybdenum cofactor.," Coord. Chem. Rev., vol. 255, no. 9-10, pp. 1016-1038, May 2011.

[11] O. Heilmann, F. M. Hornung, J. Fiedler, and W. Kaim, "Organometallic iridium(III) and rhenium(I) complexes with lumazine, alloxazine and pterin derivatives," J. Organomet. Chem., vol. 589, no. 1, pp. 2-10, Oct. 1999.

[12] C. Bessenbacher, C. Vogler, and W. Kaim, "Stabilization of biochemically interesting intermediates by metal coordination. 6 . Charge transfer in complexes of 1, 3-dimethyllumazine with low-valent metals," Inorg. Chem., vol. 3, no. Table V, pp. 4645-4648, 1989.

[13] W. Kaim, B. Schwederski, O. Heilmann, and F. M. Hornung, "Coordination compounds of pteridine, alloxazine and flavin ligands: structures and properties," Coord. Chem. Rev., vol. 182, no. 1, pp. 323-342, Feb. 1999.

[14] H. Rokos, W. D. Beazley, and K. U. Schallreuter, "Oxidative stress in vitiligo: photo-oxidation of pterins produces $\mathrm{H}(2) \mathrm{O}(2)$ and pterin-6-carboxylic acid.," Biochem. Biophys. Res. Commun., vol. 292, pp. 805-811, 2002.

[15] S. Milstien, G. Kapatos, R. A. Levine, and B. Shane, Chemistry and biology of pteridines and folates, vol. 76. 1994, p. 460. 
[16] V. Fernández-Moreira and M. Ortego, "Bioconjugated Rhenium (I) Complexes with Amino Acid Derivatives: Synthesis, Photophysical Properties, and Cell Imaging Studies," Organometallics, vol. 31, pp. 5950-5957, 2012.

[17] R. Huang, G. Langille, R. K. Gill, C. M. J. Li, Y. Mikata, M. Q. Wong, D. T. Yapp, and T. Storr, "Synthesis, characterization, and biological studies of emissive rheniumglutamine conjugates.," J. Biol. Inorg. Chem., vol. 18, no. 7, pp. 831-44, Oct. 2013.

[18] J. M. Villegas, S. R. Stoyanov, W. Huang, and D. P. Rillema, "Photophysical, spectroscopic, and computational studies of a series of $\operatorname{Re}(\mathrm{I})$ tricarbonyl complexes containing 2,6-dimethylphenylisocyanide and 5- and 6-derivatized phenanthroline ligands," Inorg. Chem., vol. 44, no. 7, pp. 2297-2309, 2005.

[19] H. H. Martinez Saavedra, C. a. Franca, G. Petroselli, R. Erra-balsells, G. T. Ruiz, E. Wolcan, H. H. Martinez, C. a. Franca, G. Petroselli, R. Erra-balsells, G. T. Ruiz, and E. Wolcan, "A new zwitterionic, water soluble, $\operatorname{Re}(\mathrm{I})$ complex: Synthesis, spectroscopic and computational characterization," J. Organomet. Chem., vol. 745-746, pp. 470-478, Nov. 2013.

[20] R. Alberto, R. Schibli, and R. Waibel, "Basic aqueous chemistry of +(M= Re, Tc) directed towards radiopharmaceutical application," Coord. Chem. ..., vol. 192, pp. 901-919, 1999.

[21] B. Higgins, B. a DeGraff, and J. N. Demas, "Luminescent transition metal complexes as sensors: structural effects on pH response.," Inorg. Chem., vol. 44, no. 19, pp. 6662-9, Sep. 2005.

[22] F. Ragone, G. T. Ruiz, O. E. Piro, G. a. Echeverría, F. M. Cabrerizo, G. Petroselli, R. Erra-Balsells, K. Hiraoka, F. S. García Einschlag, and E. Wolcan, “Water-Soluble (Pterin)rhenium(I) Complex: Synthesis, Structural Characterization, and Two Reversible Protonation-Deprotonation Behavior in Aqueous Solutions," Eur. J. Inorg. Chem., vol. 2012, no. 30, pp. $4801-4810,2012$.

[23] C. Lorente and A. H. Thomas, "Photophysics and photochemistry of pterins in aqueous solution.," Acc. Chem. Res., vol. 39, no. 6, pp. 395-402, Jun. 2006.

[24] C. N. Robertson and J. Yarwood, "Vibrational -relaxation of hydrogen-bonded species in solution.," Chem. Phys., vol. 32, pp. 291-296, 1978. 
[25] F. Ragone, H. H. Martinez Saavedra, P. M. David Gara, G. T. Ruiz, and E. Wolcan, "Photosensitized generation of singlet oxygen from $\operatorname{Re}(\mathrm{I})$ complexes: a photophysical study using LIOAS and luminescence techniques.," J. Phys. Chem. A, vol. 117, no. 21, pp. 4428-35, 2013. 


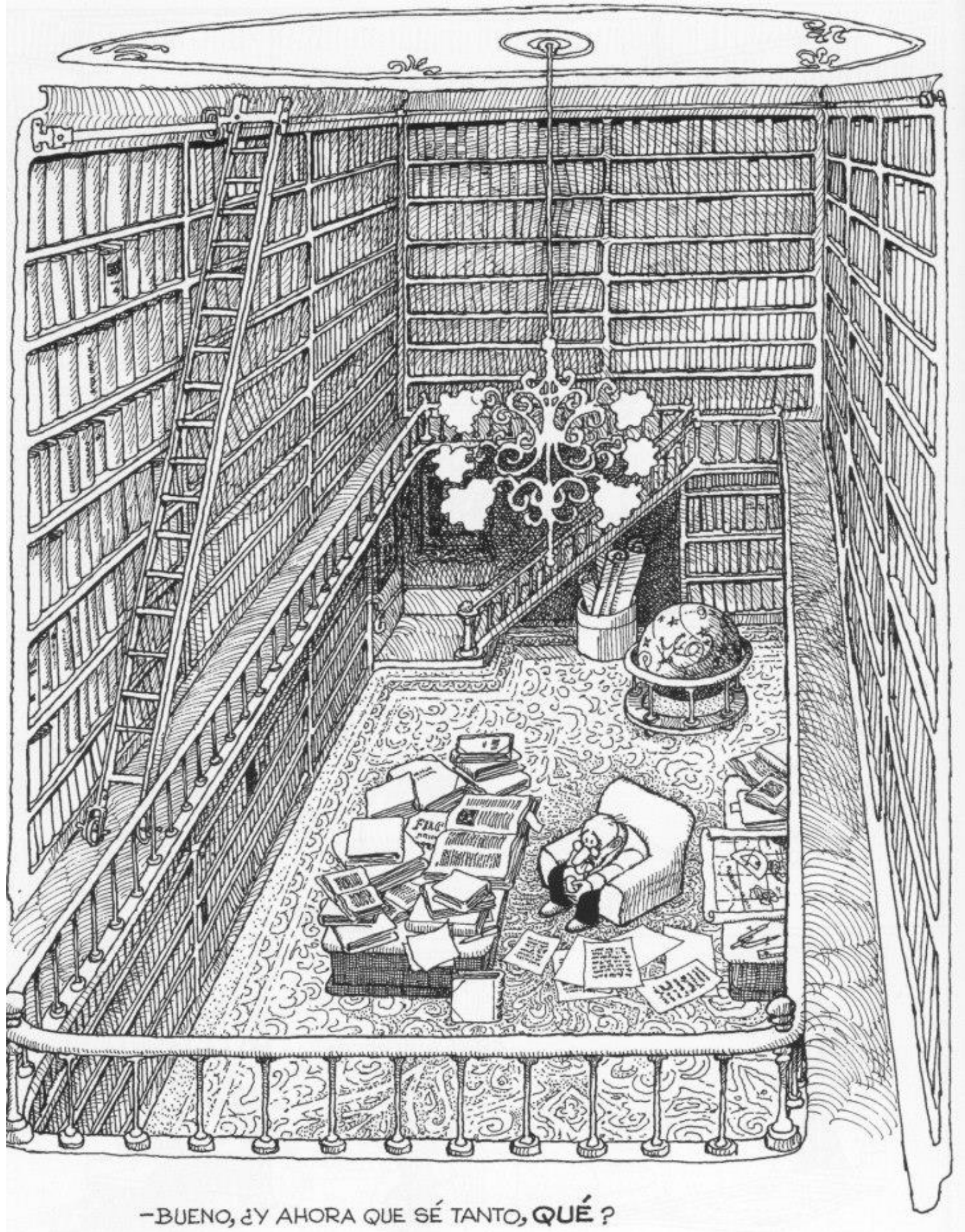

